\author{
UNIVERSIDADE DE SÃO PAULO \\ ESCOLA DE ENGENHARIA DE SÃO CARLOS \\ DEPARTAMENTO DE ENGENHARIA ELÉTRICA E DE COMPUTAÇÃO
}

ROBSON ROBERTO SGUAÇABIA

Avaliação do Impacto da Geração Distribuída sobre

- Sistema de Proteção de Sobrecorrente de uma Rede de Distribuição Operando em Ilhamento Intencional

SÃO CARLOS

2015 



\section{ROBSON ROBERTO SGUAÇABIA}

\section{Avaliação do Impacto da Geração Distribuída sobre o Sistema de Proteção de Sobrecorrente de uma Rede de Distribuição Operando em Ilhamento Intencional}

Dissertação apresentada à Escola de Engenharia de São Carlos da Universidade de São Paulo, como parte dos requisitos para obtenção do título de Mestre em Ciências pelo Programa de Engenharia Elétrica.

Área de Concentração: Sistemas Elétricos de Potência

Orientador: Prof. Dr. José Carlos de Melo Vieira Júnior

SÃO CARLOS

2015

Trata-se da versão corrigida da dissertação. A versão original se encontra disponível na EESC/USP que aloja o Programa de Pós-Graduação de Engenharia Elétrica. 
AUTORIZO A REPRODUÇÃO TOTAL OU PARCIAL DESTE TRABALHO, POR QUALQUER MEIO CONVENCIONAL OU ELETRÔNICO, PARA FINS DE ESTUDO E PESQUISA, DESDE QUE CITADA A FONTE.

Ficha catalográfica preparada pela Seção de Tratamento da Informação do Serviço de Biblioteca - EESC/USP

Avaliação do impacto da geração distribuída sobre o sistema de proteção de sobrecorrente de uma rede de distribuição operando em ilhamento intencional / Robson Roberto Sguaçabia; orientador José Carlos de Melo Viera Júnior. São Carlos, 2015.

Dissertação (Mestrado) - Programa de Pós-Graduação em Engenharia Elétrica e Área de Concentração em Sistemas Elétricos de Potência -- Escola de Engenharia de São Carlos da Universidade de São Paulo, 2015.

1. geração distribuída. 2. ilhamento intencional. 3. proteção de redes de distribuição. I. Título. 


\section{FOLHA DE JULGAMENTO}

Candidato: Engenheiro ROBSON ROBERTO SGUAC̨ABIA.

Tífulo do dissertaçāo: "Avaliaçăo do impacto da geraçāo distribuida sobre o sistema de proteção de sobrecorrente de uma rede de distribuiçâo operando em ilhamento intencional".

Dala da defesc: $26 / 03 / 2015$

Comissāo Julgadora:

Resultado:

Prof. Dr. Jasé Carlos de Melo Vieira Júnior (Orientador)

APROVADO

[Escola de Engenharia de São Cartos/EESC|

Prof. Dr. Mário Ôleskovicz

[Escola de Engenharia de Sāo Carlos/EESC)

Dr. Newton José de Salles

A $P Q O$ VA PO

(Companhio Paulista de Forca e Luz/CPFL)

Caordenador do Programa de Pós-Graduaçöo em Engenharia Elétrica: Prof. Associado Luis Fernando Costa Alberto

Presidente da Comissão de Pós-Graduação:

Prof. Associado Paulo César Lima Segantine 



\section{DEDICATÓRIA}

"Ao meu filho João, pelos momentos que não pude compartilhar por estar envolvido com este trabalho e à minha esposa Delvana, pelo exemplo de paciência, fé e perseverança, os quais me serviram de incentivo." 



\section{AGRADECIMENTOS}

A Deus, por ter me dado saúde e força para trabalhar e estudar.

Ao professor José Carlos de Melo Vieira Júnior, pela amizade, disponibilidade, ajuda e apoio prestados durante todo o desenvolvimento deste trabalho.

Ao meu amigo Matheus Verardino pela disposição em ajudar sempre que solicitado.

A todos os professores e funcionários do Departamento de Engenharia Elétrica, que de alguma forma colaboraram durante o período de pós-graduação nesta universidade.

Ao Departamento de Engenharia Elétrica da Escola de Engenharia de São Carlos (EESC) da Universidade de São Paulo (USP), pela oportunidade de realização deste curso de mestrado. 

"Nossas virtudes e nossos defeitos são inseparáveis, como a força e a matéria. Quando se separam o homem deixa de existir."

Nikola Tesla 



\section{RESUMO}

SGUAÇABIA, R.R. Avaliação do Impacto da Geração Distribuída Sobre o Sistema de Proteção de Sobrecorrente de uma Rede de Distribuição Operando em Ilhamento Intencional. 2015. 137f. Dissertação (Mestrado) - Escola de Engenharia de São Carlos, Universidade de São Paulo - USP, São Carlos, 2015.

O crescente número de geradores distribuídos conectados em redes de distribuição de energia elétrica é uma realidade dos sistemas elétricos de todo o mundo. Embora a política atual seja desconectar os geradores distribuídos do sistema elétrico de potência (SEP) caso ocorra uma falha na rede da concessionária, conforme preconizam os principais guias técnicos nacionais e internacionais, o módulo 3 dos Procedimentos de Distribuição de Energia Elétrica no Sistema Elétrico Nacional (PRODIST) mostra-se favorável à operação ilhada, pois afirma que este tipo de operação pode ser realizado em comum acordo entre as centrais geradoras de energia e o Operador Nacional do Sistema Elétrico (ONS), permitindo alcançar uma maior disponibilidade no fornecimento de energia. No entanto, para que a operação ilhada seja possível e possa ser praticada de forma segura, o ilhamento intencional precisa superar alguns desafios, dentre os quais estão aqueles relacionados ao sistema de proteção da rede de distribuição, tais como: coordenação indevida de dispositivos de proteção, perda da sensibilidade da proteção, abertura inadequada de fusíveis e religamentos automáticos fora de sincronismo. Portanto, este trabalho avalia o impacto da geração distribuída (GD) sobre o sistema de proteção de sobrecorrente de uma rede de distribuição operando ilhada. A ideia principal é dividir a rede em regiões delimitadas pelos dispositivos de proteção existentes, para em seguida, adequá-los à nova situação operacional, certificando se os ajustes propostos atendem ao comportamento síncrono e estável do sistema de geração por meio de uma análise de estabilidade transitória. Propõese então um conjunto de procedimentos para tomada de ações que permitam readequar o sistema de proteção de sobrecorrente existente à operação ilhada. Os resultados obtidos demonstram que a inibição do religamento automático e da curva de atuação instantânea acrescida de reajustes nas curvas temporizadas dos relés e religadores, melhoraram a coordenação e seletividade da rede operando ilhada.

Palavras-chave: geração distribuída, ilhamento intencional, proteção de redes de distribuição. 


\section{ABSTRACT}

SGUAÇABIA, R.R. (2105) Impact Assessment of the Distributed Generation on the Overcurrent Protection System of a Distribution Network Operating in Intentional Islanding. 2015. 137f. Dissertation (Master's Degree) - Escola de Engenharia de São Carlos, Universidade de São Paulo - USP, São Carlos, 2015.

The growing number of distributed generators connected to electricity distribution networks is a reality of electrical systems throughout the world. Although the current policy is to disconnect the distributed generators from the electric power system (EPS) in the event of loss of mains, as required by main national and international technical guides, the module 3 of the Procedures for Electric Power Distribution in the Electric National System (PRODIST) shows itself in favor of islanded operation, it states that this type of operation can be carried out in agreement between power generation plants and the National Electric System Operator (ONS), allowing achieve larger availability in energy supply. However, to make the islanded operation possible and safe, the intentional islanding must overcome some challenges, among which are those related to the protection system of the distribution network, such as improper coordination of protective devices, loss of protection sensitivity, inadequate opening of fuses and automatic reclosing out of synchronism. Therefore, this work evaluates the impact of distributed generation (DG) on the overcurrent protection system of a distribution network operating islanded. The main idea is to divide the network into regions bounded by existing protection devices, to then adapt them to the new operational situation, making sure that the proposed adjustments meet the synchronous and stable behavior of the generation system by means of a transient stability analysis. Thus, a set of procedures is proposed to indicate actions that allow readjusting the existing overcurrent protection system to the islanded operation. The results demonstrate that the inhibition of automatic restart and of the instantaneous operating curve plus adjustments in time delay curves of relays and reclosers, improved the coordination and selectivity of the network operating islanded.

Keywords: distributed generation, intentional islanding, protection of distribution system networks. 


\section{LISTA DE FIGURAS}

Figura 2.1 - Exemplos de Sistemas Illiados (IEEE Standards CoORdinAting CommitTeE 21, 2008). 12

Figura 3.1 - Chave fusível, CARTUCho PoRTA Fusível E ELOS Fusíveis (DELMAR LTDA, 2013) ..............................22

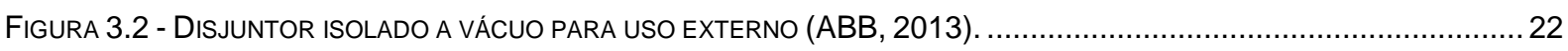

FIGURA 3.3 - CARACTERÍSTICAS DE OPERAÇÃO TEMPO X CORRENTE DE RELÉS DE SOBRECORRENTE ..............................23

FIGURA 3.4 - SEQUÊNCIA DE OPERAÇÃO DE UM RELIGADOR TíPICO (GERS \& HOLMES, 2011) ..................................26

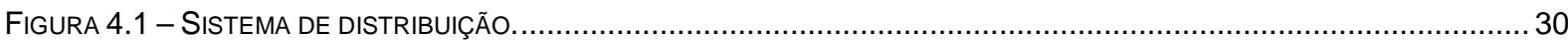

FIGURA 4.2 - COORDENAÇÃO ENTRE RELIGAdOR REL-1 E FUSÍVEL FU-3 . ...................................................... 33

FIGURA 4.3 - COORDENAÇÃO ENTRE O RELIGADOR REL-1 E O RELIGADOR REL-2 ............................................ 34

FIGURA 4.4 - COORDENAÇÃO ENTRE O RELÉ 1 do DISJUNTOR DJ-0 E O RELIGADOR REL-1 ..................................... 35

FIGURA 4.5 - COORDENAÇÃO ENTRE O RELÉ DO DISJUNTOR DJ-1 E RELIGADOR REL-2........................................... 38

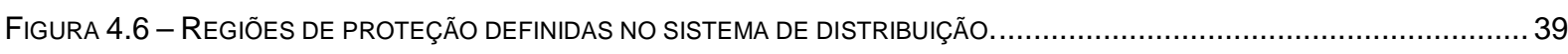

FIGURA 4.7 - COORDENAÇÃO ENTRE O RELÉ DO DISJUNTOR DJ-1 E O RELIGADOR REL-2 ........................................5 50

FIGURA 5.1 - TOPOLOGIA DO SISTEMA ILHADO RESULTANTE DE UMA FALTA TRIFÁSICA NA BARRA 11 OU NA LINHA 20 .........64

FIGURA 5.2 - ANÁLISE DA REGIÃO 1 - FALTA TRIFÁSICA (TENSÃO NOS PACS VERSUS TEMPO) ......................................65

FIGURA 5.3 - ANÁLISE DA REGIÃO 1 - FALTA TRIFÁSICA (FREQUÊNCIA NOS PACS VERSUS TEMPO)..................................65

FIGURA 5.4 - ANÁLISE DA REGIÃO 1 - FALTA TRIFÁSICA (ÂNGULO DO ROTOR DOS GERADORES VERSUS TEMPO)................66

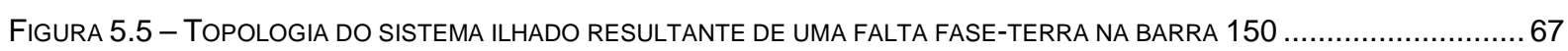

FIGURA 5.6 - ANÁLISE DA REGIÃO 1 - FALTA FASE-TERRA (TENSÃO NOS PACS VERSUS TEMPO). ..................................68

FIGURA 5.7 - ANÁLISE DA REGIÃO 1 - FALTA FASE-TERRA (FREQUÊNCIA NOS PACS VERSUS TEMPO).............................68

FIGURA 5.8 - ANÁLISE DA REGIÃO 1 - FALTA FASE-TERRA (ÂNGULO DO ROTOR DOS GERADORES VERSUS TEMPO) .............69

FIGURA 5.9 - TOPOLOGIA DO SISTEMA ILHADO RESULTANTE DE FALTAS TRIFÁSICAS NAS LINHAS 11, 45, 27 E 34 OU FALTAS

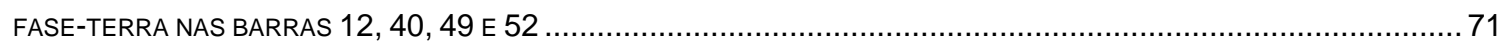

FIGURA 5.10 - ANÁLISE DAS REGIÕES 2, 6, 7 E 8 (TENSÃO NOS PACS VERSUS TEMPO) .............................................. 72

FIGURA 5.11 - ANÁLISE DAS REGIÕES 2, 6,7 E 8 (FREQUÊNCIA NOS PACS VERSUS TEMPO)........................................ 72

FIGURA 5.12 - ANÁLISE DAS REGIÕES 2, 6,7 E 8 (ÂNGULO DO ROTOR DOS GERADORES VERSUS TEMPO)........................ 73

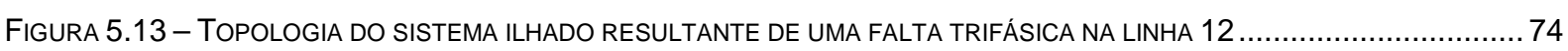

FIGURA 5.14 - ANÁLISE DA REGIÃO 3 - FALTA TRIFÁSICA (TENSÃO NOS PACS VERSUS TEMPO).................................... 75

FIGURA 5.15 - ANÁLISE DA REGIÃO 3 - FALTA TRIFÁSICA (FREQUÊNCIA NOS PACS VERSUS TEMPO) ............................... 75

FIGURA 5.16 - ANÁLISE DA REGIÃO 3 - FALTA TRIFÁSICA (ÂNGULO DO ROTOR DOS GERADORES VERSUS TEMPO)...............76

FIGURA 5.17 - TOPOLOGIA DO SISTEMA ILHADO RESULTANTE DE UMA FALTA FASE-TERRA NA BARRA $21 \ldots \ldots \ldots \ldots \ldots \ldots \ldots \ldots . . . . . . . . . . . . . .77$

FIGURA 5.18 - ANÁLISE DA REGIÃO 3 - FALTA FASE-TERRA (TENSÃO NOS PACS VERSUS TEMPO). .................................78

FIGURA 5.19 - ANÁLISE DA REGIÃO 3 - FALTA FASE-TERRA (FREQUÊNCIA NOS PACS VERSUS TEMPO) ..............................78

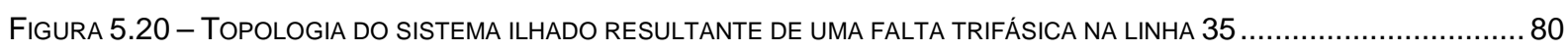

FIGURA 5.21 - ANÁLISE DA REGIÃO 4 - FALTA TRIFÁSICA (TENSÃO NOS PACS VERSUS TEMPO) ....................................81

FIGURA 5.22 - ANÁLISE DA REGIÃO 4 - FALTA TRIFÁSICA (FREQUÊNCIA NOS PACS VERSUS TEMPO) ..............................81

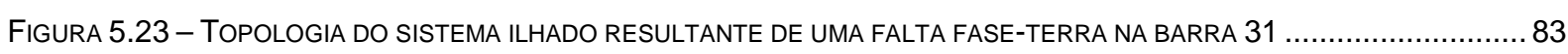

FIGURA 5.24 - ANÁLISE DA REGIÃO 4 - FALTA FASE-TERRA (TENSÃO NOS PACS VERSUS TEMPO). ............................... 84

FIGURA 5.25 - ANÁLISE DA REGIÃO 4 - FALTA FASE-TERRA (FREQUÊNCIA NOS PACS VERSUS TEMPO)........................... 84

FIGURA 5.26 - TOPOLOGIA DO SISTEMA ILHADO RESULTANTE DE UMA FALTA TRIFÁSICA NAS BARRAS 23 E $63 . \ldots \ldots \ldots \ldots \ldots . . . . . . . . . .66$

FIGURA 5.27 - ANÁLISE DA REGIÃO 5 - FALTA TRIFÁSICA (TENSÃO NOS PACS VERSUS TEMPO) .....................................8 87 
FIGURA 5.28 - TOPOLOGIA DO SISTEMA ILHADO RESULTANTE DE UMA FALTA FASE-TERRA NA BARRA $39 . . . \ldots \ldots \ldots \ldots \ldots \ldots \ldots . . . . . . . . . . . .88$

FIGURA 5.29 - ANÁLISE DA REGIÃO 5 - FALTA FASE-TERRA (TENSÃO NOS PACS VERSUS TEMPO). ...............................89

FIGURA 5.30 - ANÁLISE DA REGIÃO 5 - FALTA FASE-TERRA (FREQUÊNCIA NOS PACS VERSUS TEMPO) ...........................89

FIGURA 5.31-TOPOLOGIA DO SISTEMA ILHADO RESULTANTE DE UMA FALTA TRIFÁSICA NA LINHA 31 OU DE FALTA FASE-TERRA

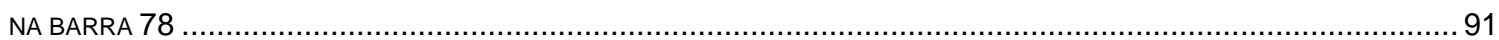

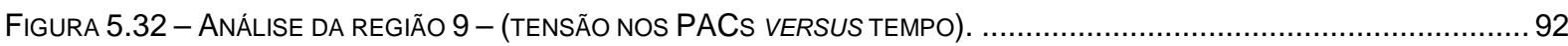

FIGURA 5.33 - ANÁLISE DA REGIÃO 9 - (FREQUÊNCIA NOS PACS VERSUS TEMPO) ............................................... 92

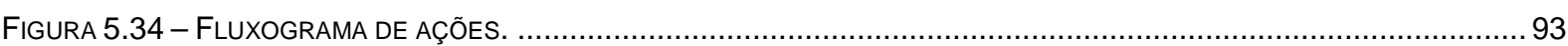

Figura A.1 - CARACTERÍSTICA TEMPO X CORRENTE dOS ELOS FUSíVEIS H PARA TEMPOS DE FUSÃo MíNIMO E MÁXIMO

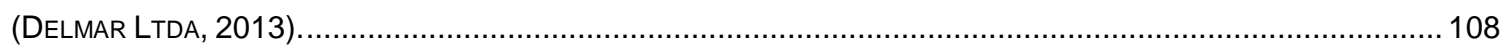

FIGURA A.2 - CARACTERÍSTICA TEMPO X CORRENTE DOS CONDUTORES DE ALUMÍNIO CAA .......................................109

FIGURA A.3 - CoORDENAÇÃo ENTRE RELIGADOR DE SUBESTAÇÃO E ELO FUSÍVEL COM FATOR K..................................122

FIGURA A.4 - COORDENAÇÃO ENTRE RELIGADOR DE SUBESTAÇÃO E ELO FUSÍVEL SEM FATOR K ................................. 123

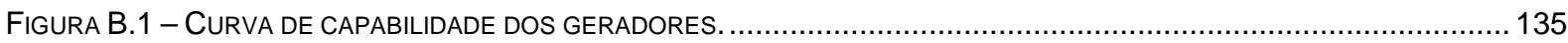

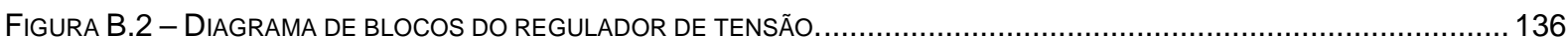

FIGURA B.3 - DIAGRAMA DE BLOCOS DO REGULADOR DE VELOCIDADE DO MOTOR. ........................................ 137 


\section{LISTA DE TABELAS}

TABELA 4.1 - DimENSIONAMENTO DOS ELOS FUSíVEIS. 32

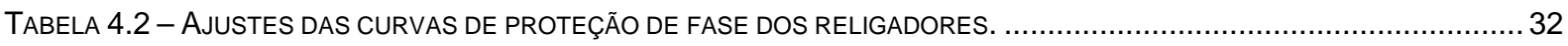

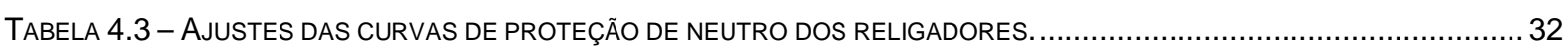

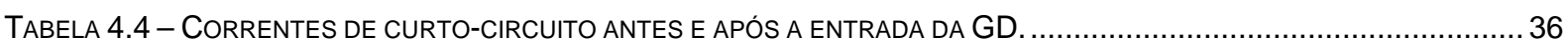

TABELA 4.5 - AJUSTES DAS CURVAS DE PROTEÇÃO DE FASE DOS RELÉS DOS PAC. …............................................ 37

TABELA 4.6 - AJUSTES DAS CURVAS DE PROTEÇÃO DE NEUTRO DOS RELÉS DOS PAC ................................................37

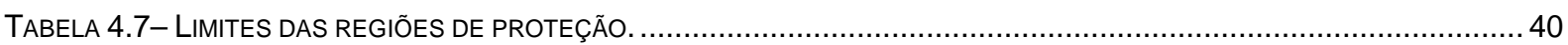

TABELA 4.8 - LOCALIZAÇÃO DAS FALTAS AVALIADAS DE ACORDO COM CADA REGIÃO DE PROTEÇÃO..............................41

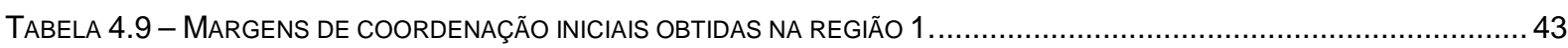

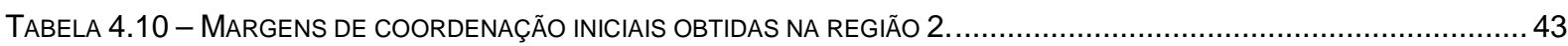

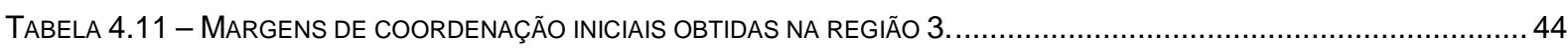

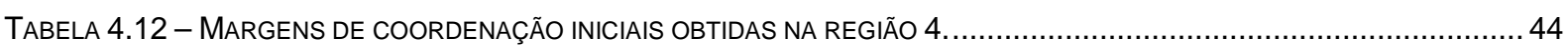

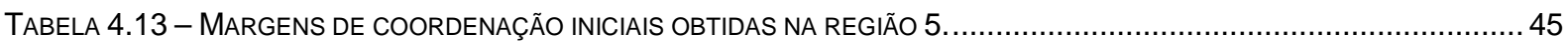

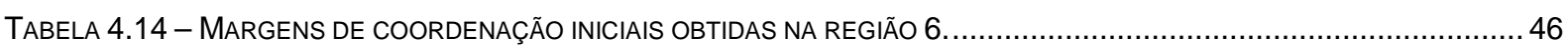

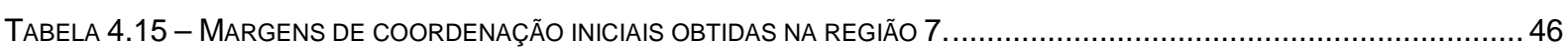

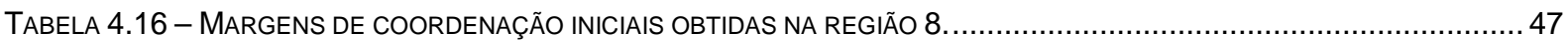

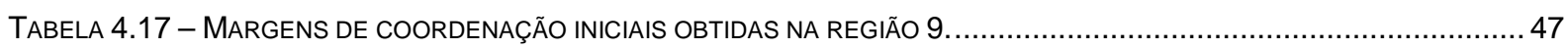

TABELA 4.18 - OCORRÊNCIAS ENCONTRADAS NA OPERAÇÃO ILHADA CONSIDERANDO OS AJUSTES INICIAIS DA PROTEÇÃO DE

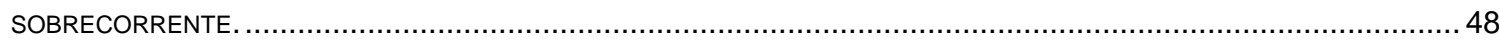

TABELA 4.19 - AJUSTES DAS CURVAS DE PROTEÇÃO DE FASE DOS RELÉS DO PAC E DOS RELIGADORES...........................5 50

TABELA 4.20 - AJUSTES DAS CURVAS DE PROTEÇÃO DE NEUTRO DOS RELÉS DO PAC E DOS RELIGADORES. .....................50

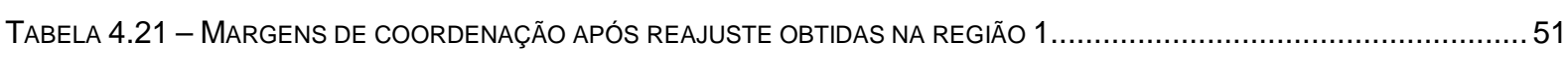

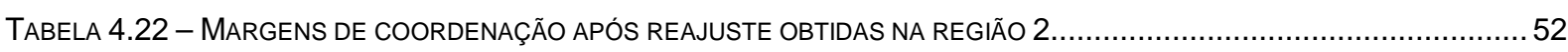

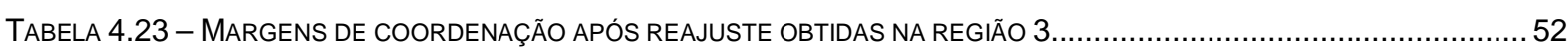

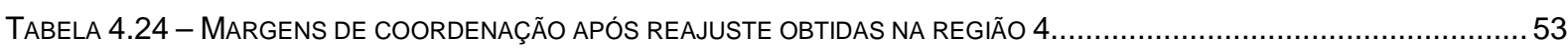

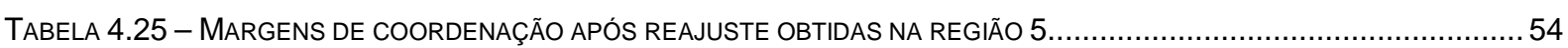

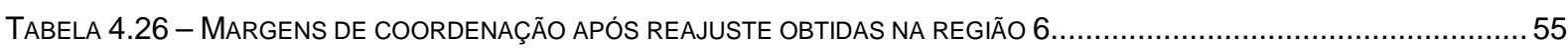

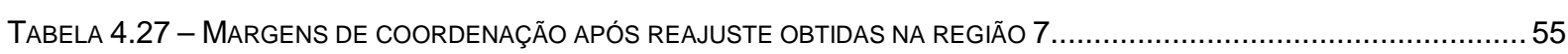

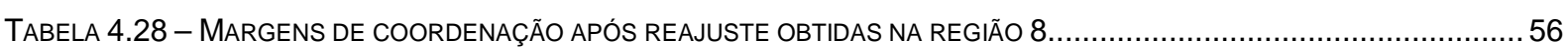

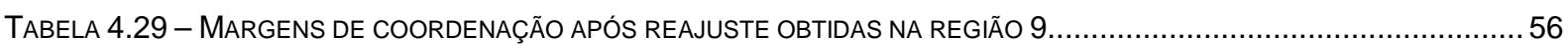

TABELA 4.30 - OCORRÊNCIAS ENCONTRADAS NA OPERAÇÃO ILHADA APÓS AJUSTES NA PROTEÇÃO. ................................5 57

TABELA 5.1 - AJUSTES DAS PROTEÇÕES DE TENSÃO E FREQUÊNCIA DOS RELÉS DO PAC .......................................62

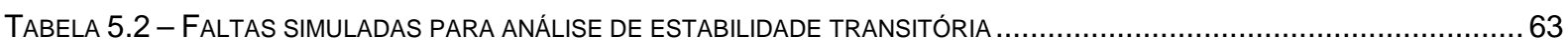

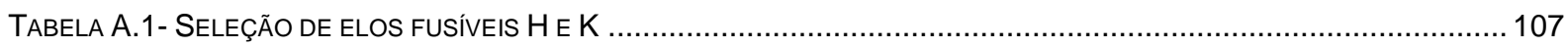

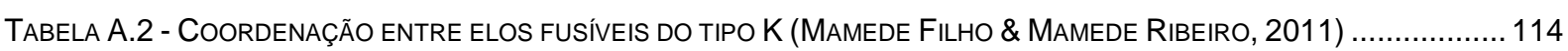

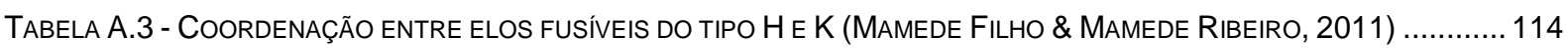

TABela A.4 - CoORdenAÇão entre elos fusíveIS do tipo T (MAMede FILHo \& Mamede RIBEIRO, 2011) ..................114

TABela A.5 - CoordenaÇÃo entre elos fusíveIS do tipo H e T (Mamede Filho \& Mamede Ribeiro, 2011) ............114

TABELA A.6 - CONSTANTES ANSI/IEEE E IEC PARA RELÉS DE SOBRECORRENTE PADRONIZADOS...............................117

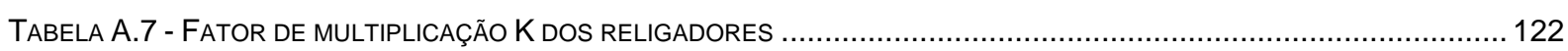




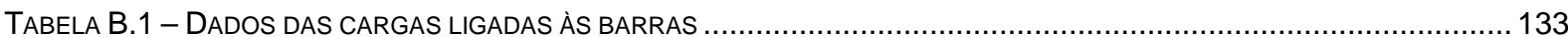

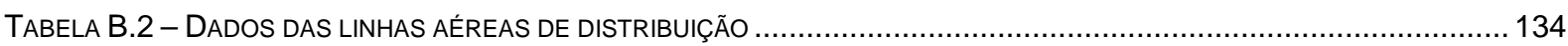

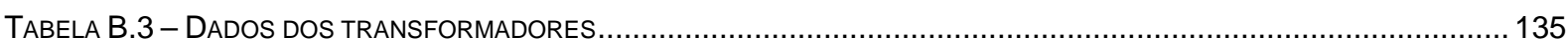

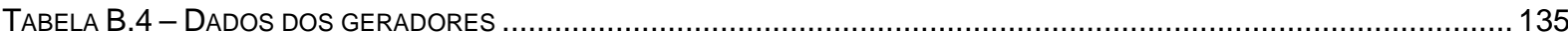

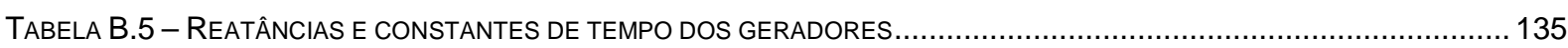

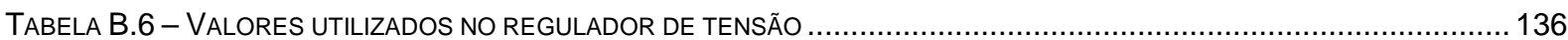

TABELA B.7 - VALORES UTILIZADOS NO REGULADOR DE VELOCIDADE DO MOTOR.............................................. 137 


\section{LISTA DE ABREVIATURAS}

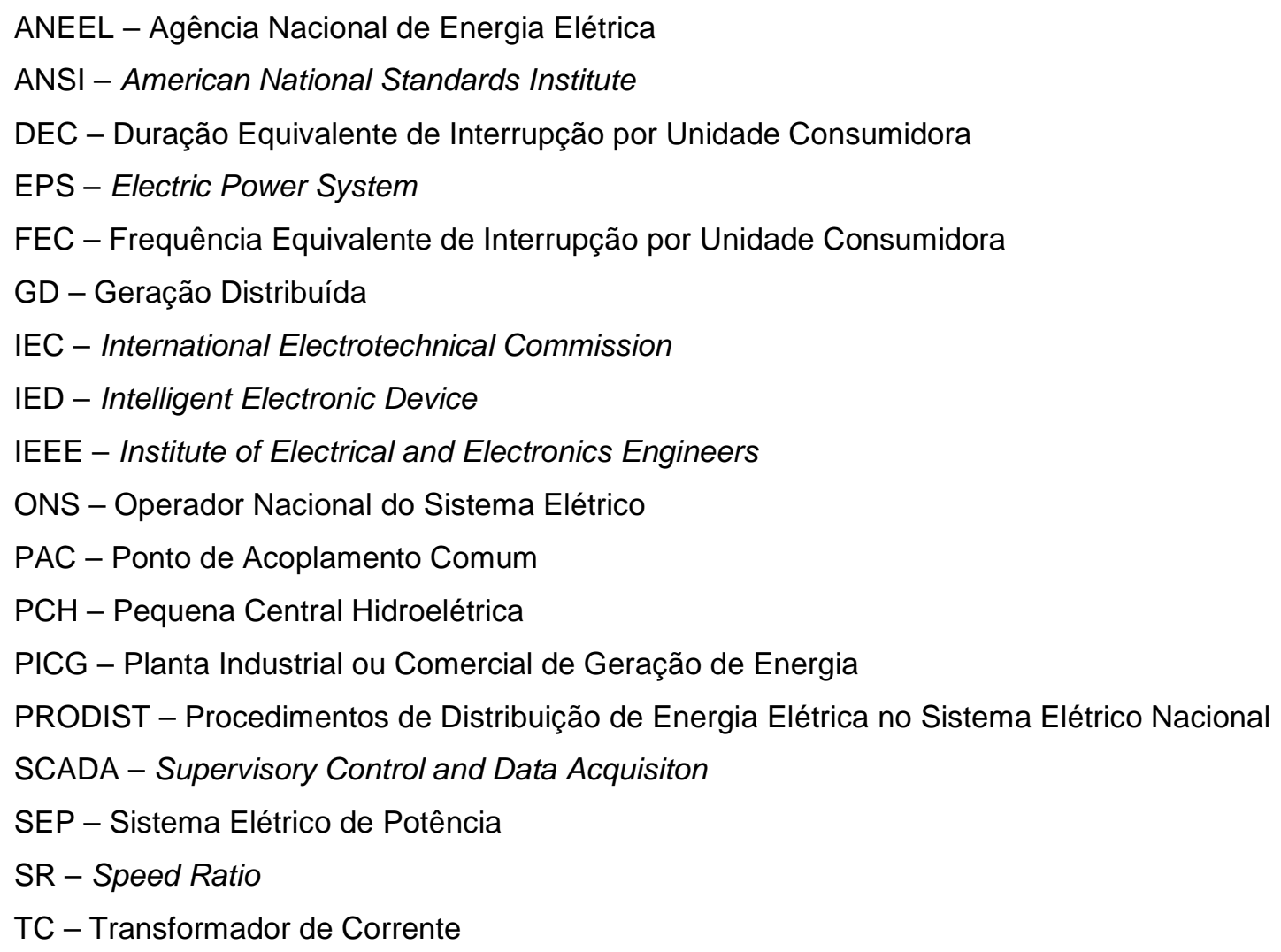




\title{
LISTA DE NOMENCLATURA ANSI
}

\author{
25 - Relé de verificação de sincronismo ou sincronização \\ 27 - Relé de subtensão \\ 32 - Relé direcional de potência \\ 46 - Relé de desbalanceamento de corrente de fase \\ 50 - Relé de sobrecorrente instantâneo \\ 51 - Relé de sobrecorrente temporizado \\ 59 - Relé de sobretensão \\ 67 - Relé direcional de sobrecorrente \\ 79 - Relé de religamento \\ 81 - Relé de sub/ sobrefrequência
}




\section{SUMÁRIO}

1. INTRODUÇÃO

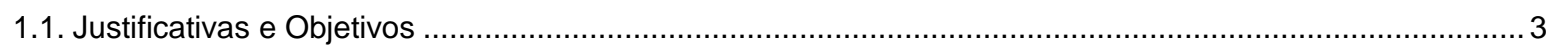

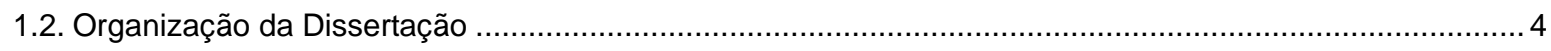

2. ASPECTOS DA PROTEÇÃO EM SISTEMAS DE DISTRIBUIÇÃO COM GERADORES DISTRIBUÍDOS .......7

2.1. A GD e o Sistema de Proteção de Sobrecorrente da Rede de Distribuição Antes do Ilhamento .................7

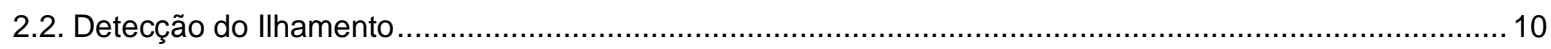

2.3. A GD e o Sistema de Proteção de Sobrecorrente da Rede de Distribuição após o Ilhamento...................13

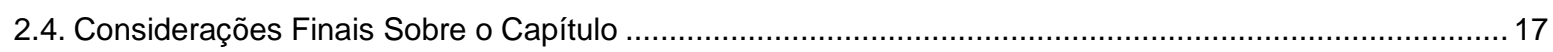

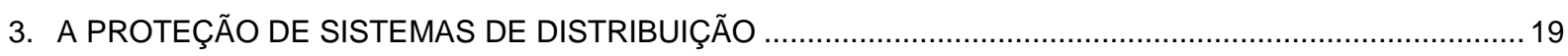

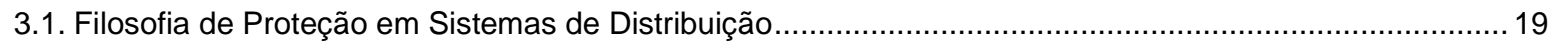

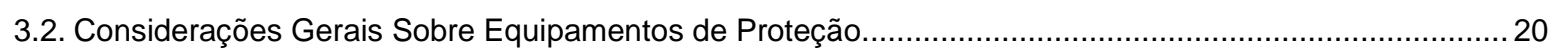

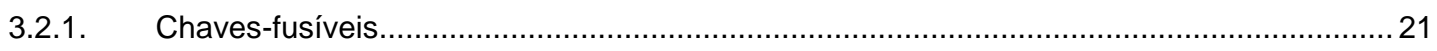

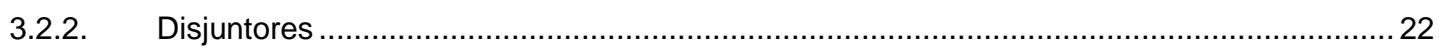

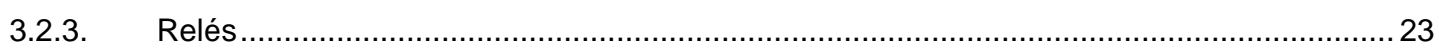

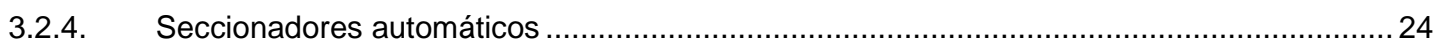

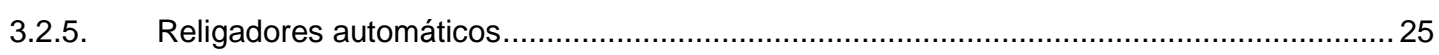

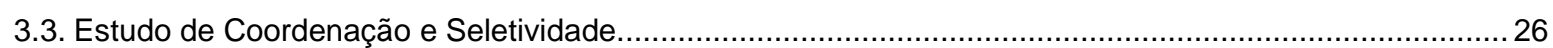

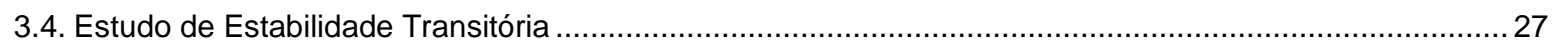

4. IMPACTO DA GERAÇÃO DISTRIBUÍDA SOBRE O SISTEMA DE PROTEÇÃO DE SOBRECORRENTE ....29

4.1. Sistema de Distribuição de Energia Estudado....................................................................... 30

4.2. Etapa 1 - Estudo de Coordenação e Seletividade sem a presença de Geradores Distribuídos ................31

4.3. Etapa 2 - Ajustes da Proteção no PAC para Entrada dos Geradores Distribuídos ................................... 35

4.4. Etapa 3 - Avaliação das Proteções de Sobrecorrente com o Sistema Operando Ilhado ............................38

4.4.1. Avaliação da proteção com os ajustes iniciais ......................................................... 41

4.4.2. Avaliação da proteção após a adoção de medidas corretivas ........................................... 49

5. ANÁLISE DINÂMICA DAS REGIÕES DE PROTEÇÃO DA REDE OPERANDO ILHADA .............................61

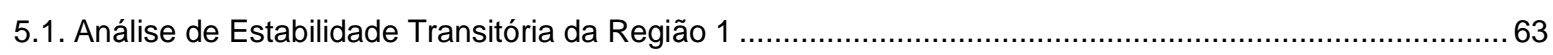

5.1.1. Curto-circuito trifásico simulado separadamente na barra 11 e na linha 20......................63

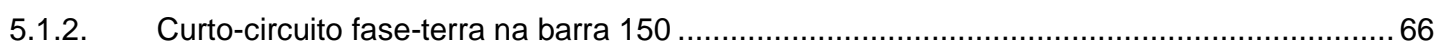

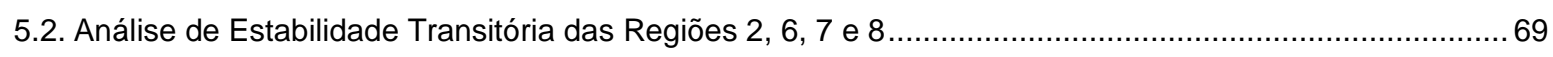

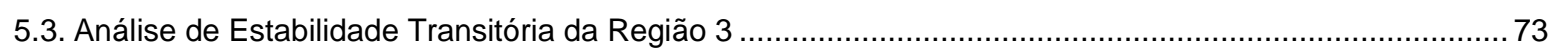

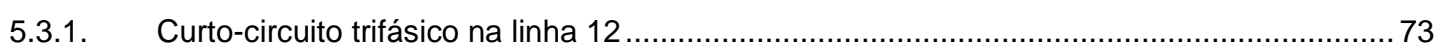

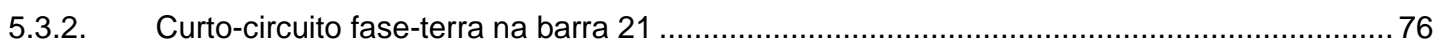

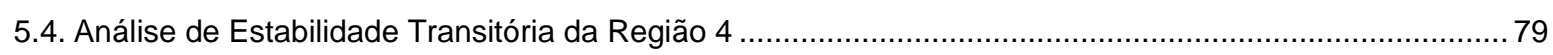

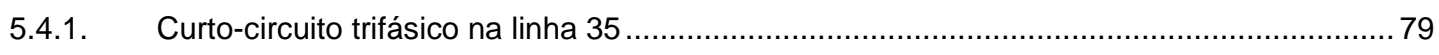

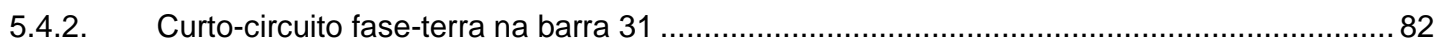

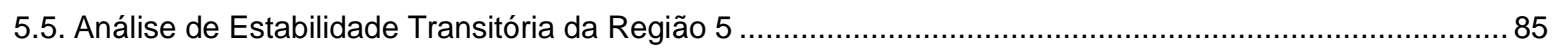

5.5.1. Curto-circuito trifásico simulado separadamente na barra 23 e na barra $63 \ldots \ldots \ldots \ldots \ldots \ldots \ldots . . . . . . . . . . . . .55$

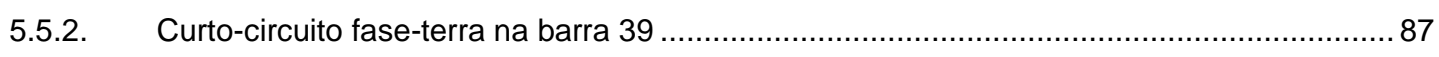

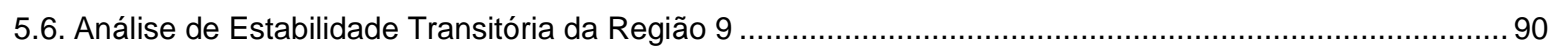

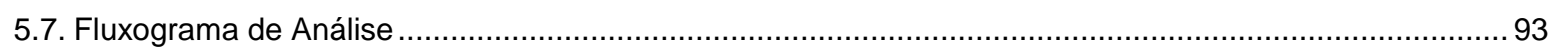




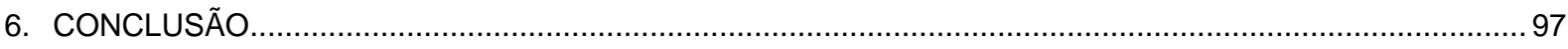

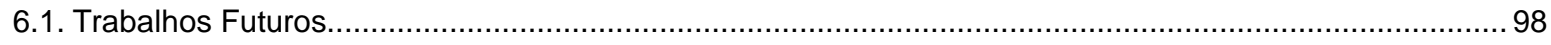

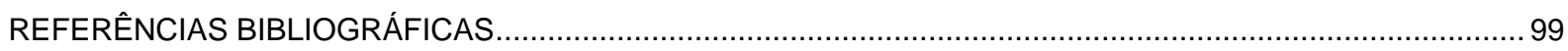

A. PROCEDIMENTO PARA REALIZAÇÃO do ESTUdO DE COORDENAÇÃO E SELETIVIDADE ................. 105

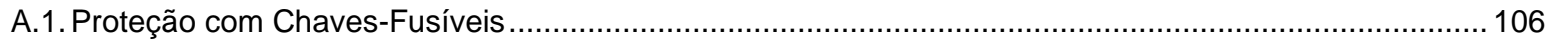

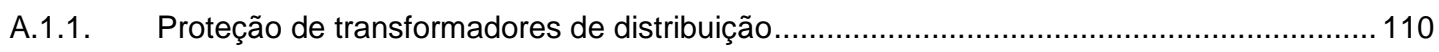

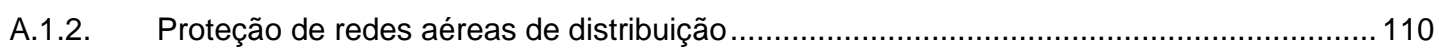

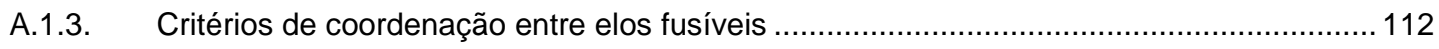

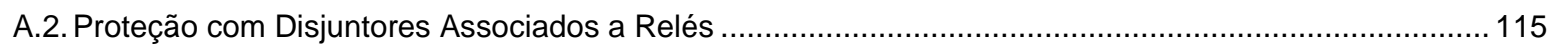

A.2.1. Ajuste da unidade temporizada do relé de sobrecorrente ............................................. 115

A.2.2. Ajuste da unidade instantânea ou de tempo definido do relé de sobrecorrente...................118

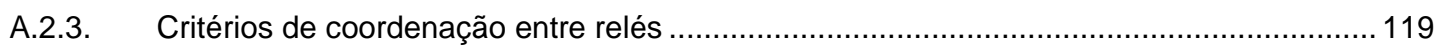

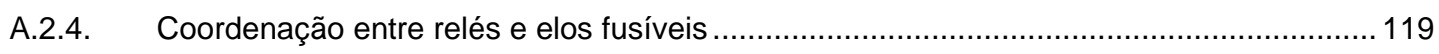

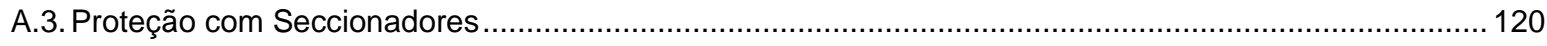

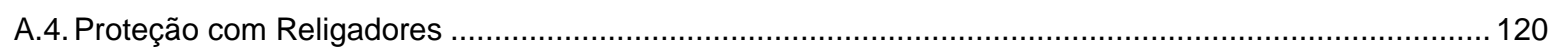

A.4.1 Ajuste da corrente de acionamento de religadores de subestação...................................... 120

A.4.2. Coordenação entre religadores de subestação e elos fusíveis ........................................... 121

A.4.3. Coordenação entre religadores de subestação e seccionadores....................................... 124

A.4.4. Coordenação entre religadores da subestação, seccionadores e elos fusíveis ................... 124

A.4.5. Coordenação entre religadores da subestação e religadores de distribuição ....................... 126

A.4.6. Coordenação entre os religadores de distribuição e elos fusíveis .....................................127

A.4.7. Coordenação entre religadores de distribuição e seccionadores....................................... 127

A.4.8. Coordenação entre religadores de distribuição, seccionadores e elos fusíveis ................... 128

A.4.9. Coordenação entre religadores de distribuição............................................................ 130

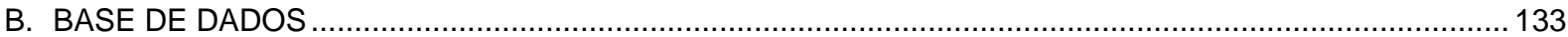




\section{INTRODUÇÃO}

A Geração Distribuída (GD) não é um conceito novo (Boberly \& Kreider, 2001). Na verdade, até que a eletricidade se consolidasse como uma alternativa comercial em substituição às outras fontes de energia até então utilizadas na primeira metade do século XIX, como vapor, calor e hidráulica, toda essa energia era produzida próxima ao local de consumo. Contudo, a criação da primeira companhia elétrica, por Thomas Edison em 1890, imitando a distribuição de gás para acendimento de lâmpadas, inaugurou uma implacável tendência em direção à geração centralizada de energia conectada a um sistema de distribuição.

Atualmente, o termo GD é utilizado para designar os projetos de geração de pequeno porte, conectados à rede de energia de forma dispersa, mais comum aos sistemas de distribuição, mas dependendo da capacidade, também são encontrados conectados aos sistemas de subtransmissão. Embora haja várias definições para o termo GD, de forma geral, refere-se à geração não despachada de forma centralizada e localizada próxima aos centros de consumo (Reis, 2003).

Esta forma de geração também tem sido denominada Geração Dispersa (Dispersed Generation), Geração Local (On Site Generation) e Geração Embutida (Embedded Generation) (Reis, 2003).

Nos últimos anos, por diversos motivos tem-se observado um interesse crescente neste tipo de geração, pois além dos aspectos técnicos, a desregulamentação do setor de energia elétrica tem gerado mudanças profundas no seu mercado. $O$ alvo principal tem sido a busca de um ambiente competitivo, inovador e voltado para os consumidores, onde os negócios têm êxito se focados nos interesses desses consumidores (Lora \& Haddad, 2006). Desta forma, a confiabilidade no suprimento, a melhoria da eficiência energética, diretamente relacionada à melhoria da qualidade da energia elétrica e os aspectos relacionados à preservação do meio ambiente, associados aos avanços tecnológicos têm colocado a GD em uma posição privilegiada em relação aos grandes sistemas centralizados.

Nesse âmbito, a operação ilhada apresenta-se como uma grande oportunidade oferecida pela GD. Logo, neste trabalho admite-se que a operação ilhada é um procedimento permitido e desejado pelas concessionárias e proprietários de geradores distribuídos.

Segundo a IEEE Standards Coordinating Committee 21 (2008), um ilhamento é definido como uma condição na qual uma parcela do Sistema Elétrico de Potência (SEP) é energizada exclusivamente por um ou mais geradores distribuídos, sendo que esta parcela está eletricamente separada do restante do sistema elétrico. Esta definição não separa 
ilhamento intencional, no qual existe a desconexão segura do alimentador, de ilhamento acidental ou não intencional, no qual a potência flui não somente direto para as cargas do usuário, mas também em direção ao alimentador e, possivelmente, para outras cargas. Daí a importância de definir se o ilhamento é intencional ou não, quando fizer referência às características da proteção.

Atualmente, as proteções instaladas no ponto de conexão do gerador distribuído com a rede elétrica são ajustadas para evitar a operação ilhada, intencional ou não, embora exista uma tendência de permitir a operação ilhada como forma de elevar a confiabilidade do suprimento de energia elétrica (Agência Nacional de Energia Elétrica - ANEEL, 2010).

Quando ocorre a formação de uma ilha sustentada, perde-se a principal fonte de corrente de curto-circuito: a subestação da concessionária. Consequentemente, perde-se a coordenação dos dispositivos de proteção de sobrecorrente no sistema ilhado, a velocidade de atuação dos mesmos também pode ser significativamente reduzida e, em casos extremos, a proteção pode não ser sensibilizada caso ocorra uma falta na ilha formada. Tem-se, neste aspecto, um grande desafio à operação ilhada, visto que ramais de distribuição de energia elétrica são normalmente protegidos por fusíveis, portanto, dispositivos de proteção de sobrecorrente não reajustáveis.

Uma alternativa para corrigir o referido problema é a substituição dos fusíveis por relés microprocessados com múltiplos ajustes. Assim, uma vez detectado o ilhamento, esses relés poderiam ser automaticamente reajustados à nova condição de operação do sistema elétrico. Embora eficiente, trata-se de uma solução de elevado custo, além de aumentar a complexidade da proteção de alimentadores de distribuição.

Outro aspecto, também relacionado à proteção, refere-se à conexão dos enrolamentos do transformador de acoplamento do gerador distribuído. Algumas concessionárias requerem que o enrolamento primário (lado da rede de distribuição) desse transformador seja conectado em delta, enquanto outras exigem que seja em estrela aterrada. Uma das razões para o uso da conexão em delta é impedir que o gerador distribuído contribua com corrente de falta quando ocorrerem curtos-circuitos fase-terra na rede de distribuição. Assim, com a ocorrência do ilhamento, perde-se o aterramento, pois a referência de terra (subestação da concessionária) fica desconectada. Como consequência disso, curtoscircuitos fase-terra na rede de distribuição não serão detectados pelos dispositivos de proteção contra sobrecorrente. No entanto, este problema pode ser resolvido pela conexão de um transformador de aterramento quando o ilhamento for detectado (Dalke, et al., 2011).

Diante do exposto, percebe-se que a manutenção de uma ilha energizada carece de estudos detalhados na área de proteção do sistema de distribuição e dos geradores distribuídos. Uma visão geral das questões relacionadas ao sistema ilhado com fonte distribuída é encontrada no documento IEEE Std 1547.4 ${ }^{T M}-2011$ - IEEE Guide for Design, 
Operation, and Integration of Distributed Resource Island Systems with Electric Power Systems, o qual contribui em evidenciar a importância de estudar os impactos da geração distribuída sobre o sistema de proteção da rede de distribuição (IEEE Standards Coordinating Committee 21, 2011).

\subsection{Justificativas e Objetivos}

Com base no exposto anteriormente, esta dissertação de mestrado tem como objetivo avaliar o impacto da GD sobre o sistema de proteção de sobrecorrente de uma rede de distribuição de energia, incluindo o ponto de acoplamento comum entre concessionária e gerador distribuído (PAC) após a ocorrência do ilhamento e propor medidas que permitam a operação ilhada de forma segura, utilizando somente os dispositivos de proteção de sobrecorrente já existentes na rede. Os novos ajustes feitos ao sistema de proteção de sobrecorrente serão validados por meio de uma análise de estabilidade transitória do sistema de geração. No final será apresentado um fluxograma para tomada de ações que permitam readequar o sistema de proteção de sobrecorrente existente à nova condição operacional.

O foco desta análise serão os geradores distribuídos baseados em máquinas síncronas, os quais estão presentes em aplicações mais comuns, tais como pequenas centrais hidroelétricas (PCHs) e centrais de cogeração movidas à biomassa, gás natural ou diesel, sendo este último, o motor de combustão a diesel, considerado como máquina primária neste trabalho.

Como a rede de distribuição de energia é geralmente protegida por dispositivos simples de proteção (Giguer, 1988; Eletrobras, Comitê de Distribuição, 1982; Gers \& Holmes, 2011; Mamede Filho \& Mamede Ribeiro, 2011), tais como relés de sobrecorrente, religadores, seccionadores e fusíveis, estas proteções sofrem alterações com a presença da GD, operando em paralelo com o sistema de distribuição. Assim, elas deverão ser novamente analisadas quando da ocorrência do ilhamento, pois problemas como redução da sensibilidade da proteção, falsa operação, descoordenação entre fusível-religador e fusível-fusível e falha no autorreligamento podem ocorrer para este tipo de operação.

Portanto, serão avaliadas as dimensões de tal impacto e com isso serão estudadas medidas alternativas para o sistema de proteção de sobrecorrente existente, visando garantir a segurança dos equipamentos e usuários da rede elétrica após a ocorrência do ilhamento. Para isso, as medidas propostas deverão procurar atender aos seguintes requisitos (Giguer, 1988; Gers \& Holmes, 2011; Mamede Filho \& Mamede Ribeiro, 2011):

- Seletividade: a proteção deve somente isolar a parte do sistema atingida pelo defeito, mantendo a continuidade do serviço das demais partes do sistema. 
- Rapidez: as sobrecorrentes geradas pelos curtos-circuitos ou sobrecargas devem ser extintas no menor tempo possível, reduzindo a probabilidade de propagação dos defeitos.

- Sensibilidade: a proteção deve ser suficientemente sensível a defeitos que possam ocorrer durante a operação do sistema. Por sensibilidade entende-se como o menor valor da grandeza capaz de ativar o dispositivo de proteção.

- Segurança: o sistema de proteção não deve realizar uma falsa operação sob condições normais de operação, ou falhar no caso de faltas no sistema.

- Economia: o sistema de proteção deve ter sua implantação viável economicamente, evitando-se um número excessivo de dispositivos de proteção.

\subsection{Organização da Dissertação}

Esta dissertação de mestrado está organizada da seguinte forma:

- No capítulo 2, serão apresentados aspectos importantes da proteção em sistemas de distribuição com geradores distribuídos, sobretudo com relação à proteção de sobrecorrente juntamente com uma revisão bibliográfica do assunto, abordando a proteção da rede antes e após o ilhamento.

- No capítulo 3, será apresentada a filosofia da proteção em sistemas de distribuição, a terminologia correspondente, os principais dispositivos empregados na proteção de sistemas de distribuição de energia, os conceitos de coordenação, seletividade e estabilidade transitória.

- No capítulo 4, serão avaliados os impactos da GD na rede de distribuição operando ilhada. Para isso, inicialmente será apresentado o dimensionamento da proteção de sobrecorrente sem a presença da GD; em seguida, será mostrado o comportamento da proteção mediante a entrada da GD operando em paralelo com a rede de distribuição, para finalmente provocar a operação ilhada e analisar seus impactos no sistema de proteção de sobrecorrente. Neste capítulo também será apresentada a metodologia utilizada para abordagem do problema. As proteções de sobrecorrente serão analisadas com o sistema ilhado, segundo a metodologia proposta, juntamente com as medidas corretivas adotadas no sistema de proteção existente para operação em ilhamento intencional.

- No capítulo 5, será apresentada uma análise dinâmica do sistema com o objetivo de validar as medidas adotadas, juntamente com um fluxograma das ações tomadas na análise do problema.

- No capítulo 6, serão apresentadas as conclusões e sugestões para futuros trabalhos. 
- O Anexo A contém o procedimento utilizado para realização do estudo de coordenação e seletividade e os critérios de coordenação entre os diferentes dispositivos de proteção.

- O Anexo B contém a base de dados da rede de distribuição de energia utilizada no estudo.

É importante informar que, considerando a forma como este trabalho está organizado, até o momento de sua apresentação, ele gerou a publicação do artigo abaixo, o qual trata dos resultados parciais obtidos por meio da realização do estudo de coordenação e seletividade, sem ainda considerar a análise dinâmica do problema.

- SGUACABIA, R. R.; VIEIRA, J. C. M. Avaliação do Impacto da Geração Distribuída sobre o Sistema de Proteção de Sobrecorrente de uma Rede de Distribuição Operando Ilhada. In: IEEE INDUSCON 2014 - XI International Conference on Industry Applications, 2014, Juiz de Fora. Anais. Juiz de Fora, 2014. P.1-7. 


\section{ASPECTOS DA PROTEÇÃO EM SISTEMAS DE DISTRIBUIÇÃO COM GERADORES DISTRIBUÍDOS}

Diferentes aspectos da proteção em sistemas de distribuição com geradores distribuídos podem ser identificados (Jenkins, et al., 2008), dentre eles estão:

- Proteção de faltas internas nos equipamentos de geração;

- Proteção da rede de distribuição contra correntes de falta sustentadas pela geração distribuída;

- Proteção de anti-ilhamento e

- Impacto da GD no sistema de proteção existente.

Desta forma, inúmeros trabalhos abordando os diversos aspectos da proteção em sistemas de distribuição com geradores distribuídos são encontrados. Para uma melhor compreensão do assunto, a revisão bibliográfica será apresentada em quatro etapas, a saber:

- Trabalhos relacionados à GD e o sistema de proteção de sobrecorrente da rede de distribuição antes do ilhamento;

- Trabalhos relacionados à detecção do ilhamento;

- Trabalhos relacionados à GD e o sistema de proteção de sobrecorrente da rede de distribuição na operação ilhada;

- Considerações sobre o presente capítulo.

\section{1. $\quad$ A GD e o Sistema de Proteção de Sobrecorrente da Rede de Distribuição Antes do Ilhamento}

Com relação aos trabalhos que exploram o impacto da GD no sistema de proteção de sobrecorrente da rede de distribuição, Brahma \& Girgis (2003) mostram como a coordenação entre fusíveis e entre fusíveis e religadores em sistemas de distribuição pode ser perdida com a alta penetração de geradores distribuídos. Nesse trabalho os autores propõem um esquema de proteção adaptativa, capaz de assumir diferentes ajustes de proteção, que atenda tanto a faltas temporárias como permanentes na rede, e sua região de implementação possa ser estendida para mais de um alimentador. O esquema proposto permite a operação ilhada intencional. No entanto, os disjuntores precisam ser equipados com função de verificação de sincronismo, os relés precisam ser digitais e capazes de armazenar grande quantidade de dados e analisá-los, além de serem capazes de se comunicar com outros dispositivos de proteção. Esta situação não representa o cenário atual da grande maioria das redes de distribuição brasileiras. No trabalho apresentado por 
Brito et al. (2004), os motivos que têm contribuído para que a geração distribuída esteja cada vez mais presente nos sistemas elétricos do mundo todo são apresentados de forma sucinta e os impactos que a inserção deste tipo de geração pode causar na coordenação da proteção são discutidos. Para isso os autores desenvolveram um programa chamado SiGDist - Simulator of Distribution Systems with Distributed Generation, o qual calcula fluxo de potência, curto-circuito e verifica a coordenação da proteção, observando basicamente se a proteção primária continua atuando antes da proteção de retaguarda, após a entrada da geração distribuída. No trabalho não foi estudado nenhum caso de verificação da coordenação da proteção considerando o sistema ilhado.

A questão da proteção durante o ilhamento é novamente abordada por Benato, Caldon \& Corsi (2005), que em seu trabalho exploram a possibilidade de aplicar novos esquemas de proteção utilizando técnicas inovadoras e tradicionais. Para detectar uma seção da rede sob falta na presença de geradores distribuídos, a solução proposta é dividir a rede em zonas separadas por disjuntores equipados com a função de verificação de sincronismo (ANSI 25), as quais podem ser ativadas por sinal remoto localizado na subestação. No entanto, isso só é conseguido através de um método de comunicação direta, um sistema de ondas portadoras em linhas de alta tensão, por exemplo, utilizado em outro trabalho desenvolvido pelos mesmos autores (Benato, et al., 2003). Além disso, os autores afirmam que a questão da proteção durante o ilhamento intencional deve ser atacada mesmo se o ilhamento não for permitido pela maioria das concessionárias, pois este tópico será importante no futuro, considerando a dificuldade de ampliação do sistema de transmissão através da construção de novas redes.

Para Zeineldin, El-Saadany \& Salama (2006), a proteção é vista como um dos mais importantes desafios a ser considerado para operação de microrredes que podem ser formadas após a desconexão da concessionária, pois as correntes de falta na região ilhada podem mudar e causar operação incorreta dos dispositivos de proteção. O trabalho desses autores é desenvolvido baseado em geradores distribuídos conectados à rede por meio de inversores, os quais não fornecem correntes de curto-circuito elevadas o suficiente para sensibilizar dispositivos de proteção de sobrecorrente. O objetivo do trabalho é propor um esquema de controle e proteção que permita a operação segura da microrrede. No que tange à estratégia utilizada para o esquema de proteção, os autores utilizam relés diferenciais nas linhas que interligam os geradores distribuídos à concessionária. Desta forma, é possível manter um ajuste baixo para a corrente de disparo, sem afetar a coordenação quando o sistema está ilhado e em paralelo. Uma lógica é desenvolvida de tal forma que o sistema de controle possa interagir com o sistema de proteção e identificar se a rede está operando em paralelo ou ilhada, e assim alterar sua forma de controle, do modo $\mathrm{P}-\mathrm{Q}$ (em que a potência ativa $\mathrm{P}$ e a potência reativa $\mathrm{Q}$ injetadas pelo gerador permanecem 
constantes) para modo de controle $f-V$ (quando a frequência $f$ e a tensão $V$ são mantidas constantes) dentro do limite de tempo permitido. O estudo não aborda outros dispositivos de proteção, tais como religadores, fusíveis e seccionadores automáticos, os quais são muito comuns em redes de distribuição.

Em Pholborisut et al. (2011), um índice para avaliação quantitativa da descoordenação da proteção do sistema de distribuição com a presença de geradores distribuídos é apresentado. O valor do índice indica a probabilidade de ocorrência de descoordenação da proteção no sistema, para com isso avaliar a capacidade máxima permitida de geradores distribuídos que poderão ser inseridos no sistema, de forma a manter a coordenação da proteção. Nesse trabalho é considerada apenas a descoordenação entre fusível e religador automático. O estudo mostrou que a capacidade e a localização dos geradores distribuídos têm impacto no valor do índice de descoordenação e, de forma geral, quanto maior a capacidade do gerador distribuído, mais alto é o valor do índice, implicando em maiores chances de haver descoordenação. A operação em ilha não é considerada no artigo.

Em Mohamad et al. (2011), os autores fazem uma revisão dos estudos relacionados ao ilhamento. Primeiramente é apresentado o conceito de ilhamento e a diferença entre ilhamento intencional e não intencional. Também são apresentadas as várias questões relativas a este último, tais como: qualidade da energia elétrica, religamento fora de sincronismo, aterramento durante o ilhamento, segurança do pessoal de manutenção da concessionária e proteção do sistema ilhado. No que diz respeito ao sistema de proteção é apenas comentado que a presença de geradores distribuídos no sistema de distribuição traz um impacto significante na operação e coordenação do sistema de proteção, pois os geradores distribuídos podem interferir na coordenação da proteção existente alterando a corrente de falta. Este mesmo problema também ocorre na proteção do sistema ilhado, com a mudança da configuração da rede de distribuição. Embora o ilhamento não intencional seja proibido, a operação ilhada será uma solução factível quando as questões apresentadas anteriormente forem resolvidas. $O$ artigo detalha as várias abordagens adotadas para permitir a operação e gerenciamento do sistema ilhado, considerando principalmente geradores síncronos. São discutidos desde os métodos de detecção do ilhamento, até o sistema de controle de velocidade e tensão para os geradores síncronos e, por último, os autores adiantam que a incorporação da tecnologia de redes inteligentes (smart grids) nos sistemas de distribuição trará grande melhoria para a realização da operação ilhada.

Dewadasa et al. (2011) mostram como a falta pode ser isolada em uma rede radial contendo geradores distribuídos conectados ao sistema elétrico por meio de inversores, de forma que a operação ilhada possa ocorrer utilizando relés de sobrecorrente e o sistema possa ser restaurado utilizando religadores automáticos. Para que o objetivo seja alcançado, 
os relés devem ter a capacidade de distinguir correntes de falta reversa e direta. Os relés devem possuir ajustes diferentes para a função reversa e direta, por este motivo são utilizados relés de sobrecorrente direcionais. Para mudar os ajustes dos relés de acordo com a configuração do sistema, função conhecida como proteção adaptativa, também é necessário um meio de comunicação entre os relés direcionais e os geradores distribuídos, e, no caso de uma falha na comunicação, cada relé assume um ajuste predefinido. Para a restauração do sistema, é considerado que o relé de sobrecorrente direcional esteja também conectado ao religador automático. Neste esquema de proteção, os inversores devem ter a capacidade de alimentar a corrente de falta por um determinado período de tempo para que os relés possam isolar a falta. O estudo limita-se apenas aos geradores com inversores.

\subsection{Detecção do Ilhamento}

No que diz respeito aos trabalhos relacionados à detecção do ilhamento, Conti \& Raiti (2009) focam no desenvolvimento de novos critérios para gerenciar as proteções da rede de distribuição com as proteções do ponto de interface do gerador distribuído, de forma coordenada. O esquema de proteção proposto é concebido para evitar o ilhamento não desejado de partes da rede de distribuição e quando necessário permitir a operação ilhada da microrrede formada. São estudadas situações considerando faltas externas com permissão para operação em ilha e faltas internas à microrrede. Para que o sistema funcione de forma autônoma, foi empregado o sistema Carrier para prover comunicação entre os relés dos geradores e da concessionária envolvidos na proteção.

Em Mahat et al. (2011), as características de atuação dos relés são atualizadas através da detecção do estado de operação do siste7ma, ou seja, GD conectada à rede principal ou ilhada, e da localização da seção em falta. O esquema adaptativo, capaz de assumir diferentes ajustes para as funções de proteção, escolhido pelos autores foi um esquema de proteção utilizando relés de sobrecorrente direcionais baseados em microprocessadores, usando somente informação local. A seção em falta é determinada através da medição de corrente usando a característica de tempo versus corrente dos relés à jusante. $\mathrm{O}$ artigo limita-se somente à faltas trifásicas e a metodologia é simulada no programa DIgSILENT Powerfactory, (DIgSILENT GmbH, 2013).

Quando se trata de detectar a perda da concessionária e a possível formação de uma ilha sustentada pela presença de geradores distribuídos no sistema, atenção especial é dada à proteção presente no PAC. Com relação a esse aspecto, a proteção da interconexão do gerador distribuído assume diferentes configurações dependendo da concessionária de distribuição de energia detentora da rede na qual o gerador será inserido. As concessionárias impõem seus padrões com relação ao sistema de proteção utilizado, tipo de 
conexão do enrolamento do transformador de acoplamento e configuração do aterramento do neutro, com o propósito de manter a segurança e funcionalidade de seu sistema.

Com esse mesmo objetivo, o IEEE Standards Coordinating Committee elaborou um guia chamado IEEE Aplication Guide for IEEE Std 1547, IEEE Standard for Interconnecting Distributed Resources with Electric Power Systems, (IEEE Standards Coordinating Committee 21, 2008), o qual cobre seis diferentes tópicos relacionados à implementação de projetos de fontes distribuídas e impactos no sistema. A cada tópico citado o referente guia de aplicação é fornecido.

O guia se aplica a todas as tecnologias de fontes distribuídas de capacidade agregada igual ou menor a 10 MVA no PAC que são interconectadas com uma área do SEP em tensão de distribuição primária ou secundária típica. O guia não define a capacidade máxima da fonte distribuída para uma instalação particular que pode ser interconectada com um único PAC ou conectada a um dado alimentador.

O ilhamento intencional é coberto pelo documento IEEE Std $1547.4^{T M}-2011$ - IEEE Guide for Design, Operation, and Integration of Distributed Resource Island Systems with Electric Power Systems, que tem como objetivo fornecer uma visão geral e dar um direcionamento para questões relacionadas ao sistema ilhado com fontes distribuídas. $\mathrm{O}$ termo "Sistema Ilhado com Fontes Distribuídas", às vezes referido como microrredes, é usado para designar o ilhamento intencional, e têm as seguintes características básicas (IEEE Standards Coordinating Committee 21, 2011):

a) Possuem fontes distribuídas e cargas;

b) Possuem capacidade para operar em paralelo com a rede elétrica e em modo isolado;

c) Incluem o sistema elétrico local e pode incluir porções de outros sistemas e

d) São intencionalmente planejados.

Para que o ilhamento intencional ocorra de forma adequada, são necessárias fontes distribuídas confiáveis e uma cuidadosa coordenação com os equipamentos de proteção e seccionamento dos sistemas de distribuição. Isto inclui preocupações com:

a) Risco de reconexão fora de fase nos pontos abertos;

b) Possível dano a equipamentos devido a anomalias na tensão e frequência;

c) Fontes distribuídas adequadas;

d) Redução da confiabilidade do sistema elétrico devido ao aumento da complexidade do sistema;

e) Segurança do público em geral, pessoal da manutenção e operação;

f) Possível redução da qualidade da energia elétrica;

g) Mudança significante do nível de curto-circuito do modo ilhado para o normal;

h) Diferentes configurações do sistema de aterramento; 
i) Coordenação com esquemas de rejeição de carga;

j) Regulação de tensão e frequência;

k) Desbalanceamento de carga nas fases;

I) Compatibilidade entre capacidades de carga e geração;

m) Consequências do possível adiamento de melhorias no sistema de distribuição devido à presença do ilhamento $\mathrm{e}$

n) Coordenação da proteção do sistema elétrico.

O último item é a preocupação principal deste trabalho, uma vez que a coordenação dos dispositivos de proteção deve ser mantida em ambos os modos de operação, ou seja, ilhado ou em paralelo, dos geradores distribuídos. Todas as faltas ocorridas dentro do sistema ilhado devem ser detectadas e eliminadas, da mesma forma como ocorria quando o sistema estava operando em paralelo. Como exemplo, a Figura 2.1, ilustra diferentes configurações de sistemas operando em ilha, como, por exemplo: ilha formada pelo gerador distribuído alimentando somente as cargas da planta do proprietário do gerador, ilha formada por mais de um gerador através da abertura do disjuntor do transformador de acoplamento, o qual pode estar instalado no secundário ou no primário do transformador, ilha formada pela abertura do disjuntor de um dos barramentos da subestação, etc.

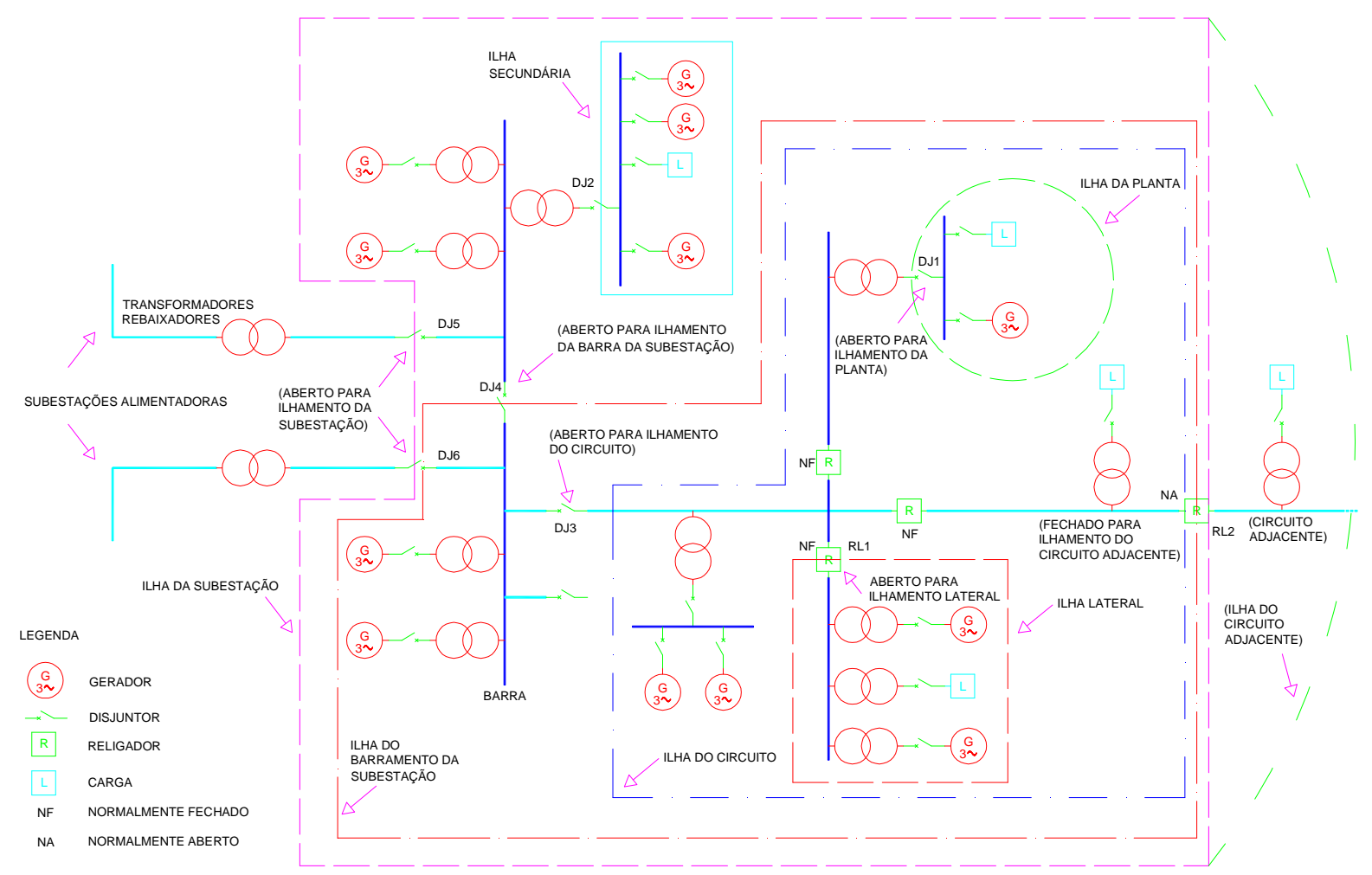

Figura 2.1 - Exemplos de Sistemas Ilhados (IEEE Standards Coordinating Committee 21, 2008). 


\subsection{A GD e o Sistema de Proteção de Sobrecorrente da Rede de Distribuição após o llhamento}

Fuangfoo et al. (2007) salientam em seu trabalho que, devido ao alto custo envolvido nos desligamentos, tanto os causados por faltas no sistema, quanto os por manutenção programada podem despertar o interesse das concessionárias pela operação em ilha intencional. Nesse estudo é admitido que o sistema de proteção é capaz de separar a parte em falta da área ilhada antes que os geradores possam realizar a operação ilhada intencional e alimentar a falta. Também é admitido que os dispositivos de proteção podem se ajustar automaticamente para início da operação em ilha. O estudo é feito considerando somente geradores síncronos. Três tipos de distúrbios são considerados no estudo dinâmico para a verificação da operação em ilha, são eles: partida de um grande motor; rejeição e absorção de carga; e falta no sistema ilhado. Nestas três situações é observada apenas a resposta dos geradores em frequência e tensão. No entanto, os autores mostram que em muitos casos o sistema de proteção precisa ser alterado durante a operação em ilha, porém, não entram em detalhes. No final do artigo é apresentado um fluxograma para realização da operação ilhada, que basicamente informa que a capacidade de geração deve ser maior que a carga total do sistema e que, caso isso não ocorra, um esquema de rejeição de carga é necessário, seguido de alterações de ajustes na proteção. Para retornar à operação em paralelo, é necessário desligar os geradores distribuídos e fazer a ressincronização com a rede principal.

Em outro trabalho, Fuangfoo et al. (2008) apresentam um guia de estudo de operação e impacto para a operação em ilha com gerador distribuído síncrono, com controle de velocidade e excitação. O estudo de impacto é dividido em três partes: formação da ilha; operação durante o ilhamento e ressincronização. A formação da ilha é classificada de acordo com a sua causa: ilha formada for falta no sistema e ilha formada por desligamento devido à manutenção programada. $\mathrm{O}$ artigo considera, no caso de falta no sistema, que a confiabilidade é melhorada pela formação da ilha da seguinte maneira: primeiro, com a desconexão da parte em falta da rede principal, ou seja, a falta é isolada; em seguida, desenergizando as cargas do sistema ilhado, através do desligamento do gerador distribuído; e por último, reconectando as cargas ao sistema ilhado. Para o ilhamento causado devido ao desligamento para manutenção, a potência das cargas que serão alimentadas pelo gerador distribuído deve ser menor e próxima à capacidade nominal do gerador. Na operação durante o ilhamento é investigada a capacidade de absorção e rejeição de carga, falta no sistema ilhado e regulação de tensão, com especial atenção ao comportamento da resposta em frequência e tensão do gerador distribuído, visando o ajuste adequado das proteções de tensão e frequência do gerador. A ressincronização é feita com 
a desconexão do gerador distribuído da ilha e posterior ressincronização, e nesse intervalo de tempo, as cargas do sistema ilhado são desenergizadas. No final do artigo é apresentado um estudo de caso. No entanto, no que se refere aos dispositivos de proteção durante a operação em ilha, o artigo preocupa-se apenas com as proteções de tensão e frequência do gerador e os impactos na proteção contra sobrecorrente da rede não são investigados.

Em Javadian \& Haghifam (2008a), os autores propõem um algoritmo para proteção de redes de distribuição na presença de geradores distribuídos. A ideia proposta é fazer um zoneamento da rede de distribuição, na qual cada zona é uma seção independente capaz de operar em ilha. Interconectando as diferentes zonas ao sistema, existem disjuntores com capacidade de abertura e fechamento através de comando remoto, sendo equipados com função de verificação de sincronismo. Depois de dividir o sistema em várias zonas independentes, deve ser instalado um relé inteligente na subestação de subtransmissão, que é um dispositivo de proteção microprocessado capaz de executar um determinado algoritmo. O diagnóstico exato da localização da falta é feito por este relé comparando as correntes medidas nas fontes geradoras com resultados de cálculos realizados off-line, tais como fluxo de carga e curto-circuito, e após a comparação são enviados comandos de abertura para os disjuntores responsáveis pelo isolamento da zona com falta. $O$ algoritmo também tem a capacidade de realizar operação de religamento de forma coordenada com fusíveis e, após a eliminação da falta, a restauração da rede é feita através de operação de sincronização enviando comando de fechamento aos disjuntores. Segundo os próprios autores, a proposta tem algumas fraquezas, como, por exemplo, não ser capaz de diagnosticar faltas de alta impedância. Além disso, quando o número de geradores distribuídos aumenta, aumenta também o número de disjuntores necessários para isolar as zonas independentes formadas. Assim, o esquema pode não ser economicamente viável.

Em Javadian \& Haghifam (2008b), os autores implementam a ideia do artigo Javadian \& Haghifam (2008a) em um sistema real de distribuição. O esquema proposto é melhorado através do acréscimo de um algoritmo de rejeição de carga, que deve ocorrer sempre que a carga da zona ilhada for maior que a capacidade de geração do gerador ou geradores distribuídos existentes nesta zona.

Em Dalke et al. (2011) são discutidas questões associadas ao ilhamento de um sistema de potência de uma Planta Industrial ou Comercial de Geração de Energia (PICG) onde um gerador síncrono opera em paralelo com a fonte da concessionária. Diferentes cenários de operação de ilhamento são apresentados e questões são levantadas, como, por exemplo: "É necessário obrigar a separação de cargas consideradas fora das regiões do proprietário da fonte de energia, enquanto mantém o serviço para cargas dentro das regiões do proprietário, ou simplesmente desligar a PICG até que a rede possa ser restaurada?" Assim, o primeiro passo em relação à proteção de ilhamento é ter uma ideia clara sobre o 
que é possível acontecer quando o ilhamento é criado. $O$ artigo discute, com base na proteção exigida, como sua operação irá prevenir consequências indesejáveis ao proprietário da PICG, à concessionária e ao público em geral. Ele discute ações que ocorrem quando o fornecimento da concessionária é interrompido criando condições de ocorrer um ilhamento, define os limites do ilhamento e explica as razões pelas quais, determinada proteção é requerida pelas agências regulatórias, concessionárias locais, e documentos, tais como IEEE Standard 1547 Standard for Interconnecting Distributed Resources with Electric Power Systems (IEEE Standards Coordinating Committee 21, 2008). As consequências de não ter uma proteção local podem danificar o gerador e/ou seu acionamento (turbina ou motor) além de ser um risco à segurança do público. As reações de diferentes tipos de geradores, motores e turbinas de diferentes modos de controle (estatismo, potência constante e base de carga), são discutidas, bem como o impacto que o tipo de conexão dos transformadores de acoplamento tem sobre a proteção do ilhamento, analisando com detalhes as diferentes funções de proteção. A conclusão mostra que as proteções de ilhamento podem ser condicionais, dependendo se a ilha é intencional ou não. O artigo mostra também que o custo da proteção pode ser mais alto para alguns tipos de geradores e turbinas ou motores e que a proteção de ilhamento é baseada na arte da aplicação de elementos de relés de proteção de acordo com as exigências das agências regulatórias.

Em Buque et al. (2012), os autores apresentam a proteção adaptativa como uma das soluções para atender à coordenação da proteção da microrrede operando em modo ilhado e conectada à rede principal. $\mathrm{O}$ artigo apresenta o desenvolvimento de um esquema de proteção de sobrecorrente adaptativa para uma micro-rede usada como teste, na qual os ajustes dos relés são alterados automaticamente, após serem informados sobre o modo de operação da rede, ilhada ou em paralelo, para se adequar ao modo de operação da microrrede e garantir a correta sensibilização da falta, mantendo a coordenação do sistema de proteção. Antes de enviar o sinal de abertura para o disjuntor, o modelo proposto identifica o modo de operação da microrrede, conectada à rede principal ou ilhada, daí a necessidade de comunicação entre os relés. Em seguida, selecionam-se os ajustes previamente determinados para cada modo de operação e finalmente envia-se o sinal de abertura. O modelo do relé foi desenvolvido utilizando o Matlab/Simulink (The MathWorks, Inc., 1994). Os relés utilizaram curva normal inversa para estudar os casos propostos. Não foram considerados outros dispositivos de proteção no sistema, tais como fusíveis e religadores, que geralmente utilizam curvas, muito inversa e extremamente inversa para conseguir maior faixa de coordenação com os relés de sobrecorrente.

Com relação à coordenação da proteção de sobrecorrente durante a operação ilhada, o sistema de proteção da rede com fonte distribuída precisa ser capaz de detectar faltas no 
sistema formado (IEEE Standards Coordinating Committee 21, 2011). Isto inclui mudanças no tempo de coordenação, sensibilidade e direcionalidade, onde aplicável. Modificações no sistema elétrico podem ser necessárias para acomodar o ilhamento planejado, devido à diminuição da corrente de falta. As práticas de religamento também precisam ser examinadas, pois há muitas configurações de sistemas de distribuição e diferentes práticas e filosofias para eliminação da falta entre as diversas concessionárias.

Como os sistemas de distribuição geralmente são radiais e não projetados para operação paralela com fontes distribuídas, as concessionárias utilizam frequentemente dispositivos de proteção monofásicos e trifásicos, tais como fusíveis e religadores monofásicos. Além disso, são feitas várias tentativas de religamento antes do dispositivo de proteção abrir permanentemente. O religamento pode ser instantâneo ou com atraso de alguns segundos ou mais. Assim, esquemas de proteção com fusível protegido são muito comuns em linhas de distribuição aéreas (Mamede Filho \& Mamede Ribeiro, 2011). No esquema de fusível protegido, o religador, ou disjuntor deve operar rapidamente e eliminar a falta antes do fusível ser danificado. Caso a falta persista, então deve ser eliminada pela queima do fusível.

Todas as verificações precisam ser feitas para determinar se a falta será eliminada de acordo com a estratégia de proteção aplicada pela concessionária. Estas verificações incluem determinar se todos os tipos de faltas em qualquer lugar no sistema ilhado serão eliminados. Os dispositivos de proteção já instalados no circuito podem estar ajustados para atuar além da corrente de falta fornecida pela GD. Como a condição de ilhamento intencional é provavelmente temporária, poderá não ser possível substituir ou reajustar os dispositivos de proteção de forma a estabelecer uma atuação seletiva para a ilha formada.

Conforme pôde ser observado nos trabalhos descritos anteriormente, a proteção adaptativa tem se mostrado como uma solução comum.

Em Coffele, Booth \& Dysko (2014), a proteção adaptativa é explorada, porém, utilizando-se de um gerenciamento ativo da rede de energia, composto de um sistema de comunicação e de um algoritmo de cálculo para ajuste em tempo real da proteção, de acordo com as características operativas do sistema elétrico. Essa proposta se diferencia das demais porque os ajustes são determinados em tempo real e não previamente. Para que essa proposta seja bem sucedida, mecanismos de comunicação e automação são determinantes para o seu correto funcionamento, entretanto, implicam em altos custos de implantação. Convém, nesses casos, realizar um estudo de viabilidade técnico-financeira para verificar se o esquema a ser implantado irá gerar benefícios econômicos à distribuidora, conforme demonstrado por Paulis et al. (2014). 


\subsection{Considerações Finais Sobre o Capítulo}

Nos vários trabalhos apresentados neste capítulo, os autores procuram apresentar uma solução definitiva para o problema da perda de coordenação entre os dispositivos de proteção de sobrecorrente para a rede de distribuição operando ilhada, sendo que em muitos desses trabalhos a proteção adaptativa, utilizando relés inteligentes dotadas de um sistema de comunicação, tem se mostrado como uma solução comum. No entanto, todas essas soluções envolvem a implementação de novos recursos, incialmente inexistentes na rede de distribuição, sendo conveniente realizar um estudo de viabilidade técnico-financeira para a implantação da solução proposta. Ainda, como parte da solução proposta, alguns autores utilizam relés direcionais de sobrecorrente e às vezes relés diferenciais para delimitar as regiões ilhadas. Essas regiões são formadas de modo a compatibilizar a carga a ser alimentada com a capacidade de geração disponível na ilha.

Mas o que é possível fazer para permitir a operação ilhada, utilizando apenas o sistema de proteção existente na rede de distribuição?

Este trabalho busca responder a essa questão através da avaliação do impacto da GD sobre o sistema de proteção de sobrecorrente da rede de distribuição, analisando diferentes tipos de faltas em diferentes pontos do sistema e, com base nos resultados obtidos, propor soluções que possibilitem a operação em ilha ajustando a proteção de sobrecorrente existente na rede. A abordagem principal seguida no trabalho é analisar a ilha formada propondo a divisão da rede de distribuição em regiões de proteção e fazendo um estudo detalhado dos elementos de atuação, em especial, da função instantânea dos religadores e relés instalados nos pontos de acoplamento comum entre concessionária e gerador distribuído (PAC). Conforme mencionado anteriormente, o foco desta análise serão os geradores síncronos. 


\section{A PROTEÇÃO DE SISTEMAS DE DISTRIBUIÇÃO}

Os sistemas de distribuição de energia são constituídos por alimentadores que suprem cargas de áreas urbanas e rurais. Cada tipo de alimentador, urbano e rural, apresenta particularidades quanto aos defeitos a que são submetidos. No entanto, existe um tipo de interrupção bastante característico a esses dois sistemas, denominado defeito temporário, ou momentâneo. Esse tipo de defeito corresponde à falta monopolar à terra, como, por exemplo, um galho de árvore tocando um condutor de uma rede aérea de distribuição, que segundo estatísticas, corresponde a cerca de $80 \%$ do total de interrupções (Mamede Filho \& Mamede Ribeiro, 2011). Portanto, para que se consiga uma boa proteção para um sistema de distribuição é necessário seguir uma filosofia de proteção, que permita isolar a linha ou o equipamento em falta o mais rápido possível com o mínimo de distúrbio para o resto do sistema.

\subsection{Filosofia de Proteção em Sistemas de Distribuição}

Segundo Giguer (1988), a filosofia de proteção consiste na técnica de selecionar, coordenar e ajustar os dispositivos protetores do sistema elétrico para que uma anormalidade no sistema possa ser removida, sem que as outras partes sejam afetadas.

Para isso, primeiramente, é necessário levantar um diagrama unifilar detalhado do sistema, que mostre as correntes de carga, a localização das cargas críticas e as correntes de falta (máxima e mínima) em cada trecho a ser protegido. O segundo passo consiste em determinar quais os critérios a serem aplicados para cada dispositivo de proteção.

Segundo Vicentini (2003), alguns dos critérios normalmente utilizados na especificação de equipamento e dispositivos de proteção de sobrecorrente são:

- Curvas de tempo versus corrente dos dispositivos de proteção;

- Condições especiais do circuito, como considerações de terreno, densidade de carga, natureza crítica da carga, etc e

- Definição da zona de proteção de cada dispositivo de proteção, evitando a invasão de zonas e a existência de zonas desprotegidas.

Por essa razão, em sistemas de distribuição, os esquemas de proteção devem atender aos seguintes aspectos (Eletrobrás, Comite de Distribuição, 1982):

- Proteção de materiais e equipamentos contra danos causados por curtos-circuitos e sobrecargas;

- Melhoria da confiabilidade dos circuitos de distribuição em consequência da possibilidade de restringir os efeitos de uma falha ao menor trecho possível do 
circuito, no menor tempo, diminuindo assim a potência envolvida e o número de consumidores atingidos e

- Racionalização dos custos dos esquemas, que não devem exceder os benefícios decorrentes de sua utilização.

Nos estudos de proteção em sistemas de distribuição, deve-se levar sempre em consideração que o aspecto da proteção de materiais e equipamentos é um dos objetivos do estudo, mas não se constitui em sua finalidade única. Considere-se que esse objetivo, em princípio, já deve ter sido atingido no âmbito dos esquemas de proteção da subestação e, portanto, a proteção de distribuição pode dar ênfase ao aspecto da continuidade do suprimento, evitando que uma falha tenha um envolvimento muito grande em termos de carga e/ou consumidores atingidos, além de procurar reduzir os tempos de localização dessa falha e de reposição do sistema em serviço. Contudo, convém ressaltar que a colocação de vários dispositivos de proteção em série, como geralmente requer um esquema de boa confiabilidade, tende a tornar mais lenta a proteção dos alimentadores na subestação, o que pode acarretar, em alguns casos, danos a materiais e equipamentos, até em consequência de fadiga mecânica. Assim sendo, quando se procura atingir altos níveis de confiabilidade, em termos de continuidade do suprimento, a preocupação com os aspectos de proteção e segurança deve aumentar proporcionalmente.

Por outro lado, com relação ao aspecto de custos, além do que foi dito anteriormente, deve-se ressaltar que, no momento em que o esquema de proteção tem o objetivo de proporcionar segurança ao pessoal, a relação custo/ benefício perde sua validade.

\subsection{Considerações Gerais Sobre Equipamentos de Proteção}

Durante o curto-circuito, podem surgir correntes de elevada intensidade, as quais podem provocar danos devido a efeitos mecânicos e térmicos nos equipamentos ligados ao circuito sob falta. Os efeitos mecânicos, cujas forças são proporcionais ao quadrado da corrente instantânea, podem deformar condutores e romper materiais isolantes. Já os efeitos térmicos estão ligados ao tempo de permanência da falta e ao valor eficaz da corrente e podem produzir um aquecimento excessivo dos materiais condutores e isolantes, com sua consequente deterioração (Mamede Filho \& Mamede Ribeiro, 2011).

Por outro lado, correntes de curto-circuito de pequeno valor podem causar danos permanentes e/ou temporários a pessoas e animais, se elas não forem interrompidas em um intervalo de tempo adequado.

Para minimizar os efeitos produzidos pelas correntes de falta, é comum o uso dos seguintes equipamentos em redes de distribuição (Gers \& Holmes, 2011):

- Chaves-fusíveis; 
- Disjuntores associados a relés;

- Seccionadores automáticos, também chamados por alguns autores de Seccionalizadores e

- Religadores automáticos.

Todos esses equipamentos estão relacionados à proteção de sobrecorrente.

Conforme mencionado anteriormente, as correntes de falta geralmente possuem valores muito altos em relação às correntes de operação normal do sistema. Por este motivo, elas podem ser usadas para detectar a presença de faltas e fazer operar dispositivos de proteção, os quais podem variar no projeto dependendo da complexidade e disposição requerida. Portanto, é importante que sejam feitas algumas breves considerações, para uma melhor compreensão sobre as funções de cada um dos equipamentos anteriormente citados, dentro do esquema de proteção.

\subsubsection{Chaves-fusíveis}

Chaves-fusíveis são os elementos mais utilizados na proteção de redes de distribuição, devido ao custo reduzido e satisfatório desempenho para o nível de proteção desejado. No interior do cartucho da chave-fusível está instalado o elo fusível, o qual é diretamente aquecido pela passagem de corrente e destruído quando a corrente excede um valor predeterminado. Assim, a chave-fusível tem como função abrir o circuito através da fusão do elo fusível, eliminar o arco estabelecido durante a destruição do elemento e então manter as condições de circuito aberto com tensão nominal aplicada aos seus terminais, ou seja, sem arco através do elemento fusível.

A maioria das chaves-fusíveis usadas em sistemas de distribuição opera com o princípio de expulsão, isto é, elas possuem um tubo para confinar o arco, com o seu interior coberto com fibra desionizante e um elemento fusível. Na presença de uma falta, a fibra interior do tubo é aquecida até que o elemento fusível derreta e produza gases desionizantes que se acumulam no tubo. O arco é então comprimido e expelido para fora do tubo. O escape dos gases pelas extremidades do tubo permite que as partículas que mantêm o arco sejam expelidas. Desta forma o arco é extinto quando a corrente chega à zero. A presença de gases desionizantes e a turbulência dentro do tubo garantem que a corrente de falta não seja restabelecida depois da corrente passar por zero (Mamede Filho, 1994). A Figura 3.1 mostra uma chave fusível do fabricante Delmar, com o respectivo cartucho porta fusível e elos fusíveis. 

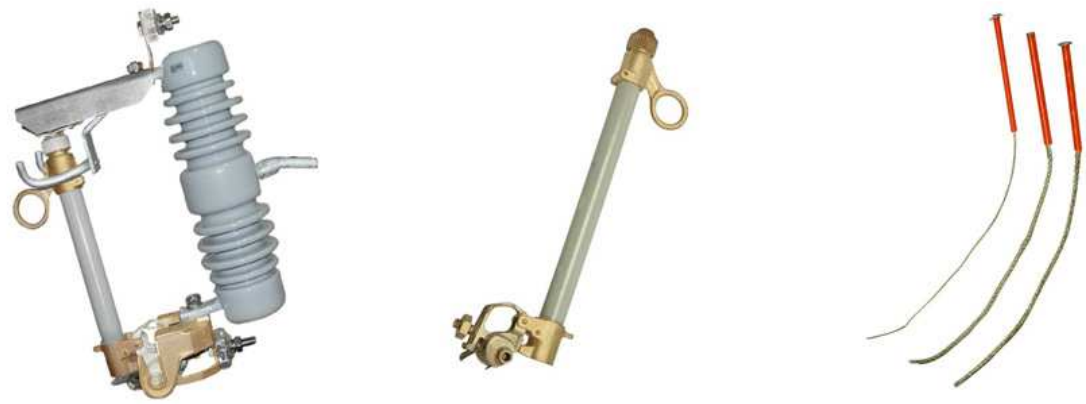

Figura 3.1 - Chave fusível, cartucho porta fusível e elos fusíveis (Delmar Ltda, 2013).

\subsubsection{Disjuntores}

Todo alimentador de distribuição deve ser protegido na saída da subestação, e esta proteção geralmente é feita por disjuntores associados a relés de sobrecorrente.

Os disjuntores são dispositivos de interrupção capazes de abrir e fechar um circuito sob quaisquer condições, isto é, tanto em condições de falta, quanto em situações normais (Gönen, 1986). A principal função de um disjuntor é extinguir o arco que se desenvolve devido à separação de seus contatos em um meio extinguível, que pode ser o ar, óleo, $\mathrm{SF}_{6}$ (hexafluoreto de enxofre), ou vácuo. Para os sistemas de distribuição são utilizados disjuntores do tipo a ar ou a óleo.

Os disjuntores usados em sistemas de distribuição, normalmente têm tempo mínimo de operação de 5 ciclos e geralmente são dimensionados com base na corrente de falta simétrica. Em geral, disjuntores controlados por relés são preferidos em relação à religadores devido à sua grande flexibilidade, precisão, margens de projeto, e estética. Entretanto, são muito mais caros que os religadores (Gönen, 1986). A Figura 3.2 mostra um disjuntor modelo OVB-SDB a vácuo, classe de tensão $15 \mathrm{kV}$, para uso externo, de fabricação da ABB.

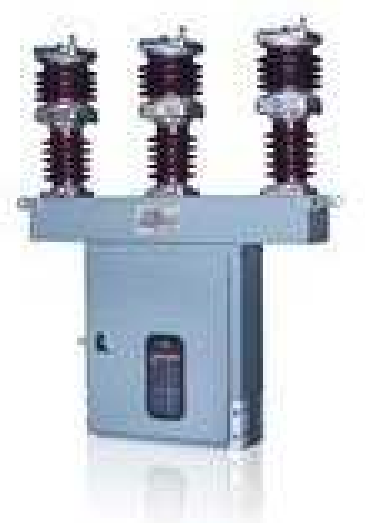

Figura 3.2 - Disjuntor isolado a vácuo para uso externo (ABB, 2013). 


\subsubsection{Relés}

Relés de sobrecorrente associados a disjuntores são muito comuns como proteção usada contra correntes excessivas em sistemas de potência, as quais podem ter como origem uma sobrecarga ou um curto-circuito.

Com base nas características de operação do relé, os relés de sobrecorrente podem ser classificados dentro de três grupos (Gers \& Holmes, 2011), são eles:

- Corrente definida ou instantâneo;

- Tempo definido e

- Tempo inverso.

As curvas características destes três tipos de relés são mostradas na Figura 3.3, as quais também ilustram a combinação de um relé instantâneo com um relé com curva característica de tempo inverso.
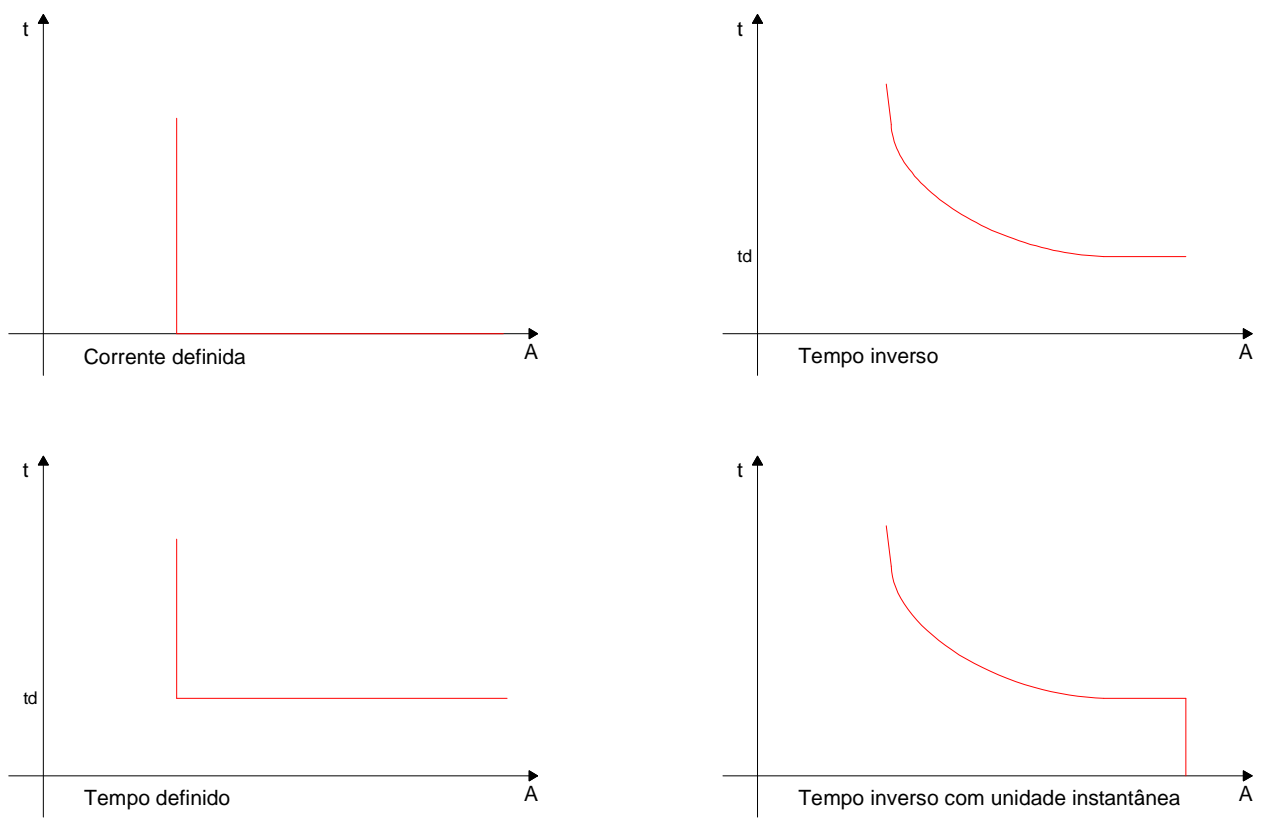

Figura 3.3 - Características de operação tempo x corrente de relés de sobrecorrente (Gers \& Holmes, 2011).

A curva de corrente definida opera instantaneamente quando a corrente alcança um valor predeterminado. Este tipo de curva não é usado como a única proteção de sobrecorrente, mas seu uso como uma unidade instantânea é comum.

A curva de tempo definido permite que o ajuste do relé seja variado para lidar com diferentes níveis de corrente usando diferentes tempos de operação. A diferença entre os tempos de atuação para a mesma corrente é chamada de margem de coordenação. Este 
tipo de curva tem um ajuste de corrente de disparo também chamado de ajuste de corrente de pick-up. Além disso, há o ajuste de atraso, ou dial de tempo, para obter a temporização exata da operação do relé. Deve ser notado que o ajuste de atraso de tempo (dial de tempo) é independente do valor da sobrecorrente necessária para operar o relé (corrente de pickup).

A curva de tempo inverso, como o próprio nome diz, opera em um tempo inversamente proporcional à corrente de falta. As curvas de tempo inverso são geralmente classificadas de acordo com sua velocidade de operação; assim, são definidas como sendo de tempo inverso, muito inverso, extremamente inverso ou inversa longa (Mamede Filho \& Mamede Ribeiro, 2011).

Ainda relacionado aos relés de sobrecorrente, existem os relés de sobrecorrente de sequência negativa (tipo 50/51Q), os quais permitem aumentar a sensibilidade para detecção de faltas fase à fase, visto que cargas equilibradas não têm componente de corrente $\left(\mathrm{I}_{2}\right)$ de sequência negativa. Esta também é a situação para faltas de fase à terra se forem utilizados relés do tipo (50/51) para cargas equilibradas que não possuam componente de sequência zero $\left(I_{0}\right)$ (Gers \& Holmes, 2011).

Todas essas funções de proteção e outras, tais como: funções de controle, lógica digital, autodiagnóstico, possibilidade de utilização de diferentes grupos de ajustes etc, podem ser encontradas reunidas nos relés digitais.

A utilização de relés numéricos digitais exige um método adequado para operação das ferramentas lógicas do relé, as quais incluem blocos com entradas de controle e saídas analógicas e digitais.

Essas ferramentas podem ser ajustadas para configurar a operação de uma determinada proteção ou função de controle, permitindo que o relé realize mudanças de ajuste, de acordo com as mudanças de topologia do sistema, já que tais mudanças podem afetar os níveis de curto-circuito, e provocar uma descoordenação, se os relés não forem reprogramados para a nova condição do sistema de potência. Esse tipo de proteção é conhecido como proteção adaptativa. Isso significa que a característica de abertura muda com as alterações nas condições do sistema, mantendo-se desta forma a eficiência da proteção (Coury, et al., 2007).

\subsubsection{Seccionadores automáticos}

Um seccionador automático é um dispositivo que automaticamente isola seções em falta de um circuito de distribuição após um disjuntor ou religador à montante ter interrompido a corrente de falta. Geralmente é instalado à jusante do religador (Gers \& Holmes, 2011). 
Como os seccionadores não têm capacidade para interromper correntes de falta, eles devem ser usados como proteção de retaguarda de um dispositivo que tenha a capacidade de interromper tal corrente. Como não têm característica de operação de tempo inverso, podem ser usados entre dois dispositivos de proteção, dos quais as curvas de operação estejam muito próximas e que um passo adicional na coordenação seria impraticável, pois poderia infringir a margem de segurança que garante que o dispositivo mais próximo da falta atue primeiro.

Os seccionadores automáticos contam o número de operações do religador durante as condições de falta e depois de um número predeterminado de aberturas do religador, o seccionador abre e isola a seção em falta da linha, durante o período em que o religador está aberto. Isto permite ao religador fechar e reestabelecer a alimentação às áreas livres de faltas. Se a falta for temporária, a contagem do mecanismo de abertura do seccionador será zerada.

\subsubsection{Religadores automáticos}

Um religador automático é um dispositivo com a capacidade de detectar condições de sobrecorrente de fase e fase à terra, interromper o circuito se a sobrecorrente persistir depois de um tempo predeterminado e então, automaticamente, religar-se para reenergizar a linha. Se a falta que deu início à operação ainda existir, o religador permanecerá aberto depois de um determinado número de operações, isolando assim, a seção com falta do resto do sistema (Gers \& Holmes, 2011).

Uma sequência típica de operação de um religador para uma falta permanente é mostrada na Figura 3.4. O primeiro disparo é realizado no modo instantâneo para limpar as faltas temporárias antes que elas causem danos às linhas. As três operações seguintes operam de maneira retardada, com ajustes de tempo predeterminados. Se a falta for permanente, a operação retardada permitirá que outros dispositivos de proteção mais próximos à falta abram, limitando a porção da rede a ser desconectada. 


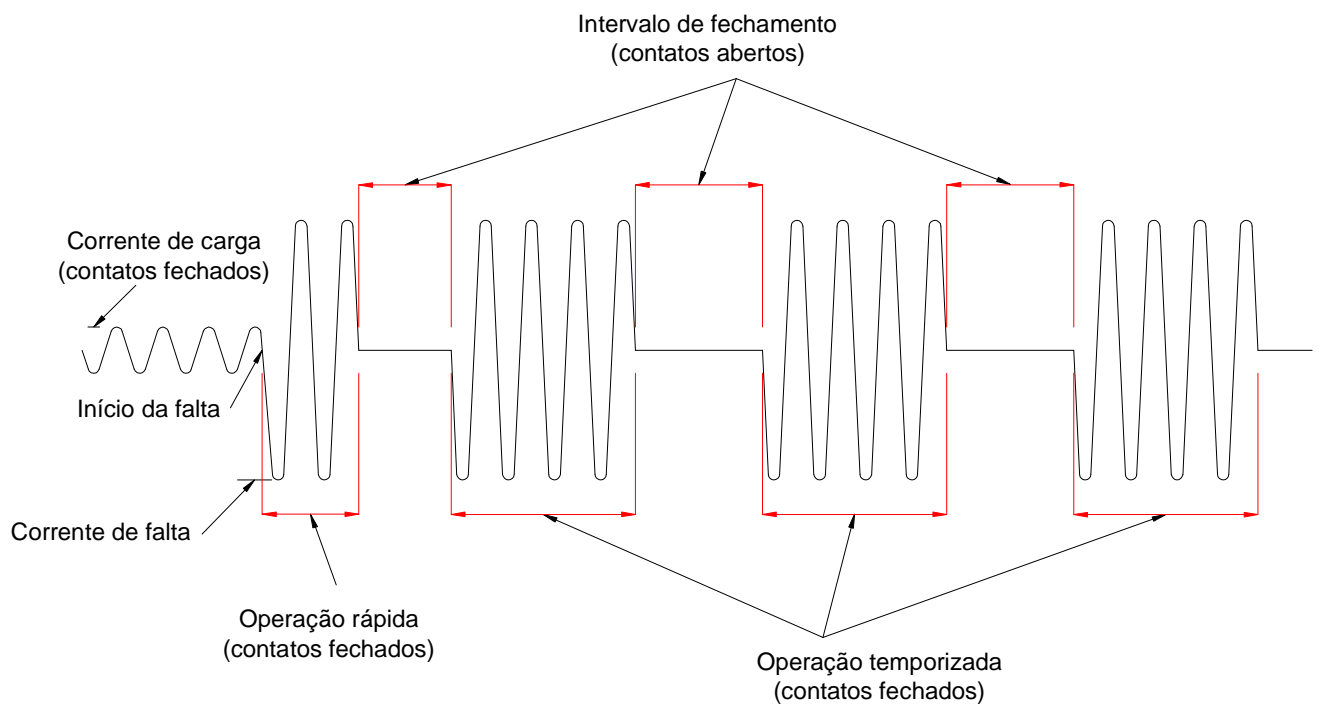

Figura 3.4 - Sequência de operação de um religador típico (Gers \& Holmes, 2011).

Os religadores são usados nos seguintes pontos da rede de distribuição:

- Em subestações, para fornecer proteção primária para um circuito;

- Em circuitos alimentadores, com o objetivo de permitir o seccionamento de linhas longas e assim prevenir a perda de um circuito completo devido a uma falta no final do circuito e

- Em ramos ou derivações, para prevenir o desligamento do circuito principal devido à faltas nas derivações.

\subsection{Estudo de Coordenação e Seletividade}

O estudo de coordenação e seletividade tem como objetivo determinar os ajustes dos dispositivos de proteção para que na ocorrência de uma falta, apenas o dispositivo mais próximo desta opere, isolando a menor porção do sistema, no menor intervalo de tempo possível de forma a proteger os equipamentos e o próprio sistema elétrico.

Cada elemento protetor tem uma abrangência de atuação, denominada de zona de proteção. Dessa forma, são considerados dois tipos de proteção: proteção principal e proteção de retaguarda. O conceito de proteção de retaguarda está associado ao estudo de coordenação da proteção.

A seletividade pode ser efetuada por meio de três formas diferentes (Mamede Filho \& Mamede Ribeiro, 2011):

- Seletividade amperimétrica - baseia-se no princípio de que as correntes de curtocircuito aumentam à medida que a falta se aproxima da fonte; assim, a corrente de falta vista pelo dispositivo de proteção à montante deve ser bem maior que a corrente vista pelo dispositivo à jusante; 
- Seletividade cronológica - é realizada aplicando-se intervalos de tempo entre os dispositivos de proteção localizados à jusante e à montante, isto significa que a atuação da proteção instalada à montante é retardada para que a proteção à jusante tenha tempo suficiente para operar e

- Seletividade lógica - é um conceito mais moderno e é conseguida através da utilização de relés digitais através de uma combinação de proteção de sobrecorrente com um esquema de comunicação.

A seletividade convencional é realizada através da utilização de recursos da seletividade amperimétrica combinada com a seletividade cronológica. Ainda hoje a seletividade convencional é bastante utilizada na proteção de sistemas elétricos de distribuição.

O Anexo A apresenta os procedimentos para realização de um estudo de coordenação e seletividade juntamente com os critérios utilizados na coordenação dos diversos equipamentos de proteção presentes em sistemas elétricos de distribuição.

\subsection{Estudo de Estabilidade Transitória}

A estabilidade em sistemas de potência pode ser definida como a propriedade que o sistema tem de permanecer em estado de equilíbrio sob condições operacionais normais e recuperar um estado aceitável de equilíbrio depois de estar sujeito a uma perturbação (Kundur, 1994). Tradicionalmente, o problema da estabilidade tem sido o da manutenção da operação síncrona, visto que a confiabilidade do sistema de potência se baseia na confiabilidade da operação das máquinas síncronas usadas para geração de potência elétrica. Uma condição necessária para a operação satisfatória do sistema é que as máquinas síncronas permaneçam em sincronismo. Este aspecto da estabilidade é influenciado pela dinâmica da relação entre os ângulos do rotor do gerador e o ângulo de potência, daí a importância de se definir estabilidade transitória, a qual consiste na habilidade que o sistema de potência tem de se manter em sincronismo quando sujeito a um distúrbio transiente severo (Kundur, 1994). A estabilidade transitória depende das condições iniciais de operação do sistema e da severidade do distúrbio.

Não é comum a realização do estudo de estabilidade transitória em redes de distribuição, mas com a expansão da geração distribuída, juntamente com a possibilidade da operação em ilhamento intencional, este tipo de análise será tido como uma ferramenta indispensável para avaliação dos ajustes de tempo e corrente da proteção de sobrecorrente do sistema de distribuição de energia.

Portanto, neste trabalho o estudo de estabilidade transitória tem como objetivo avaliar se os tempos ajustados na proteção atendem ao comportamento síncrono e estável do 
sistema de geração na ocorrência de perturbações como curto-circuito ou perdas de fontes. Logo, serão simuladas diversas situações de falta dentro da ilha formada, visando obter as condições limítrofes de atuação da proteção de forma que o sistema possa manter e/ou retornar às condições estáveis de operação. 


\section{IMPACTO DA GERAÇÃO DISTRIBUÍDA SOBRE O SISTEMA DE PROTEÇÃO DE SOBRECORRENTE}

O objetivo deste capítulo é avaliar os impactos da GD sobre o sistema de proteção de sobrecorrente de uma rede de distribuição operando ilhada, buscando primeiramente, compreender como eles surgem no sistema. Esta avaliação será feita de acordo com as seguintes etapas:

Etapa 1 - Inicialmente será feito o dimensionamento da proteção de sobrecorrente da rede de distribuição sem a presença da GD, uma vez que os dados originais do sistema de distribuição utilizados na análise não apresentavam as características detalhadas dos elementos de proteção existentes na rede.

Etapa 2 - Será acrescentada a GD com as devidas proteções de sobrecorrente exigidas no PAC pela maioria das concessionárias de distribuição de energia, para observação do comportamento da proteção mediante a simulação computacional de faltas em diversos pontos da rede de distribuição.

Etapa 3 - Nesta etapa, a rede de distribuição passará, obrigatoriamente, a operar ilhada, por meio da abertura do disjuntor da subestação da concessionária. As faltas estudadas na Etapa 2 serão novamente simuladas, para que os impactos no sistema de proteção de sobrecorrente sejam compreendidos e avaliados. Esta etapa é uma importante contribuição desta dissertação, pois permitirá propor uma metodologia de avaliação e busca de soluções para o problema da perda de coordenação e seletividade da rede de distribuição operando ilhada. A rede será dividida em regiões delimitadas pelos dispositivos de proteção de sobrecorrente existentes. Para cada região, chamada região de proteção, a margem de coordenação entre o dispositivo de proteção principal e o dispositivo de proteção de retaguarda será verificada.

Em seguida, com base nas informações obtidas, serão propostas medidas corretivas que busquem garantir a coordenação entre os elementos de proteção, principais e de retaguarda, após a efetivação dessas medidas, a margem de coordenação será novamente verificada, permitindo, desta forma, avaliar se houve ou não melhoria na coordenação e seletividade do sistema de proteção de sobrecorrente da rede.

Finalmente, como forma de validar as medidas adotadas, será feito um estudo de estabilidade transitória, e objetivando a aplicação da metodologia proposta na análise de outras redes de distribuição, será apresentado um fluxograma reunindo todos os passos utilizados na solução do problema. 


\subsection{Sistema de Distribuição de Energia Estudado}

O sistema de distribuição utilizado nesta dissertação é apresentado na Figura 4.1. Este sistema opera com tensão nominal de $13,8 \mathrm{kV}$, frequência de $60 \mathrm{~Hz}$ e carga total de 6,46 MW e 3,24 MVAr de potência ativa e reativa, respectivamente. Os dados foram adaptados do sistema de distribuição obtido de Campitelli (2007) e estão apresentados no anexo B.

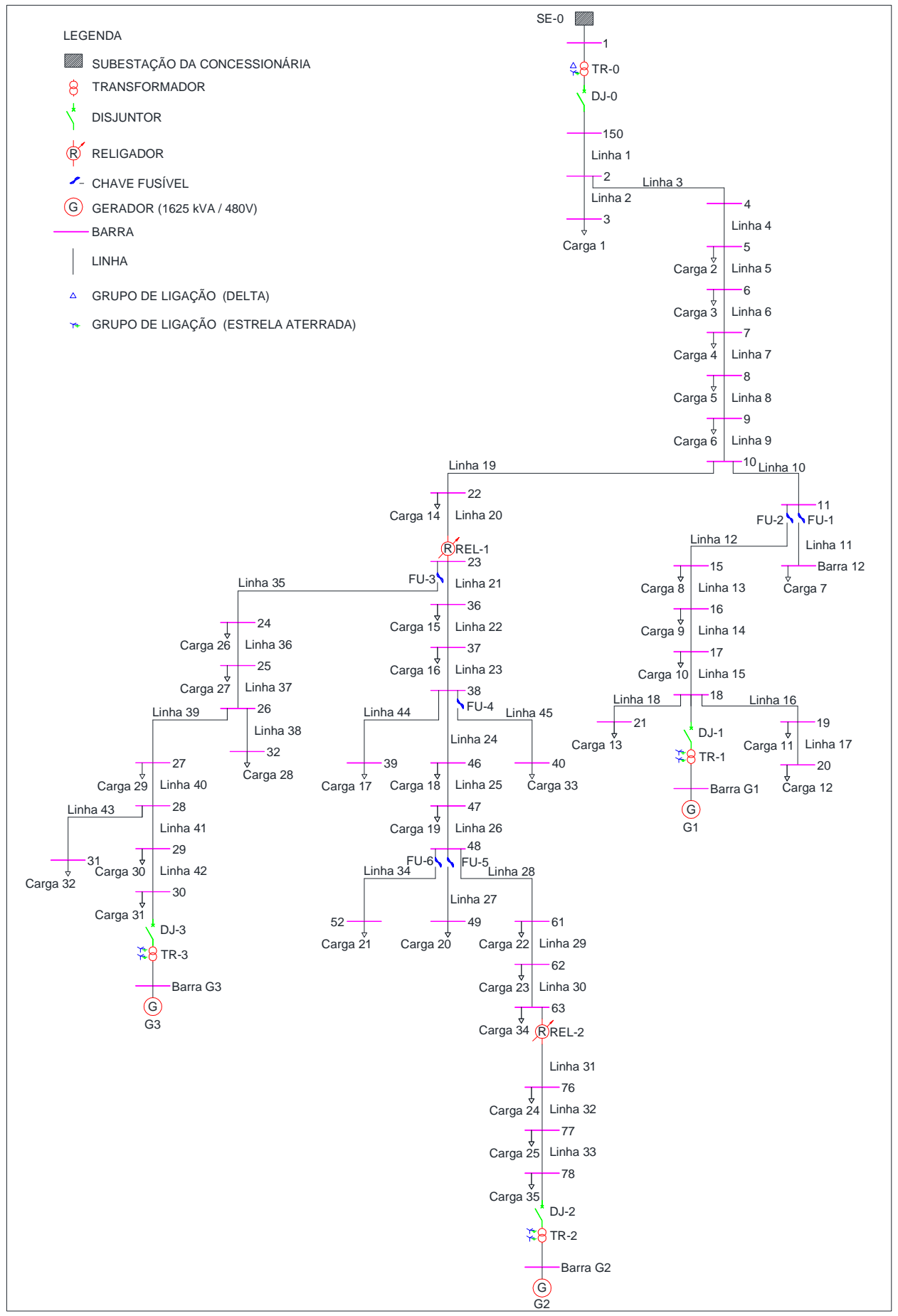

Figura 4.1 - Sistema de distribuição. 


\subsection{Etapa 1 - Estudo de Coordenação e Seletividade sem a presença de Geradores Distribuídos}

Através do estudo de coordenação e seletividade, segundo a filosofia de proteção apresentada no Anexo A, faz-se a determinação dos ajustes dos dispositivos de proteção para que apenas o dispositivo mais próximo da falta opere, isolando a menor porção do sistema, no menor intervalo de tempo possível. Cada elemento protetor tem uma abrangência de atuação, denominada de zona de proteção. Dessa forma, são considerados dois tipos de proteção: proteção principal e proteção de retaguarda, cujas curvas características de tempo versus corrente devem ser separadas por um intervalo de tempo, chamado de margem de coordenação, a qual leva em consideração, tempos de abertura, tolerâncias e erros dos dispositivos envolvidos na proteção do sistema (Mamede Filho \& Mamede Ribeiro, 2011).

Os ajustes das proteções de sobrecorrente instantânea e temporizada, de fase e neutro, função ANSI 50/51 e 50/51N, respectivamente, assim como a capacidade e tipo de curva dos elos fusíveis foram determinados com base nas correntes de falta e correntes de carga dos diversos ramais alimentadores, visando à proteção dos equipamentos e cabos existentes no sistema de distribuição. A filosofia adotada para coordenação entre fusíveis e religadores foi definida em função das características operacionais dos ramais em que esses equipamentos encontram-se instalados.

Os elos fusíveis foram dimensionados utilizando as Equações A.1 e A.2 (ver Anexo A), e estão apresentados na Tabela 4.1, enquanto que os ajustes de tempo (TDS) - Time Dial Setting - e corrente de partida - Pick-up - das curvas do relé do disjuntor DJ-0 da subestação e religadores REL-1 e REL-2 da rede foram ajustados utilizando as Equações A.5 e A.6 (Anexo A), e estão apresentados nas Tabelas 4.2 e 4.3, para fase e neutro, respectivamente. Buscou-se, sempre que possível, obedecer aos critérios de coordenação recomendados nos itens A.1.3, A.2.3 e A.2.4, apresentados no Anexo A. 
Tabela 4.1 - Dimensionamento dos elos fusíveis.

\begin{tabular}{|cccccc|}
\hline \multicolumn{7}{|c|}{ Dimensionamento dos elos fusiveis } \\
\hline FU-1 & FU-2 & FU-3 & FU-4 & FU-5 & FU-6 \\
\hline Linha 11 & Linha 12 & Linha 35 & Linha 45 & Linha 27 & Linha 34 \\
\hline 6,85 & 24,64 & 34,55 & 15,52 & 19,575 & 8,21 \\
\hline Corrente de curto-circuito fase-terra no ponto mais distante do elemento protetor (A) \\
\hline Barra 12 & Barra 21 & Barra 30 & Barra 40 & Barra 49 & Barra 52 \\
\hline 185 & 184 & 183 & 185 & 184 & 184 \\
\hline $6 \mathrm{~K}$ & $25 \mathrm{~K}^{*}$ & Fusível adotado & & $10 \mathrm{~K}$ \\
\hline
\end{tabular}

${ }^{*}$ ) Não foi possível utilizar o fusível $15 \mathrm{~K}$, devido à corrente solicitada pela carga na linha ser maior que a corrente nominal do fusível $15 \mathrm{~K}$.

Tabela 4.2 - Ajustes das curvas de proteção de fase dos religadores.

\begin{tabular}{|c|c|c|}
\hline \multirow{2}{*}{\multicolumn{3}{|c|}{$\begin{array}{c}\text { Ajuste de curvas - Padrão ANSI - Categoria Muito Inversa } \\
\text { Nome do Elemento de Proteção }\end{array}$}} \\
\hline & & \\
\hline REL-1 & REL-2 & DJ-0 \\
\hline \multicolumn{3}{|c|}{ Valor de sobrecarga admissível $K_{t f}$} \\
\hline 1,2 & 1,2 & 1,2 \\
\hline \multicolumn{3}{|c|}{ Corrente de carga máxima $I_{c}(\mathrm{~A})$} \\
\hline 240,72 & 128,67 & 296,57 \\
\hline \multicolumn{3}{|c|}{ Relação de transformação do transformador de corrente (RTC) } \\
\hline 1 & 1 & 1 \\
\hline \multicolumn{3}{|c|}{ Ajuste da Unidade Temporizada } \\
\hline \multicolumn{3}{|c|}{ Pick-up (A) } \\
\hline 289 & 155 & 356 \\
\hline \multicolumn{3}{|c|}{ Time Dial Setting (TDS) } \\
\hline 1,84 & 0,61 & 2,94 \\
\hline \multicolumn{3}{|c|}{ Ajuste da Unidade Instantânea } \\
\hline \multicolumn{3}{|c|}{ Pick-up (A) } \\
\hline 289 & 155 & Desabilitado \\
\hline
\end{tabular}

Tabela 4.3 - Ajustes das curvas de proteção de neutro dos religadores.

\begin{tabular}{|c|c|c|}
\hline \multicolumn{3}{|c|}{ Ajuste de curvas - Padrão ANSI - Categoria Muito Inversa } \\
\hline \multicolumn{3}{|c|}{ Nome do Elemento de Proteção } \\
\hline REL-1 & REL-2 & DJ-0 \\
\hline \multicolumn{3}{|c|}{ Valor de desequilíbrio das correntes $K_{n}$} \\
\hline 0,2 & 0,2 & 0,2 \\
\hline \multicolumn{3}{|c|}{ Corrente de carga máxima $I_{c}(\mathrm{~A})$} \\
\hline 240,72 & 128,67 & 296,57 \\
\hline \multicolumn{3}{|c|}{ Relação de transformação do transformador de corrente (RTC) } \\
\hline 1 & 1 & 1 \\
\hline \multicolumn{3}{|c|}{ Ajuste da Unidade Temporizada } \\
\hline \multicolumn{3}{|c|}{ Pick-up (A) } \\
\hline 62 & 26 & 63,2 \\
\hline \multicolumn{3}{|c|}{ Time Dial Setting (TDS) } \\
\hline 1,78 & 0,77 & 2,18 \\
\hline \multicolumn{3}{|c|}{ Ajuste da Unidade Instantânea } \\
\hline \multicolumn{3}{|c|}{ Pick-up (A) } \\
\hline 49 & 26 & Desabilitado \\
\hline
\end{tabular}


A seguir, são apresentados os coordenogramas dos elementos envolvidos na proteção.

A Figura 4.2 corresponde à coordenação realizada entre o religador REL-1 e o fusível FU-3, com as respectivas correntes de curto-circuito, trifásica (2366 A) e fase-terra (186 A), na linha 35, imediatamente após o fusível FU-3.

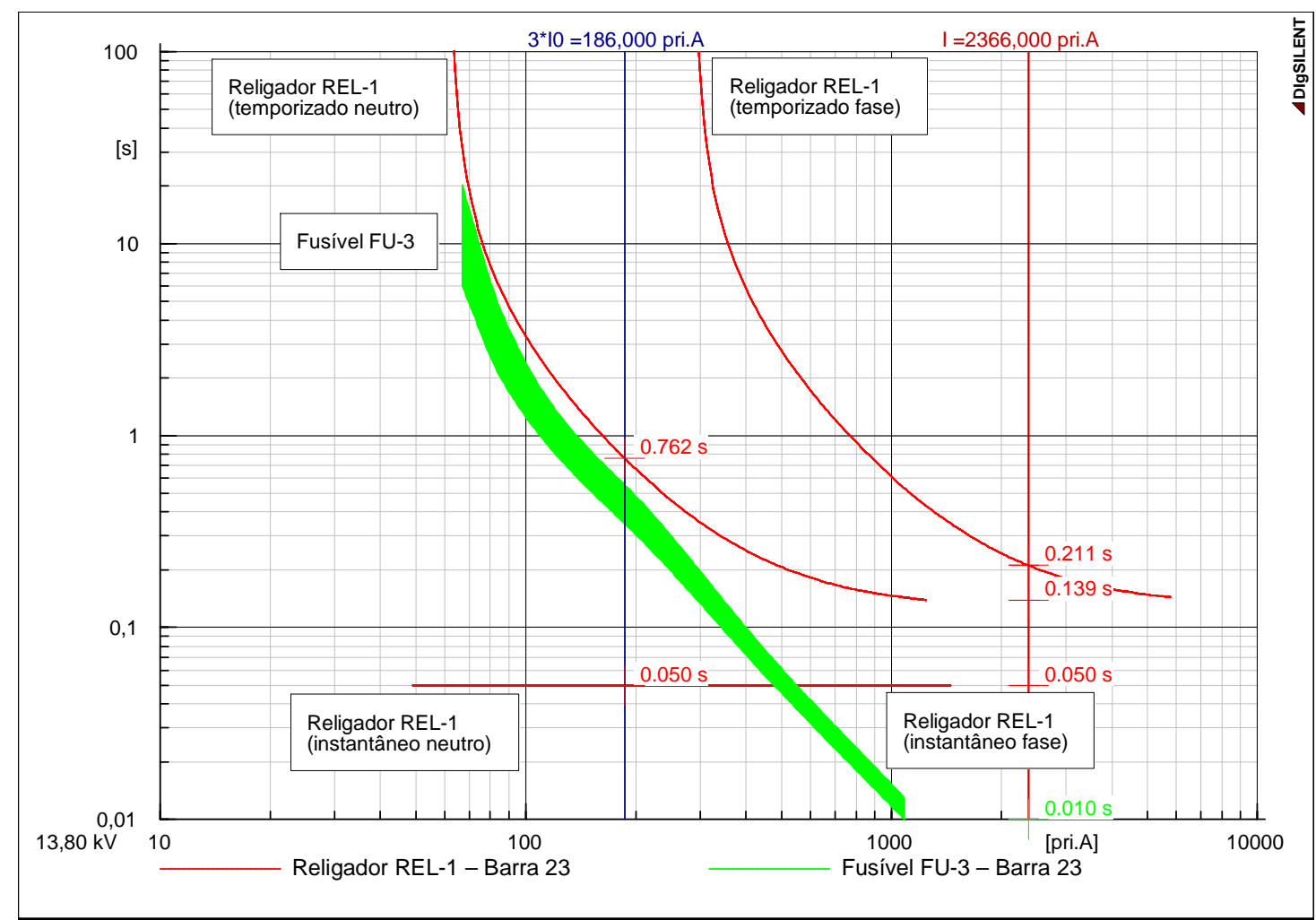

Figura 4.2 - Coordenação entre religador REL-1 e fusível FU-3.

A Figura 4.3 mostra a coordenação realizada entre o religador REL-1 e o religador REL-2, com as respectivas correntes de curto-circuito, trifásica (2110 A) e fase-terra (183 A), na linha 31, imediatamente após o religador REL-2. 


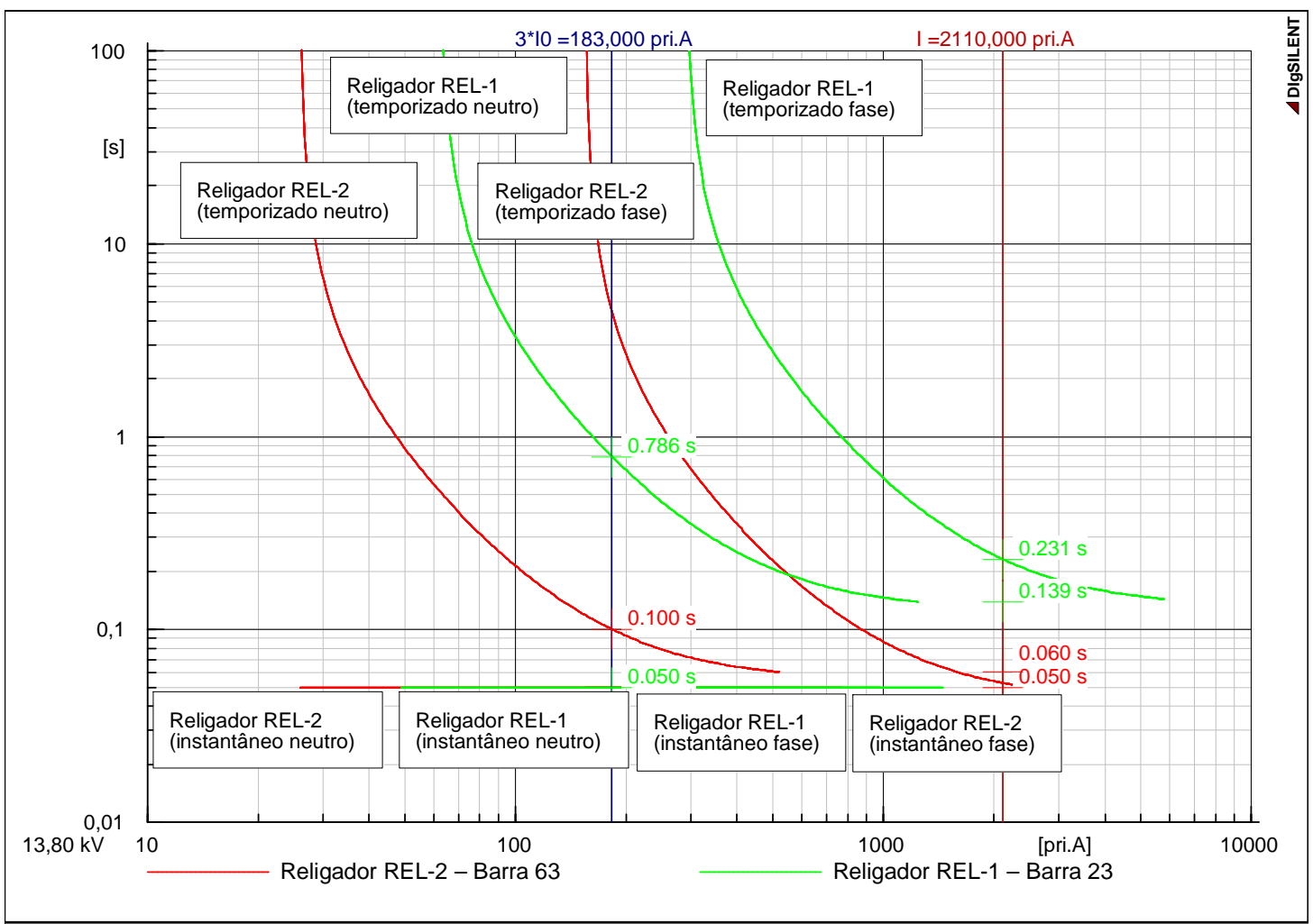

Figura 4.3 - Coordenação entre o religador REL-1 e o religador REL-2.

É importante notar, que devido à filosofia de coordenação fusível protegido, a faixa de coordenação das curvas instantâneas ficou muito estreita, conforme pode ser observado nas Tabelas 4.2 e 4.3.

As correntes de curto-circuito apresentadas na Figura 4.4 correspondem às correntes de curto-circuito trifásico (2366 A) e fase-terra (183 A), obtidas imediatamente após o religador REL-1.

A Figura 4.4 apresenta a coordenação entre o relé 1 do disjuntor DJ-0 e o religador REL-1. Para garantir a coordenação foi necessário desabilitar a curva instantânea do relé 1 , localizado na entrada da subestação da concessionária. 


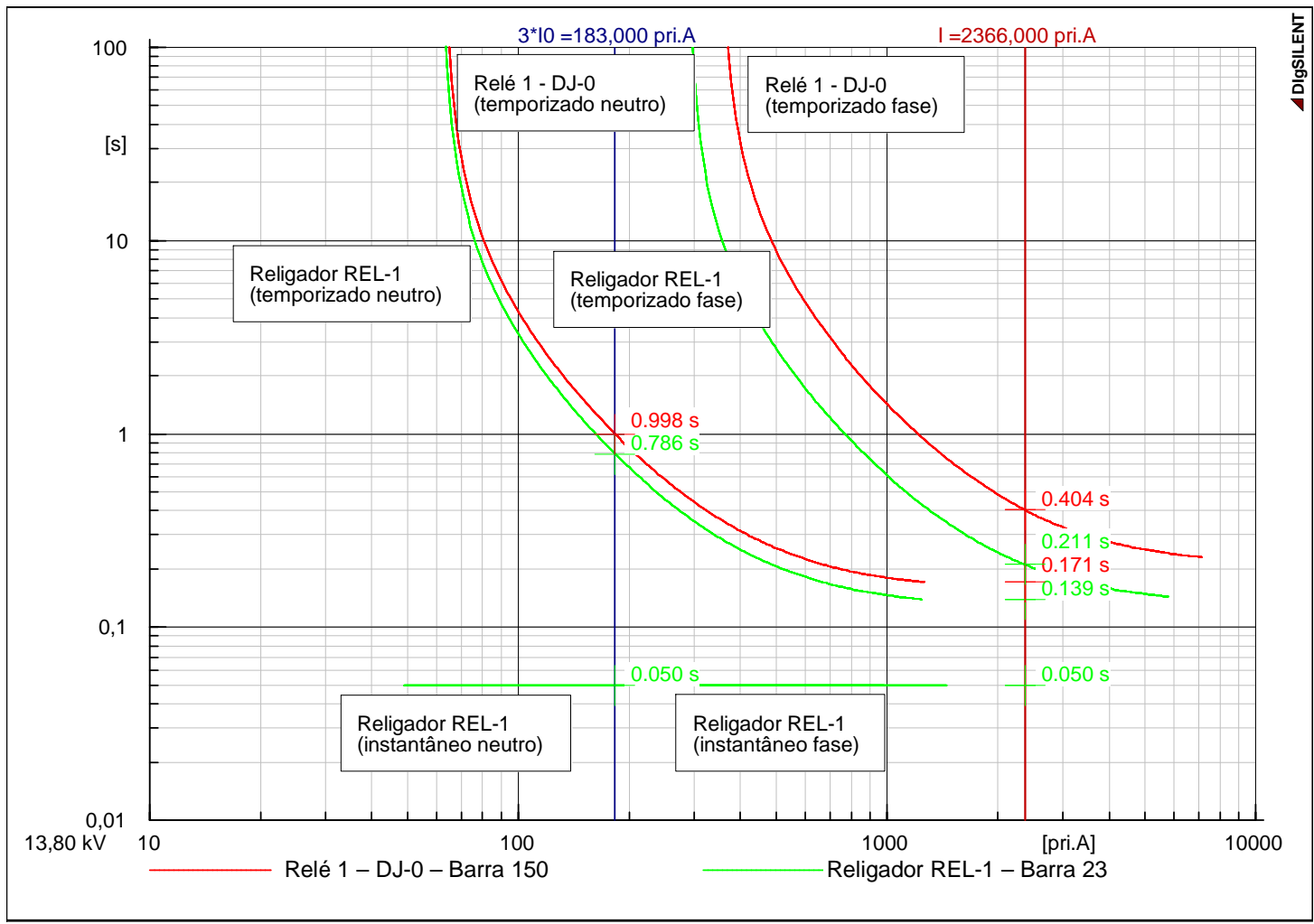

Figura 4.4 - Coordenação entre o Relé 1 do disjuntor DJ-0 e o religador REL-1.

\subsection{Etapa 2 - Ajustes da Proteção no PAC para Entrada dos Geradores Distribuídos}

Após a entrada dos geradores distribuídos no sistema, G1, G2 e G3, através de seus respectivos transformadores de acoplamento, TR-1, TR-2 e TR-3, com conexão YNyn0, ou seja, enrolamento de alta tensão e enrolamento de baixa tensão conectados em estrela aterrada, as proteções nos PACs foram ajustadas. Optou-se pela utilização desse tipo de conexão, para evitar a utilização de um transformador de aterramento, após a realização do ilhamento intencional, uma vez que o programa utilizado no estudo limita a quantidade de barras a serem inseridas para análise.

Com a entrada dos geradores distribuídos no sistema de distribuição, verificou-se um aumento do nível das correntes de curto-circuito. As correntes de curto-circuito trifásico e bifásico aumentaram em média $30 \%$, enquanto as correntes de curto-circuito fase-terra aumentaram em torno de $5 \%$.

As correntes de curto-circuito verificadas antes e após a entrada da GD estão apresentadas na Tabela 4.4 . 
Tabela 4.4 - Correntes de curto-circuito antes e após a entrada da GD.

\begin{tabular}{|ccccccc|}
$\begin{array}{r}\text { Local da } \\
\text { Falta }\end{array}$ & $\begin{array}{c}\text { Corrente de Falta Trifásica } \\
\text { (A) }\end{array}$ & Sem GD & Corrente de Falta Bifásica & \multicolumn{3}{c|}{$\begin{array}{c}\text { Corrente de Falta } \\
\text { Fase-Terra (A) }\end{array}$} \\
\hline Barra 11 & 2330 & 3240 & 2020 & 2660 & 185 & 194 \\
\hline Barra 12 & 2270 & 3130 & 1960 & 2570 & 185 & 193 \\
\hline Barra 21 & 2100 & 2870 & 1890 & 2360 & 184 & 192 \\
\hline Barra 23 & 2370 & 3310 & 2050 & 2710 & 186 & 194 \\
\hline Barra 30 & 2070 & 2870 & 1790 & 2360 & 183 & 193 \\
\hline Barra 38 & 2300 & 3210 & 1990 & 2630 & 185 & 193 \\
\hline Barra 39 & 2250 & 3120 & 1950 & 2560 & 185 & 193 \\
\hline Barra 40 & 2230 & 3080 & 1930 & 2530 & 185 & 193 \\
\hline Barra 49 & 2140 & 2960 & 1850 & 2430 & 184 & 192 \\
\hline Barra 52 & 2110 & 2900 & 1820 & 2380 & 184 & 192 \\
\hline Barra 63 & 2110 & 2930 & 1830 & 2400 & 183 & 192 \\
\hline Barra 78 & 2050 & 2840 & 1780 & 2330 & 183 & 192 \\
\hline
\end{tabular}

A coordenação e a seletividade são afetadas em virtude da bidirecionalidade das correntes de falta, além de poder haver religamento entre duas porções do sistema fora de sincronismo.

Para solucionar esses problemas, as concessionárias utilizam esquemas típicos de proteção anti-ilhamento, dentre os quais, as funções ANSI mais comumente utilizadas são (Companhia Paulista de Força e Luz - Energia, 2007), (Comanhia Energética de Minas Gerais - CEMIG, 2011):

- Função 32 (direcional de potência) - utilizada para detectar inversão de fluxo de potência ativa quando o gerador distribuído opera gerando energia apenas ao proprietário;

- Função $67 / 67 \mathrm{~N}$ (direcional de sobrecorrente de fase e neutro) - utilizada para detectar faltas na rede da concessionária;

- Funções 27/59 (subtensão e sobretensão) e 810/U (sobrefrequência e subfrequência) - utilizadas para auxiliar na perda de paralelismo com a concessionária.

- Função 59N (sobretensão de neutro) - utilizada especialmente para detectar faltas à terra quando o transformador instalado no PAC possuir enrolamento conectado em delta do lado da rede de distribuição.

Essas funções são ajustadas de tal forma que provoquem a atuação do disjuntor instalado no PAC antes da primeira tentativa de religamento automático dos religadores 
instalados na rede. Portanto, para que o sistema de proteção atenda essa exigência, as funções ANSI 67 e 67N dos relés dos disjuntores DJ-1, DJ-2 e DJ-3 foram ajustadas conforme indicado nas Tabelas 4.5 e 4.6. Como o foco deste trabalho são as proteções de sobrecorrente, as demais funções de proteção do PAC apresentadas anteriormente não serão analisadas por enquanto.

Tabela 4.5 - Ajustes das curvas de proteção de fase dos relés dos PAC.

\begin{tabular}{|ccc|}
\hline \multicolumn{3}{|c|}{ Ajuste de curvas - Padrão ANSI - Categoria Muito Inversa } \\
Nome do Elemento de Proteção \\
DJ-1 & DJ-2 & DJ-3 \\
& Ajuste da Unidade Temporizada \\
Pick-up (A) & \\
\hline & 85 \\
\hline & Time Dial Setting (TDS) & 85 \\
\hline 0,62 & 0,62 & 0,62 \\
\hline & Ajuste da Unidade Instantânea \\
\hline 150 & Pick-up (A) & 150 \\
\hline
\end{tabular}

Tabela 4.6 - Ajustes das curvas de proteção de neutro dos relés dos PAC.

\begin{tabular}{|c|c|c|}
\hline \multicolumn{3}{|c|}{ Ajuste de curvas - Padrão ANSI - Categoria Muito Inversa } \\
\hline \multicolumn{3}{|c|}{ Nome do Elemento de Proteção } \\
\hline DJ-1 & DJ-2 & DJ-3 \\
\hline \multicolumn{3}{|c|}{ Ajuste da Unidade Temporizada } \\
\hline \multicolumn{3}{|c|}{ Pick-up (A) } \\
\hline 13,6 & 13,6 & 13,6 \\
\hline \multicolumn{3}{|c|}{ Time Dial Setting (TDS) } \\
\hline 0,50 & 0,50 & 0,50 \\
\hline \multicolumn{3}{|c|}{ Ajuste da Unidade Instantânea } \\
\hline \multicolumn{3}{|c|}{ Pick-up (A) } \\
\hline 20 & 20 & 20 \\
\hline
\end{tabular}

A Figura 4.5 apresenta a coordenação entre o religador REL-2 e o relé do disjuntor DJ1 localizado no PAC do gerador G1.

Os relés instalados no PAC dos geradores G2 e G3 possuem os mesmos ajustes do relé do gerador G1, uma vez que os geradores e transformadores são idênticos. 


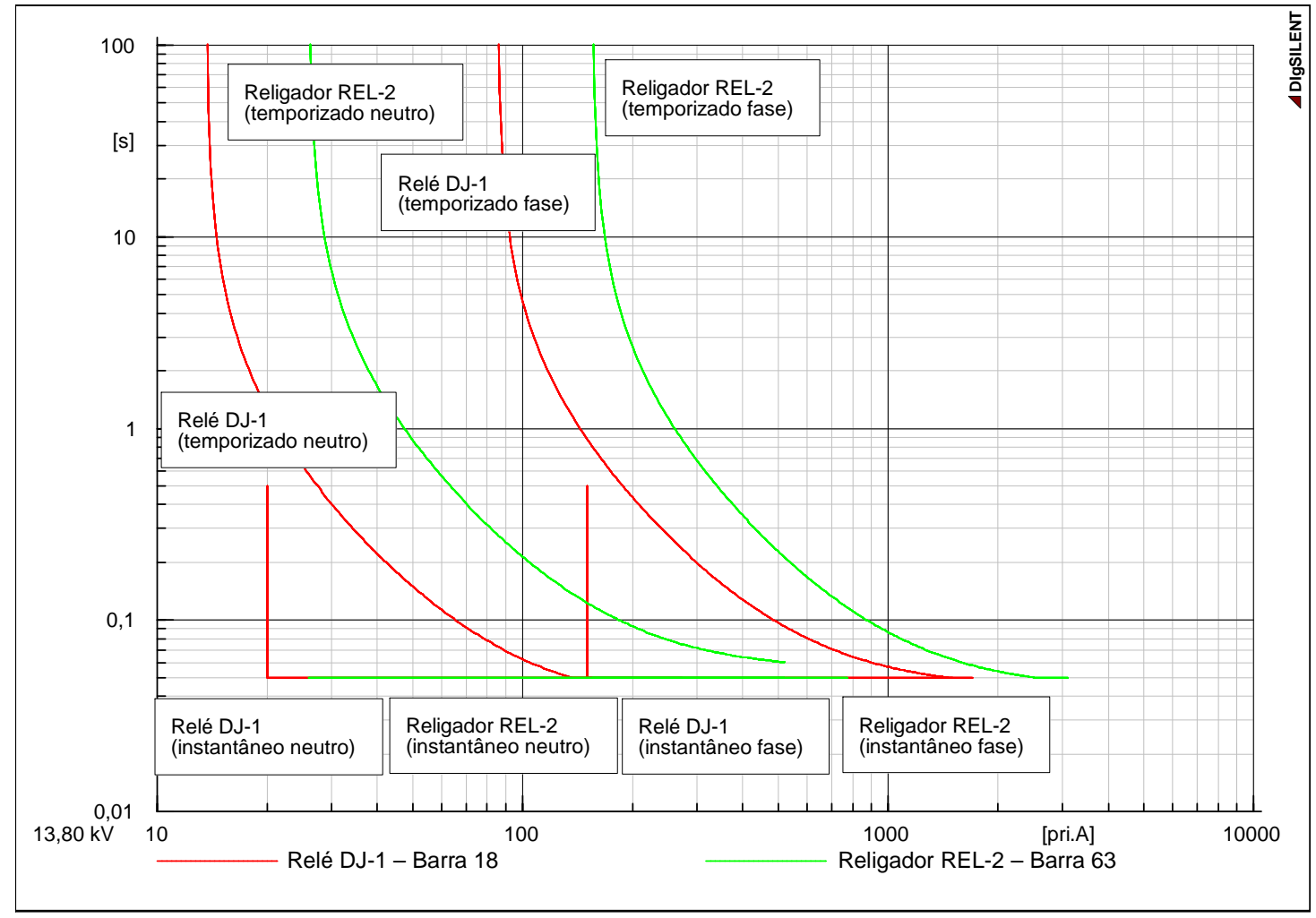

Figura 4.5 - Coordenação entre o relé do disjuntor DJ-1 e religador REL-2.

\subsection{Etapa 3 - Avaliação das Proteções de Sobrecorrente com o Sistema Operando Ilhado}

Conforme comentado anteriormente, nesta etapa é proposta uma metodologia para avaliação do impacto da GD sobre o sistema de proteção de sobrecorrente da rede de distribuição operando em ilhamento intencional.

A metodologia consiste em analisar o comportamento da proteção de sobrecorrente dividindo a rede de distribuição em regiões de proteção, as quais são delimitadas pelos dispositivos de proteção de sobrecorrente existentes em suas extremidades, conforme indicado na Figura 4.6.

No interior de cada região de proteção, serão simulados diferentes tipos de faltas, nos locais em que as correntes de curto-circuito sejam a maior e a menor possíveis, de tal sorte que os dispositivos de proteção possam ter suas margens de coordenação postas em prova, ou seja, que o intervalo de tempo entre a atuação do dispositivo de proteção principal e o de retaguarda seja grande o suficiente para que o dispositivo mais próximo da falta atue primeiro. 


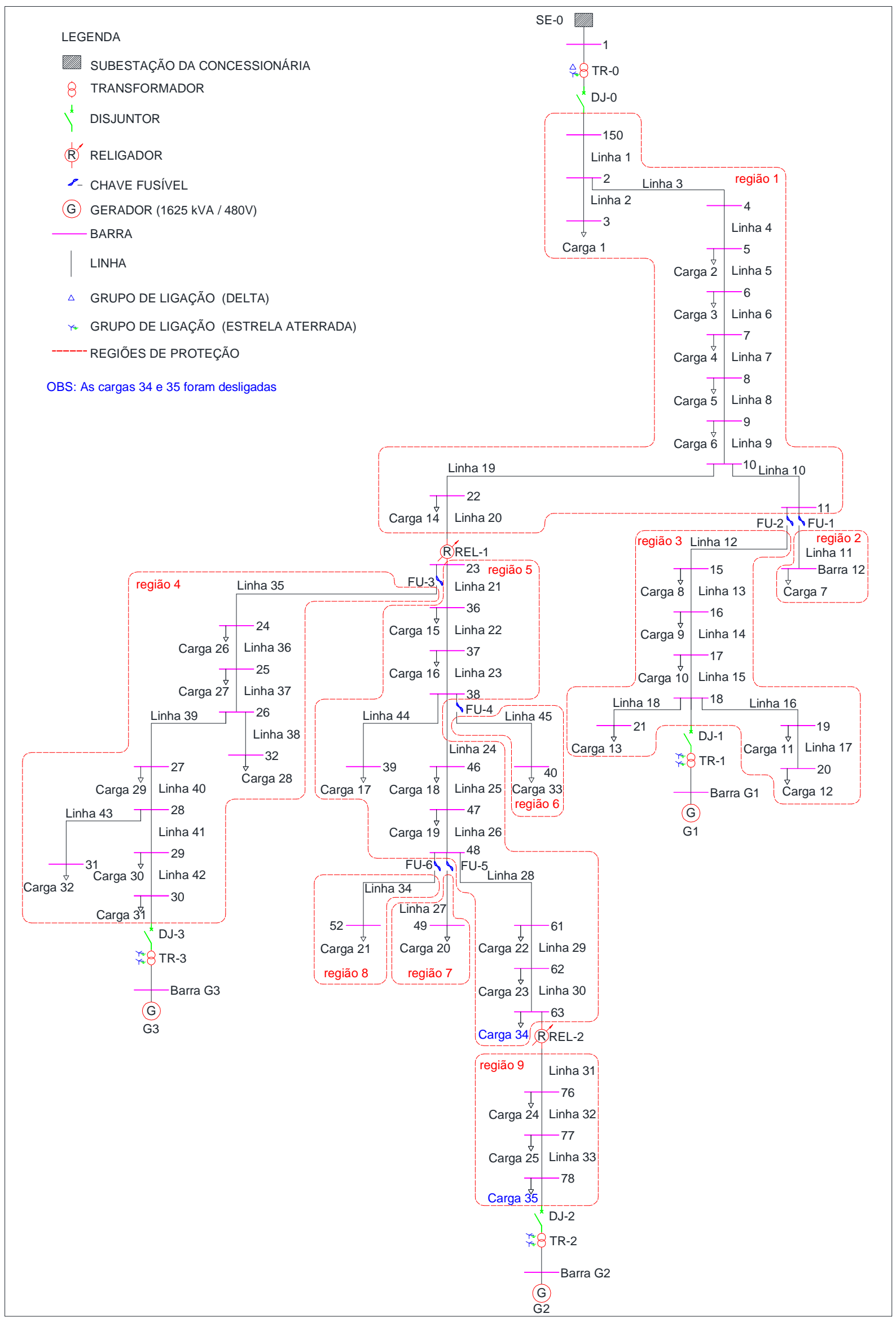

Figura 4.6 - Regiões de proteção definidas no sistema de distribuição. 
Após a avaliação das margens de coordenação, serão tomadas medidas corretivas para reajuste do sistema de proteção de sobrecorrente existente. Em seguida, a margem de coordenação será novamente verificada, considerando os mesmos pontos e tipos de faltas simuladas anteriormente.

Por fim, as duas situações estudas, ou seja, antes e após o reajuste da proteção, serão comparadas e avaliadas.

Para aplicação da metodologia, o disjuntor DJ-0 da subestação da concessionária foi aberto e o sistema passou a ser alimentado apenas pelos geradores G1, G2 e G3.

Com auxílio do programa DIgSILENT, verificou-se o fluxo de potência do sistema. Para que o mesmo pudesse operar com níveis de tensão adequados em todas as barras, as cargas 34 e 35, localizadas nas barras 63 e 78 da Figura 4.6, tiveram que ser desligadas.

A Tabela 4.7 apresenta as regiões de proteção definidas na Figura 4.6, com a identificação das regiões delimitadas pelos dispositivos de proteção de sobrecorrente principais e de retaguarda.

Tabela 4.7- Limites das regiões de proteção.

\begin{tabular}{|c|c|c|c|}
\hline \multirow[b]{2}{*}{ Região de Proteção } & \multicolumn{3}{|c|}{ Dispositivos Envolvidos na Proteção } \\
\hline & $\begin{array}{l}\text { Delimitação } \\
\text { da Região }\end{array}$ & $\begin{array}{l}\text { Proteção } \\
\text { Principal }\end{array}$ & $\begin{array}{l}\text { Proteção de } \\
\text { Retaguarda }\end{array}$ \\
\hline Região 1 & $\begin{array}{c}\text { barras } 150,2,3,4,5,6,7 \\
8,9,10,11,22 \text { e linha } 20\end{array}$ & FU-2, REL-1 & DJ-1, FU-3, REL-2 \\
\hline Região 2 & linha 11 e barra 12 & FU-1 & FU-2, REL-1 \\
\hline Região 3 & $\begin{array}{c}\text { linha } 12 \text { e barras } 15,16,17 \\
18,19,20,21\end{array}$ & FU-2, DJ-1 & REL-1 \\
\hline Região 4 & $\begin{array}{c}\text { linha } 35 \text { e barras } 24,25,26 \text {, } \\
27,28,29,30,31,32\end{array}$ & FU-3, DJ-3 & REL-1, REL-2 \\
\hline Região 5 & $\begin{array}{c}\text { barras } 23,36,37,38,39 \\
46,47,48,61,62,63\end{array}$ & $\begin{array}{l}\text { REL-1, FU-3, } \\
\text { REL-2 }\end{array}$ & FU-2, DJ-3, DJ-2 \\
\hline Região 6 & linha 45 e barra 40 & $\mathrm{FU}-4$ & REL-1, FU-3, REL-2 \\
\hline Região 7 & linha 27 e barra 49 & FU-5 & REL-1, FU-3, REL-2 \\
\hline Região 8 & linha 34 e barra 52 & FU-6 & REL-1, FU-3, REL-2 \\
\hline Região 9 & linha 31 e barras $76,77,78$ & REL-2, DJ-2 & REL-1, FU-3 \\
\hline
\end{tabular}

Para análise do comportamento da proteção de sobrecorrente de cada região de proteção definida anteriormente, foram calculadas as correntes de curto-circuito nos locais apresentados na Tabela 4.8. As faltas nas linhas de distribuição foram simuladas à distância de $10 \%$ do comprimento da linha, a partir da barra onde se encontra instalado o elemento de proteção principal da respectiva região. A distância foi escolhida de forma aleatória, mas 
levando em consideração que, o ponto onde há a ocorrência do curto-circuito não seja muito distante do elemento de proteção principal.

Tabela 4.8 - Localização das faltas avaliadas de acordo com cada região de proteção.

\begin{tabular}{|c|c|c|c|}
\hline \multirow{2}{*}{$\begin{array}{l}\text { Região de } \\
\text { Proteção }\end{array}$} & \multicolumn{3}{|c|}{ Localização do Curto-circuito } \\
\hline & $\begin{array}{c}\text { Curto-circuito } \\
\text { Trifásico }\end{array}$ & $\begin{array}{c}\text { Curto-circuito } \\
\text { Bifásico }\end{array}$ & $\begin{array}{l}\text { Curto-circuito } \\
\text { Fase-Terra }\end{array}$ \\
\hline Região 1 & linha 20 e barra 11 & barra 150 & barra 150 , barra 11 e linha 20 \\
\hline Região 2 & linha 11 & barra 12 & barra 12 e linha 11 \\
\hline Região 3 & linha 12 & barra 21 & barra 21 e linha 12 \\
\hline Região 4 & linha 35 & barra 31 & barra 31 e linha 35 \\
\hline Região 5 & barra 23 e barra 63 & barra 39 & barra 39 , barra 23 e barra 63 \\
\hline Região 6 & linha 45 & barra 40 & barra 40 e linha 45 \\
\hline Região 7 & linha 27 & barra 49 & barra 49 e linha 27 \\
\hline Região 8 & linha 34 & barra 52 & barra 52 e linha 34 \\
\hline Região 9 & linha 31 & barra 78 & barra 78 e linha 31 \\
\hline
\end{tabular}

\subsubsection{Avaliação da proteção com os ajustes iniciais}

As correntes de curto-circuito obtidas nos locais citados na Tabela 4.8 estão apresentadas nas Tabelas de 4.9 a 4.17. Nelas também são apresentados os valores das correntes de curto-circuito vistas por cada dispositivo de proteção de sobrecorrente envolvido na falta da região estudada. Os tempos de atuação, mínimo e máximo, correspondem ao tempo de atuação considerando a curva instantânea dos relés e religadores ou curva de tempo mínimo de fusão dos elos fusíveis, e curva temporizada dos relés e religadores ou curva de tempo máximo de interrupção dos elos fusíveis, respectivamente.

Os ajustes da proteção de sobrecorrente correspondem aos ajustes iniciais obtidos após a inserção dos geradores distribuídos na rede com a operação em paralelo, indicados nas Tabelas 4.1, 4.2, 4.3, 4.5 e 4.6.

Os dispositivos de proteção são identificados de acordo com a função de proteção exercida para cada tipo de falta e local estudados, ou seja, um determinado dispositivo de proteção pode exercer a função de proteção principal ou de retaguarda, dependendo do local onde ocorre a falta.

A margem de coordenação utilizada para fusíveis foi obtida da Equação A.4, enquanto, para a coordenação entre relés e religadores, foi utilizada a margem de 0,2 s, ambas apresentas no Anexo A. 
A margem de coordenação foi calculada subtraindo o tempo de atuação do elemento de proteção de retaguarda do tempo de atuação do elemento de proteção principal, nos locais em que este valor aparece com o sinal negativo, significa que o elemento de proteção de retaguarda atua antes do elemento de proteção principal, no intervalo de tempo calculado.

Nos casos de coordenação entre relés ou religadores e elos fusíveis, quando os relés ou religadores exercem a função de proteção de retaguarda, a margem de coordenação foi calculada subtraindo o tempo de atuação obtido das curvas instantâneas dos relés ou religadores, das curvas de tempo máximo de fusão dos fusíveis. Quando os elos fusíveis exercem a função de proteção de retaguarda, a margem de coordenação é calculada subtraindo o tempo de atuação obtido das curvas de tempo mínimo de fusão dos elos fusíveis, das curvas instantâneas dos relés ou religadores.

É importante informar que nos casos de curto-circuito fase-terra, a corrente vista pelos elos fusíveis é a própria corrente da fase em contato com a terra, enquanto que, para os relés e religadores ela consiste na componente de sequência zero $\left(3 \mathrm{I}_{0}\right)$.

Após a verificação da margem de coordenação em cada situação, conclui-se se há ou não coordenação entre os elementos de proteção.

Devido à grande quantidade de situações analisadas, não seria viável apresentar os resultados obtidos em forma de coordenogramas, por esse motivo optou-se por apresentálos em forma de tabelas, reunindo num mesmo local todas as informações necessárias para análise. 
Tabela 4.9 - Margens de coordenação iniciais obtidas na região 1.

\begin{tabular}{|c|c|c|c|c|c|c|c|c|c|c|}
\hline \multicolumn{11}{|c|}{ Região 1 de Proteção } \\
\hline $\begin{array}{l}\text { Local } \\
\text { da } \\
\text { Falta }\end{array}$ & $\begin{array}{c}\text { Tipo } \\
\text { de } \\
\text { Falta }\end{array}$ & $\begin{array}{c}\text { Corrente } \\
\text { de } \\
\text { Falta } \\
\text { (A) }\end{array}$ & $\begin{array}{c}\text { Elemento } \\
\text { de } \\
\text { Proteção }\end{array}$ & $\begin{array}{l}\text { Corrente } \\
\text { vista } \\
\text { pelo } \\
\text { elemento } \\
\text { de } \\
\text { proteção } \\
\text { (A) }\end{array}$ & $\begin{array}{c}\text { Tempo } \\
\text { de } \\
\text { atuação } \\
\text { mínimo } \\
\text { (ms) }\end{array}$ & $\begin{array}{c}\text { Tempo } \\
\text { de } \\
\text { atuação } \\
\text { máximo } \\
\text { (ms) }\end{array}$ & $\begin{array}{l}\text { Proteção } \\
\text { Principal }\end{array}$ & $\begin{array}{l}\text { Proteção de } \\
\text { Retaguarda }\end{array}$ & 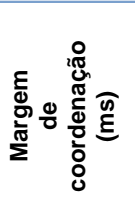 & 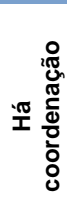 \\
\hline \multirow{10}{*}{$\begin{array}{c}\text { Barra } \\
150\end{array}$} & \multirow{5}{*}{ Bifásico } & \multirow{5}{*}{555} & FU-2 & 208 & 299 & 474 & \multirow{2}{*}{ FU-2 } & \multirow{2}{*}{ DJ-1 } & \multirow{2}{*}{-424} & \multirow{2}{*}{ Não } \\
\hline & & & REL-1 & 336 & 50 & 15067 & & & & \\
\hline & & & DJ-1 & 198 & 50 & 447 & \multirow{2}{*}{ REL-1 } & \multirow{2}{*}{ FU-3 } & \multirow{2}{*}{374} & \multirow{2}{*}{ Sim } \\
\hline & & & FU-3 & 167 & 424 & 680 & & & & \\
\hline & & & REL-2 & 157 & 50 & 67096 & REL-1 & REL-2 & 0 & Não \\
\hline & \multirow{5}{*}{$\begin{array}{l}\text { Fase } \\
\text { Terra }\end{array}$} & \multirow{5}{*}{176} & FU-2 & 70 & 4881 & 15122 & \multirow{2}{*}{ FU-2 } & \multirow{2}{*}{ DJ-1 } & \multirow{2}{*}{-4831} & \multirow{2}{*}{ Não } \\
\hline & & & REL-1 & 116 & 50 & 2159 & & & & \\
\hline & & & DJ-1 & 60 & 50 & 113 & \multirow{2}{*}{ REL-1 } & \multirow{2}{*}{ FU-3 } & \multirow{2}{*}{2530} & \multirow{2}{*}{ Sim } \\
\hline & & & FU-3 & 80 & 2580 & 6344 & & & & \\
\hline & & & REL-2 & 58 & 50 & 608 & REL-1 & REL-2 & 0 & Não \\
\hline \multirow{10}{*}{$\begin{array}{c}\text { Barra } \\
11\end{array}$} & \multirow{5}{*}{ Trifásico } & \multirow{5}{*}{950} & FU-2 & 343 & 100 & 143 & \multirow{2}{*}{ FU-2 } & \multirow{2}{*}{ DJ-1 } & \multirow{2}{*}{-93} & \\
\hline & & & REL-1 & 610 & 50 & 1651 & & & & INao \\
\hline & & & DJ-1 & 343 & 50 & 160 & RFI -1 & $\mathrm{F} U-3$ & 77 & \\
\hline & & & FU-3 & 306 & 127 & 187 & REL-I & $1-U-3$ & 78 & INao \\
\hline & & & REL-2 & 305 & 50 & 650 & REL-1 & REL-2 & 0 & Não \\
\hline & & & FU-2 & 72 & 4253 & 12533 & FU-2 & DJ-1 & -12483 & Não \\
\hline & & & REL-1 & 119 & 50 & 2020 & $1-U-2$ & DJ-1 & -12483 & INao \\
\hline & rase & 180 & DJ-1 & 62 & 50 & 108 & RFI - 1 & $\mathrm{FH}-3$ & 2397 & \\
\hline & & & FU-3 & 81 & 2447 & 5903 & REL-1 & $1-U-3$ & 2391 & SIm \\
\hline & & & REL-2 & 59 & 50 & 585 & REL-1 & REL-2 & 0 & Não \\
\hline & & & FU-2 & 341 & 101 & 145 & FII-? & & & \\
\hline & & & REL-1 & 618 & 50 & 1601 & FU-2 & DJ-1 & -95 & Nao \\
\hline & Trifásico & 957 & DJ-1 & 341 & 50 & 161 & REL - 1 & FU-3 & 74 & Não \\
\hline & & & FU-3 & 310 & 124 & 181 & REL-1 & FU-3 & 14 & \\
\hline Linha & & & REL-2 & 309 & 50 & 629 & REL-1 & REL-2 & 0 & Não \\
\hline 20 & & & FU-2 & 71 & 4555 & 13763 & FUI-? & D.J-1 & -13713 & Não \\
\hline & & & REL-1 & 120 & 50 & 1977 & 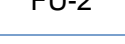 & DJ-1 & $-13 / 10$ & INau \\
\hline & Terra & 181 & DJ-1 & 61 & 50 & 110 & & & 2276 & Sim \\
\hline & & & FU-3 & 82 & 2326 & 5512 & Rㄷ-1 & rU-3 & $\angle 210$ & SIII \\
\hline & & & REL-2 & 60 & 50 & 563 & REL-1 & REL-2 & 0 & Não \\
\hline
\end{tabular}

Tabela 4.10 - Margens de coordenação iniciais obtidas na região 2.

\begin{tabular}{|c|c|c|c|c|c|c|c|c|c|c|}
\hline \multicolumn{11}{|c|}{ Região 2 de Proteção } \\
\hline $\begin{array}{c}\text { Local } \\
\text { da } \\
\text { Falta }\end{array}$ & $\begin{array}{c}\text { Tipo } \\
\text { de } \\
\text { Falta }\end{array}$ & $\begin{array}{l}\text { Corrente } \\
\text { de } \\
\text { Falta } \\
\text { (A) }\end{array}$ & $\begin{array}{c}\text { Elemento } \\
\text { de } \\
\text { Proteção }\end{array}$ & $\begin{array}{l}\text { Corrente } \\
\text { vista } \\
\text { pelo } \\
\text { elemento } \\
\text { de } \\
\text { proteção } \\
\text { (A) }\end{array}$ & $\begin{array}{c}\text { Tempo } \\
\text { de } \\
\text { atuação } \\
\text { mínimo } \\
\text { (ms) }\end{array}$ & $\begin{array}{c}\text { Tempo } \\
\text { de } \\
\text { atuação } \\
\text { máximo } \\
\text { (ms) }\end{array}$ & $\begin{array}{l}\text { Proteção } \\
\text { Principal }\end{array}$ & $\begin{array}{l}\text { Proteção de } \\
\text { Retaguarda }\end{array}$ & 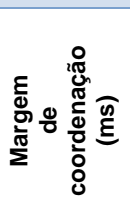 & 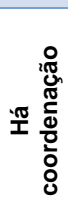 \\
\hline \multirow{5}{*}{$\begin{array}{c}\text { Barra } \\
12\end{array}$} & \multirow[t]{2}{*}{ Bifásico } & \multirow[t]{2}{*}{643} & $\begin{array}{l}\text { FU-1 } \\
\text { FU-2 }\end{array}$ & $\begin{array}{l}639 \\
237\end{array}$ & $\begin{array}{c}10 \\
218\end{array}$ & $\begin{array}{c}10 \\
337\end{array}$ & FU-1 & FU-2 & 208 & Sim \\
\hline & & & REL-1 & 391 & 50 & 6457 & FU-1 & REL-1 & 40 & Não \\
\hline & \multirow{3}{*}{$\begin{array}{l}\text { Fase } \\
\text { Terra }\end{array}$} & \multirow{3}{*}{180} & FU-1 & 186 & 14 & 20 & \multirow{2}{*}{ FU-1 } & \multirow[t]{2}{*}{ FU-2 } & \multirow[t]{2}{*}{4233} & \multirow[t]{2}{*}{ Sim } \\
\hline & & & FU-2 & 72 & 4253 & 12533 & & & & \\
\hline & & & REL-1 & 118 & 50 & 2065 & FU-1 & REL-1 & 36 & Não \\
\hline \multirow{6}{*}{$\underset{11}{\text { Linha }}$} & \multirow{3}{*}{ Trifásico } & \multirow{3}{*}{950} & FU-1 & 950 & 10 & 10 & \multirow{2}{*}{ FU-1 } & \multirow{2}{*}{ FU-2 } & \multirow{2}{*}{90} & \multirow{2}{*}{ Sim } \\
\hline & & & FU-2 & 343 & 100 & 143 & & & & \\
\hline & & & REL-1 & 610 & 50 & 1651 & $\mathrm{FU}-1$ & REL-1 & 40 & Não \\
\hline & \multirow{3}{*}{$\begin{array}{l}\text { Fase } \\
\text { Terra }\end{array}$} & \multirow{3}{*}{180} & FU-1 & 186 & 14 & 20 & \multirow{2}{*}{ FU-1 } & \multirow{2}{*}{ FU-2 } & \multirow{2}{*}{4233} & \multirow{2}{*}{ Sim } \\
\hline & & & FU-2 & 72 & 4253 & 12533 & & & & \\
\hline & & & REL-1 & 119 & 50 & 2020 & FU-1 & REL-1 & 36 & Não \\
\hline
\end{tabular}


Tabela 4.11 - Margens de coordenação iniciais obtidas na região 3.

\begin{tabular}{|c|c|c|c|c|c|c|c|c|c|c|}
\hline \multicolumn{11}{|c|}{ Região 3 de Proteção } \\
\hline $\begin{array}{l}\text { Local } \\
\text { da } \\
\text { Falta }\end{array}$ & $\begin{array}{l}\text { Tipo } \\
\text { de } \\
\text { Falta }\end{array}$ & $\begin{array}{l}\text { Corrente } \\
\text { de } \\
\text { Falta } \\
\text { (A) }\end{array}$ & $\begin{array}{c}\text { Elemento } \\
\text { de } \\
\text { Proteção }\end{array}$ & $\begin{array}{l}\text { Corrente } \\
\text { vista } \\
\text { pelo } \\
\text { elemento } \\
\text { de } \\
\text { proteção } \\
\text { (A) }\end{array}$ & $\begin{array}{c}\text { Tempo } \\
\text { de } \\
\text { atuação } \\
\text { mínimo } \\
\text { (ms) }\end{array}$ & $\begin{array}{c}\text { Tempo } \\
\text { de } \\
\text { atuação } \\
\text { máximo } \\
\text { (ms) }\end{array}$ & $\begin{array}{l}\text { Proteção } \\
\text { Principal }\end{array}$ & $\begin{array}{l}\text { Proteção de } \\
\text { Retaguarda }\end{array}$ & 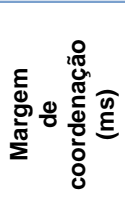 & 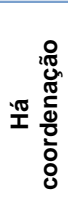 \\
\hline \multirow{6}{*}{$\begin{array}{c}\text { Barra } \\
21\end{array}$} & \multirow{3}{*}{ Bifásico } & \multirow{3}{*}{633} & FU-2 & 397 & 73 & 102 & \multirow{3}{*}{ FU-2 } & \multirow{3}{*}{ REL-1 } & \multirow{3}{*}{-52} & \multirow{3}{*}{ Não } \\
\hline & & & DJ-1 & 225 & 50 & 339 & & & & \\
\hline & & & REL-1 & 384 & 50 & 6993 & & & & \\
\hline & \multirow{3}{*}{$\begin{array}{l}\text { Fase } \\
\text { Terra }\end{array}$} & \multirow{3}{*}{179} & FU-2 & 123 & 766 & 1296 & \multirow{3}{*}{ FU-2 } & \multirow{3}{*}{ REL-1 } & \multirow{3}{*}{-1246} & \multirow{3}{*}{ Não } \\
\hline & & & DJ-1 & 62 & 50 & 108 & & & & \\
\hline & & & REL-1 & 117 & 50 & 2111 & & & & \\
\hline \multirow{6}{*}{$\begin{array}{c}\text { Linha } \\
12\end{array}$} & \multirow{3}{*}{ Trifásico } & \multirow{3}{*}{950} & FU-2 & 610 & 31 & 41 & \multirow{3}{*}{ FU-2 } & \multirow{3}{*}{ REL-1 } & \multirow{3}{*}{9} & \multirow{3}{*}{ Não } \\
\hline & & & DJ-1 & 343 & 50 & 160 & & & & \\
\hline & & & REL-1 & 610 & 50 & 1651 & & & & \\
\hline & \multirow{3}{*}{$\begin{array}{l}\text { Fase } \\
\text { Terra }\end{array}$} & \multirow{3}{*}{180} & FU-2 & 124 & 753 & 1270 & \multirow{3}{*}{ FU-2 } & \multirow{3}{*}{ REL-1 } & \multirow{3}{*}{-1220} & \multirow{3}{*}{ Não } \\
\hline & & & DJ-1 & 62 & 50 & 108 & & & & \\
\hline & & & REL-1 & 119 & 50 & 2020 & & & & \\
\hline
\end{tabular}

Tabela 4.12 - Margens de coordenação iniciais obtidas na região 4.

\begin{tabular}{|c|c|c|c|c|c|c|c|c|c|c|}
\hline \multicolumn{11}{|c|}{ Região 4 de Proteção } \\
\hline $\begin{array}{c}\text { Local } \\
\text { da } \\
\text { Falta }\end{array}$ & $\begin{array}{c}\text { Tipo } \\
\text { de } \\
\text { Falta }\end{array}$ & $\begin{array}{c}\text { Corrente } \\
\text { de } \\
\text { Falta } \\
\text { (A) }\end{array}$ & $\begin{array}{c}\text { Elemento } \\
\text { de } \\
\text { Proteção }\end{array}$ & $\begin{array}{l}\text { Corrente } \\
\text { vista } \\
\text { pelo } \\
\text { elemento } \\
\text { de } \\
\text { proteção } \\
\text { (A) }\end{array}$ & $\begin{array}{c}\text { Tempo } \\
\text { de } \\
\text { atuação } \\
\text { mínimo } \\
\text { (ms) }\end{array}$ & $\begin{array}{c}\text { Tempo } \\
\text { de } \\
\text { atuação } \\
\text { máximo } \\
\text { (ms) }\end{array}$ & $\begin{array}{l}\text { Proteção } \\
\text { Principal }\end{array}$ & $\begin{array}{l}\text { Proteção de } \\
\text { Retaguarda }\end{array}$ & 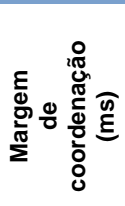 & 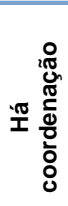 \\
\hline \multirow{8}{*}{$\begin{array}{c}\text { Barra } \\
31\end{array}$} & \multirow{4}{*}{ Bifásico } & \multirow{4}{*}{645} & FU-3 & 447 & 57 & 78 & \multirow{2}{*}{ FU-3 } & \multirow{2}{*}{ REL-1 } & \multirow{2}{*}{ * } & \multirow{2}{*}{ Sim } \\
\hline & & & DJ-3 & 184 & 50 & 524 & & & & \\
\hline & & & REL-1 & 248 & $\mathrm{~N} / \mathrm{A}$ & N/A & \multirow{2}{*}{ FU-3 } & \multirow{2}{*}{ REL-2 } & \multirow{2}{*}{-28} & \multirow{2}{*}{ Não } \\
\hline & & & REL-2 & 181 & 50 & 4833 & & & & \\
\hline & \multirow{4}{*}{$\begin{array}{l}\text { Fase } \\
\text { Terra }\end{array}$} & \multirow{4}{*}{180} & FU-3 & 98 & 1315 & 2568 & \multirow{2}{*}{ FU-3 } & \multirow{2}{*}{ REL-1 } & \multirow{2}{*}{-2518} & \multirow{2}{*}{ Não } \\
\hline & & & DJ-3 & 62 & 50 & 108 & & & & \\
\hline & & & REL-1 & 60 & 50 & $\mathrm{~N} / \mathrm{A}$ & \multirow{2}{*}{ FU-3 } & \multirow{2}{*}{ REL-2 } & \multirow{2}{*}{-2518} & \multirow{2}{*}{ Não } \\
\hline & & & REL-2 & 59 & 50 & 585 & & & & \\
\hline \multirow{8}{*}{$\begin{array}{c}\text { Linha } \\
35\end{array}$} & \multirow{4}{*}{ Trifásico } & \multirow{4}{*}{959} & FU-3 & 648 & 27 & 36 & \multirow{2}{*}{ FU-3 } & \multirow{2}{*}{ REL-1 } & \multirow{2}{*}{-28} & \multirow{2}{*}{ Não } \\
\hline & & & DJ-3 & 312 & 50 & 186 & & & & \\
\hline & & & REL-1 & 339 & 50 & 14104 & \multirow{2}{*}{ FU-3 } & \multirow{2}{*}{ REL-2 } & \multirow{2}{*}{14} & \multirow{2}{*}{ Não } \\
\hline & & & REL-2 & 310 & 50 & 188 & & & & \\
\hline & \multirow{4}{*}{$\begin{array}{l}\text { Fase } \\
\text { Terra }\end{array}$} & \multirow{4}{*}{181} & FU-3 & 99 & 1279 & 2476 & $\mathrm{Ell} 3$ & REI 1 & 2126 & N|̃̃ \\
\hline & & & DJ-3 & 60 & 50 & 113 & $1 \times U-3$ & Rㄷ-1 & $-<4<0$ & INAO \\
\hline & & & REL-1 & 60 & 50 & N/A & & & & \\
\hline & & & REL-2 & 60 & 50 & 563 & FU-3 & REL-2 & -2426 & Nao \\
\hline
\end{tabular}

* O elemento de proteção de retaguarda não atua. 
Tabela 4.13 - Margens de coordenação iniciais obtidas na região 5.

\begin{tabular}{|c|c|c|c|c|c|c|c|c|c|c|}
\hline \multicolumn{11}{|c|}{ Região 5 de Proteção } \\
\hline $\begin{array}{c}\text { Local } \\
\text { da } \\
\text { Falta }\end{array}$ & $\begin{array}{l}\text { Tipo } \\
\text { de } \\
\text { Falta }\end{array}$ & $\begin{array}{l}\text { Corrente } \\
\text { de } \\
\text { Falta } \\
\text { (A) }\end{array}$ & $\begin{array}{c}\begin{array}{c}\text { Elemento } \\
\text { de } \\
\text { Proteção }\end{array}\end{array}$ & $\begin{array}{l}\text { Corrente } \\
\text { vista } \\
\text { pelo } \\
\text { elemento } \\
\text { de } \\
\text { proteção } \\
\text { (A) }\end{array}$ & $\begin{array}{c}\text { Tempo } \\
\text { de } \\
\text { atuação } \\
\text { mínimo } \\
\text { (ms) }\end{array}$ & $\begin{array}{c}\text { Tempo } \\
\text { de } \\
\text { atuação } \\
\text { máximo } \\
\text { (ms) }\end{array}$ & $\begin{array}{l}\text { Proteção } \\
\text { Principal }\end{array}$ & $\begin{array}{l}\text { Proteção de } \\
\text { Retaguarda }\end{array}$ & 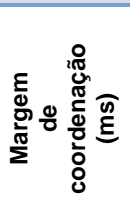 & 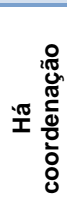 \\
\hline \multirow{12}{*}{$\begin{array}{c}\text { Barra } \\
39\end{array}$} & \multirow{6}{*}{ Bifásico } & \multirow{6}{*}{646} & REL-1 & 249 & $\mathrm{~N} / \mathrm{A}$ & $\mathrm{N} / \mathrm{A}$ & \multirow{2}{*}{ REL-1 } & \multirow{2}{*}{ FU-2 } & \multirow{2}{*}{ ** } & \multirow{2}{*}{ Não } \\
\hline & & & FU-3 & 195 & 319 & 508 & & & & \\
\hline & & & REL-2 & 183 & 50 & 4464 & \multirow{2}{*}{ FU-3 } & \multirow{2}{*}{ DJ-3 } & \multirow{2}{*}{-269} & \multirow{2}{*}{ Não } \\
\hline & & & FU-2 & 234 & 224 & 347 & & & & \\
\hline & & & DJ-3 & 180 & 50 & 552 & \multirow{2}{*}{ REL-2 } & \multirow{2}{*}{ DJ-2 } & \multirow{2}{*}{0} & \multirow{2}{*}{ Não } \\
\hline & & & DJ-2 & 181 & 50 & 545 & & & & \\
\hline & \multirow{6}{*}{$\begin{array}{l}\text { Fase } \\
\text { Terra }\end{array}$} & \multirow{6}{*}{180} & REL-1 & 60 & 50 & N/A & \multirow{2}{*}{ REL-1 } & \multirow{2}{*}{ FU-2 } & \multirow{2}{*}{4831} & \multirow{2}{*}{ Sim } \\
\hline & & & FU-3 & 82 & 2326 & 5512 & & & & \\
\hline & & & REL-2 & 60 & 50 & 563 & \multirow{2}{*}{ FU-3 } & \multirow{2}{*}{ DJ-3 } & \multirow{2}{*}{-5462} & \\
\hline & & & FU-2 & 70 & 4881 & 15122 & & & & Nao \\
\hline & & & DJ-3 & 60 & 50 & 113 & & & & \\
\hline & & & DJ-2 & 60 & 50 & 113 & REL-2 & $D J-2$ & U & INao \\
\hline & & & REL-1 & 339 & 50 & 14104 & & & & \\
\hline & & & FU-3 & 312 & 122 & 179 & REL-1 & FU-2 & 52 & Nao \\
\hline & & & REL-2 & 310 & 50 & 624 & $\mathrm{FH}-3$ & D।-3 & -72 & \\
\hline & Imasico & 950 & FU-2 & 340 & 102 & 146 & rU-3 & DJ-3 & -12 & INao \\
\hline & & & DJ-3 & 312 & 50 & 186 & & & & \\
\hline Barra & & & DJ-2 & 310 & 50 & 188 & REL-2 & $\mathrm{DJ}-2$ & 0 & INao \\
\hline 23 & & & REL-1 & 60 & 50 & $\mathrm{~N} / \mathrm{A}$ & RFI -1 & FII-? & 4831 & Sim \\
\hline & & & FU-3 & 82 & 2326 & 5512 & REL-I & $r U-<$ & 4831 & SIm \\
\hline & Fase & 181 & REL-2 & 60 & 50 & 563 & Ell 3 & 3 & 5162 & \\
\hline & Terra & 101 & FU-2 & 70 & 4881 & 15122 & $10-3$ & DJ-3 & $-540<$ & INaO \\
\hline & & & DJ-3 & 60 & 50 & 113 & REL -2 & DJ-2 & 0 & Não \\
\hline & & & DJ-2 & 60 & 50 & 113 & & Du-c & 0 & INau \\
\hline & & & REL-1 & 328 & 50 & 18365 & & & & \\
\hline & & & FU-3 & 302 & 131 & 193 & REL-1 & $1-U-2$ & 80 & INao \\
\hline & Trifásico & 943 & REL-2 & 315 & 50 & 600 & & DJ-3 & -81 & Não \\
\hline & masico & 943 & FU-2 & 329 & 130 & 191 & FU-3 & DJ-3 & -01 & INaU \\
\hline & & & DJ-3 & 303 & 50 & 195 & & DJ-2 & 0 & \\
\hline Barra & & & DJ-2 & 315 & 50 & 183 & REL-2 & $D J-2$ & 0 & INao \\
\hline 63 & & & REL-1 & 59 & 50 & $\mathrm{~N} / \mathrm{A}$ & REL -1 & FU-2 & 5180 & \\
\hline & & & FU-3 & 81 & 2447 & 5903 & REL-I & $r U-2$ & 5180 & INao \\
\hline & Fase & 180 & REL-2 & 62 & 50 & 524 & $\mathrm{FH}-3$ & Dו-3 & -5853 & Nãก \\
\hline & Terra & 180 & FU-2 & 69 & 5230 & 16619 & rU-3 & DJ-3 & -5853 & INao \\
\hline & & & DJ-3 & 59 & 50 & 116 & & ?-2 & 0 & Não \\
\hline & & & DJ-2 & 62 & 50 & 108 & nடL-く & $D J-2$ & 0 & INaO \\
\hline
\end{tabular}

O elemento de proteção principal não atua 
Tabela 4.14 - Margens de coordenação iniciais obtidas na região 6.

\begin{tabular}{|c|c|c|c|c|c|c|c|c|c|c|}
\hline \multicolumn{11}{|c|}{ Região 6 de Proteção } \\
\hline $\begin{array}{c}\text { Local } \\
\text { da } \\
\text { Falta }\end{array}$ & $\begin{array}{c}\text { Tipo } \\
\text { de } \\
\text { Falta }\end{array}$ & $\begin{array}{c}\text { Corrente } \\
\text { de } \\
\text { Falta } \\
\text { (A) }\end{array}$ & $\begin{array}{c}\text { Elemento } \\
\text { de } \\
\text { Proteção }\end{array}$ & $\begin{array}{l}\text { Corrente } \\
\text { vista } \\
\text { pelo } \\
\text { elemento } \\
\text { de } \\
\text { proteção } \\
\text { (A) }\end{array}$ & $\begin{array}{c}\text { Tempo } \\
\text { de } \\
\text { atuação } \\
\text { mínimo } \\
\text { (ms) }\end{array}$ & $\begin{array}{l}\text { Tempo } \\
\text { de } \\
\text { atuação } \\
\text { máximo } \\
\text { (ms) }\end{array}$ & $\begin{array}{l}\text { Proteção } \\
\text { Principal }\end{array}$ & $\begin{array}{l}\text { Proteção de } \\
\text { Retaguarda }\end{array}$ & 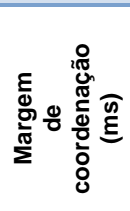 & 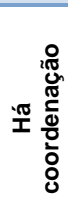 \\
\hline \multirow{8}{*}{$\begin{array}{c}\text { Barra } \\
40\end{array}$} & \multirow{4}{*}{ Bifásico } & \multirow{4}{*}{644} & FU-4 & 630 & 12 & 18 & \multirow{2}{*}{ FU-4 } & \multirow{2}{*}{ REL-1 } & \multirow{2}{*}{ * } & \multirow{2}{*}{ Sim } \\
\hline & & & REL-1 & 249 & $\mathrm{~N} / \mathrm{A}$ & $\mathrm{N} / \mathrm{A}$ & & & & \\
\hline & & & FU-3 & 194 & 322 & 513 & FU-4 & FU-3 & 304 & Sim \\
\hline & & & REL-2 & 183 & 50 & 4464 & FU-4 & REL-2 & 32 & Não \\
\hline & \multirow{4}{*}{$\begin{array}{l}\text { Fase } \\
\text { Terra }\end{array}$} & \multirow{4}{*}{180} & FU-4 & 193 & 116 & 173 & \multirow{2}{*}{ FU-4 } & \multirow{2}{*}{ REL-1 } & \multirow{2}{*}{-123} & \multirow{2}{*}{ Não } \\
\hline & & & REL-1 & 60 & 50 & $\mathrm{~N} / \mathrm{A}$ & & & & \\
\hline & & & FU-3 & 82 & 2326 & 5512 & $\mathrm{FU}-4$ & FU-3 & 2153 & Sim \\
\hline & & & REL-2 & 60 & 50 & 563 & FU-4 & REL-2 & -123 & Não \\
\hline \multirow{8}{*}{$\begin{array}{c}\text { Linha } \\
45\end{array}$} & \multirow{4}{*}{ Trifásico } & \multirow{4}{*}{955} & FU-4 & 955 & 10 & 10 & \multirow{2}{*}{ FU-4 } & \multirow{2}{*}{ REL-1 } & \multirow{2}{*}{40} & \multirow{2}{*}{ Não } \\
\hline & & & REL-1 & 337 & 50 & 14733 & & & & \\
\hline & & & FU-3 & 309 & 125 & 183 & FU-4 & FU-3 & 115 & Sim \\
\hline & & & REL-2 & 311 & 50 & 619 & FU-4 & REL-2 & 40 & Não \\
\hline & \multirow{4}{*}{$\begin{array}{l}\text { Fase } \\
\text { Terra }\end{array}$} & \multirow{4}{*}{181} & $\mathrm{FU}-4$ & 193 & 116 & 173 & \multirow{2}{*}{ FU-4 } & \multirow{2}{*}{ REL-1 } & \multirow{2}{*}{-123} & \multirow{2}{*}{ Não } \\
\hline & & & REL-1 & 60 & 50 & $\mathrm{~N} / \mathrm{A}$ & & & & \\
\hline & & & FU-3 & 82 & 2326 & 5512 & FU-4 & FU-3 & 2153 & Sim \\
\hline & & & REL-2 & 60 & 50 & 563 & $\mathrm{FU}-4$ & REL-2 & -123 & Não \\
\hline
\end{tabular}

O elemento de proteção de retaguarda não atua.

Tabela 4.15 - Margens de coordenação iniciais obtidas na região 7.

\begin{tabular}{|c|c|c|c|c|c|c|c|c|c|c|}
\hline \multirow{2}{*}{\multicolumn{11}{|c|}{ Correntes de curto-circuito e tempos de atuação dos dispositivos de proteção }} \\
\hline \multicolumn{2}{|c|}{ Região 7 de Proteção } & & & & & & & & & \\
\hline $\begin{array}{c}\text { Local } \\
\text { da } \\
\text { Falta }\end{array}$ & $\begin{array}{l}\text { Tipo } \\
\text { de } \\
\text { Falta }\end{array}$ & $\begin{array}{c}\text { Corrente } \\
\text { de } \\
\text { Falta } \\
\text { (A) }\end{array}$ & $\begin{array}{c}\text { Elemento } \\
\text { de } \\
\text { Proteção }\end{array}$ & $\begin{array}{l}\text { Corrente } \\
\text { vista } \\
\text { pelo } \\
\text { elemento } \\
\text { de } \\
\text { proteção } \\
\text { (A) }\end{array}$ & $\begin{array}{c}\text { Tempo } \\
\text { de } \\
\text { atuação } \\
\text { mínimo } \\
\text { (ms) }\end{array}$ & $\begin{array}{c}\text { Tempo } \\
\text { de } \\
\text { atuação } \\
\text { máximo } \\
\text { (ms) }\end{array}$ & $\begin{array}{l}\text { Proteção } \\
\text { Principal }\end{array}$ & $\begin{array}{l}\text { Proteção de } \\
\text { Retaguarda }\end{array}$ & 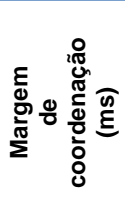 & 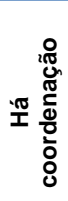 \\
\hline \multirow{8}{*}{$\begin{array}{c}\text { Barra } \\
49\end{array}$} & \multirow{4}{*}{ Bifásico } & \multirow{4}{*}{644} & FU-5 & 630 & 12 & 18 & \multirow{2}{*}{ FU-5 } & \multirow{2}{*}{ REL-1 } & \multirow{2}{*}{ * } & \multirow{2}{*}{ Sim } \\
\hline & & & REL-1 & 249 & $\mathrm{~N} / \mathrm{A}$ & $\mathrm{N} / \mathrm{A}$ & & & & \\
\hline & & & FU-3 & 194 & 322 & 513 & FU-5 & FU-3 & 310 & Sim \\
\hline & & & REL-2 & 183 & 50 & 4464 & FU-5 & REL-2 & 32 & Não \\
\hline & \multirow{4}{*}{$\begin{array}{l}\text { Fase } \\
\text { Terra }\end{array}$} & \multirow{4}{*}{180} & FU-5 & 193 & 116 & 173 & \multirow{2}{*}{ FU-5 } & \multirow{2}{*}{ REL-1 } & \multirow{2}{*}{-123} & \multirow{2}{*}{ Não } \\
\hline & & & REL-1 & 60 & 50 & $\mathrm{~N} / \mathrm{A}$ & & & & \\
\hline & & & FU-3 & 82 & 2326 & 5512 & FU-5 & FU-3 & 2153 & Sim \\
\hline & & & REL-2 & 60 & 50 & 563 & FU-5 & REL-2 & -123 & Não \\
\hline \multirow{8}{*}{$\begin{array}{c}\text { Linha } \\
27\end{array}$} & \multirow{4}{*}{ Trifásico } & \multirow{4}{*}{947} & FU-5 & 947 & 10 & 10 & \multirow{2}{*}{ FU-5 } & \multirow{2}{*}{ REL-1 } & \multirow{2}{*}{40} & \multirow{2}{*}{ Não } \\
\hline & & & REL-1 & 331 & 50 & 16980 & & & & \\
\hline & & & FU-3 & 304 & 129 & 190 & FU-5 & FU-3 & 119 & Sim \\
\hline & & & REL-2 & 314 & 50 & 605 & FU-5 & REL-2 & 40 & Não \\
\hline & \multirow{4}{*}{$\begin{array}{l}\text { Fase } \\
\text { Terra }\end{array}$} & \multirow{4}{*}{180} & FU-5 & 192 & 117 & 175 & \multirow{2}{*}{ FU-5 } & \multirow{2}{*}{ REL-1 } & \multirow{2}{*}{-125} & \multirow{2}{*}{ Não } \\
\hline & & & REL-1 & 59 & 50 & $\mathrm{~N} / \mathrm{A}$ & & & & \\
\hline & & & FU-3 & 81 & 2447 & 5903 & FU-5 & FU-3 & 2272 & Sim \\
\hline & & & REL-2 & 62 & 50 & 524 & FU-5 & REL-2 & -125 & Não \\
\hline
\end{tabular}

\footnotetext{
O elemento de proteção de retaguarda não atua.
} 
Tabela 4.16 - Margens de coordenação iniciais obtidas na região 8.

\begin{tabular}{|c|c|c|c|c|c|c|c|c|c|c|}
\hline \multirow{2}{*}{\multicolumn{11}{|c|}{$\begin{array}{r}\text { Correntes de curto-circuito e tempos de atuação do } \\
\text { Região } 8 \text { de Proteção }\end{array}$}} \\
\hline & & & & & & & & & & \\
\hline $\begin{array}{c}\text { Local } \\
\text { da } \\
\text { Falta }\end{array}$ & $\begin{array}{c}\text { Tipo } \\
\text { de } \\
\text { Falta }\end{array}$ & $\begin{array}{c}\text { Corrente } \\
\text { de } \\
\text { Falta } \\
\text { (A) }\end{array}$ & $\begin{array}{c}\text { Elemento } \\
\text { de } \\
\text { Proteção }\end{array}$ & $\begin{array}{l}\text { Corrente } \\
\text { vista } \\
\text { pelo } \\
\text { elemento } \\
\text { de } \\
\text { proteção } \\
\text { (A) }\end{array}$ & $\begin{array}{c}\text { Tempo } \\
\text { de } \\
\text { atuação } \\
\text { mínimo } \\
\text { (ms) }\end{array}$ & $\begin{array}{c}\text { Tempo } \\
\text { de } \\
\text { atuação } \\
\text { máximo } \\
\text { (ms) }\end{array}$ & $\begin{array}{l}\text { Proteção } \\
\text { Principal }\end{array}$ & $\begin{array}{l}\text { Proteção de } \\
\text { Retaguarda }\end{array}$ & 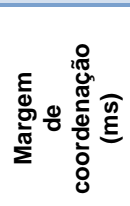 & 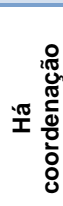 \\
\hline \multirow{8}{*}{$\begin{array}{l}\text { Barra } \\
52\end{array}$} & \multirow{4}{*}{ Bifásico } & \multirow{4}{*}{640} & FU-6 & 636 & 10 & 10 & \multirow{2}{*}{ FU-6 } & \multirow{2}{*}{ REL-1 } & \multirow{2}{*}{ * } & \multirow{2}{*}{ Sim } \\
\hline & & & REL-1 & 246 & $\mathrm{~N} / \mathrm{A}$ & $\mathrm{N} / \mathrm{A}$ & & & & \\
\hline & & & FU-3 & 192 & 329 & 523 & FU-6 & FU-3 & 319 & Sim \\
\hline & & & REL-2 & 184 & 50 & 4299 & FU-6 & REL-2 & 40 & Não \\
\hline & \multirow{4}{*}{$\begin{array}{l}\text { Fase } \\
\text { Terra }\end{array}$} & \multirow{4}{*}{180} & FU-6 & 187 & 45 & 61 & \multirow{2}{*}{ FU-6 } & \multirow{2}{*}{ REL-1 } & \multirow{2}{*}{-11} & \multirow{2}{*}{ Não } \\
\hline & & & REL-1 & 59 & 50 & $\mathrm{~N} / \mathrm{A}$ & & & & \\
\hline & & & FU-3 & 81 & 2447 & 5903 & FU-6 & FU-3 & 2386 & Sim \\
\hline & & & REL-2 & 62 & 50 & 524 & FU-6 & REL-2 & -11 & Não \\
\hline \multirow{8}{*}{$\begin{array}{l}\text { Linha } \\
34\end{array}$} & \multirow{4}{*}{ Trifásico } & \multirow{4}{*}{947} & FU-6 & 947 & 10 & 10 & \multirow{2}{*}{ FU-6 } & \multirow{2}{*}{ REL-1 } & \multirow{2}{*}{40} & \multirow{2}{*}{ Não } \\
\hline & & & REL-1 & 331 & 50 & 16980 & & & & \\
\hline & & & FU-3 & 304 & 129 & 190 & FU-6 & FU-3 & 119 & Sim \\
\hline & & & REL-2 & 314 & 50 & 605 & FU-6 & REL-2 & 40 & Não \\
\hline & \multirow{4}{*}{$\begin{array}{l}\text { Fase } \\
\text { Terra }\end{array}$} & \multirow{4}{*}{180} & FU-6 & 188 & 44 & 60 & \multirow{2}{*}{ FU-6 } & \multirow{2}{*}{ REL-1 } & \multirow{2}{*}{-10} & \multirow{2}{*}{ Não } \\
\hline & & & REL-1 & 59 & 50 & $\mathrm{~N} / \mathrm{A}$ & & & & \\
\hline & & & FU-3 & 81 & 2447 & 5903 & FU-6 & FU-3 & 2387 & Sim \\
\hline & & & REL-2 & 62 & 50 & 524 & FU-6 & REL-2 & -10 & Não \\
\hline
\end{tabular}

O elemento de proteção de retaguarda não atua.

Tabela 4.17 - Margens de coordenação iniciais obtidas na região 9.

\begin{tabular}{|c|c|c|c|c|c|c|c|c|c|c|}
\hline \multicolumn{11}{|c|}{ Região 9 de Proteção } \\
\hline $\begin{array}{c}\text { Local } \\
\text { da } \\
\text { Falta }\end{array}$ & $\begin{array}{c}\text { Tipo } \\
\text { de } \\
\text { Falta }\end{array}$ & $\begin{array}{c}\text { Corrente } \\
\text { de } \\
\text { Falta } \\
\text { (A) }\end{array}$ & $\begin{array}{c}\text { Elemento } \\
\text { de } \\
\text { Proteção }\end{array}$ & $\begin{array}{l}\text { Corrente } \\
\text { vista } \\
\text { pelo } \\
\text { elemento } \\
\text { de } \\
\text { proteção } \\
\text { (A) }\end{array}$ & $\begin{array}{c}\text { Tempo } \\
\text { de } \\
\text { atuação } \\
\text { mínimo } \\
\text { (ms) }\end{array}$ & $\begin{array}{c}\text { Tempo } \\
\text { de } \\
\text { atuação } \\
\text { máximo } \\
\text { (ms) }\end{array}$ & $\begin{array}{l}\text { Proteção } \\
\text { Principal }\end{array}$ & $\begin{array}{l}\text { Proteção de } \\
\text { Retaguarda }\end{array}$ & 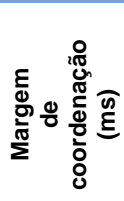 & 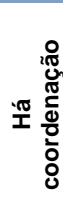 \\
\hline \multirow{8}{*}{$\begin{array}{c}\text { Barra } \\
78\end{array}$} & \multirow{4}{*}{ Bifásico } & \multirow{4}{*}{641} & REL-2 & 456 & 50 & 271 & \multirow{2}{*}{ REL-2 } & \multirow{2}{*}{ REL-1 } & \multirow{2}{*}{ * } & \multirow{2}{*}{ Sim } \\
\hline & & & DJ-2 & 185 & 50 & 518 & & & & \\
\hline & & & REL-1 & 245 & $\mathrm{~N} / \mathrm{A}$ & $\mathrm{N} / \mathrm{A}$ & \multirow{2}{*}{ REL-2 } & \multirow{2}{*}{ FU-3 } & \multirow{2}{*}{282} & \multirow{2}{*}{ Sim } \\
\hline & & & FU-3 & 191 & 332 & 528 & & & & \\
\hline & \multirow{4}{*}{$\begin{array}{l}\text { Fase } \\
\text { Terra }\end{array}$} & \multirow{4}{*}{180} & REL-2 & 117 & 50 & 169 & \multirow{2}{*}{ REL-2 } & \multirow{2}{*}{ REL-1 } & \multirow{2}{*}{0} & \multirow{2}{*}{ Não } \\
\hline & & & DJ-2 & 63 & 50 & 105 & & & & \\
\hline & & & REL-1 & 59 & 50 & $\mathrm{~N} / \mathrm{A}$ & \multirow{2}{*}{ REL-2 } & \multirow{2}{*}{ FU-3 } & \multirow{2}{*}{2397} & \multirow{2}{*}{ Sim } \\
\hline & & & FU-3 & 81 & 2447 & 5903 & & & & \\
\hline \multirow{8}{*}{$\begin{array}{c}\text { Linha } \\
31\end{array}$} & \multirow{4}{*}{ Trifásico } & \multirow{4}{*}{943} & REL-2 & 628 & 50 & 156 & \multirow{2}{*}{ REL-2 } & \multirow{2}{*}{ REL-1 } & \multirow{2}{*}{0} & \multirow{2}{*}{ Não } \\
\hline & & & DJ-2 & 315 & 50 & 183 & & & & \\
\hline & & & REL-1 & 328 & 50 & 18365 & \multirow{2}{*}{ REL-2 } & \multirow{2}{*}{ FU-3 } & \multirow{2}{*}{81} & \multirow{2}{*}{ Não } \\
\hline & & & FU-3 & 302 & 131 & 193 & & & & \\
\hline & \multirow{4}{*}{$\begin{array}{l}\text { Fase } \\
\text { Terra }\end{array}$} & \multirow{4}{*}{180} & REL-2 & 118 & 50 & 167 & BFI_? & RFI-1 & 0 & Não \\
\hline & & & DJ-2 & 62 & 50 & 108 & REL-2 & REL-1 & U & Nao \\
\hline & & & REL-1 & 59 & 50 & $\mathrm{~N} / \mathrm{A}$ & $\mathrm{REL}$ & & 230 & $\mathrm{Sim}$ \\
\hline & & & FU-3 & 81 & 2447 & 5903 & REL-2 & FU-3 & 2391 & SIm \\
\hline
\end{tabular}

* O elemento de proteção de retaguarda não atua.

A Tabela 4.18 apresenta a análise dos resultados obtidos após a verificação da coordenação dos elementos de proteção de sobrecorrente para as faltas simuladas em cada região de proteção com os ajustes iniciais. 
Tabela 4.18 - Ocorrências encontradas na operação ilhada considerando os ajustes iniciais da proteção de sobrecorrente.

\begin{tabular}{|c|c|}
\hline $\begin{array}{l}0 \text { de } \\
\text { cão }\end{array}$ & Ocorrências Encontradas \\
\hline Região 1 & $\begin{array}{l}\text { Não há coordenação entre o fusível FU-2 e o relé do disjuntor DJ-1 para faltas entre } \\
\text { fases. } \\
\text { A coordenação entre o religador REL-1 e o fusível FU-3 é perdida para faltas entre } \\
\text { fases à medida que o local da falta se aproxima do religador REL-1, mas é mantida } \\
\text { para faltas fase-terra. } \\
\text { Não há coordenação entre os religadores REL-1 e REL-2. }\end{array}$ \\
\hline Região 2 & $\begin{array}{l}\text { O fusível FU-1 se mantém coordenado com o fusível FU-2. } \\
\text { Não há coordenação entre o fusível FU-1 e o religador REL-1. }\end{array}$ \\
\hline Região 3 & Não há coordenação entre o fusível FU-2 e o religador REL-1. \\
\hline Região 4 & $\begin{array}{l}\text { Não há coordenação entre o fusível FU-3 e o religador REL-1. } \\
\text { Não há coordenação entre o fusível FU-3 e o religador REL-2. }\end{array}$ \\
\hline Região 5 & $\begin{array}{l}\text { Não há coordenação entre o religador REL-1 e o fusível FU-2 para faltas entre fases, } \\
\text { mas ela ainda existe para faltas fase-terra. } \\
\text { Não há coordenação entre o fusível FU-3 e o relé do disjuntor DJ-3. } \\
\text { Não há coordenação entre o religador REL-2 e o relé do disjuntor DJ-2. }\end{array}$ \\
\hline Região 6 & $\begin{array}{l}\text { O fusível FU-4 se mantém coordenado com o fusível FU-3. } \\
\text { O religador REL-1 deixa de ser sensibilizado à medida que o local da falta se afasta } \\
\text { deste. } \\
\text { Não há coordenação entre o fusível FU-4 e o religador REL-1. } \\
\text { Não há coordenação entre o fusível FU-4 e o religador REL-2. }\end{array}$ \\
\hline Região 7 & $\begin{array}{l}\text { O fusível FU-5 se mantém coordenado com o fusível FU- } 3 \text {. } \\
\text { O religador REL-1 deixa de ser sensibilizado à medida que o local da falta se afaste } \\
\text { deste. } \\
\text { Não há coordenação entre o fusível FU- } 5 \text { e o religador REL-1. } \\
\text { Não há coordenação entre o fusível FU- } 5 \text { e o religador REL-2. }\end{array}$ \\
\hline Região 8 & $\begin{array}{l}\text { O fusível FU-6 se mantém coordenado com o fusível FU-3. } \\
\text { O religador REL-1 deixa de ser sensibilizado à medida que o local da falta se afasta } \\
\text { deste. } \\
\text { Não há coordenação entre o fusível FU-6 e o religador REL-1. } \\
\text { Não há coordenação entre o fusível FU-6 e o religador REL-2. }\end{array}$ \\
\hline Região 9 & $\begin{array}{l}\text { Não há coordenação entre o religador REL- } 2 \text { e o fusível FU-3 para faltas entre fases à } \\
\text { medida que a falta se aproxima do religador REL-2, mas ainda existe para faltas fase- } \\
\text { terra. } \\
\text { O religador REL- } 1 \text { deixa de ser sensibilizado para faltas entre fases à medida que o } \\
\text { local da falta se afasta deste. } \\
\text { Não há coordenação entre o religador REL-2 e o religador REL-1. }\end{array}$ \\
\hline
\end{tabular}


Com base nas ocorrências apresentadas na Tabela 4.18, pode-se concluir que:

- Não há coordenação entre o dispositivo de proteção principal e o dispositivo de proteção de retaguarda das regiões definidas na Tabela 4.7;

- Os fusíveis se mantêm coordenados entre si nas regiões em que são elementos de proteção principal e retaguarda, por exemplo, fusíveis FU-1 e FU-2 na região 2;

- Nas regiões 5, 6, 7 e 8, o religador REL-1 deixa de ser sensibilizado à medida que o local da falta se afasta deste;

- Os disjuntores do PAC atuam antes das proteções à jusante, desligando os geradores;

- As funções instantâneas dos religadores REL-1 e REL-2 não estão coordenadas com as funções instantâneas dos disjuntores DJ-1, DJ-2 e DJ-3;

- Não há verificação de sincronismo se houver religamento.

\subsubsection{Avaliação da proteção após a adoção de medidas corretivas}

Após análise das ocorrências encontradas no sistema de proteção de sobrecorrente da rede de distribuição e objetivando melhorar a coordenação e seletividade utilizando apenas os dispositivos de proteção existentes na rede, optou-se por desabilitar as curvas instantâneas dos relés dos disjuntores DJ-1, DJ-2 e DJ-3 e dos religadores REL-1 e REL-2, bem como a função de religamento automático.

As curvas temporizadas dos religadores foram ajustadas para se aproximarem 0 máximo possível das curvas temporizadas dos relés dos disjuntores DJ-1, DJ-2 e DJ-3, instalados no PAC.

As correntes de partida (pick-up) das curvas temporizadas dos disjuntores do PAC foram mantidas, mas o ajuste de tempo (TDS - time dial setting) foram alterados de forma a se obter um atraso maior na atuação e permitir que as proteções à jusante pudessem operar primeiro. É importante ressaltar que o atraso da curva temporizada não pode comprometer os limites térmicos dos equipamentos, os quais, ela protege.

Essas medidas corretivas poderão ser adotadas na análise de outros sistemas de distribuição, considerando que o objetivo principal é atrasar a atuação das proteções localizadas no PAC, coordenando as proteções ajustáveis à jusante e, desta forma, permitindo que os fusíveis obtenham tempo suficiente para sua abertura.

Os novos ajustes adotados são apresentados nas Tabelas 4.19 e 4.20. O coordenograma apresentado na Figura 4.7 corresponde às curvas de coordenação entre o relé do disjuntor DJ-1 e o religador REL-2. Além disso, ele representa também a coordenação entre todos os disjuntores do PAC e os religadores, visto que, os ajustes são exatamente iguais. 
Tabela 4.19 - Ajustes das curvas de proteção de fase dos relés do PAC e dos religadores.

\begin{tabular}{|c|c|c|c|c|}
\hline \multicolumn{5}{|c|}{ Ajuste de curvas - Padrão ANSI - Categoria Muito Inversa } \\
\hline \multicolumn{5}{|c|}{ Nome do Elemento de Proteção } \\
\hline DJ-1 & DJ-2 & DJ-3 & REL-1 & REL-2 \\
\hline \multicolumn{5}{|c|}{ Ajuste da Unidade Temporizada } \\
\hline \multicolumn{5}{|c|}{ Pick-up (A) } \\
\hline 85 & 85 & 85 & 81 & 81 \\
\hline \multicolumn{5}{|c|}{ Time Dial Setting (TDS) } \\
\hline 2,65 & 2,65 & 2,65 & 0,55 & 0,55 \\
\hline \multicolumn{5}{|c|}{ Ajuste da Unidade Instantânea } \\
\hline \multicolumn{5}{|c|}{ Pick-up (A) } \\
\hline Desabilitado & Desabilitado & Desabilitado & Desabilitado & Desabilitado \\
\hline
\end{tabular}

Tabela 4.20 - Ajustes das curvas de proteção de neutro dos relés do PAC e dos religadores.

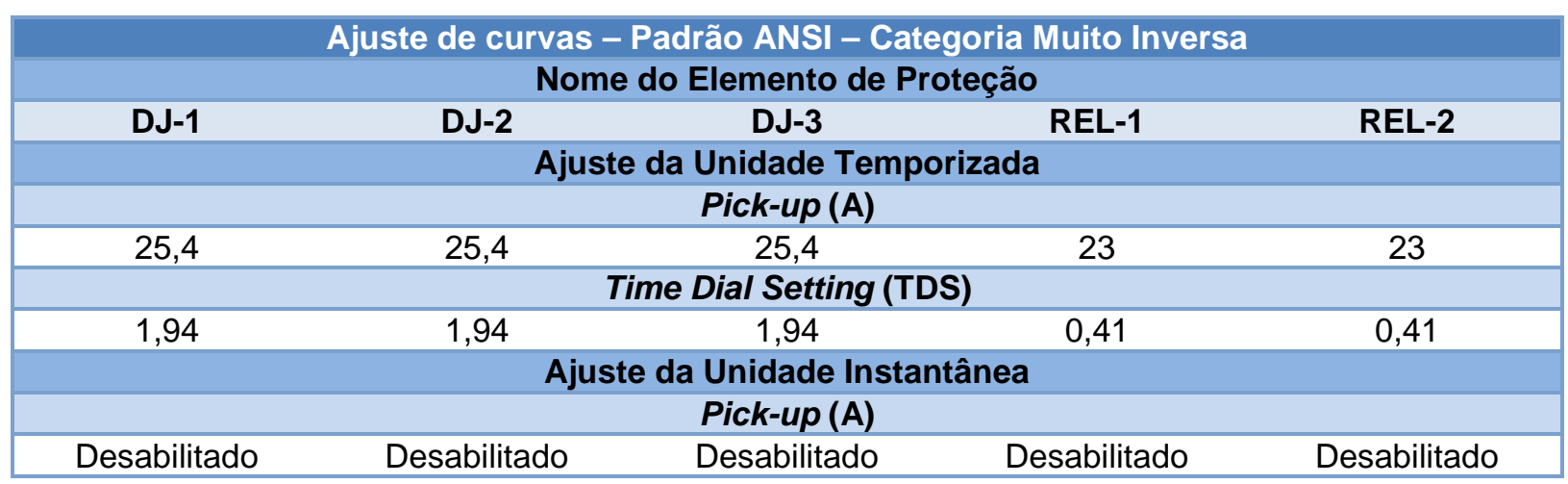

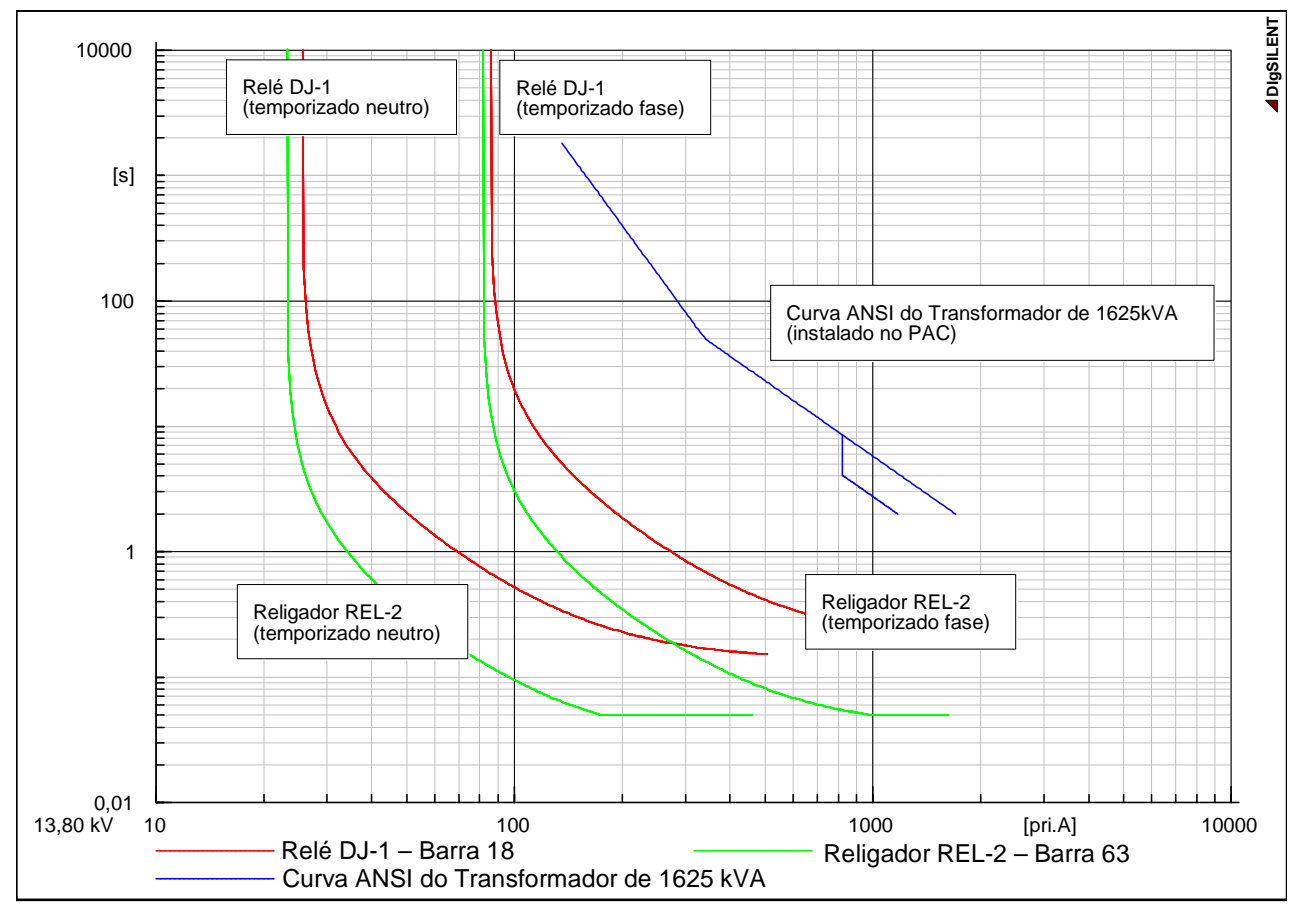

Figura 4.7 - Coordenação entre o relé do disjuntor DJ-1 e o Religador REL-2. 
Seguindo o procedimento adotado nas Tabelas 4.9 a 4.17, as Tabelas 4.21 a 4.29 apresentam os resultados obtidos após a realização dos ajustes mencionados anteriormente nos elementos de proteção de sobrecorrente.

Tabela 4.21 - Margens de coordenação após reajuste obtidas na região 1.

\begin{tabular}{|c|c|c|c|c|c|c|c|c|c|c|}
\hline \multicolumn{11}{|c|}{ Região 1 de Proteção } \\
\hline $\begin{array}{c}\text { Local } \\
\text { da } \\
\text { Falta }\end{array}$ & $\begin{array}{c}\text { Tipo } \\
\text { de } \\
\text { Falta }\end{array}$ & $\begin{array}{c}\text { Corrente } \\
\text { de } \\
\text { Falta } \\
\text { (A) }\end{array}$ & $\begin{array}{c}\text { Elemento } \\
\text { de } \\
\text { Proteção }\end{array}$ & $\begin{array}{l}\text { Corrente } \\
\text { vista } \\
\text { pelo } \\
\text { elemento } \\
\text { de } \\
\text { proteção } \\
\text { (A) }\end{array}$ & $\begin{array}{c}\text { Tempo } \\
\text { de } \\
\text { atuação } \\
\text { mínimo } \\
\text { (ms) }\end{array}$ & $\begin{array}{c}\text { Tempo } \\
\text { de } \\
\text { atuação } \\
\text { máximo } \\
\text { (ms) }\end{array}$ & $\begin{array}{l}\text { Proteção } \\
\text { Principal }\end{array}$ & $\begin{array}{l}\text { Proteção de } \\
\text { Retaguarda }\end{array}$ & 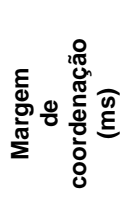 & 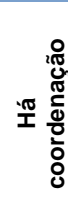 \\
\hline \multirow{10}{*}{$\begin{array}{c}\text { Barra } \\
150\end{array}$} & \multirow{5}{*}{ Bifásico } & \multirow{5}{*}{555} & FU-2 & 208 & 229 & 474 & \multirow{2}{*}{ FU-2 } & \multirow{2}{*}{ DJ-1 } & \multirow{2}{*}{1424} & \multirow{2}{*}{ Sim } \\
\hline & & & REL-1 & 336 & & 136 & & & & \\
\hline & & & DJ-1 & 198 & & 1898 & \multirow{2}{*}{ REL-1 } & \multirow{2}{*}{ FU-3 } & \multirow{2}{*}{288} & \multirow{2}{*}{ Sim } \\
\hline & & & FU-3 & 167 & 424 & 680 & & & & \\
\hline & & & REL-2 & 157 & & 609 & REL-1 & REL-2 & 473 & Sim \\
\hline & \multirow{5}{*}{$\begin{array}{l}\text { Fase } \\
\text { Terra }\end{array}$} & \multirow{5}{*}{176} & FU-2 & 70 & 4881 & 15122 & \multirow{2}{*}{ FU-2 } & \multirow{2}{*}{ DJ-1 } & \multirow{2}{*}{-13775} & \multirow{2}{*}{ Não } \\
\hline & & & REL-1 & 116 & & 77 & & & & \\
\hline & & & DJ-1 & 60 & & 1347 & \multirow{2}{*}{ REL-1 } & \multirow{2}{*}{ FU-3 } & \multirow{2}{*}{2503} & \multirow{2}{*}{ Sim } \\
\hline & & & FU-3 & 80 & 2580 & 6344 & & & & \\
\hline & & & REL-2 & 58 & & 248 & REL-1 & REL-2 & 171 & Não \\
\hline \multirow{10}{*}{$\begin{array}{c}\text { Barra } \\
11\end{array}$} & \multirow{5}{*}{ Trifásico } & \multirow{5}{*}{950} & FU-2 & 343 & 100 & 143 & \multirow{2}{*}{ FU-2 } & \multirow{2}{*}{ DJ-1 } & \multirow{2}{*}{541} & Sim \\
\hline & & & REL-1 & 610 & & 67 & & & & SIII \\
\hline & & & DJ-1 & 343 & & 684 & & EI/ 3 & & \\
\hline & & & FU-3 & 306 & 127 & 187 & REL-I & FU-3 & 60 & Nao \\
\hline & & & REL-2 & 305 & & 158 & REL-1 & REL-2 & 91 & Não \\
\hline & & & FU-2 & 72 & 4253 & 12533 & EII? & & & \\
\hline & & & REL-1 & 119 & & 75 & $1-U-2$ & DJ-I & -11218 & Nao \\
\hline & $\begin{array}{l}\text { Fase } \\
\text { Terra }\end{array}$ & 180 & DJ-1 & 62 & & 1255 & RFI -1 & FHI-3 & 2372 & Sim \\
\hline & & & FU-3 & 81 & & 5903 & REL-I & $10-3$ & 2312 & SIIm \\
\hline & & & REL-2 & 59 & & 239 & REL-1 & REL-2 & 164 & Não \\
\hline & & & FU-2 & 341 & 101 & 145 & FU।? & Rl-1 & & \\
\hline & & & REL-1 & 618 & & 67 & $1-U-2$ & DJ-1 & 545 & Sim \\
\hline & Trifásico & 957 & DJ-1 & 341 & & 690 & REL-1 & FU-3 & 57 & Sim \\
\hline & & & FU-3 & 310 & 124 & 181 & REL-I & rU.J & 31 & \\
\hline Linha & & & REL-2 & 309 & & 155 & REL-1 & REL-2 & 88 & Sim \\
\hline 20 & & & FU-2 & 71 & 4555 & 13763 & FU-2 & DJ-1 & -12463 & Não \\
\hline & & & REL-1 & 120 & & 74 & FU-2 & DJ-1 & -12463 & Ivau \\
\hline & rase & 181 & DJ-1 & 61 & & 1300 & & & & \\
\hline & & & FU-3 & 82 & 2326 & 5512 & REL-1 & FU-3 & 2252 & Sim \\
\hline & & & REL-2 & 60 & & 231 & REL-1 & REL-2 & 157 & Não \\
\hline
\end{tabular}


Tabela 4.22 - Margens de coordenação após reajuste obtidas na região 2.

\begin{tabular}{|c|c|c|c|c|c|c|c|c|c|c|}
\hline \multicolumn{11}{|c|}{ Região 2 de Proteção } \\
\hline $\begin{array}{c}\text { Local } \\
\text { da } \\
\text { Falta }\end{array}$ & $\begin{array}{c}\text { Tipo } \\
\text { de } \\
\text { Falta }\end{array}$ & $\begin{array}{l}\text { Corrente } \\
\text { de } \\
\text { Falta } \\
\text { (A) }\end{array}$ & $\begin{array}{c}\text { Elemento } \\
\text { de } \\
\text { Proteção }\end{array}$ & $\begin{array}{l}\text { Corrente } \\
\text { vista } \\
\text { pelo } \\
\text { elemento } \\
\text { de } \\
\text { proteção } \\
\text { (A) }\end{array}$ & $\begin{array}{c}\text { Tempo } \\
\text { de } \\
\text { atuação } \\
\text { mínimo } \\
\text { (ms) }\end{array}$ & $\begin{array}{c}\text { Tempo } \\
\text { de } \\
\text { atuação } \\
\text { máximo } \\
\text { (ms) }\end{array}$ & $\begin{array}{l}\text { Proteção } \\
\text { Principal }\end{array}$ & $\begin{array}{l}\text { Proteção de } \\
\text { Retaguarda }\end{array}$ & 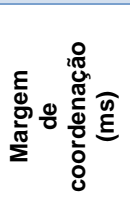 & 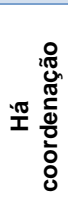 \\
\hline \multirow{6}{*}{$\begin{array}{c}\text { Barra } \\
12\end{array}$} & & \multirow{3}{*}{643} & FU-1 & 639 & 10 & 10 & \multirow{2}{*}{ FU-1 } & \multirow{2}{*}{ FU-2 } & \multirow{2}{*}{208} & \multirow{2}{*}{ Sim } \\
\hline & Bifásico & & FU-2 & 237 & 218 & 337 & & & & \\
\hline & & & REL-1 & 391 & & 110 & FU-1 & REL-1 & 100 & Não \\
\hline & \multirow{3}{*}{$\begin{array}{l}\text { Fase } \\
\text { Terra }\end{array}$} & \multirow{3}{*}{180} & FU-1 & 186 & 14 & 20 & \multirow{2}{*}{$\mathrm{FU}-1$} & \multirow{2}{*}{ FU-2 } & \multirow{2}{*}{4233} & \multirow{2}{*}{ Sim } \\
\hline & & & FU-2 & 72 & 4253 & 12533 & & & & \\
\hline & & & REL-1 & 118 & & 75 & FU-1 & REL-1 & 55 & Não \\
\hline \multirow{6}{*}{$\begin{array}{c}\text { Linha } \\
11\end{array}$} & \multirow{3}{*}{ Trifásico } & \multirow{3}{*}{950} & FU-1 & 950 & 10 & 10 & \multirow{2}{*}{ FU-1 } & \multirow{2}{*}{ FU-2 } & \multirow{2}{*}{90} & \multirow{2}{*}{ Sim } \\
\hline & & & FU-2 & 343 & 100 & 143 & & & & \\
\hline & & & REL-1 & 610 & & 67 & FU-1 & REL-1 & 57 & Não \\
\hline & \multirow{3}{*}{$\begin{array}{l}\text { Fase } \\
\text { Terra }\end{array}$} & \multirow{3}{*}{180} & FU-1 & 186 & 14 & 20 & \multirow{2}{*}{$\mathrm{FU}-1$} & \multirow{2}{*}{ FU-2 } & \multirow{2}{*}{4233} & \multirow{2}{*}{ Sim } \\
\hline & & & FU-2 & 72 & 4253 & 12533 & & & & \\
\hline & & & REL-1 & 119 & & 75 & FU-1 & REL-1 & 55 & Não \\
\hline
\end{tabular}

Tabela 4.23 - Margens de coordenação após reajuste obtidas na região 3.

\begin{tabular}{|c|c|c|c|c|c|c|c|c|c|c|}
\hline \multicolumn{11}{|c|}{ Região 3 de Proteção } \\
\hline $\begin{array}{l}\text { Local } \\
\text { da } \\
\text { Falta }\end{array}$ & $\begin{array}{l}\text { Tipo } \\
\text { de } \\
\text { Falta }\end{array}$ & $\begin{array}{c}\text { Corrente } \\
\text { de } \\
\text { Falta } \\
\text { (A) }\end{array}$ & $\begin{array}{c}\text { Elemento } \\
\text { de } \\
\text { Proteção }\end{array}$ & $\begin{array}{l}\text { Corrente } \\
\text { vista } \\
\text { pelo } \\
\text { elemento } \\
\text { de } \\
\text { proteção } \\
\text { (A) }\end{array}$ & $\begin{array}{c}\text { Tempo } \\
\text { de } \\
\text { atuação } \\
\text { mínimo } \\
\text { (ms) }\end{array}$ & $\begin{array}{c}\text { Tempo } \\
\text { de } \\
\text { atuação } \\
\text { máximo } \\
\text { (ms) }\end{array}$ & $\begin{array}{l}\text { Proteção } \\
\text { Principal }\end{array}$ & $\begin{array}{l}\text { Proteção de } \\
\text { Retaguarda }\end{array}$ & 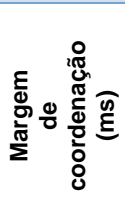 & 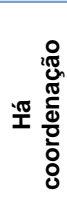 \\
\hline \multirow{6}{*}{$\begin{array}{c}\text { Barra } \\
21\end{array}$} & \multirow{3}{*}{ Bifásico } & \multirow{3}{*}{633} & FU-2 & 397 & 73 & 102 & \multirow{3}{*}{ FU-2 } & \multirow{3}{*}{ REL-1 } & \multirow{3}{*}{10} & \multirow{3}{*}{ Não } \\
\hline & & & DJ-1 & 225 & & 1448 & & & & \\
\hline & & & REL-1 & 384 & & 112 & & & & \\
\hline & \multirow{3}{*}{$\begin{array}{l}\text { Fase } \\
\text { Terra }\end{array}$} & \multirow{3}{*}{179} & FU-2 & 123 & 766 & 1296 & \multirow{3}{*}{ FU-2 } & \multirow{3}{*}{ REL-1 } & \multirow{3}{*}{-1220} & \multirow{3}{*}{ Não } \\
\hline & & & DJ-1 & 62 & & 1255 & & & & \\
\hline & & & REL-1 & 117 & & 76 & & & & \\
\hline \multirow{6}{*}{$\begin{array}{c}\text { Linha } \\
12\end{array}$} & \multirow{3}{*}{ Trifásico } & \multirow{3}{*}{950} & FU-2 & 610 & 31 & 41 & \multirow{3}{*}{ FU-2 } & \multirow{3}{*}{ REL-1 } & \multirow{3}{*}{26} & \multirow{3}{*}{ Não } \\
\hline & & & DJ-1 & 343 & & 684 & & & & \\
\hline & & & REL-1 & 610 & & 67 & & & & \\
\hline & \multirow{3}{*}{$\begin{array}{l}\text { Fase } \\
\text { Terra }\end{array}$} & \multirow{3}{*}{180} & FU-2 & 124 & 753 & 1270 & \multirow{3}{*}{ FU-2 } & \multirow{3}{*}{ REL-1 } & \multirow{3}{*}{-1195} & \multirow{3}{*}{ Não } \\
\hline & & & DJ-1 & 62 & & 1255 & & & & \\
\hline & & & REL-1 & 119 & & 75 & & & & \\
\hline
\end{tabular}


Tabela 4.24 - Margens de coordenação após reajuste obtidas na região 4.

\begin{tabular}{|c|c|c|c|c|c|c|c|c|c|c|}
\hline \multicolumn{11}{|c|}{ Região 4 de Proteção } \\
\hline $\begin{array}{c}\text { Local } \\
\text { da } \\
\text { Falta }\end{array}$ & $\begin{array}{l}\text { Tipo } \\
\text { de } \\
\text { Falta }\end{array}$ & $\begin{array}{c}\text { Corrente } \\
\text { de } \\
\text { Falta } \\
\text { (A) }\end{array}$ & $\begin{array}{l}\text { Elemento } \\
\text { de } \\
\text { Proteção }\end{array}$ & $\begin{array}{l}\text { Corrente } \\
\text { vista } \\
\text { pelo } \\
\text { elemento } \\
\text { de } \\
\text { proteção } \\
\text { (A) }\end{array}$ & $\begin{array}{c}\text { Tempo } \\
\text { de } \\
\text { atuação } \\
\text { mínimo } \\
\text { (ms) }\end{array}$ & $\begin{array}{l}\text { Tempo } \\
\text { de } \\
\text { atuação } \\
\text { máximo } \\
\text { (ms) }\end{array}$ & $\begin{array}{l}\text { Proteção } \\
\text { Principal }\end{array}$ & $\begin{array}{l}\text { Proteção de } \\
\text { Retaguarda }\end{array}$ & 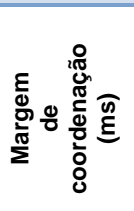 & 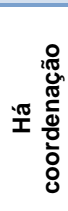 \\
\hline \multirow{8}{*}{$\begin{array}{c}\text { Barra } \\
31\end{array}$} & \multirow{4}{*}{ Bifásico } & \multirow{4}{*}{645} & FU-3 & 447 & 57 & 78 & \multirow[b]{2}{*}{ FU-3 } & \multirow[b]{2}{*}{ REL-1 } & \multirow{2}{*}{149} & \multirow{2}{*}{ Não } \\
\hline & & & DJ-3 & 184 & & 2241 & & & & \\
\hline & & & REL-1 & 248 & & 227 & \multirow{2}{*}{ FU-3 } & \multirow{2}{*}{ REL-2 } & \multirow{2}{*}{354} & \multirow{2}{*}{ Sim } \\
\hline & & & REL-2 & 181 & & 432 & & & & \\
\hline & \multirow{4}{*}{$\begin{array}{l}\text { Fase } \\
\text { Terra }\end{array}$} & \multirow{4}{*}{180} & FU-3 & 98 & 1315 & 2568 & \multirow{2}{*}{ FU-3 } & \multirow{2}{*}{ REL-1 } & \multirow{2}{*}{-2337} & \multirow{2}{*}{ Não } \\
\hline & & & DJ-3 & 62 & & 1255 & & & & \\
\hline & & & REL-1 & 60 & & 231 & \multirow{2}{*}{ FU-3 } & \multirow{2}{*}{ REL-2 } & \multirow{2}{*}{-2329} & \multirow{2}{*}{ Não } \\
\hline & & & REL-2 & 59 & & 239 & & & & \\
\hline \multirow{8}{*}{$\begin{array}{c}\text { Linha } \\
35\end{array}$} & \multirow{4}{*}{ Trifásico } & \multirow{4}{*}{959} & FU-3 & 648 & 27 & 36 & \multirow{2}{*}{ FU-3 } & \multirow{2}{*}{ REL-1 } & \multirow{2}{*}{98} & \multirow{2}{*}{ Não } \\
\hline & & & DJ-3 & 312 & & 795 & & & & \\
\hline & & & REL-1 & 339 & & 134 & \multirow{2}{*}{ FU-3 } & \multirow{2}{*}{ REL-2 } & \multirow{2}{*}{118} & \multirow{2}{*}{ Não } \\
\hline & & & REL-2 & 310 & & 154 & & & & \\
\hline & \multirow{4}{*}{$\begin{array}{l}\text { Fase } \\
\text { Terra }\end{array}$} & \multirow{4}{*}{181} & FU-3 & 99 & 1279 & 2476 & FUl-3 & RFI -1 & -2245 & Sim \\
\hline & & & DJ-3 & 60 & & 1347 & IU -3 & nடL-1 & $-<<40$ & ОाII \\
\hline & & & REL-1 & 60 & & 231 & $\mathrm{~F} \mid-3$ & & & \\
\hline & & & REL-2 & 60 & & 231 & rU-3 & REL-2 & $-<<45$ & SIII \\
\hline
\end{tabular}


Tabela 4.25 - Margens de coordenação após reajuste obtidas na região 5.

\begin{tabular}{|c|c|c|c|c|c|c|c|c|c|c|}
\hline \multicolumn{11}{|c|}{ Região 5 de Proteção } \\
\hline $\begin{array}{c}\text { Local } \\
\text { da } \\
\text { Falta }\end{array}$ & $\begin{array}{l}\text { Tipo } \\
\text { de } \\
\text { Falta }\end{array}$ & $\begin{array}{l}\text { Corrente } \\
\text { de } \\
\text { Falta } \\
\text { (A) }\end{array}$ & $\begin{array}{c}\begin{array}{c}\text { Elemento } \\
\text { de } \\
\text { Proteção }\end{array}\end{array}$ & $\begin{array}{l}\text { Corrente } \\
\text { vista } \\
\text { pelo } \\
\text { elemento } \\
\text { de } \\
\text { proteção } \\
\text { (A) }\end{array}$ & $\begin{array}{c}\text { Tempo } \\
\text { de } \\
\text { atuação } \\
\text { mínimo } \\
\text { (ms) }\end{array}$ & $\begin{array}{c}\text { Tempo } \\
\text { de } \\
\text { atuação } \\
\text { máximo } \\
\text { (ms) }\end{array}$ & $\begin{array}{l}\text { Proteção } \\
\text { Principal }\end{array}$ & $\begin{array}{l}\text { Proteção de } \\
\text { Retaguarda }\end{array}$ & 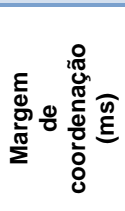 & 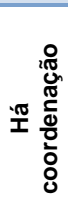 \\
\hline \multirow{12}{*}{$\begin{array}{c}\text { Barra } \\
39\end{array}$} & \multirow{6}{*}{ Bifásico } & \multirow{6}{*}{646} & REL-1 & 249 & & 225 & \multirow{2}{*}{ REL-1 } & \multirow{2}{*}{ FU-2 } & \multirow{2}{*}{-1} & \multirow{2}{*}{ Não } \\
\hline & & & FU-3 & 195 & 319 & 508 & & & & \\
\hline & & & REL-2 & 183 & & 422 & \multirow{2}{*}{ FU-3 } & \multirow[b]{2}{*}{ DJ-3 } & \multirow{2}{*}{1852} & \multirow{2}{*}{ Sim } \\
\hline & & & FU-2 & 234 & 224 & 347 & & & & \\
\hline & & & DJ-3 & 180 & & 2360 & \multirow{2}{*}{ REL-2 } & \multirow{2}{*}{ DJ-2 } & \multirow{2}{*}{1907} & \multirow{2}{*}{ Sim } \\
\hline & & & DJ-2 & 181 & & 2329 & & & & \\
\hline & \multirow{6}{*}{$\begin{array}{l}\text { Fase } \\
\text { Terra }\end{array}$} & \multirow{6}{*}{180} & REL-1 & 60 & & 231 & \multirow{2}{*}{ REL-1 } & \multirow{2}{*}{ FU-2 } & \multirow{2}{*}{4650} & \multirow{2}{*}{ Sim } \\
\hline & & & FU-3 & 82 & 2326 & 5512 & & & & \\
\hline & & & REL-2 & 60 & & 231 & \multirow{2}{*}{ FU-3 } & \multirow{2}{*}{ DJ-3 } & \multirow{2}{*}{-4165} & \\
\hline & & & FU-2 & 70 & 4881 & 15122 & & & & Nao \\
\hline & & & DJ-3 & 60 & & 1347 & & & & \\
\hline & & & DJ-2 & 60 & & 1347 & REL-2 & $D J-2$ & 1116 & sim \\
\hline & & & REL-1 & 339 & & 134 & & & -32 & Não \\
\hline & & & FU-3 & 312 & 122 & 179 & REL-I & $r U-2$ & $-3<$ & NaU \\
\hline & & & REL-2 & 310 & & 154 & & & & \\
\hline & Iriasico & 950 & FU-2 & 340 & 102 & 146 & rU-3 & DJ-3 & 010 & SIII \\
\hline & & & DJ-3 & 312 & & 795 & REL-2 & DJ-2 & 650 & Sim \\
\hline Barra & & & DJ-2 & 310 & & 804 & & & & SIII \\
\hline 23 & & & REL-1 & 60 & & 231 & RFI -1 & FUl-? & 4650 & \\
\hline & & & FU-3 & 82 & 2326 & 5512 & RELL-I & $1-U-2$ & 4050 & SII \\
\hline & Fase & & REL-2 & 60 & & 231 & & & & \\
\hline & Terra & 181 & FU-2 & 70 & 4881 & 15122 & FU-3 & DJ-3 & -4165 & Nao \\
\hline & & & DJ-3 & 60 & & 1347 & REI -2 & DJ-2 & 1116 & Sim \\
\hline & & & DJ-2 & 60 & & 1347 & nடL-く & $5 J-2$ & 1110 & SIII \\
\hline & & & REL-1 & 328 & & 141 & RFI-1 & Fl।-? & -11 & \\
\hline & & & FU-3 & 302 & 131 & 193 & nLL-I & $10-2$ & -11 & inau \\
\hline & Trifásico & 943 & REL-2 & 315 & & 150 & FU-3 & DJ-3 & 642 & Sim \\
\hline & IIIIasico & 943 & FU-2 & 329 & 130 & 191 & rU-3 & כ-5 & $04<$ & SाII \\
\hline & & & DJ-3 & 303 & & 835 & RFI -? & ח। & 633 & \\
\hline Barra & & & DJ-2 & 315 & & 783 & กㄴ- - & DJ-2 & 030 & Sim \\
\hline 63 & & & REL-1 & 59 & & 239 & REL -1 & FU-2 & 4991 & Sim \\
\hline & & & FU-3 & 81 & 2447 & 5903 & & & 4001 & SIII \\
\hline & Fase & & REL-2 & 62 & & 216 & & & & \\
\hline & Terra & 180 & FU-2 & 69 & 5230 & 16619 & rU-3 & DJ-3 & -4505 & Nao \\
\hline & & & DJ-3 & 59 & & 1398 & REL-2 & DJ-2 & 1039 & Sim \\
\hline & & & DJ-2 & 62 & & 1255 & & $50-2$ & 1000 & UाII \\
\hline
\end{tabular}


Tabela 4.26 - Margens de coordenação após reajuste obtidas na região 6.

\begin{tabular}{|c|c|c|c|c|c|c|c|c|c|c|}
\hline \multicolumn{11}{|c|}{$\begin{array}{r}\text { Correntes de curto-circuito e tempos de atuação do } \\
\text { Região } 6 \text { de Proteção }\end{array}$} \\
\hline $\begin{array}{c}\text { Local } \\
\text { da } \\
\text { Falta }\end{array}$ & $\begin{array}{c}\text { Tipo } \\
\text { de } \\
\text { Falta }\end{array}$ & $\begin{array}{c}\text { Corrente } \\
\text { de } \\
\text { Falta } \\
\text { (A) }\end{array}$ & $\begin{array}{c}\text { Elemento } \\
\text { de } \\
\text { Proteção }\end{array}$ & $\begin{array}{l}\text { Corrente } \\
\text { vista } \\
\text { pelo } \\
\text { elemento } \\
\text { de } \\
\text { proteção } \\
\text { (A) }\end{array}$ & $\begin{array}{c}\text { Tempo } \\
\text { de } \\
\text { atuação } \\
\text { mínimo } \\
\text { (ms) }\end{array}$ & $\begin{array}{c}\text { Tempo } \\
\text { de } \\
\text { atuação } \\
\text { máximo } \\
\text { (ms) }\end{array}$ & $\begin{array}{l}\text { Proteção } \\
\text { Principal }\end{array}$ & $\begin{array}{l}\text { Proteção de } \\
\text { Retaguarda }\end{array}$ & 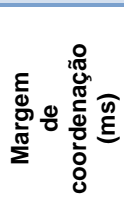 & 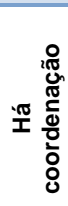 \\
\hline \multirow{8}{*}{$\begin{array}{c}\text { Barra } \\
40\end{array}$} & \multirow{4}{*}{ Bifásico } & \multirow{4}{*}{644} & FU-4 & 630 & 12 & 18 & \multirow{2}{*}{ FU-4 } & \multirow{2}{*}{ REL-1 } & \multirow{2}{*}{207} & \multirow{2}{*}{ Sim } \\
\hline & & & REL-1 & 249 & & 225 & & & & \\
\hline & & & FU-3 & 194 & 322 & 513 & FU-4 & FU-3 & 304 & Sim \\
\hline & & & REL-2 & 183 & & 422 & FU-4 & REL-2 & 404 & Sim \\
\hline & \multirow{4}{*}{$\begin{array}{l}\text { Fase } \\
\text { Terra }\end{array}$} & \multirow{4}{*}{180} & FU-4 & 193 & 116 & 173 & \multirow{2}{*}{ FU-4 } & \multirow{2}{*}{ REL-1 } & \multirow{2}{*}{58} & \multirow{2}{*}{ Não } \\
\hline & & & REL-1 & 60 & & 231 & & & & \\
\hline & & & FU-3 & 82 & 2326 & 5512 & FU-4 & FU-3 & 2153 & Sim \\
\hline & & & REL-2 & 60 & & 231 & FU-4 & REL-2 & 58 & Não \\
\hline \multirow{8}{*}{$\begin{array}{l}\text { Linha } \\
45\end{array}$} & \multirow{4}{*}{ Trifásico } & \multirow{4}{*}{955} & FU-4 & 955 & 10 & 10 & \multirow{2}{*}{ FU-4 } & \multirow{2}{*}{ REL-1 } & \multirow{2}{*}{125} & \multirow{2}{*}{ Não } \\
\hline & & & REL-1 & 337 & & 135 & & & & \\
\hline & & & FU-3 & 309 & 125 & 183 & FU-4 & FU-3 & 115 & Sim \\
\hline & & & REL-2 & 311 & & 153 & FU-4 & REL-2 & 143 & Não \\
\hline & \multirow{4}{*}{$\begin{array}{l}\text { Fase } \\
\text { Terra }\end{array}$} & \multirow{4}{*}{181} & FU-4 & 193 & 116 & 173 & \multirow{2}{*}{ FU-4 } & \multirow{2}{*}{ REL-1 } & \multirow{2}{*}{58} & \multirow{2}{*}{ Não } \\
\hline & & & REL-1 & 60 & & 231 & & & & \\
\hline & & & FU-3 & 82 & 2326 & 5512 & FU-4 & FU-3 & 2153 & Sim \\
\hline & & & REL-2 & 60 & & 231 & FU-4 & REL-2 & 58 & Não \\
\hline
\end{tabular}

Tabela 4.27 - Margens de coordenação após reajuste obtidas na região 7.

\begin{tabular}{|c|c|c|c|c|c|c|c|c|c|c|}
\hline \multicolumn{11}{|c|}{ Região 7 de Proteção } \\
\hline $\begin{array}{c}\text { Local } \\
\text { da } \\
\text { Falta }\end{array}$ & $\begin{array}{c}\text { Tipo } \\
\text { de } \\
\text { Falta }\end{array}$ & $\begin{array}{c}\text { Corrente } \\
\text { de } \\
\text { Falta } \\
\text { (A) }\end{array}$ & $\begin{array}{c}\text { Elemento } \\
\text { de } \\
\text { Proteção }\end{array}$ & $\begin{array}{l}\text { Corrente } \\
\text { vista } \\
\text { pelo } \\
\text { elemento } \\
\text { de } \\
\text { proteção } \\
\text { (A) }\end{array}$ & $\begin{array}{c}\text { Tempo } \\
\text { de } \\
\text { atuação } \\
\text { mínimo } \\
\text { (ms) }\end{array}$ & $\begin{array}{c}\text { Tempo } \\
\text { de } \\
\text { atuação } \\
\text { máximo } \\
\text { (ms) }\end{array}$ & $\begin{array}{l}\text { Proteção } \\
\text { Principal }\end{array}$ & $\begin{array}{l}\text { Proteção de } \\
\text { Retaguarda }\end{array}$ & 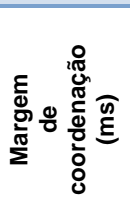 & 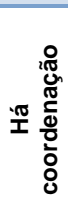 \\
\hline \multirow{8}{*}{$\begin{array}{c}\text { Barra } \\
49\end{array}$} & \multirow{4}{*}{ Bifásico } & \multirow{4}{*}{644} & FU-5 & 630 & 12 & 18 & \multirow{2}{*}{ FU-5 } & \multirow{2}{*}{ REL-1 } & \multirow{2}{*}{210} & \multirow{2}{*}{ Sim } \\
\hline & & & REL-1 & 249 & & 228 & & & & \\
\hline & & & FU-3 & 194 & 326 & 518 & FU-5 & FU-3 & 314 & Sim \\
\hline & & & REL-2 & 183 & & 412 & FU-5 & REL-2 & 394 & Sim \\
\hline & \multirow{4}{*}{$\begin{array}{l}\text { Fase } \\
\text { Terra }\end{array}$} & \multirow{4}{*}{180} & FU-5 & 193 & 117 & 175 & \multirow{2}{*}{ FU-5 } & \multirow{2}{*}{ REL-1 } & \multirow{2}{*}{64} & \multirow{2}{*}{ Não } \\
\hline & & & REL-1 & 60 & & 239 & & & & \\
\hline & & & FU-3 & 82 & 2447 & 5903 & FU-5 & FU-3 & 2272 & Sim \\
\hline & & & REL-2 & 60 & & 216 & FU-5 & REL-2 & 41 & Não \\
\hline \multirow{8}{*}{$\begin{array}{c}\text { Linha } \\
27\end{array}$} & \multirow{4}{*}{ Trifásico } & \multirow{4}{*}{947} & FU-5 & 947 & 10 & 10 & \multirow{2}{*}{ FU-5 } & \multirow{2}{*}{ REL-1 } & \multirow{2}{*}{129} & \multirow{2}{*}{ Não } \\
\hline & & & REL-1 & 331 & & 139 & & & & \\
\hline & & & FU-3 & 304 & 129 & 190 & FU-5 & FU-3 & 119 & Sim \\
\hline & & & REL-2 & 314 & & 151 & FU-5 & REL-2 & 141 & Não \\
\hline & \multirow{4}{*}{$\begin{array}{l}\text { Fase } \\
\text { Terra }\end{array}$} & \multirow{4}{*}{180} & FU-5 & 192 & 117 & 175 & \multirow{2}{*}{ FU-5 } & \multirow{2}{*}{ REL-1 } & \multirow{2}{*}{64} & \multirow{2}{*}{ Não } \\
\hline & & & REL-1 & 59 & & 239 & & & & \\
\hline & & & FU-3 & 81 & 2447 & 5903 & FU-5 & FU-3 & 2272 & Sim \\
\hline & & & REL-2 & 62 & & 216 & FU-5 & REL-2 & 41 & Não \\
\hline
\end{tabular}


Tabela 4.28 - Margens de coordenação após reajuste obtidas na região 8.

\begin{tabular}{|c|c|c|c|c|c|c|c|c|c|c|}
\hline \multicolumn{11}{|c|}{$\begin{array}{r}\text { Correntes de curto-circuito e tempos de atuação do } \\
\text { Região } 8 \text { de Proteção }\end{array}$} \\
\hline $\begin{array}{c}\text { Local } \\
\text { da } \\
\text { Falta }\end{array}$ & $\begin{array}{c}\text { Tipo } \\
\text { de } \\
\text { Falta }\end{array}$ & $\begin{array}{c}\text { Corrente } \\
\text { de } \\
\text { Falta } \\
\text { (A) }\end{array}$ & $\begin{array}{c}\text { Elemento } \\
\text { de } \\
\text { Proteção }\end{array}$ & $\begin{array}{l}\text { Corrente } \\
\text { vista } \\
\text { pelo } \\
\text { elemento } \\
\text { de } \\
\text { proteção } \\
\text { (A) }\end{array}$ & $\begin{array}{c}\text { Tempo } \\
\text { de } \\
\text { atuação } \\
\text { mínimo } \\
\text { (ms) }\end{array}$ & $\begin{array}{c}\text { Tempo } \\
\text { de } \\
\text { atuação } \\
\text { máximo } \\
\text { (ms) }\end{array}$ & $\begin{array}{l}\text { Proteção } \\
\text { Principal }\end{array}$ & $\begin{array}{l}\text { Proteção de } \\
\text { Retaguarda }\end{array}$ & 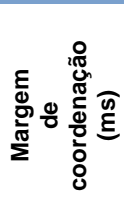 & 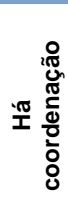 \\
\hline \multirow{8}{*}{$\begin{array}{c}\text { Barra } \\
52\end{array}$} & \multirow{4}{*}{ Bifásico } & \multirow{4}{*}{640} & FU-6 & 636 & 10 & 10 & \multirow{2}{*}{ FU-6 } & \multirow{2}{*}{ REL-1 } & \multirow{2}{*}{220} & \multirow{2}{*}{ Sim } \\
\hline & & & REL-1 & 246 & & 230 & & & & \\
\hline & & & FU-3 & 192 & 329 & 523 & FU-6 & FU-3 & 319 & Sim \\
\hline & & & REL-2 & 184 & & 417 & FU-6 & REL-2 & 407 & Sim \\
\hline & \multirow{4}{*}{$\begin{array}{l}\text { Fase } \\
\text { Terra }\end{array}$} & \multirow{4}{*}{180} & FU-6 & 187 & 45 & 61 & \multirow{2}{*}{ FU-6 } & \multirow{2}{*}{ REL-1 } & \multirow{2}{*}{178} & \multirow{2}{*}{ Não } \\
\hline & & & REL-1 & 59 & & 239 & & & & \\
\hline & & & FU-3 & 81 & 2447 & 5903 & FU-6 & FU-3 & 2386 & Sim \\
\hline & & & REL-2 & 62 & & 216 & FU-6 & REL-2 & 155 & Não \\
\hline \multirow{8}{*}{$\begin{array}{c}\text { Linha } \\
34\end{array}$} & \multirow{4}{*}{ Trifásico } & \multirow{4}{*}{947} & FU-6 & 947 & 10 & 10 & \multirow{2}{*}{ FU-6 } & \multirow{2}{*}{ REL-1 } & \multirow{2}{*}{129} & \multirow{2}{*}{ Não } \\
\hline & & & REL-1 & 331 & & 139 & & & & \\
\hline & & & FU-3 & 304 & 129 & 190 & FU-6 & FU-3 & 119 & Sim \\
\hline & & & REL-2 & 314 & & 151 & FU-6 & REL-2 & 141 & Não \\
\hline & \multirow{4}{*}{$\begin{array}{l}\text { Fase } \\
\text { Terra }\end{array}$} & \multirow{4}{*}{180} & FU-6 & 188 & 44 & 60 & \multirow{2}{*}{ FU-6 } & \multirow{2}{*}{ REL-1 } & \multirow{2}{*}{179} & \multirow{2}{*}{ Não } \\
\hline & & & REL-1 & 59 & & 239 & & & & \\
\hline & & & FU-3 & 81 & 2447 & 5903 & FU-6 & FU-3 & 2387 & Sim \\
\hline & & & REL-2 & 62 & & 216 & FU-6 & REL-2 & 156 & Não \\
\hline
\end{tabular}

Tabela 4.29 - Margens de coordenação após reajuste obtidas na região 9.

\begin{tabular}{|c|c|c|c|c|c|c|c|c|c|c|}
\hline \multicolumn{11}{|c|}{ Região 9 de Proteção } \\
\hline $\begin{array}{c}\text { Local } \\
\text { da } \\
\text { Falta }\end{array}$ & $\begin{array}{c}\text { Tipo } \\
\text { de } \\
\text { Falta }\end{array}$ & $\begin{array}{c}\text { Corrente } \\
\text { de } \\
\text { Falta } \\
\text { (A) }\end{array}$ & $\begin{array}{c}\text { Elemento } \\
\text { de } \\
\text { Proteção }\end{array}$ & $\begin{array}{l}\text { Corrente } \\
\text { vista } \\
\text { pelo } \\
\text { elemento } \\
\text { de } \\
\text { proteção } \\
\text { (A) }\end{array}$ & $\begin{array}{c}\text { Tempo } \\
\text { de } \\
\text { atuação } \\
\text { mínimo } \\
\text { (ms) }\end{array}$ & $\begin{array}{c}\text { Tempo } \\
\text { de } \\
\text { atuação } \\
\text { máximo } \\
\text { (ms) }\end{array}$ & $\begin{array}{l}\text { Proteção } \\
\text { Principal }\end{array}$ & $\begin{array}{l}\text { Proteção de } \\
\text { Retaguarda }\end{array}$ & 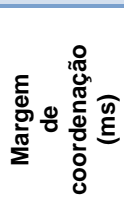 & 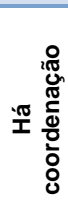 \\
\hline \multirow{8}{*}{$\begin{array}{c}\text { Barra } \\
78\end{array}$} & \multirow{4}{*}{ Bifásico } & \multirow{4}{*}{641} & REL-2 & 456 & & 90 & \multirow{2}{*}{ REL-2 } & \multirow{2}{*}{ REL-1 } & \multirow{2}{*}{142} & \multirow{2}{*}{ Não } \\
\hline & & & DJ-2 & 185 & & 2213 & & & & \\
\hline & & & REL-1 & 245 & & 232 & \multirow{2}{*}{ REL-2 } & \multirow{2}{*}{ FU-3 } & \multirow{2}{*}{242} & \multirow{2}{*}{ Sim } \\
\hline & & & FU-3 & 191 & 332 & 528 & & & & \\
\hline & \multirow{4}{*}{$\begin{array}{l}\text { Fase } \\
\text { Terra }\end{array}$} & \multirow{4}{*}{180} & REL-2 & 117 & & 76 & \multirow{2}{*}{ REL-2 } & \multirow{2}{*}{ REL-1 } & \multirow{2}{*}{163} & \multirow{2}{*}{ Não } \\
\hline & & & DJ-2 & 63 & & 1213 & & & & \\
\hline & & & REL-1 & 59 & & 239 & \multirow{2}{*}{ REL-2 } & \multirow{2}{*}{ FU-3 } & \multirow{2}{*}{2371} & \multirow{2}{*}{ Sim } \\
\hline & & & FU-3 & 81 & 2447 & 5903 & & & & \\
\hline \multirow{8}{*}{$\begin{array}{c}\text { Linha } \\
31\end{array}$} & \multirow{4}{*}{ Trifásico } & \multirow{4}{*}{943} & REL-2 & 628 & & 66 & \multirow{2}{*}{ REL-2 } & \multirow{2}{*}{ REL-1 } & \multirow{2}{*}{75} & \multirow{2}{*}{ Não } \\
\hline & & & DJ-2 & 315 & & 783 & & & & \\
\hline & & & REL-1 & 328 & & 141 & \multirow{2}{*}{ REL-2 } & \multirow{2}{*}{ FU-3 } & \multirow{2}{*}{127} & \multirow{2}{*}{ Não } \\
\hline & & & FU-3 & 302 & 131 & 193 & & & & \\
\hline & \multirow{4}{*}{$\begin{array}{l}\text { Fase } \\
\text { Terra }\end{array}$} & \multirow{4}{*}{180} & REL-2 & 118 & & 75 & BFI_? & RFI-1 & & \\
\hline & & & DJ-2 & 62 & & 1255 & REL-2 & REL-1 & 164 & Nao \\
\hline & & & REL-1 & 59 & & 239 & & & & \\
\hline & & & FU-3 & 81 & 2447 & 5903 & REL-2 & FU-3 & 2312 & Sim \\
\hline
\end{tabular}

A Tabela 4.30 apresenta a análise dos resultados obtidos nas Tabelas 4.21 a 4.29, após a verificação da coordenação dos elementos de proteção de sobrecorrente para as mesmas faltas simuladas nos locais referidos na Tabela 4.8, depois da realização dos reajustes mencionados anteriormente. 
Tabela 4.30 - Ocorrências encontradas na operação ilhada após ajustes na proteção.

\begin{tabular}{|c|c|}
\hline $\begin{array}{l}\text { Região de } \\
\text { Proteção }\end{array}$ & Ocorrências Encontradas \\
\hline Região 1 & $\begin{array}{l}\text { A coordenação entre o fusível FU-2 e o disjuntor DJ-1 passa a existir para faltas entre } \\
\text { fases, mas não existe para faltas fase-terra. } \\
\text { A coordenação entre o religador REL-1 e o fusível FU-3 é perdida para faltas entre } \\
\text { fases à medida que o local da falta se aproxima do religador REL-1, mas é mantida } \\
\text { para faltas fase-terra. } \\
\text { A coordenação entre o religador REL-1 e o religador REL-2 é perdida para faltas entre } \\
\text { fases à medida que o local da falta se aproxima do religador REL-1. } \\
\text { Não é possível garantir a coordenação entre o religador REL-1 e o religador REL-2 } \\
\text { para faltas fase-terra, pois o intervalo de coordenação é menor que } 0,2 \text { segundos. }\end{array}$ \\
\hline Região 2 & $\begin{array}{l}\text { O fusível FU-1 se mantém coordenado com o fusível FU-2. } \\
\text { Não é possível garantir a coordenação entre o fusível FU-1 e o religador REL-1, pois } \\
\text { o intervalo de coordenação é menor que } 0,2 \text { segundos. }\end{array}$ \\
\hline Região 3 & $\begin{array}{l}\text { Não é possível garantir a coordenação entre o fusível FU-2 e o religador REL-1 para } \\
\text { faltas entre fases, pois o intervalo de coordenação é menor que } 0,2 \text { segundos. } \\
\text { Não há coordenação entre o fusível FU-2 e o religador REL-1 para faltas fase-terra. }\end{array}$ \\
\hline Região 4 & $\begin{array}{l}\text { Não é possível garantir a coordenação entre o fusível FU-3 e o religador REL-1 para } \\
\text { faltas entre fases, pois o intervalo de coordenação é menor que } 0,2 \text { segundos. } \\
\text { A coordenação entre o fusível FU-3 e o religador REL-2 é perdida para faltas entre } \\
\text { fases à medida que o local da falta se aproxima do fusível FU-3. } \\
\text { Não há coordenação entre o fusível FU-3 e o religador REL-1 para faltas fase-terra. } \\
\text { Não há coordenação entre o fusível FU-3 e o religador REL-2 para faltas fase-terra. }\end{array}$ \\
\hline Região 5 & $\begin{array}{l}\text { Não há coordenação entre o religador REL-1 e o fusível FU-2 para faltas entre fases. } \\
\text { A coordenação entre o fusível FU-3 e o disjuntor DJ-3 passa a existir para faltas entre } \\
\text { fases, mas deixa de existir para faltas fase-terra. } \\
\text { A coordenação entre o religador REL-2 e o disjuntor DJ-2 passa a existir para faltas } \\
\text { entre fases e fase-terra. }\end{array}$ \\
\hline Região 6 & $\begin{array}{l}\text { O fusível FU-4 se mantém coordenado com o fusível FU-3. } \\
\text { A coordenação entre o fusível FU-4 e o religador REL-1 é perdida para faltas entre } \\
\text { fases à medida que o local da falta se aproxima do fusível FU-4. Não há coordenação } \\
\text { para faltas fase-terra. } \\
\text { A coordenação entre o fusível FU-4 e o religador REL-2 é perdida para faltas entre } \\
\text { fases à medida que o local da falta se aproxima do fusível FU-4. Não há coordenação } \\
\text { para faltas fase-terra. }\end{array}$ \\
\hline Região 7 & $\begin{array}{l}\text { O fusível FU-5 se mantém coordenado com o fusível FU-3. } \\
\text { A coordenação entre o fusível FU-5 e o religador REL-1 é perdida para faltas entre } \\
\text { fases à medida que o local da falta se aproxima do fusível FU-5. Não há coordenação }\end{array}$ \\
\hline
\end{tabular}




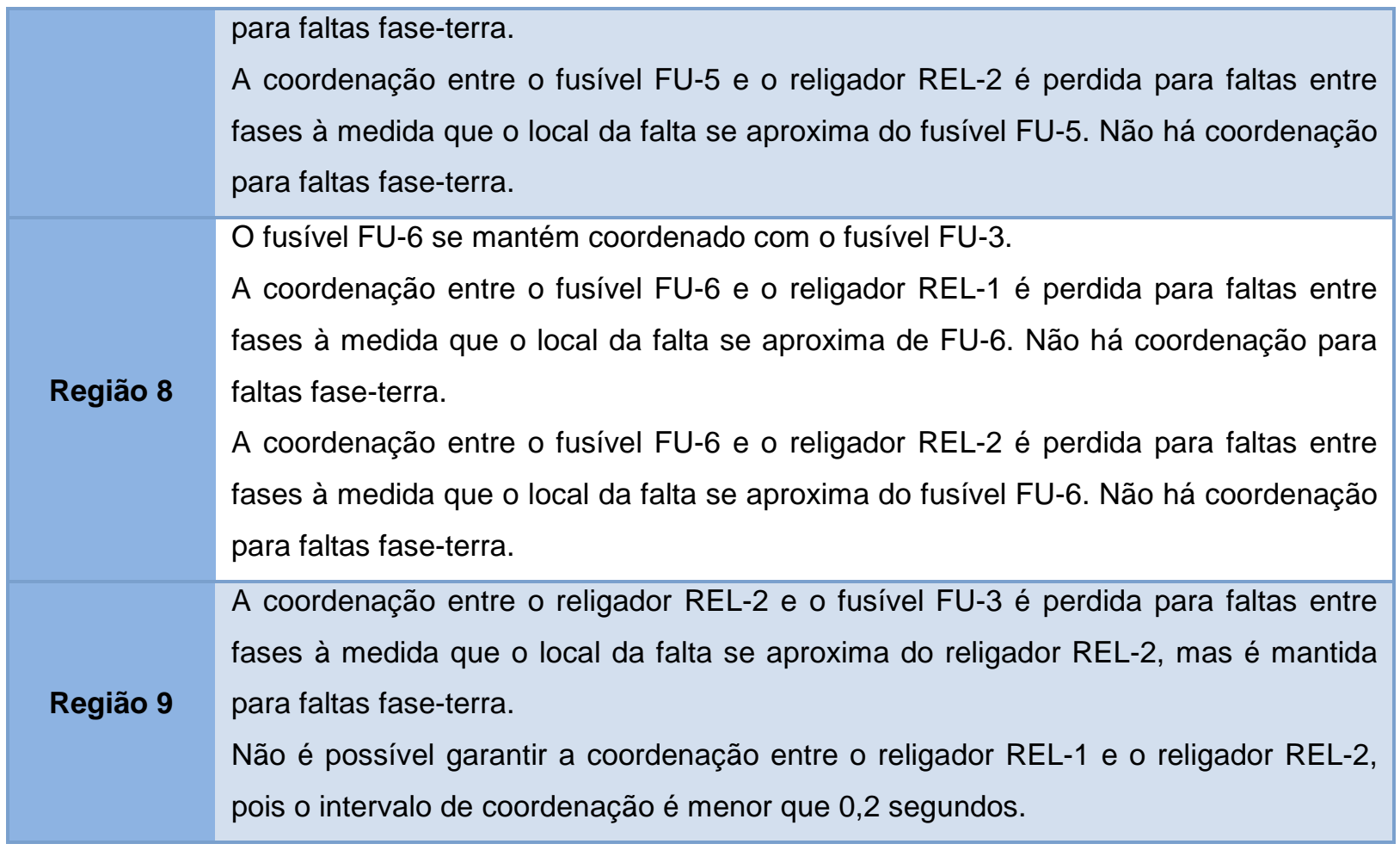

Com base nas ocorrências apresentadas na Tabela 4.30 pode-se afirmar que:

- A coordenação entre o elemento de proteção principal e de retaguarda passa a existir, mas é perdida à medida que o local da falta se aproxima do elemento de proteção principal;

- Os fusíveis continuam coordenados entre si nas regiões em que são elementos de proteção principal e retaguarda;

- Não há falta de sensibilidade dos equipamentos de proteção envolvidos na falta;

- Os religadores REL-1 e REL-2 se mantêm coordenados entre si e entre os disjuntores DJ-1, DJ-2 e DJ-3 em todas as regiões;

- Não há religamento automático dos religadores sem sincronismo.

A inibição do religamento automático e das curvas instantâneas dos religadores e dos relés dos disjuntores do PAC, somados à utilização de um segundo grupo de ajustes das curvas temporizadas desses dispositivos, garantiu segurança na operação e demonstrou melhorar a coordenação e seletividade das regiões de proteção, embora não seja possível garantir a coordenação à medida que o local da falta se aproxima do elemento de proteção principal da região estudada.

Foram analisados 100 casos de coordenação, dos quais, apenas 30 deles apresentavam o elemento de proteção principal coordenado com o elemento de proteção de retaguarda antes das medidas corretivas. Após a realização dos reajustes na proteção, o número de casos em que o elemento de proteção principal ficou coordenado com o elemento de proteção de retaguarda aumentou para 50 , ou seja, houve uma melhora de 
aproximadamente $66,7 \%$ na coordenação. Todas as regiões de proteção apresentaram melhora da coordenação, com exceção da região 3 que se manteve igual, isto é, antes e depois do reajuste todos os dispositivos de proteção envolvidos na falta permaneceram descoordenados. Na região 9, antes do reajuste, haviam 4 casos em que os elementos permaneciam coordenados e depois passou a apresentar 3 casos em que a coordenação foi mantida. Essa condição ocorreu, porque é considerado existência de coordenação quando o elemento de proteção principal atua antes do elemento de proteção de retaguarda e nesse caso o elemento de proteção principal atuava antes porque o elemento de proteção de retaguarda não era sensibilizado. Apesar de após o reajuste ele tenha passado a ser sensibilizado, ele atuava antes do elemento de proteção principal e era contabilizado como perda de coordenação.

A região que apresentou maior número de casos com coordenação foi a região 5 , a qual possuía 2 casos de coordenação antes do reajuste da proteção e passou a apresentar 12 casos depois da realização dos reajustes.

Os resultados desta análise são apenas quantitativos. A análise qualitativa não foi considerada, todas as cargas possuem o mesmo nível de prioridade, com relação à permanência da alimentação.

Embora a melhora na coordenação seja sensível, ainda é necessário avaliar se os tempos ajustados na proteção atendem ao comportamento síncrono e estável do sistema de geração na ocorrência das faltas simuladas anteriormente. Esta análise é apresentada no capítulo seguinte. 


\section{ANÁLISE DINÂMICA DAS REGIÕES DE PROTEÇÃO DA REDE OPERANDO ILHADA}

Neste capítulo serão avaliados se os tempos ajustados na proteção de sobrecorrente atendem ao comportamento síncrono e estável do sistema de geração da rede operando ilhada.

Conforme comentado anteriormente, a realização de estudos de estabilidade transitória para redes de distribuição não tem sido comum. Porém, com a expansão da geração distribuída juntamente com a possibilidade da operação em ilhamento intencional, este tipo de análise será tido como uma ferramenta indispensável para avaliação dos ajustes de tempo e corrente da proteção de sobrecorrente do sistema de distribuição de energia.

O sistema de controle das máquinas, responsáveis pela manutenção da tensão e frequência da ilha formada, precisa ser considerado. Os distúrbios causados por faltas na região ilhada podem colocar em risco tanto a estabilidade do sistema de geração quanto os limites de tensão e frequência permitidos para operação do sistema de distribuição de energia. A violação desses limites pode causar danos irreversíveis às cargas alimentadas pela rede e também aos próprios geradores distribuídos.

Por esse motivo, embora o interesse seja em relação à proteção de sobrecorrente, não se pode deixar de observar os ajustes das proteções de frequência e tensão existentes no PAC, pois os mesmos serão determinantes na recuperação ou não da estabilidade após a ocorrência do distúrbio causado no sistema pelas faltas simuladas.

Os ajustes das proteções de subtensão e sobretensão, funções ANSI 27 e 59, respectivamente, bem como os de subfrequência e sobrefrequência, funções $81 \mathrm{U}$ e 810 , foram determinados utilizando valores típicos para proteção de máquinas síncronas com motores a diesel (Mardegan, 2013), respeitando os limites mecânicos das máquinas e de qualidade da energia elétrica. Esses valores são apresentados na Tabela 5.1. 
Tabela 5.1 - Ajustes das proteções de tensão e frequência dos relés do PAC.

\begin{tabular}{|c|c|c|}
\hline \multicolumn{3}{|c|}{ Ajuste da Proteção } \\
\hline \multicolumn{3}{|c|}{ Nome do Elemento de Proteção } \\
\hline DJ-1 & DJ-2 & DJ-3 \\
\hline \multicolumn{3}{|c|}{ Subtensão - Função ANSI 27 (Tensão Fase-Neutro) } \\
\hline $0,8 \mathrm{pu}-2$ segundos & $0,8 \mathrm{pu}-2$ segundos & $0,8 \mathrm{pu}-2$ segundos \\
\hline \multicolumn{3}{|c|}{ Sobretensão - Função ANSI 59 (Tensão Fase-Neutro) } \\
\hline $1,10 \mathrm{pu}-2$ segundos & $1,10 \mathrm{pu}-2$ segundos & $1,10 \mathrm{pu}-2$ segundos \\
\hline 1,15 pu - instantâneo & 1,15 pu - instantâneo & 1,15 pu - instantâneo \\
\hline \multicolumn{3}{|c|}{ Subfrequência - Função ANSI 81U } \\
\hline $57 \mathrm{~Hz}-1$ segundo & $57 \mathrm{~Hz}-1$ segundo & $57 \mathrm{~Hz}-1$ segundo \\
\hline $56 \mathrm{~Hz}$ - instantâneo & $56 \mathrm{~Hz}$ - instantâneo & $56 \mathrm{~Hz}$ - instantâneo \\
\hline \multicolumn{3}{|c|}{ Sobrefrequência - Função ANSI 810} \\
\hline $63 \mathrm{~Hz}-3$ segundos & $63 \mathrm{~Hz}-3$ segundos & $63 \mathrm{~Hz}-3$ segundos \\
\hline
\end{tabular}

As reatâncias e constantes de tempo dos geradores, utilizadas no estudo, estão apresentadas na Tabela B.5 do Anexo B. Neste mesmo anexo (Figura B.1) é encontrada a curva de capabilidade dos geradores distribuídos, bem como os modelos do regulador de tensão e de velocidade utilizados, apresentados nos diagramas de blocos das Figuras B.2 e B.3, respectivamente. Os ajustes de cada parâmetro do regulador de tensão e do regulador de velocidade estão dispostos na Tabela B.6 e Tabela B.7.

As faltas analisadas estão apresentadas na Tabela 5.2, de acordo com cada região de proteção. Foram selecionados os curtos-circuitos trifásicos e fase-terra por se tratar das situações em que a corrente de curto-circuito é a maior e a menor, respectivamente.

Nas condições iniciais de operação, antes das simulações das faltas apresentadas na Tabela 5.2, a rede de distribuição de energia opera em ilha sendo alimentada pelos 3 geradores distribuídos, G1, G2 e G3. O gerador G2 opera no modo isócrono, como sendo referência de tensão e frequência dos demais geradores, isso significa que o regulador de tensão controla a tensão terminal em 1 pu e o controlador de velocidade regula a frequência em $60 \mathrm{~Hz}$, enquanto nos demais geradores o controle de tensão foi configurado para $1 \mathrm{pu}$ de referência, e o controle de velocidade foi configurado para o modo estatismo (droop), com ganho igual a 5\%. Essas condições de operação configuram o caso base de pré-falta e em todos eles o gerador G1 fornece 960 kW e 490 kVA, o gerador G2 970 kW e 480 kVA, e o gerador G3 960 kW e 470 kVA.

As faltas foram simuladas após 10 segundos do sistema operando nas condições anteriormente mencionadas, ou seja, em regime permanente. As faltas simuladas nas linhas de distribuição foram localizadas a $10 \%$ do comprimento da linha a partir da barra onde está localizado o elemento de proteção principal, da mesma forma em que foram calculadas na análise estática. 
Tabela 5.2 - Faltas simuladas para análise de estabilidade transitória.

\begin{tabular}{|lcc|}
\hline Região de & \multicolumn{2}{c|}{ Localização do Curto-circuito } \\
\hline Proteção & Curto-circuito Trifásico & Curto-circuito Fase-Terra \\
\hline Região 1 & barra 11, linha 20 & barra 150 \\
\hline Região 2 & linha 11 & barra 12 \\
\hline Região 3 & linha 12 & barra 21 \\
\hline Região 4 & linha 35 & barra 31 \\
\hline Região 5 & barra 23, barra 63 & barra 39 \\
\hline Região 6 & linha 45 & barra 40 \\
\hline Região 7 & linha 27 & barra 49 \\
\hline Região 8 & linha 34 & barra 52 \\
\hline Região 9 & linha 31 & barra 78 \\
\hline
\end{tabular}

\subsection{Análise de Estabilidade Transitória da Região 1}

O comportamento dinâmico dos geradores para as faltas trifásicas simuladas separadamente, a saber; primeiramente na barra 11 e, posteriormente na linha 20 , ocorridas na região 1 é bastante similar, isto é, as ocorrências e os tempos de atuação das proteções são praticamente os mesmos, por este motivo, estas situações são comentadas em um único tópico.

\subsubsection{Curto-circuito trifásico simulado separadamente na barra 11 e na linha 20}

Durante a ocorrência do curto-circuito trifásico há uma forte queda de tensão nos três geradores, acompanhada de uma breve aceleração das máquinas, mas os geradores G2 e G3 recuperam a tensão e frequência antes que as proteções de subtensão e sobrefrequência possam atuar. Logo após a abertura do religador REL-1, a carga restante na região 1 corresponde a $77,90 \%$ da capacidade do gerador $\mathrm{G} 1$, ao passo que o ângulo do rotor atinge um deslocamento máximo igual a $-9,7692^{\circ}$. Como o gerador $\mathrm{G} 1$ não consegue recuperar a tensão antes da abertura do fusível FU-2, o relé do disjuntor DJ-1 atua por subtensão, deixando as regiões 1, 2 e 3 desenergizadas, conforme indicado na área hachurada da Figura 5.1.

Esse comportamento pode ser observando através das Figuras 5.2, 5.3 e 5.4. Como a resposta de frequência dos geradores G2 e G3 apresentam desempenho idêntico, a linha que representa o comportamento da frequência do gerador G2 sobrepõe a do gerador G3, na Figura 5.3. A frequência do gerador G1 aparece alta, devido ao aumento da potência 
acelerante causada pela abertura do disjuntor DJ-1, instalado no PAC. A frequência medida no PAC do gerador G1 torna-se constante a partir da abertura do disjuntor Dj-1. Isso ocorre devido a uma característica do programa que repete o último valor de frequência registrado até o final da simulação sempre que a tensão no PAC vai à zero.

É importante observar que o estudo de coordenação e seletividade aponta a existência de coordenação entre o FU-2 (proteção principal) e o relé do disjuntor DJ-1 (proteção de retaguarda) para esse tipo de falta ocorrida da região 1. No entanto, o que ocorre na realidade é abertura do disjuntor DJ-1 por subtensão antes do fusível FU-2. Isto ilustra a importância de realizar estudos de transitórios nessas situações.

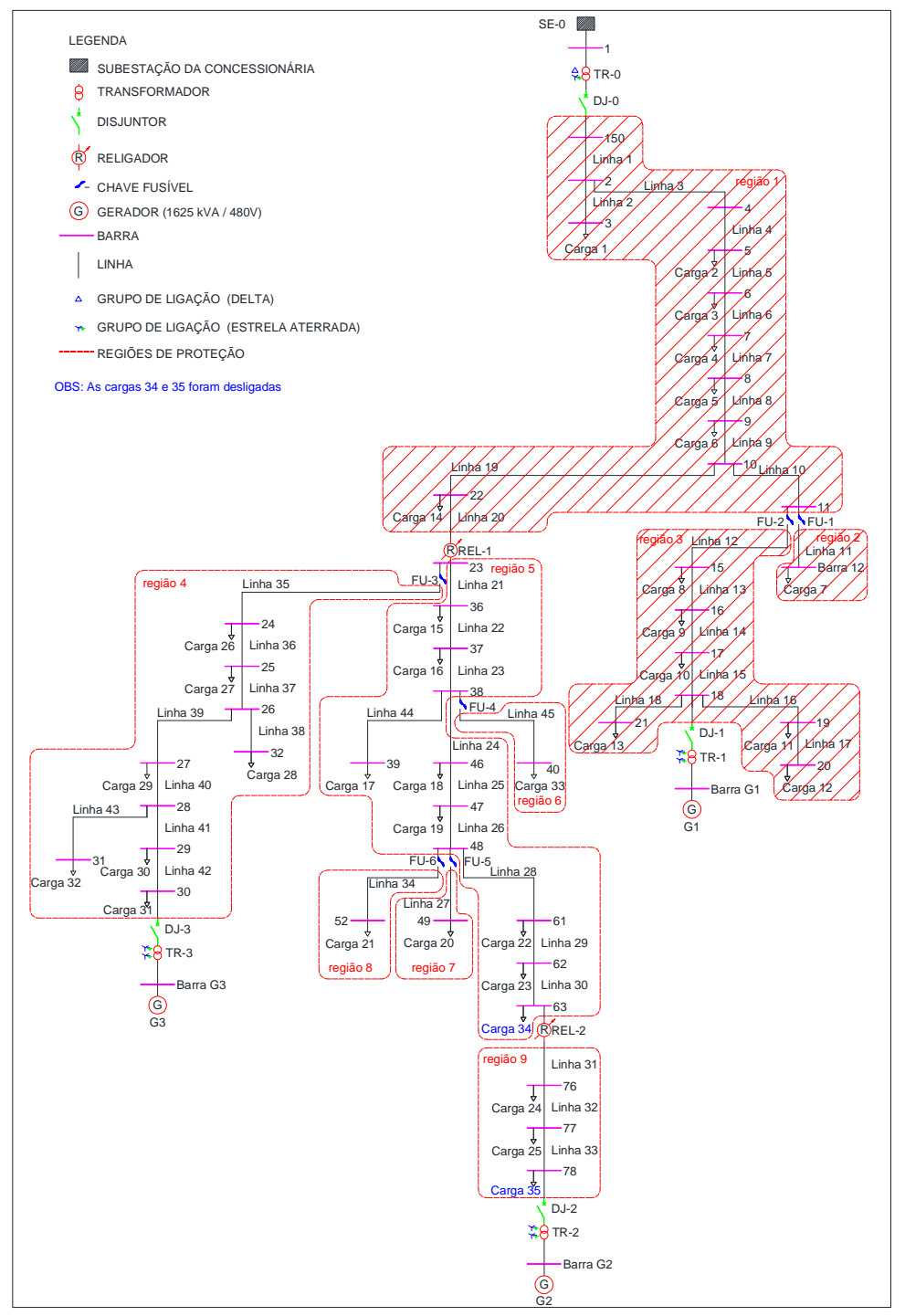

Figura 5.1 - Topologia do sistema ilhado resultante de uma falta trifásica na barra 11 ou na linha 20 (a área hachurada correspondente à região desenergizada). 


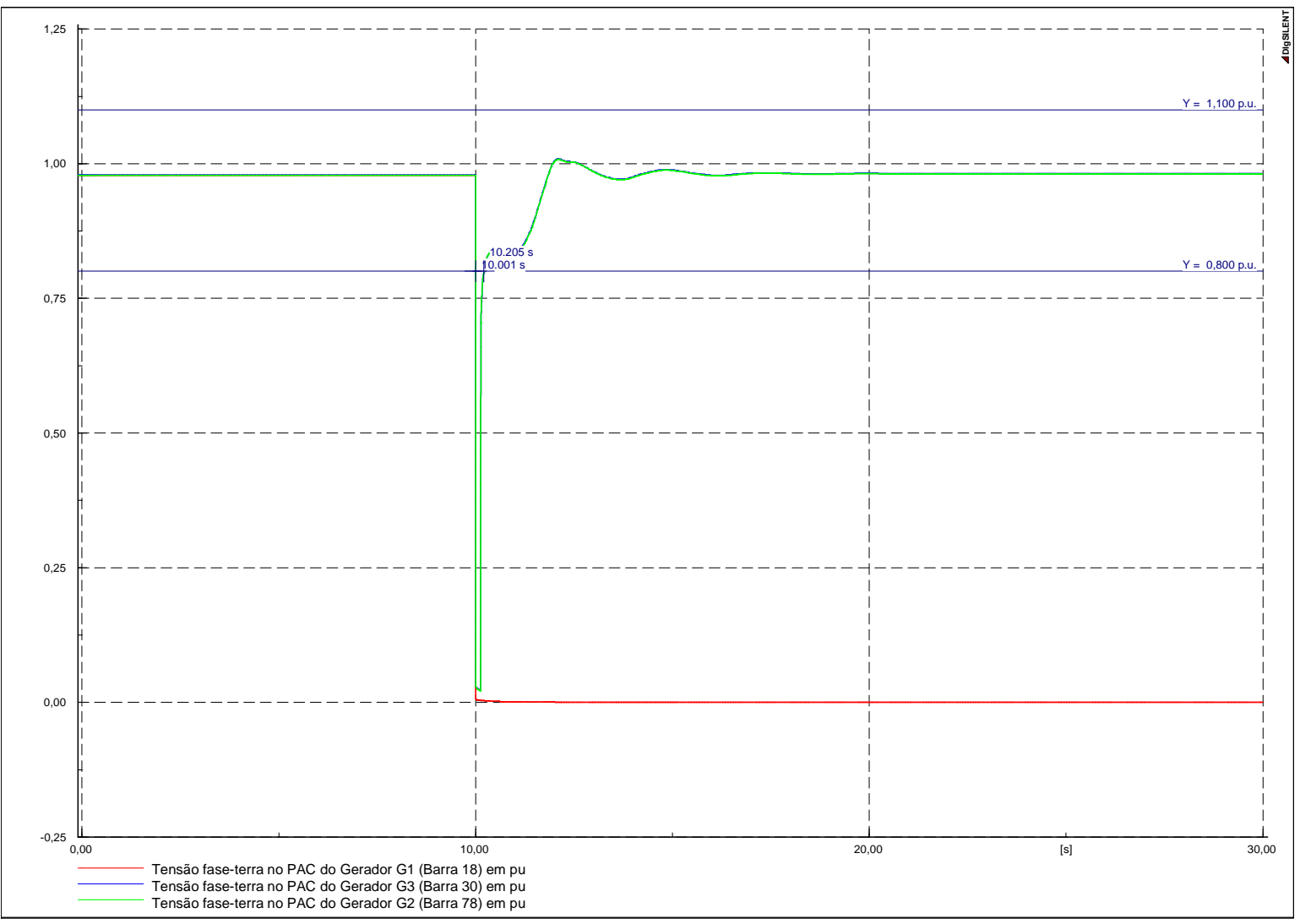

Figura 5.2 - Análise da região 1 - falta trifásica (tensão nos PACs versus tempo).

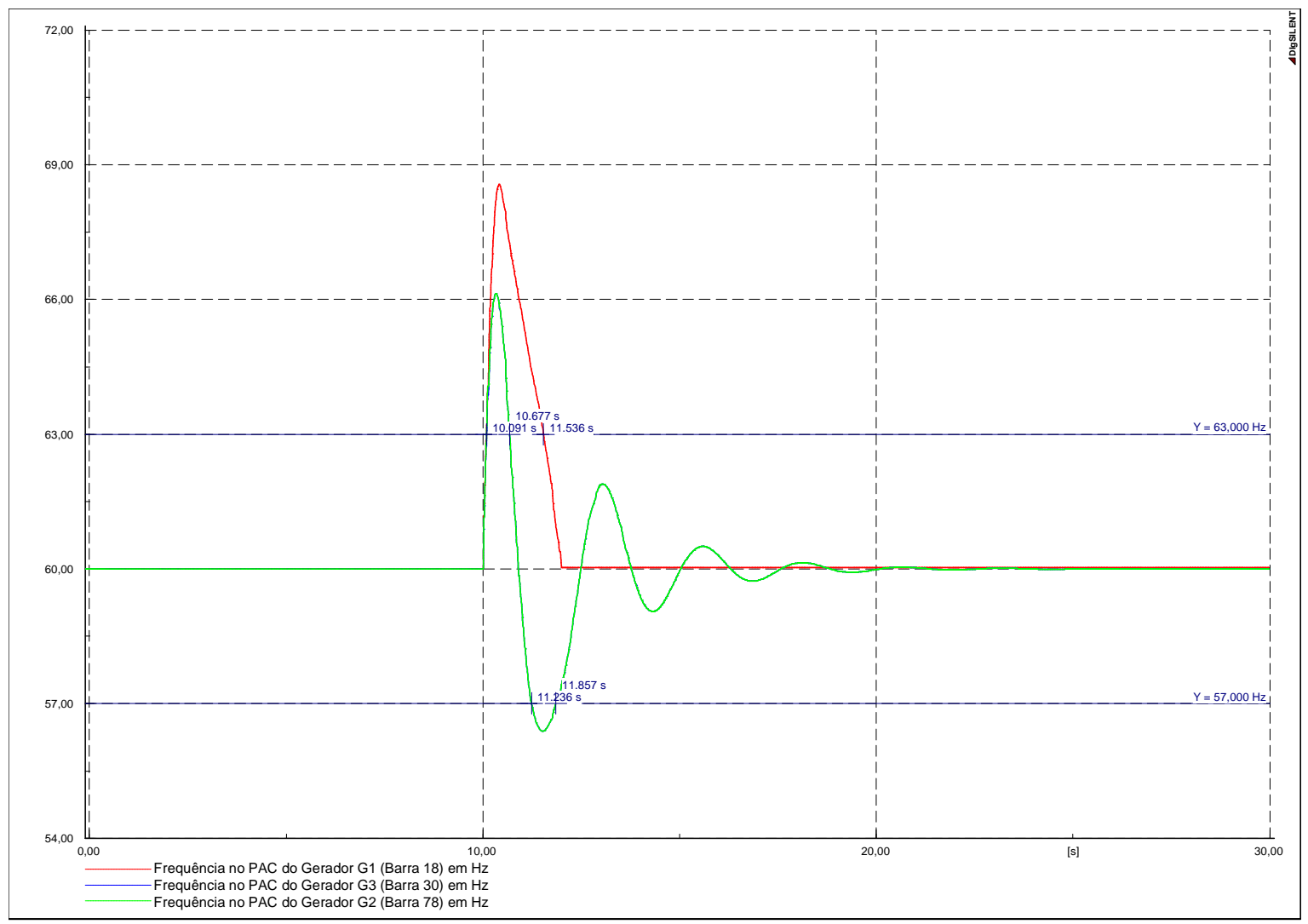

Figura 5.3 - Análise da região 1 - falta trifásica (frequência nos PACs versus tempo). 


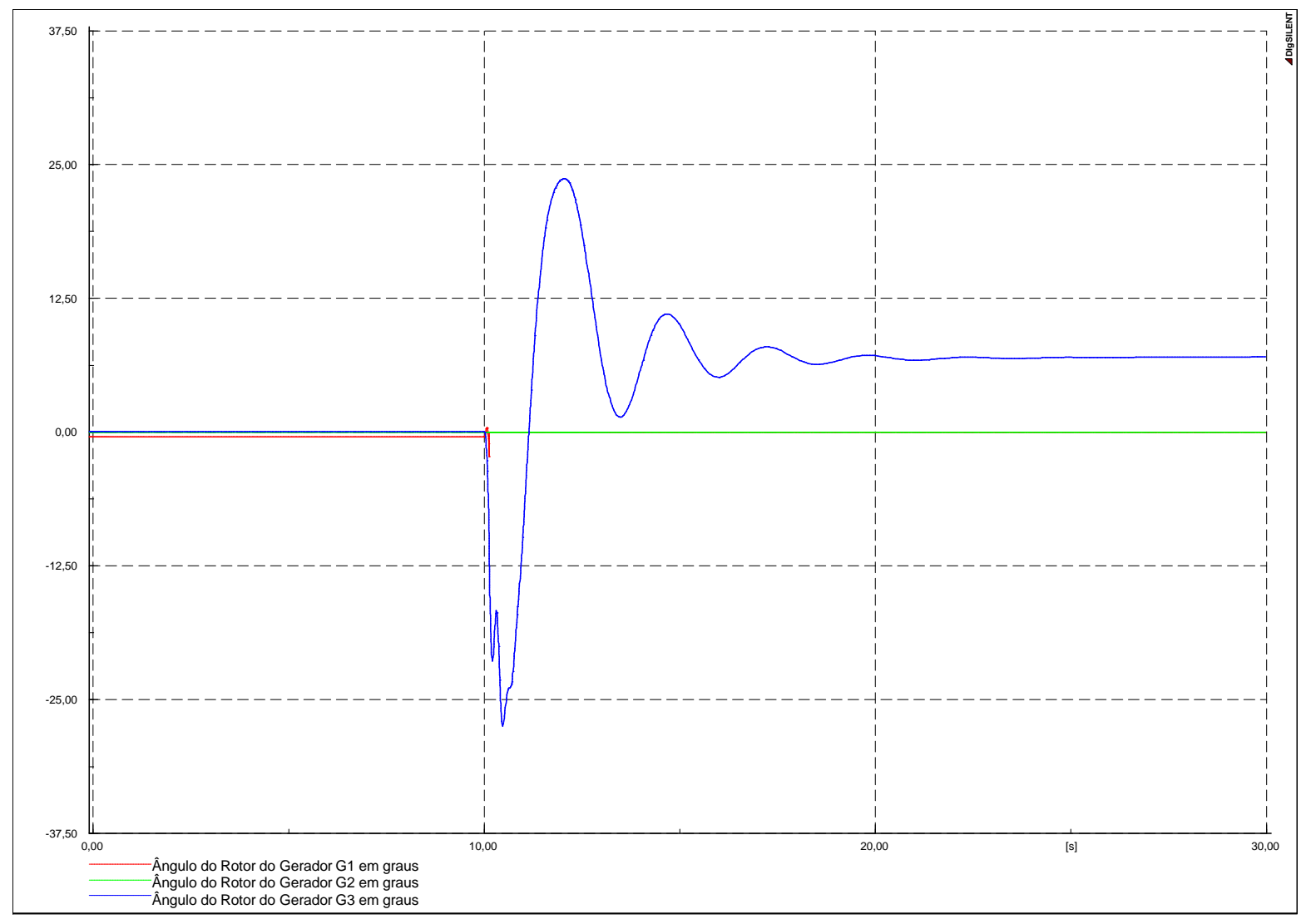

Figura 5.4 - Análise da região 1 - falta trifásica (ângulo do rotor dos geradores versus tempo).

\subsubsection{Curto-circuito fase-terra na barra 150}

Quando ocorre o curto-circuito fase-terra na barra 150, as tensões dos três geradores caem, registrando uma queda mais acentuada no gerador $\mathrm{G} 1$, mas se recuperam antes da atuação da proteção de subtensão do PAC. Em seguida o religador REL-1 abre, isolando a região 1 das demais regiões à jusante do religador REL-1, conforme previamente indicado no estudo de coordenação e seletividade. Embora o estudo de coordenação e seletividade afirme não existir coordenação entre o fusível FU-2 e o disjuntor DJ-1 para faltas fase-terra, o fusível FU-2 atua antes do disjuntor DJ-1. O fusível FU-2 abre a fase A em 764 ms após a ocorrência da falta, neste momento o gerador G1 acelera até a velocidade máxima de $1,0997 \mathrm{pu}$, mas retorna para 1,0032 pu dentro de 4,448 s e permanece alimentando a região 3 em condições normais de operação, e as regiões 1 e 2 com apenas duas fases, conforme indicado na Figura 5.5. Os ângulos dos rotores das máquinas permanecem dentro dos limites aceitáveis. Essa situação é apresentada nas Figuras 5.6, 5.7 e 5.8.

Com a queima do fusível de apenas uma das fases ocorre um desequilíbrio de tensão provocando a circulação de correntes de sequência negativa no sistema, podendo provocar danos à máquina e às cargas trifásicas ligadas ao sistema. 
Na Figura 5.7, a linha que representa o comportamento da frequência do gerador G3 não aparece no gráfico, porque é idêntica à linha que representa o comportamento da frequência do gerador G2, sendo, portanto, coberta por esta última.

A frequência do gerador G1 estabiliza em um valor maior que $60 \mathrm{~Hz}$, porque esse gerador, além de estar em modo droop, também sofre um alívio de carga. Neste caso, devese fazer um controle suplementar para corrigir a frequência de volta a $60 \mathrm{~Hz}$.

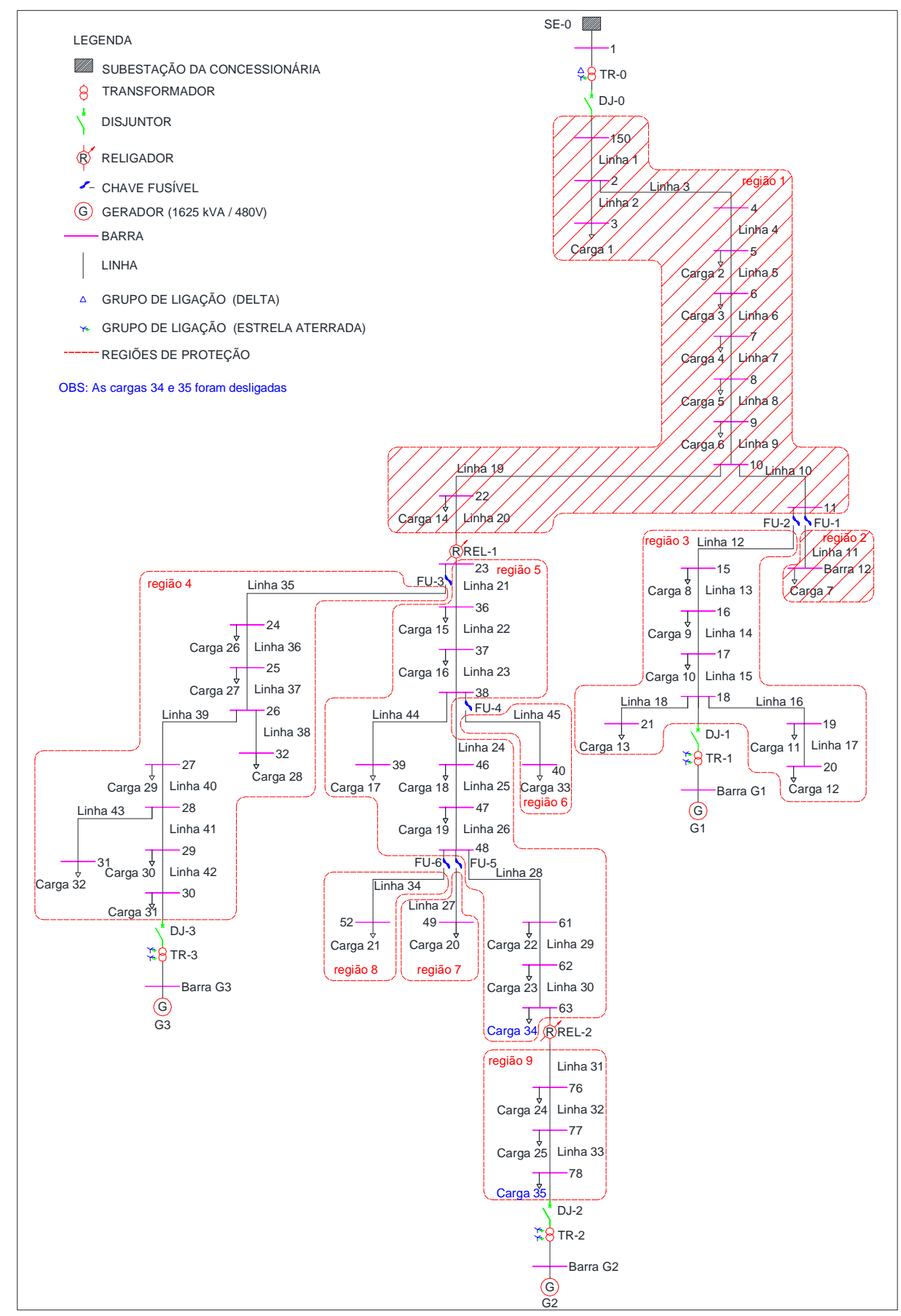

Figura 5.5 - Topologia do sistema ilhado resultante de uma falta fase-terra na barra 150 (a área hachurada correspondente à região alimentada com apenas duas fases). 


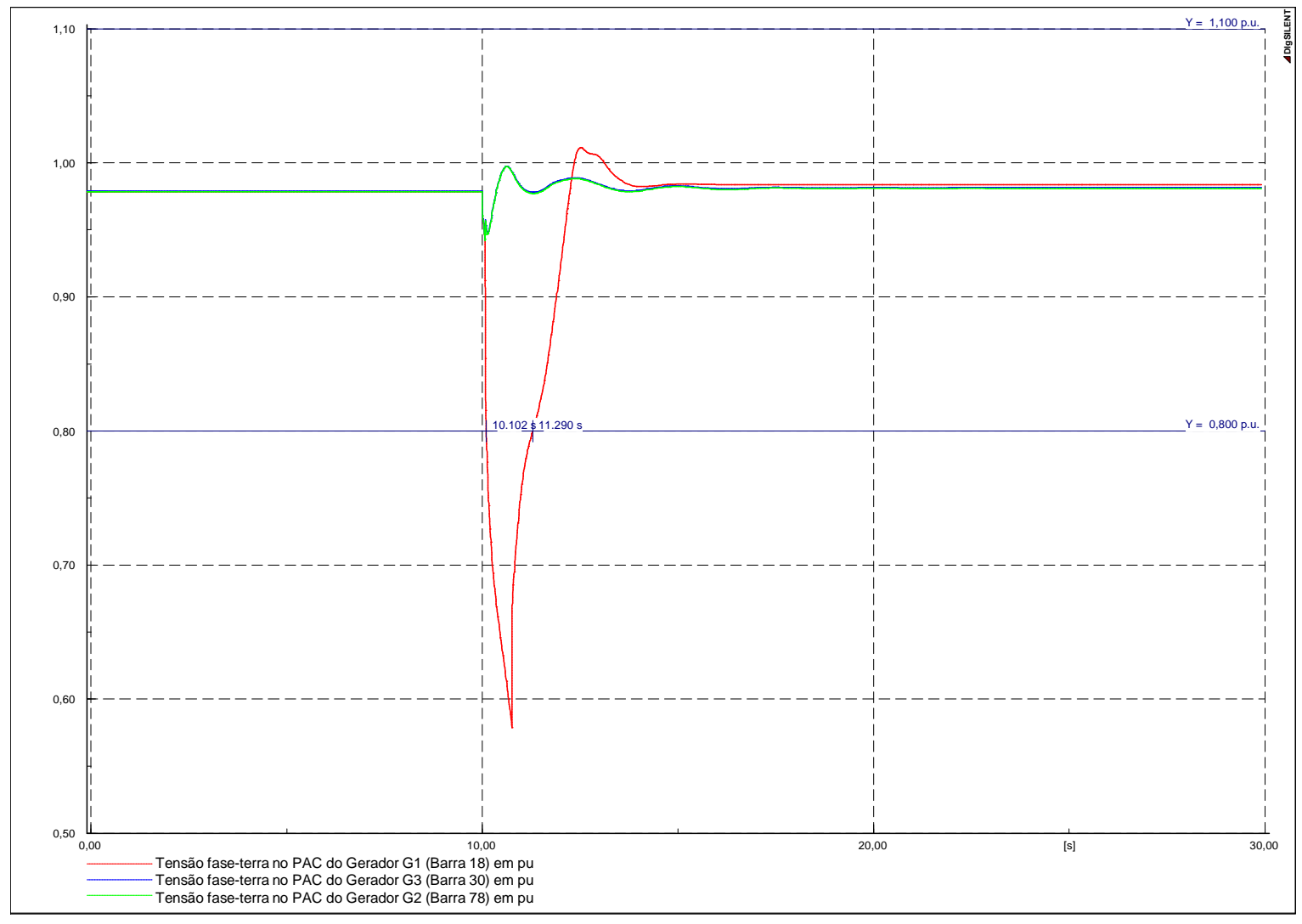

Figura 5.6 - Análise da região 1 - falta fase-terra (tensão nos PACs versus tempo).

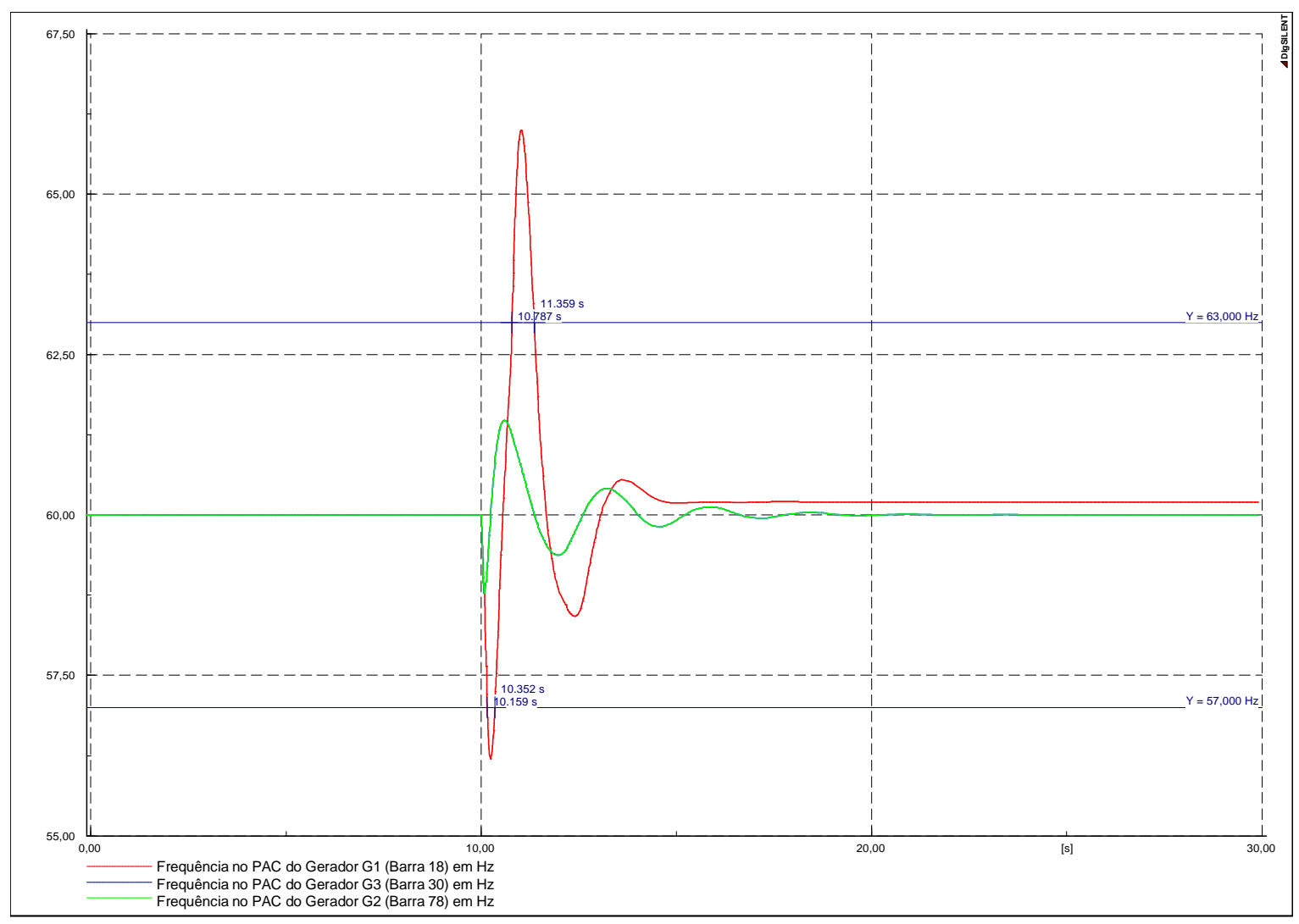

Figura 5.7 - Análise da região 1 - falta fase-terra (frequência nos PACs versus tempo). 


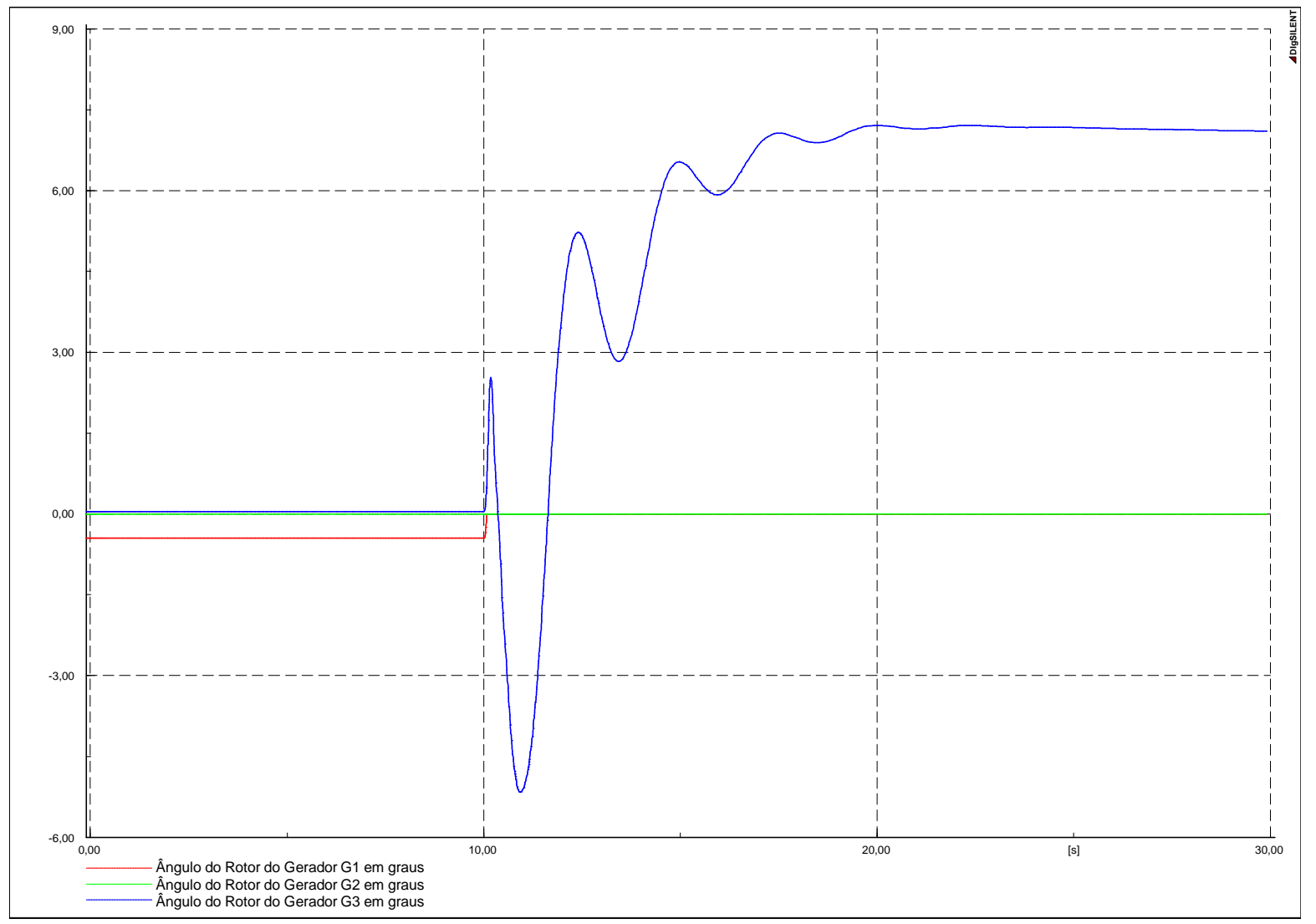

Figura 5.8 - Análise da região 1 - falta fase-terra (ângulo do rotor dos geradores versus tempo).

\subsection{Análise de Estabilidade Transitória das Regiões 2, 6, 7 e 8}

As regiões 2, 6, 7 e 8 apresentam respostas similares para as faltas trifásicas e faseterra, ocorridas dentro de suas respectivas áreas de abrangência. Por este motivo serão todas comentadas juntas nesta seção.

Os elementos responsáveis pela proteção dessas regiões são:

- Região 2 - fusível FU-1 sendo proteção principal e fusível FU-2 e religador REL-1 e sendo retaguarda;

- Região 6 - fusível FU-4 sendo proteção principal e fusível FU-3 e religador REL-2 sendo retaguarda;

- Região 7 - fusível FU-5 sendo proteção principal e fusível FU-3, religador REL-1 e religador $\mathrm{REL}-2$ sendo retaguarda;

- Região 8 - fusível FU-6 sendo proteção principal e fusível FU-3, religador REL-1 e religador REL-2 sendo retaguarda.

As faltas simuladas nessas regiões foram as seguintes:

- Região 2 - falta trifásica na linha 11 e fase-terra na barra 12;

- Região 6 - falta trifásica na linha 45 e fase-terra na barra 40;

- Região 7 - falta trifásica na linha 27 e fase-terra na barra 49; 
- Região 8 - falta trifásica na linha 34 e fase-terra na barra 52.

Os fusíveis FU-1, FU-4, FU-5 e FU-6, atuam em tempo hábil, para que os geradores G1, G2 e G3 recuperem tensão e frequência, isolando as linhas 11, 45, 27 e 39 em falta, conforme apresentado na Figura 5.9, onde a região hachurada representa a região desenergizada após a ocorrência da falta trifásica ou alimentada por apenas duas fases depois da ocorrência da falta fase-terra.

Embora o estudo estático de coordenação e seletividade informe que não há garantia de coordenação entre os fusíveis e religadores nessas regiões, pois as margens de coordenação são bastante estreitas, os fusíveis ainda atuam antes dos religadores.

Neste caso, o estudo de estabilidade transitória apontou para os mesmos resultados obtidos no estudo estático, uma vez que as proteções de tensão e frequência não influenciaram.

As Figuras 5.10, 5.11 e 5.12 representam o comportamento da tensão, da frequência e do deslocamento angular do rotor da máquina.

As linhas se sobrepõem nas Figuras 5.10 e 5.11, por este motivo é possível visualizar apenas a linha que representa o comportamento da tensão e da frequência do gerador G2. 


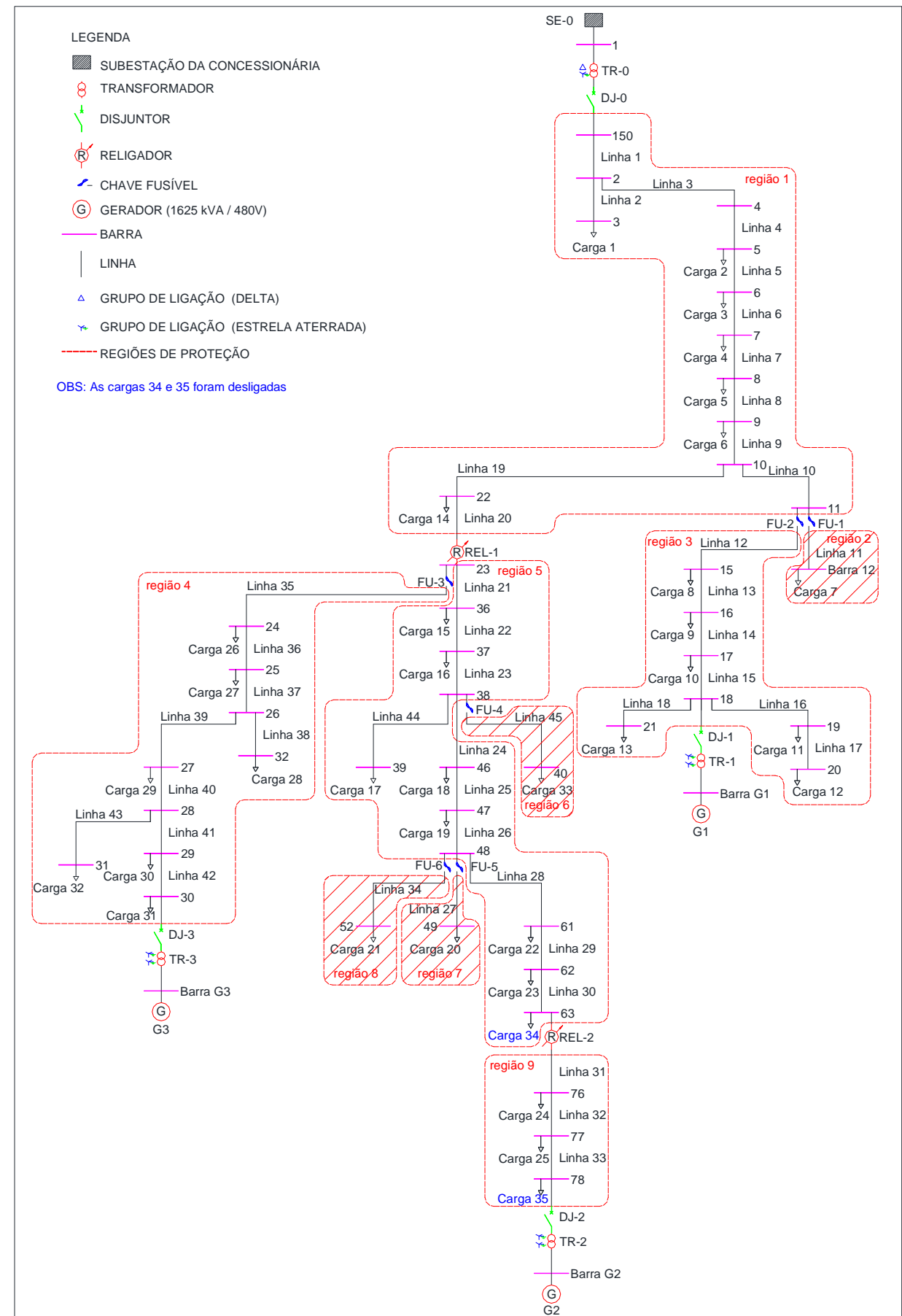

Figura 5.9 - Topologia do sistema ilhado resultante de faltas trifásicas nas linhas 11, 45, 27 e 34 ou faltas fase-terra nas barras 12, 40, 49 e 52

(a área hachurada correspondente à região desenergizada ou alimentada com 2 fases). 


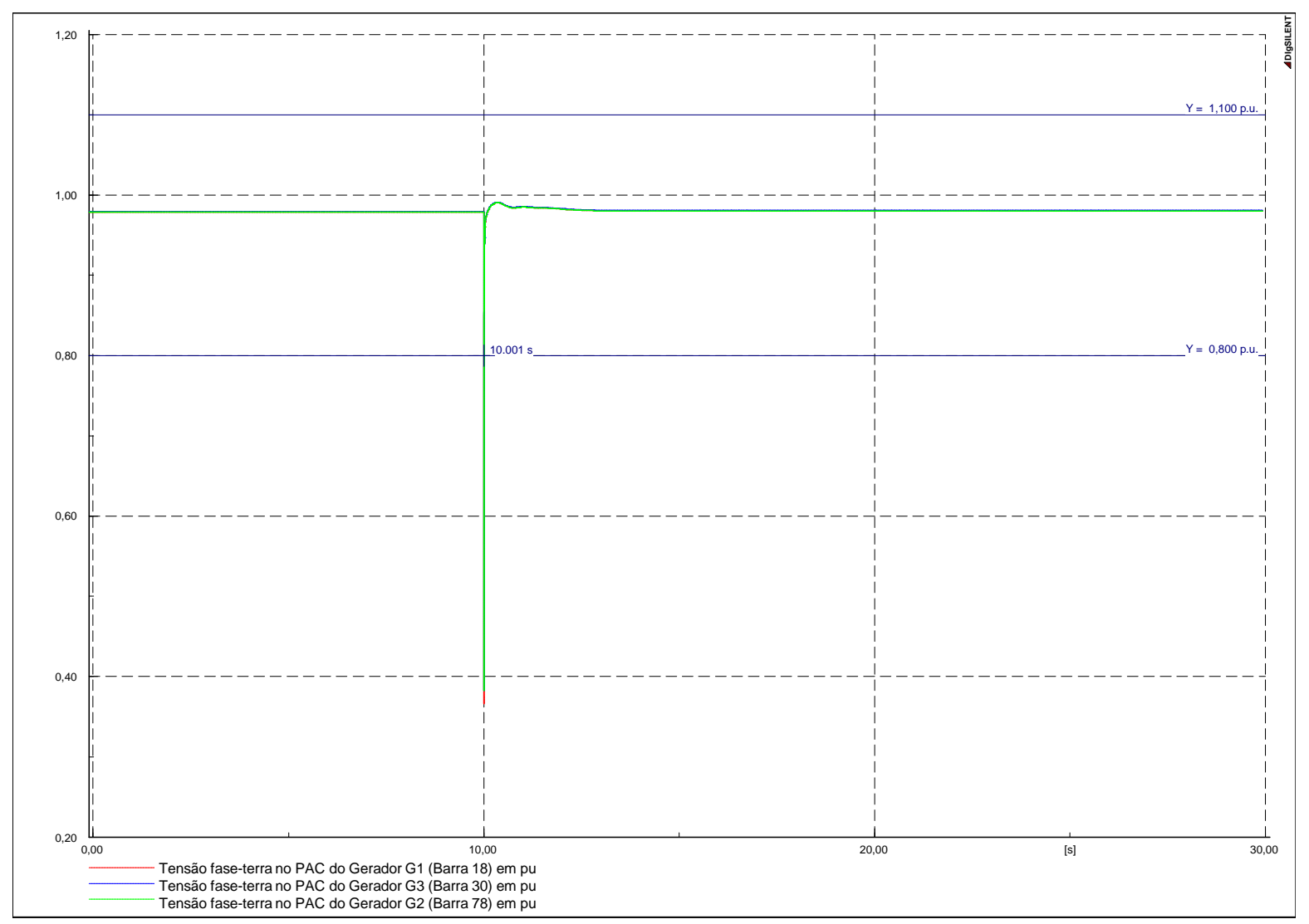

Figura 5.10 - Análise das regiões 2, 6, 7 e 8 (tensão nos PACs versus tempo).

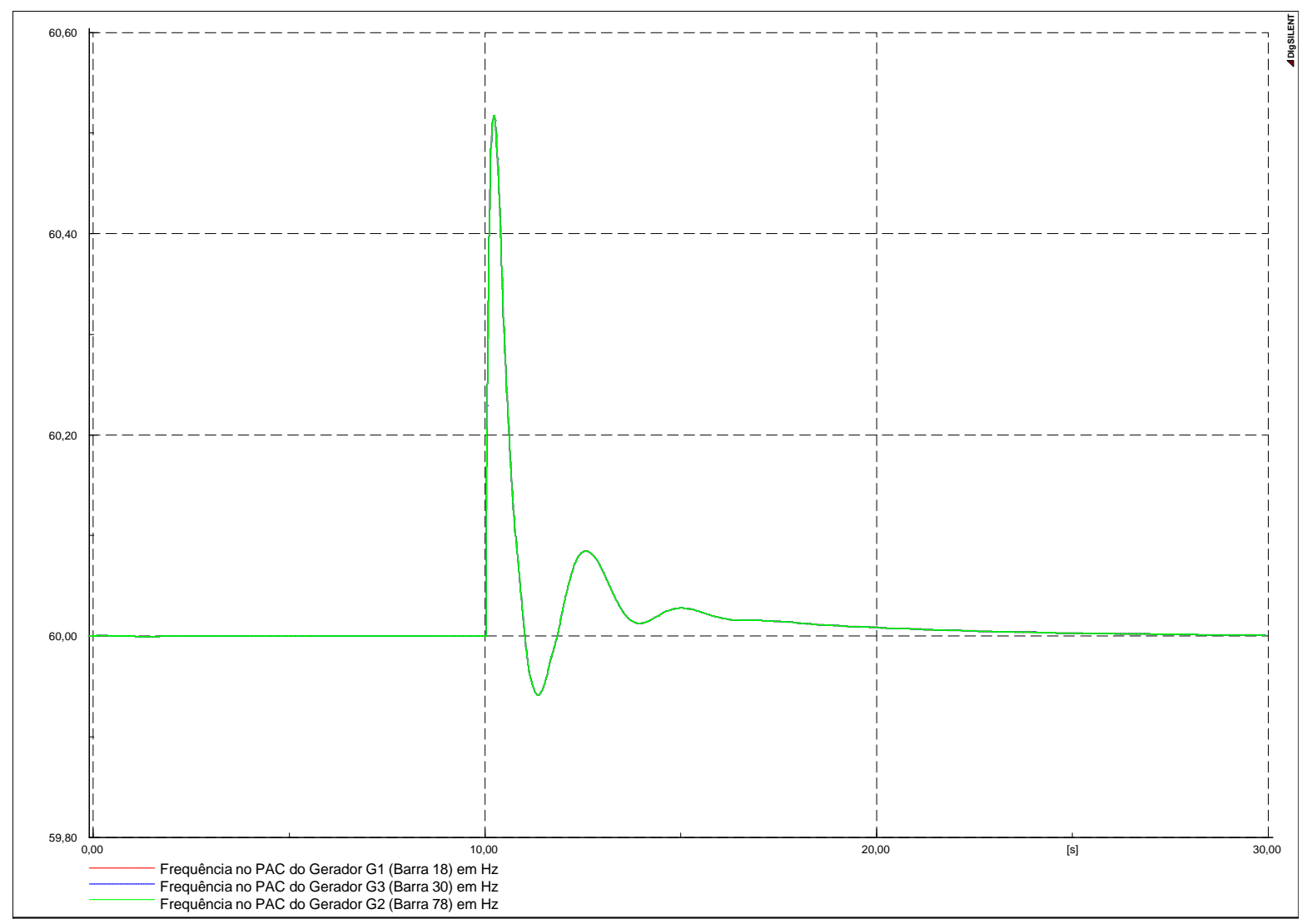

Figura 5.11 - Análise das regiões 2, 6, 7 e 8 (frequência nos PACs versus tempo). 


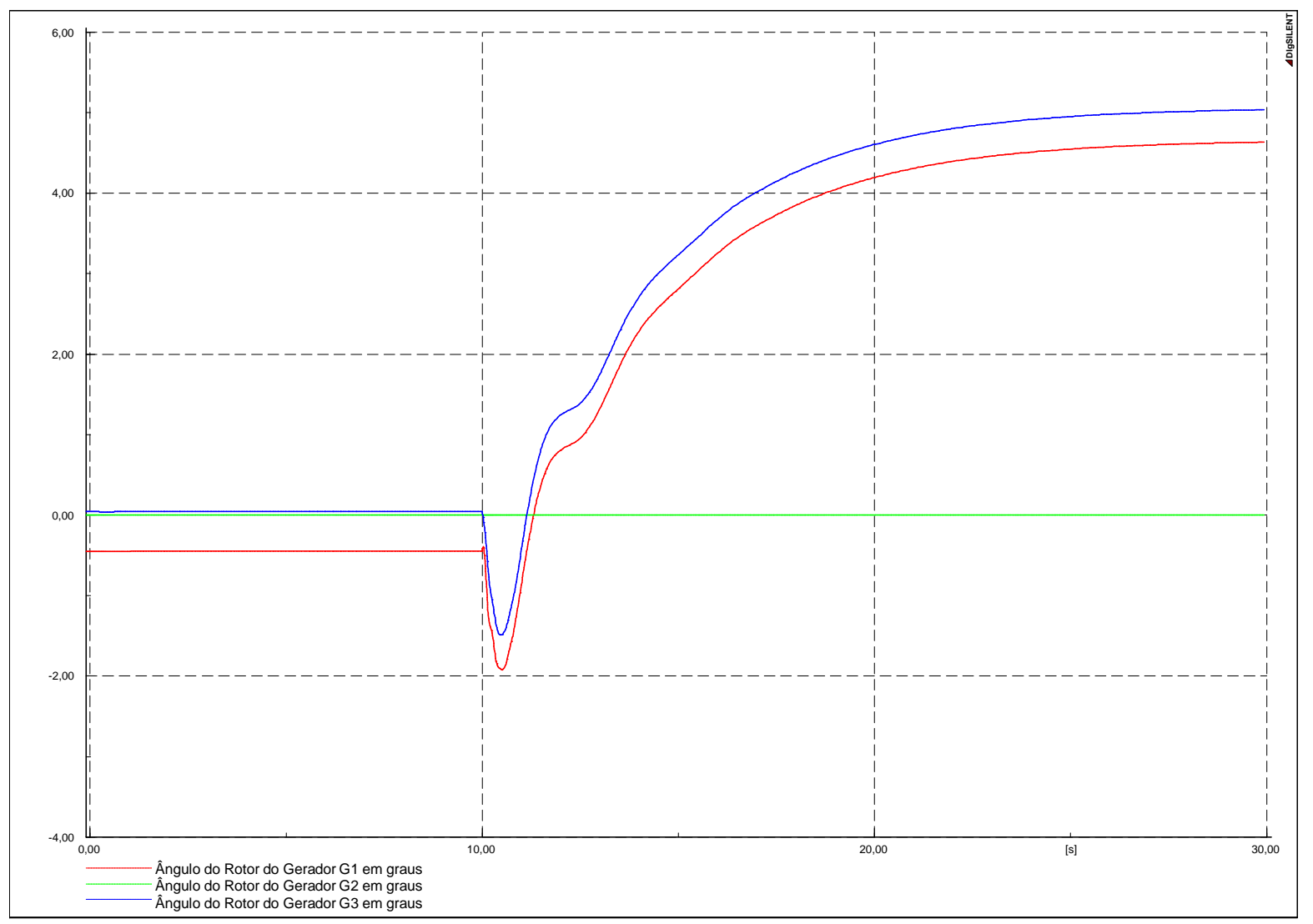

Figura 5.12 - Análise das regiões 2, 6, 7 e 8 (ângulo do rotor dos geradores versus tempo).

\subsection{Análise de Estabilidade Transitória da Região 3}

$\mathrm{Na}$ região 3 os elementos de proteção envolvidos na falta são o fusível FU-2, 0 religador REL-1 e o disjuntor DJ-1 instalado no PAC do gerador G1. Os elementos de proteção principal são o fusível FU-2 e o disjuntor DJ-1, e o de retaguarda é o religador REL-1.

\subsubsection{Curto-circuito trifásico na linha 12}

O estudo de coordenação e seletividade indica inexistência de coordenação entre o fusível FU-2 e o religador REL-1, pois a margem de coordenação é de apenas 26 ms. No entanto, quando ocorre o curto-circuito trifásico na linha 12, o fusível FU-2 atua antes do religador REL-1. A região 3 é desenergizada e as demais regiões permanecem alimentadas pelos geradores G2 e G3, os quais recuperam a tensão e frequência em tempo hábil. $A$ ilha remanescente solicita $68,92 \%$ da potência do gerador G3 e $77,13 \%$ da potência do gerador G2, conforme indicado na Figura 5.13. O relé do disjuntor DJ-1 do PAC atua por subtensão antes que a proteção de sobrecorrente possa atuar. Os ângulos dos rotores das máquinas G2 e G3 permanecem dentro dos limites aceitáveis. As Figuras 5.14, 5.15 e 5.16 apresentam o comportamento acima descrito. 
A frequência do gerador $\mathrm{G} 1$ estabiliza imediatamente, devido ao programa manter o último valor de frequência registrado antes da abertura do disjuntor DJ-1 até o final da simulação, conforme comentado anteriormente.

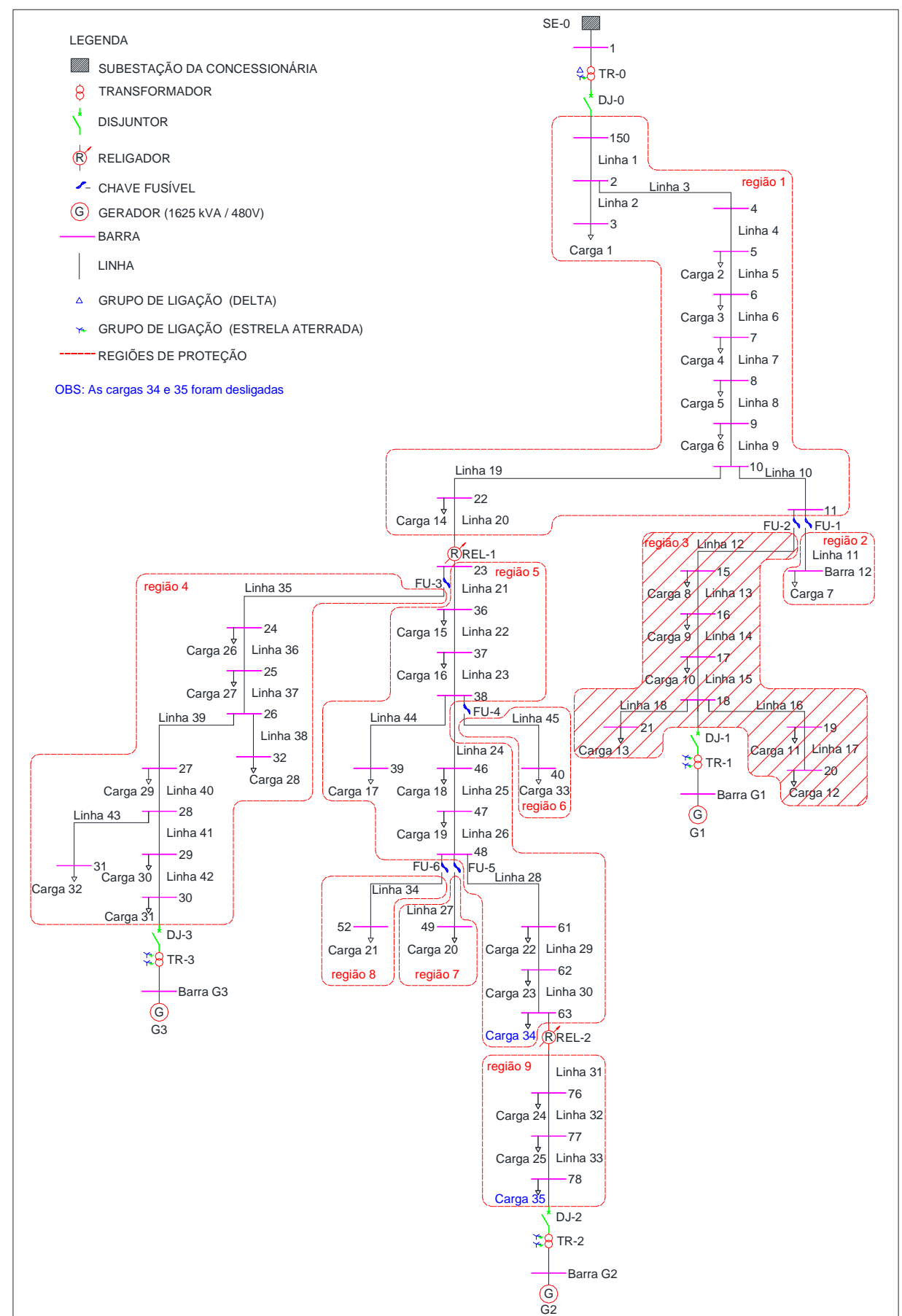

Figura 5.13 - Topologia do sistema ilhado resultante de uma falta trifásica na linha 12 (a área hachurada correspondente à região desenergizada). 


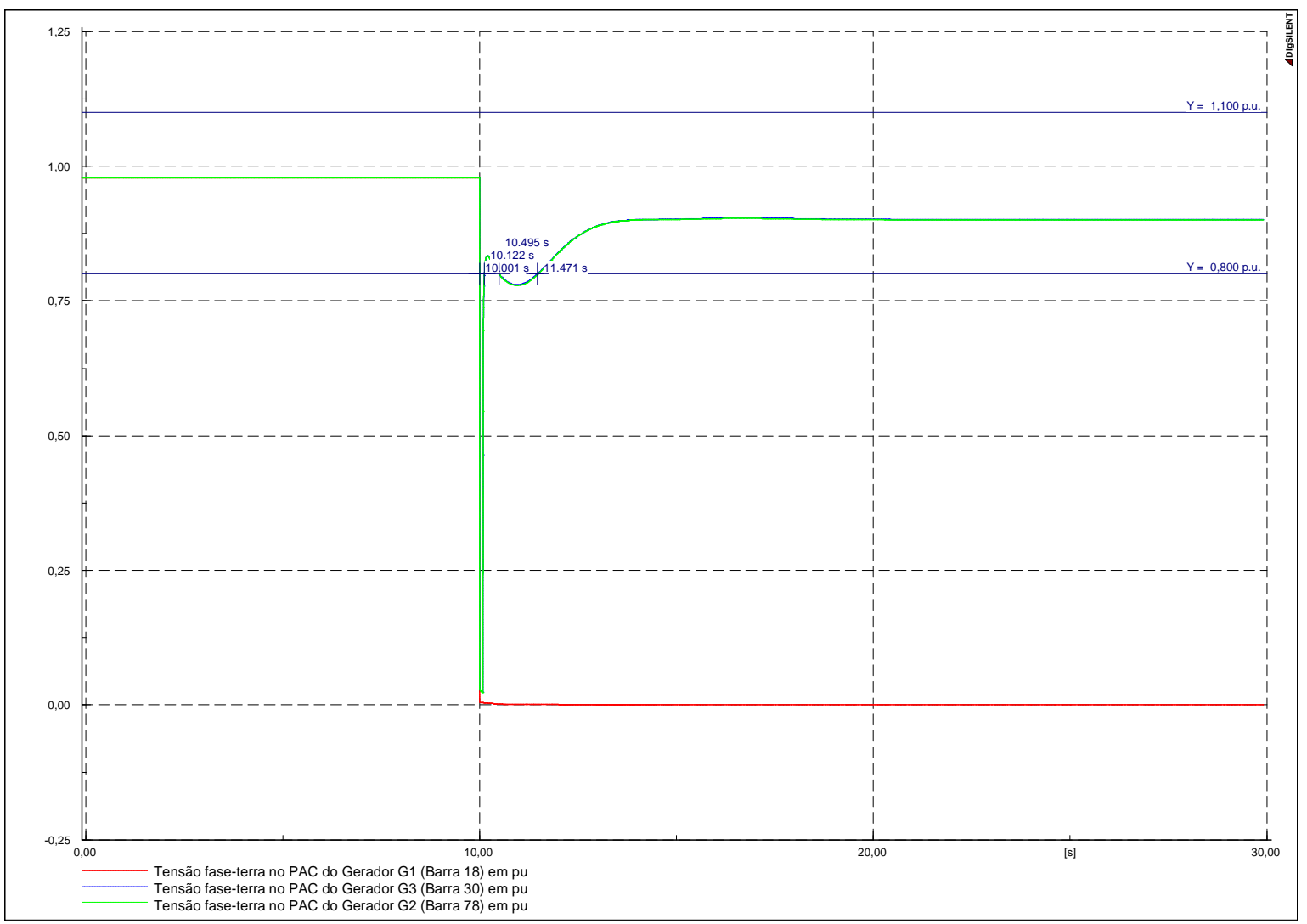

Figura 5.14 - Análise da região 3 - falta trifásica (tensão nos PACs versus tempo).

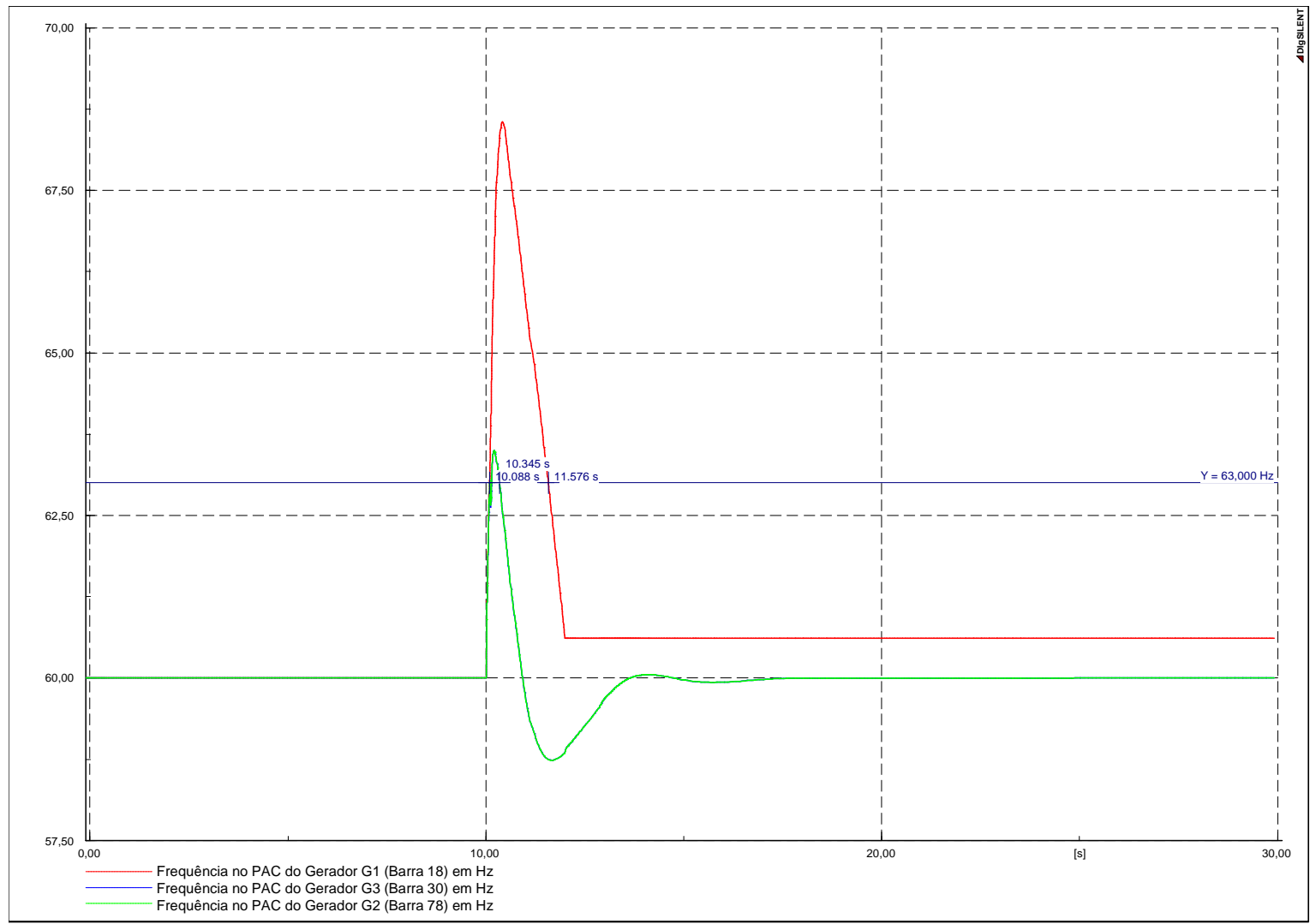

Figura 5.15 - Análise da região 3 - falta trifásica (frequência nos PACs versus tempo). 


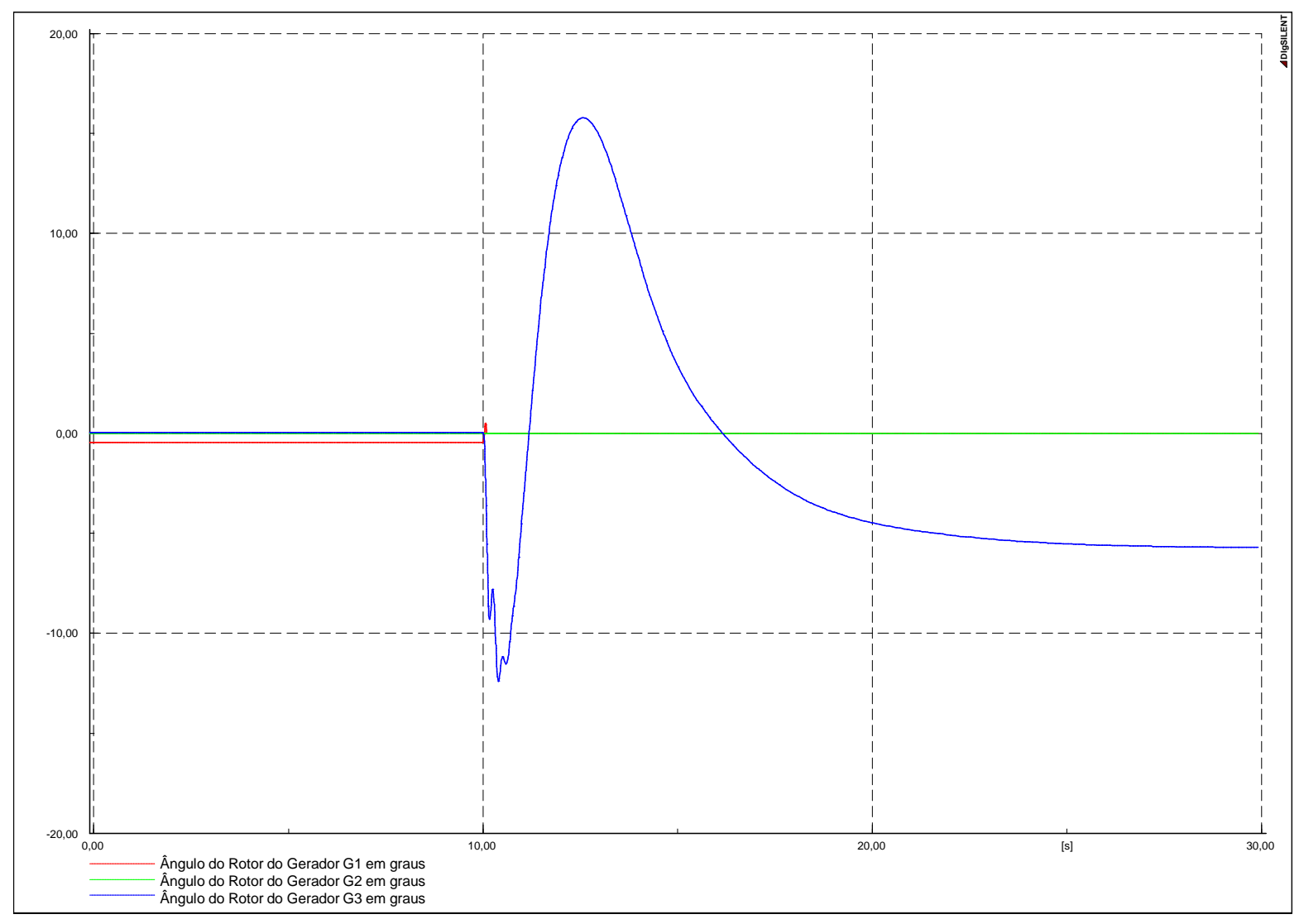

Figura 5.16 - Análise da região 3 - falta trifásica (ângulo do rotor dos geradores versus tempo).

\subsubsection{Curto-circuito fase-terra na barra 21}

Após a ocorrência do curto-circuito fase-terra na fase $A$ da barra 21, o religador REL-1 abre as três fases antes da atuação do fusível FU-2, conforme mostrado no estudo de coordenação e seletividade. Os geradores G2 e G3 permanecem alimentando a ilha formada pelas regiões de proteção 4, 5, 6, 7, 8 e 9. A tensão e a frequência do gerador $\mathrm{G} 1$ caem e a proteção de subtensão do disjuntor DJ-1 atua em 12,100 ms, ou seja, antes da proteção de sobrecorrente, deixando as regiões 1, 2 e 3 desenergizadas, conforme indicado na Figura 5.17. O comportamento descrito acima é ilustrado nas Figuras 5.18 e 5.19 . Na Figura 5.18, a linha que mostra o comportamento da tensão do gerador G2 é exatamente igual à linha que descreve o comportamento da tensão do gerador G3, por este motivo ela se sobrepõe à do gerador G3.

Como os ângulos dos rotores das máquinas mantêm-se sempre dentro dos limites aceitáveis, optou-se por não mais ilustrar essas situações em gráficos, sempre que eles ocorrerem.

Na Figura 5.19, o comportamento da frequência do gerador G2 também é igual ao do gerador G3, por isso a linha que representa o comportamento da frequência do gerador G2 sobrepõe a linha do gerador G3. 
Como não há tensão na barra 18, PAC do gerador G1, após a abertura do disjuntor DJ-1, o programa registra o último valor de frequência obtido antes da abertura do disjuntor DJ-1 e o mantém até o final da simulação, por este motivo, na Figura 5.19, a frequência do gerador G1 é estabilizada imediatamente. Esta situação irá ocorrer sempre que não houver tensão na barra em que a frequência é medida.

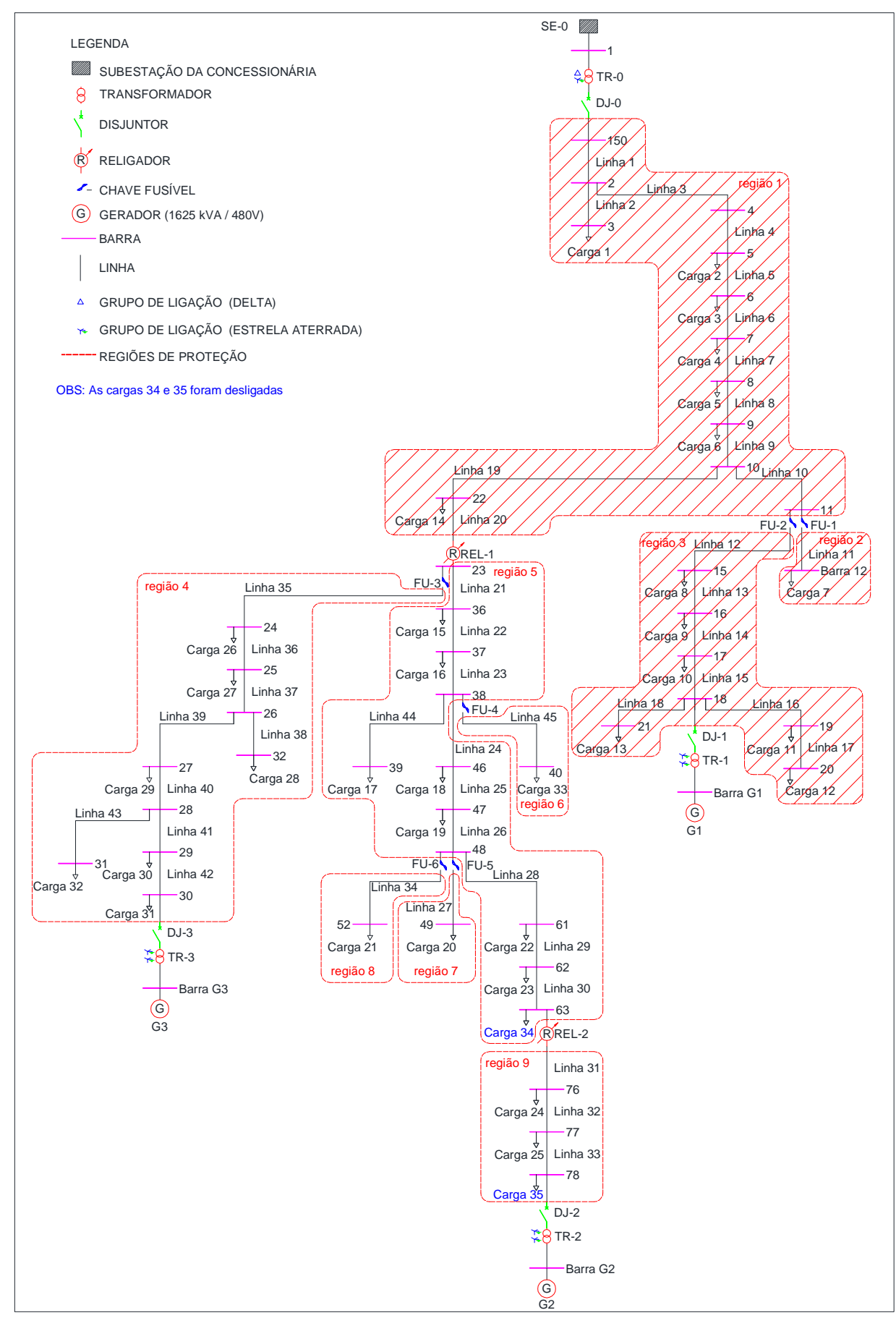

Figura 5.17 - Topologia do sistema ilhado resultante de uma falta fase-terra na barra 21 (a área hachurada correspondente à região desenergizada). 


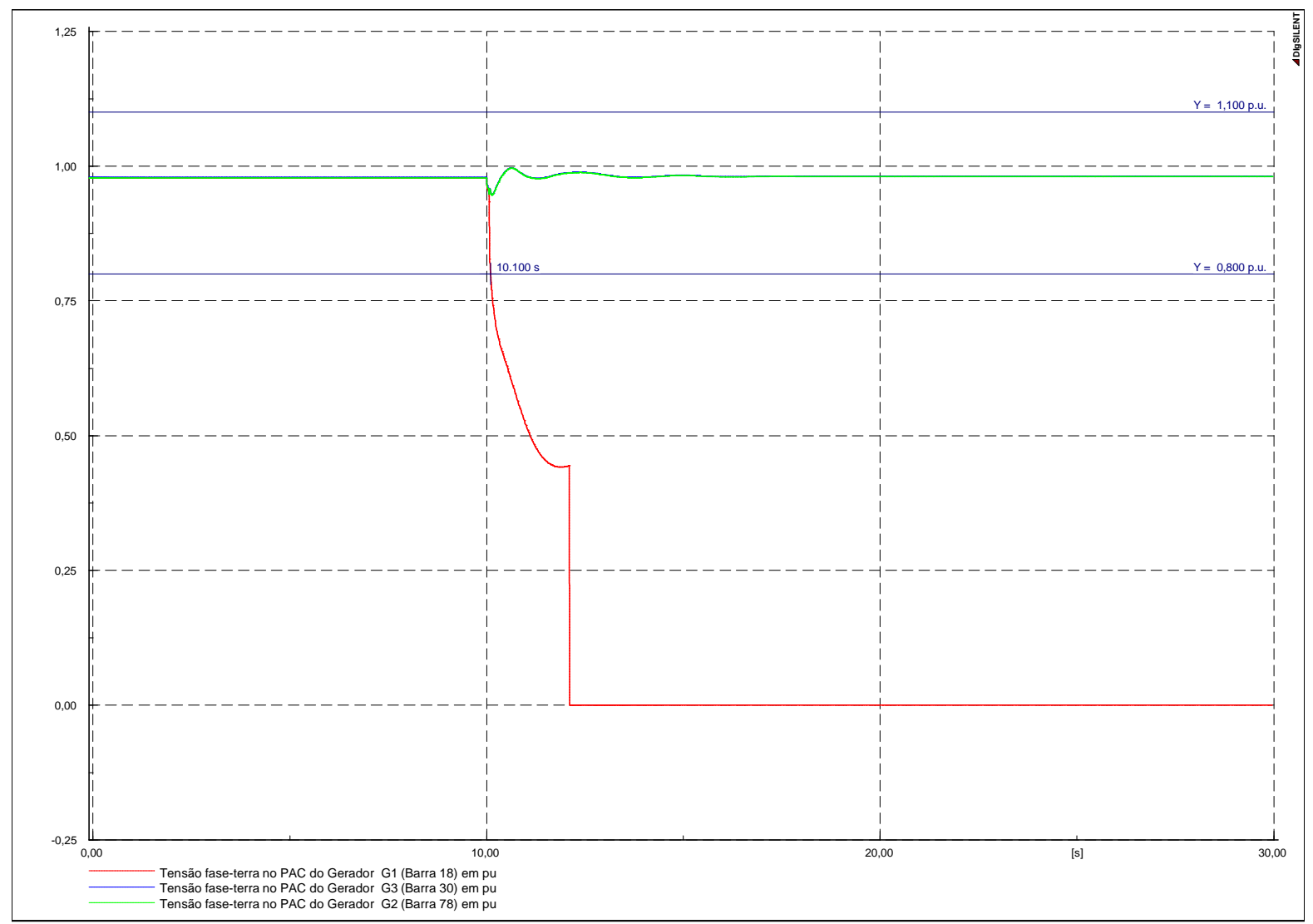

Figura 5.18 - Análise da região 3 - falta fase-terra (tensão nos PACs versus tempo).

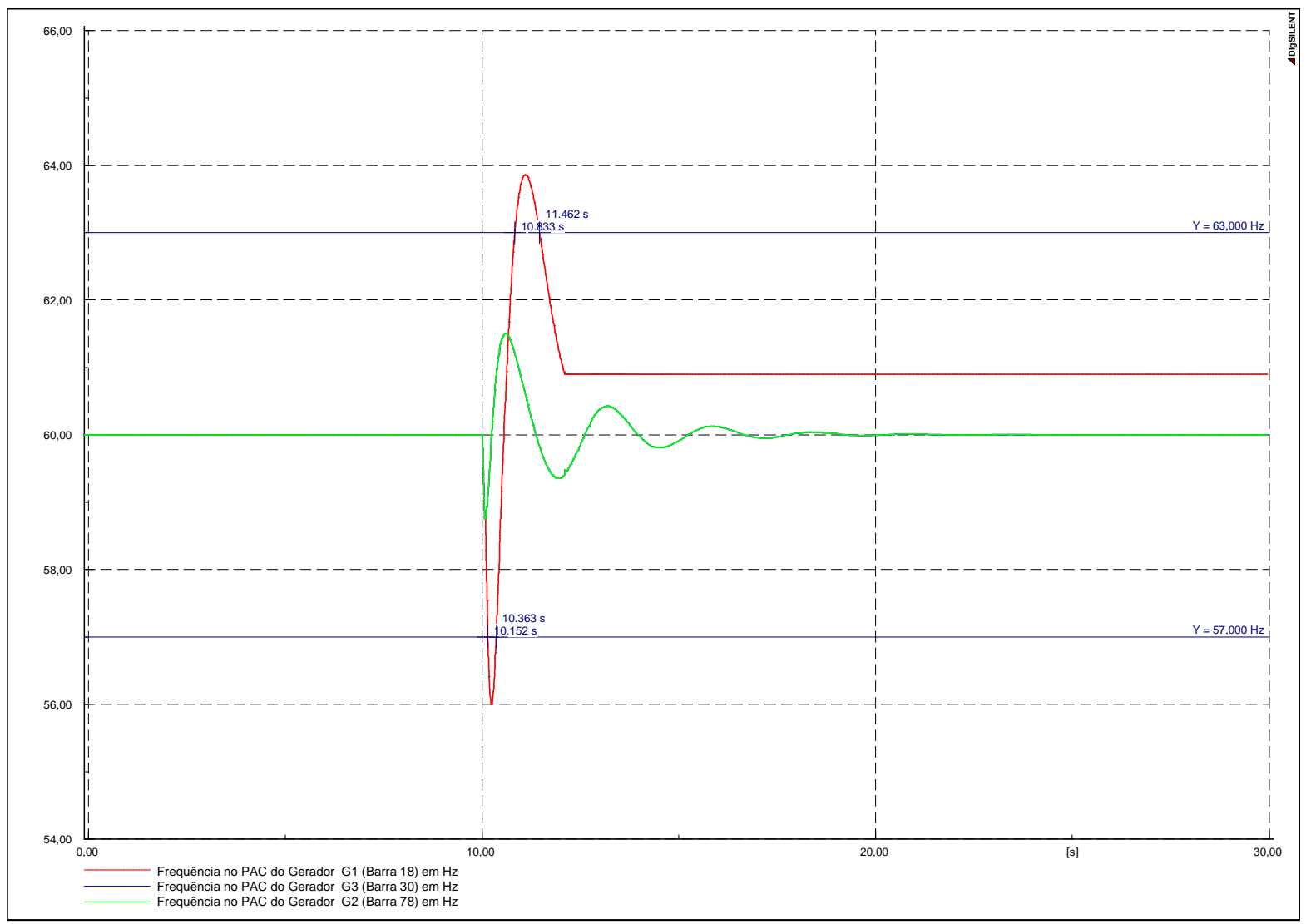

Figura 5.19 - Análise da região 3 - falta fase-terra (frequência nos PACs versus tempo). 


\subsection{Análise de Estabilidade Transitória da Região 4}

Os elementos de proteção envolvidos na falta da região 4 são o fusível FU-3, o relé do disjuntor DJ-3 e os religadores REL-1 e REL-2, sendo o fusível FU-3 e o relé do disjuntor DJ-3 os elementos de proteção principal, e os religadores, os elementos de proteção de retaguarda.

\subsubsection{Curto-circuito trifásico na linha 35}

O estudo de coordenação e seletividade demonstrou não ser possível garantir a coordenação entre o elemento de proteção principal e o de retaguarda. No entanto, o fusível FU-3, elemento de proteção principal, abre as três fases isolando a ilha formada pelas demais regiões, após a ocorrência do curto-circuito trifásico na linha 35. A ilha formada solicita $71,36 \%$ da capacidade do gerador G1 e 76,18\% da capacidade do gerador G2. Logo após a ocorrência da falta, os geradores apresentam uma queda de tensão, a qual é recuperada em seguida, com exceção do gerador G3. A proteção de subtensão do disjuntor DJ-3 atua antes da proteção de sobrecorrente, deixando a região 4 desenergizada, conforme observado na Figura 5.20. As Figuras 5.21 e 5.22 ilustram a ocorrência descrita. Os ângulos dos rotores das máquinas permanecem dentro dos limites aceitáveis. 


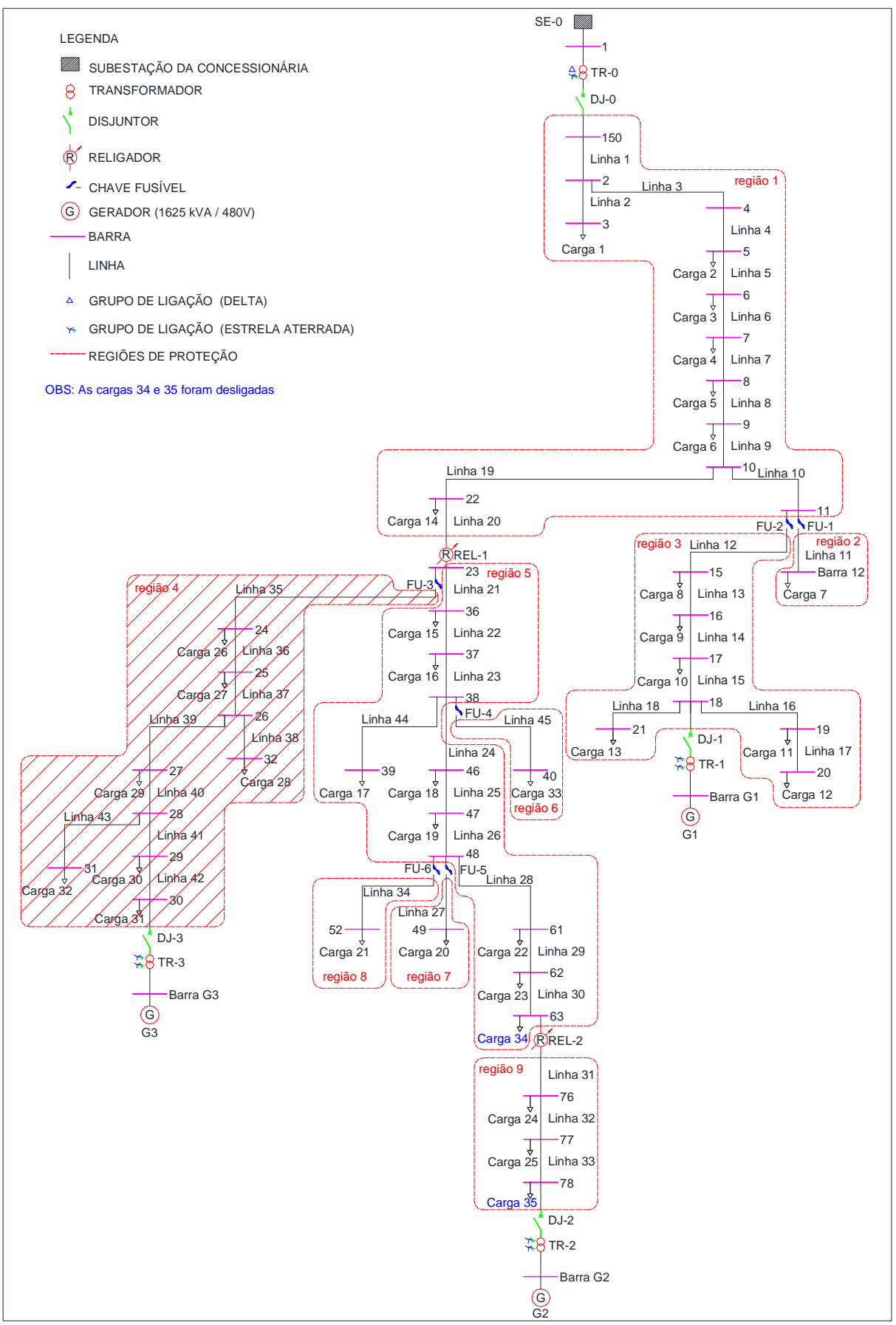

Figura 5.20 - Topologia do sistema ilhado resultante de uma falta trifásica na linha 35 (a área hachurada correspondente à região desenergizada). 


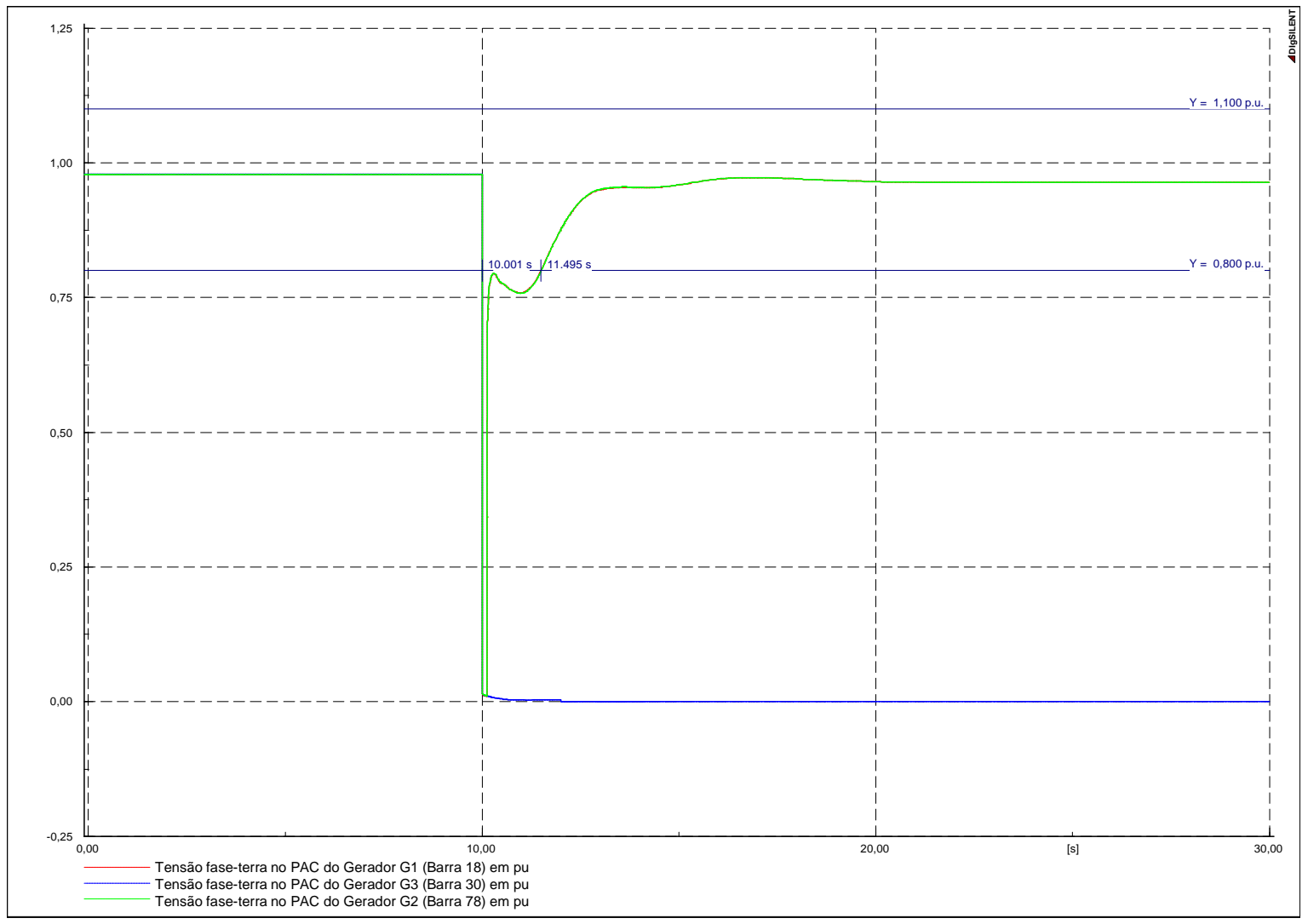

Figura 5.21 - Análise da região 4 - falta trifásica (tensão nos PACs versus tempo).

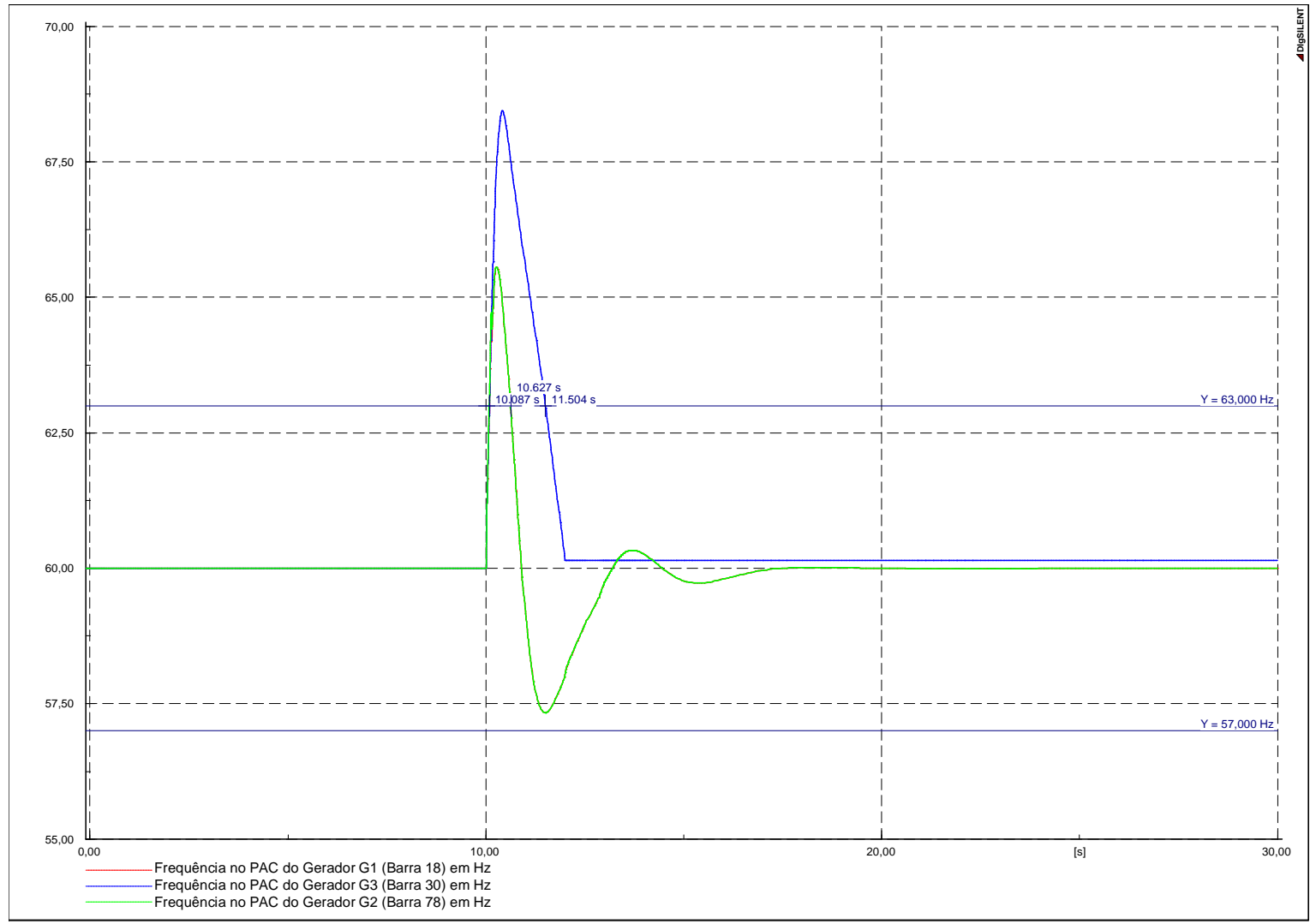

Figura 5.22 - Análise da região 4 - falta trifásica (frequência nos PACs versus tempo). 


\subsubsection{Curto-circuito fase-terra na barra 31}

$\mathrm{Na}$ ocorrência do curto-circuito fase-terra na fase $\mathrm{A}$ da barra 31, o religador REL-1 abre as três fases antes da queima do fusível 3, em concordância com o resultado obtido no estudo de curto-circuito e seletividade. A ilha formada pelas regiões 1, 2 e 3 é alimentada pelo gerador $\mathrm{G} 1$, o qual fornece $77,90 \%$ de sua capacidade para alimentar toda a região. Simultaneamente à abertura do religador REL-1, o religador REL-2 abre isolando a ilha alimentada pelo gerador G2 da ilha alimentada pelo gerador G3. A ilha alimentada pelo gerador G2 exige apenas 7,27\% da potência do gerador G2, provocando sobretensão e sobrevelocidade. A sobretensão ultrapassa o valor de 1,15 pu ocasionando a abertura do disjuntor DJ-2 pela função de sobretensão instantânea. A tensão do gerador G3 cai abaixo de 0,8 pu e não se recupera, provocando a abertura do disjuntor DJ-3 após 2 segundos, por subtensão, antes que a proteção de sobrecorrente atue. A região desenergizada é apresentada na Figura 5.23. As Figuras 5.24 e 5.25 ilustram o comportamento descrito acima. Os ângulos dos rotores das máquinas permanecem dentro dos limites aceitáveis.

Como não há tensão nas barras 30 e 78, PACs dos geradores G3 e G2, após a abertura dos disjuntores DJ-2 e DJ-3, o programa registra os últimos valores de frequência obtidos antes da abertura desses disjuntores e os mantém até o final da simulação, por este motivo, na Figura 5.25, a frequência dos geradores G2 e G3 é estabilizada imediatamente. 


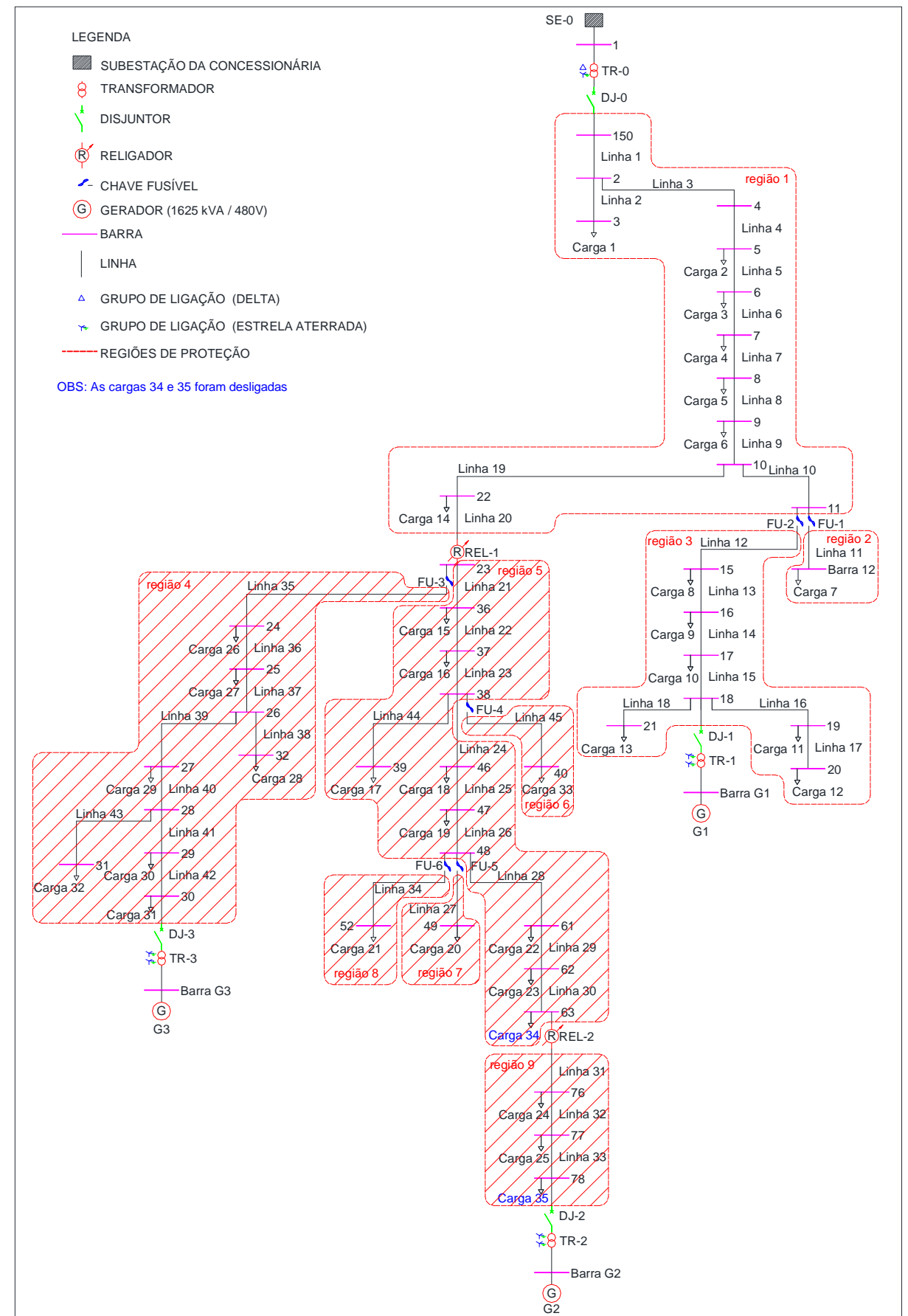

Figura 5.23 - Topologia do sistema ilhado resultante de uma falta fase-terra na barra 31 (a área hachurada correspondente à região desenergizada). 


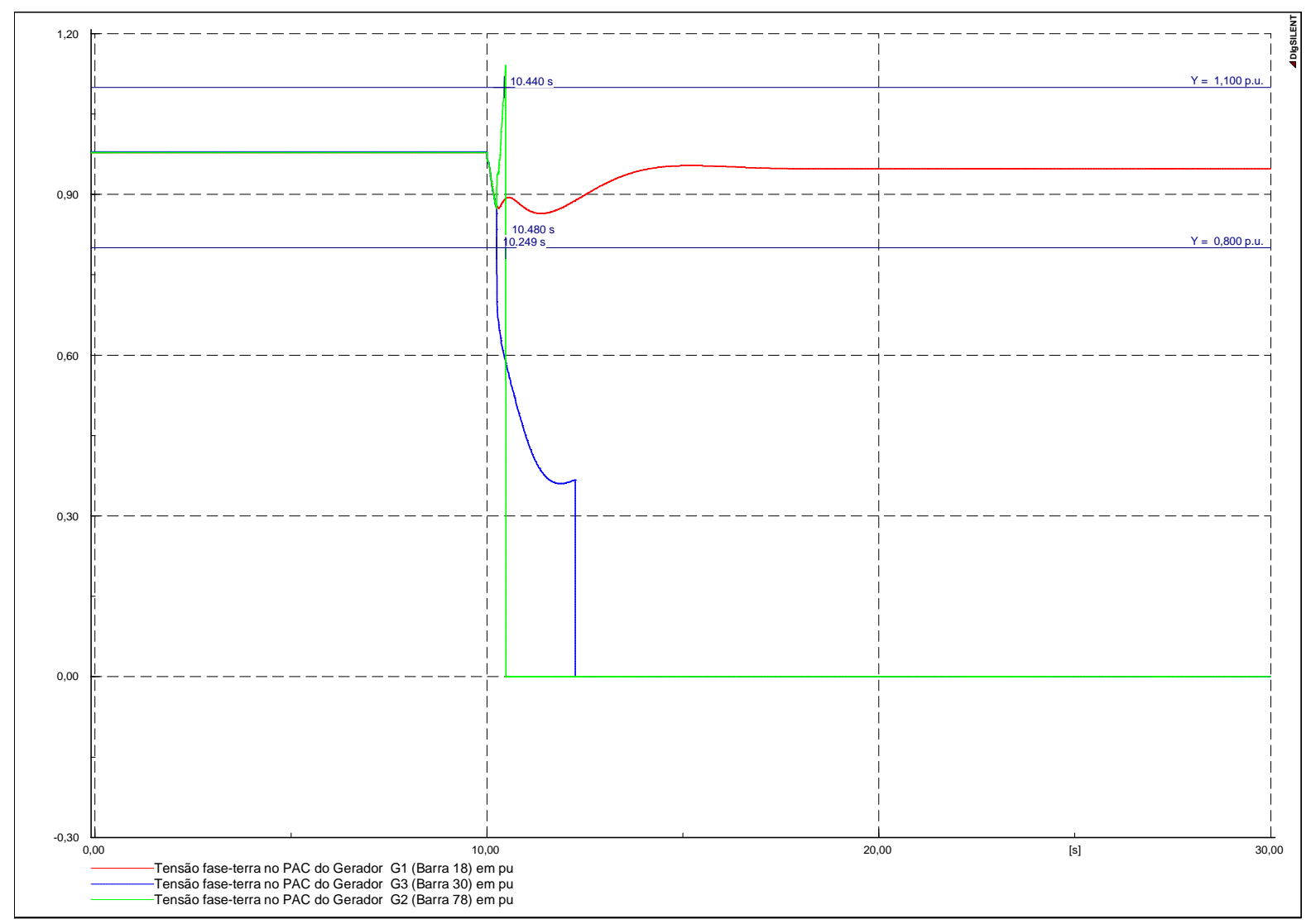

Figura 5.24 - Análise da região 4 - falta fase-terra (tensão nos PACs versus tempo).

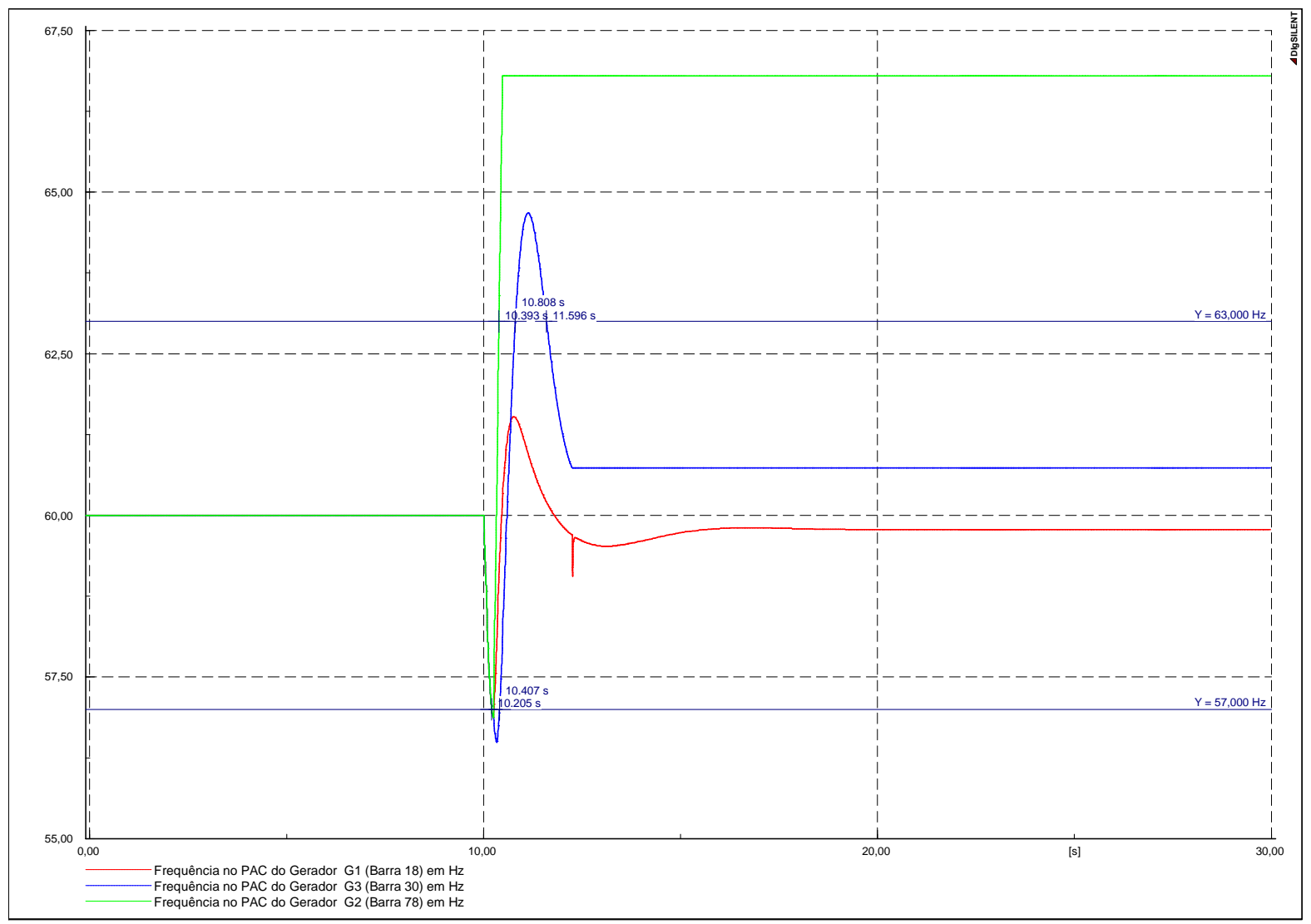

Figura 5.25 - Análise da região 4 - falta fase-terra (frequência nos PACs versus tempo). 


\subsection{Análise de Estabilidade Transitória da Região 5}

O comportamento dinâmico dos geradores G1, G2 e G3 é bastante similar nos dois casos de falta trifásica simulados, na barra 23 e na barra 63, por este motivo serão comentados em uma única seção.

Os elementos de proteção principal envolvidos na falta são os religadores REL-1 e REL-2 e o fusível FU-3, ao passo que os elementos de proteção de retaguarda são o fusível FU-2, o relé do disjuntor DJ-3 e o relé do disjuntor DJ-2.

\subsubsection{Curto-circuito trifásico simulado separadamente na barra 23 e na barra 63}

Após a ocorrência da falta há um afundamento de tensão das três máquinas. Nessa situação, os elementos de proteção REL-1, FU-3 e REL-2 enxergam somente a contribuição de cada máquina para a corrente de curto-circuito, de tal sorte que esses elementos não são sensibilizados em tempo hábil para que os geradores recuperem a tensão. Sendo assim, os relés dos disjuntores DJ-1, DJ-2 e DJ-3 atuam por subtensão desligando todo o sistema, conforme mostrado na Figura 5.26. Nesta situação todo o sistema entra em colapso, conforme indicado na Figura 5.27. Esta situação não é possível de ser identificada no estudo de coordenação e seletividade, pois segundo o estudo, as regiões 4 e 9 deveriam permanecer energizadas, pois o fusível FU-3 abriria antes do disjuntor DJ-3 e o religador REL-2 abriria antes dos disjuntor DJ-2 pelas funções de sobrecorrente.

As proteções de tensão e frequência, por não terem sido consideradas nas análises do estudo de coordenação e seletividade, mas por fazerem parte da análise do estudo dinâmico, novamente alteraram as conclusões obtidas do estudo estático. 


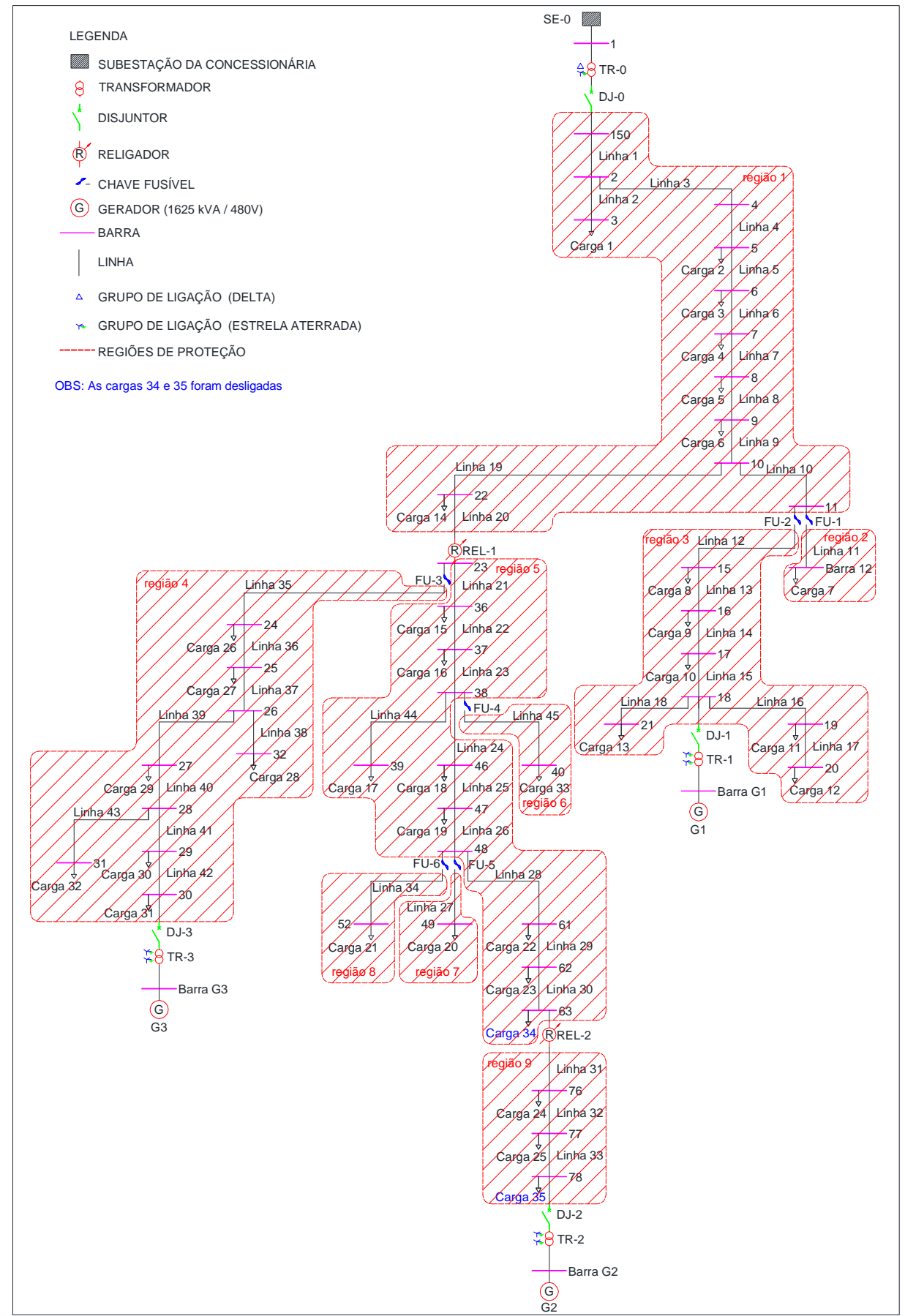

Figura 5.26 - Topologia do sistema ilhado resultante de uma falta trifásica nas barras 23 e 63 (a área hachurada correspondente à região desenergizada). 


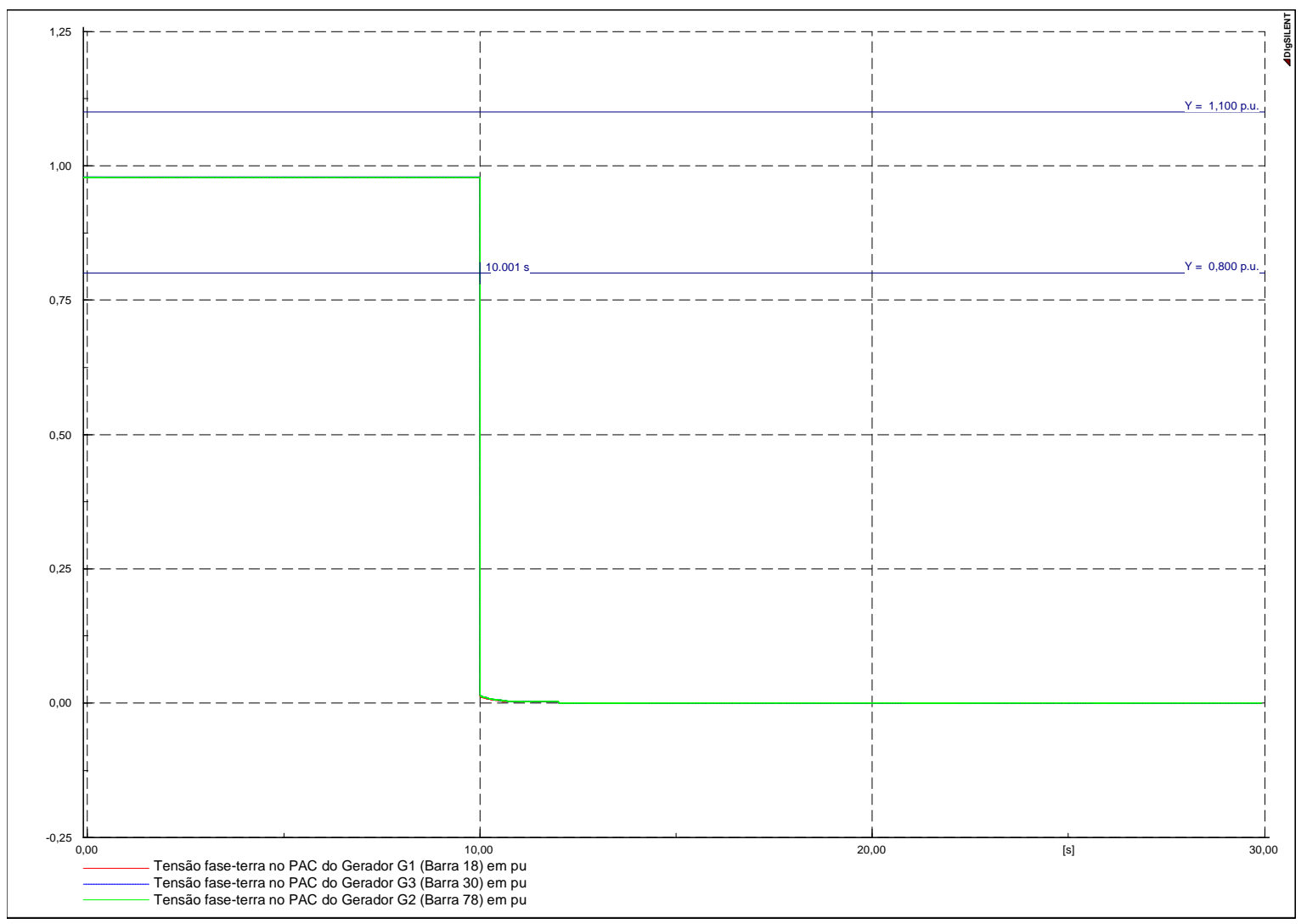

Figura 5.27 - Análise da região 5 - falta trifásica (tensão nos PACs versus tempo).

\subsubsection{Curto-circuito fase-terra na barra 39}

No curto-circuito fase-terra na barra 39, o religador REL-1 abre após 234 ms e o gerador G1 passa a alimentar a ilha formada pelas regiões 1, 2 e 3. Neste momento o religador REL-2 também abre, provocando aceleração e sobretensão do gerador G2, devido a pouca carga (120 kVA) no restante nesta ilha. Assim, o disjuntor DJ-2 abre instantaneamente por sobretensão, a qual ultrapassa 1,15 pu desenergizando a região 9. Caso o disjuntor DJ-2 não abrisse por sobretensão, certamente abriria por sobrefrequência.

A tensão do gerador G3 cai abaixo de 0,8 pu e não se recupera dentro do limite de 2 segundos, ajustado no relé, provocando a abertura do disjuntor DJ-3 por subtensão. $O$ estudo de coordenação e seletividade aponta a abertura do relé do disjuntor DJ-3 por sobrecorrente antes da abertura do fusível FU-3. No entanto, o estudo dinâmico mostrou que o motivo da abertura é a subtensão. Os ângulos dos rotores das máquinas permanecem dentro dos limites aceitáveis. A região desenergizada está ilustrada na Figura 5.28. As Figuras 5.29 e 5.30 ilustram o comportamento acima descrito.

A frequência do gerador G1 estabiliza em um valor menor que $60 \mathrm{~Hz}$, porque esse gerador está em modo droop. Também neste caso, deve-se fazer um controle suplementar para corrigir a frequência de volta a $60 \mathrm{~Hz}$. 
Como não há tensão nas barras 30 e 78, PACs dos geradores G3 e G2, após a abertura dos disjuntores DJ-2 e DJ-3, o programa registra os últimos valores de frequência obtidos antes da abertura desses disjuntores e os mantém até o final da simulação, por este motivo, na Figura 5.25, a frequência dos geradores G2 e G3 é estabilizada imediatamente.

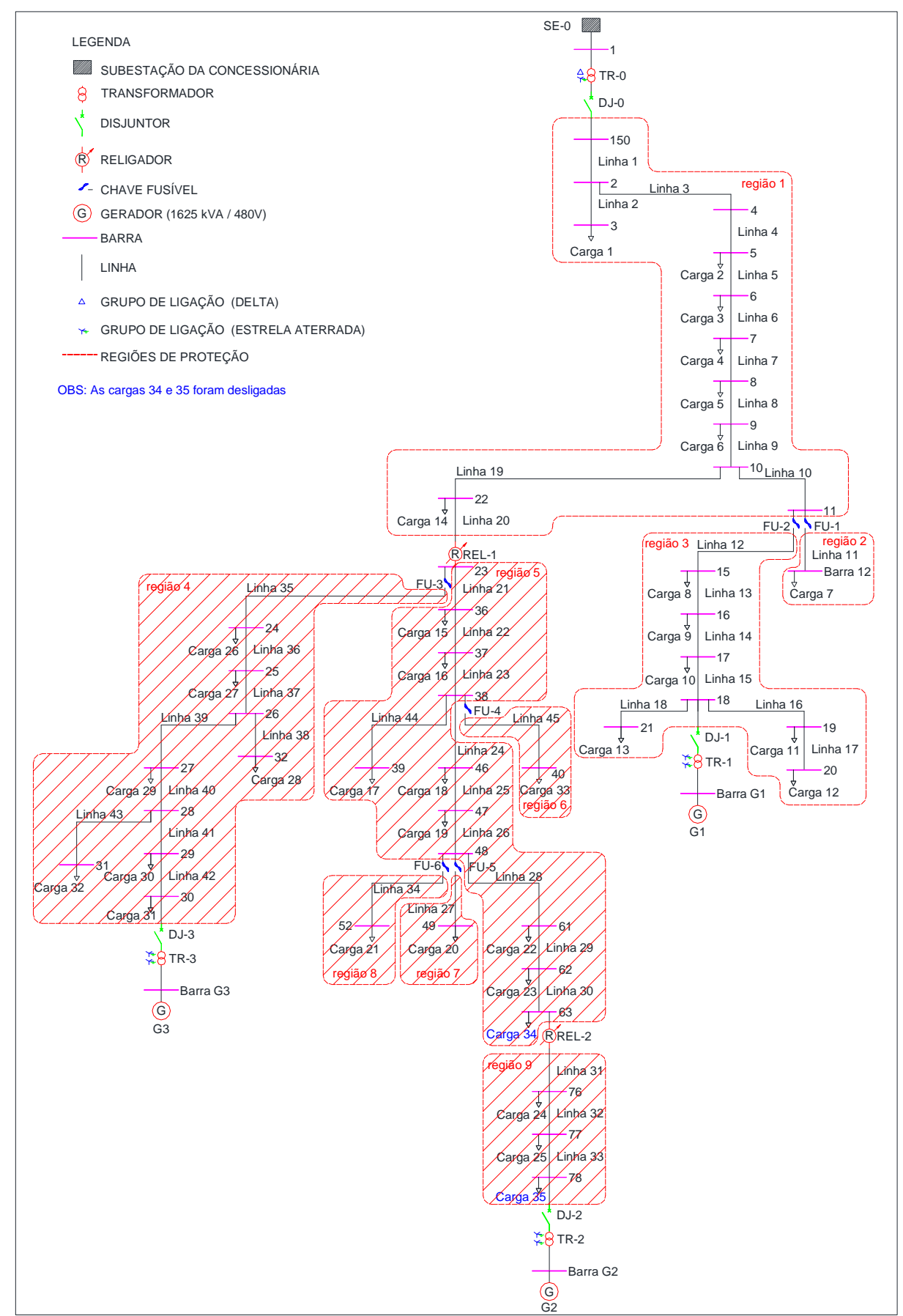

Figura 5.28 - Topologia do sistema ilhado resultante de uma falta fase-terra na barra 39 (a área hachurada correspondente à região desenergizada). 


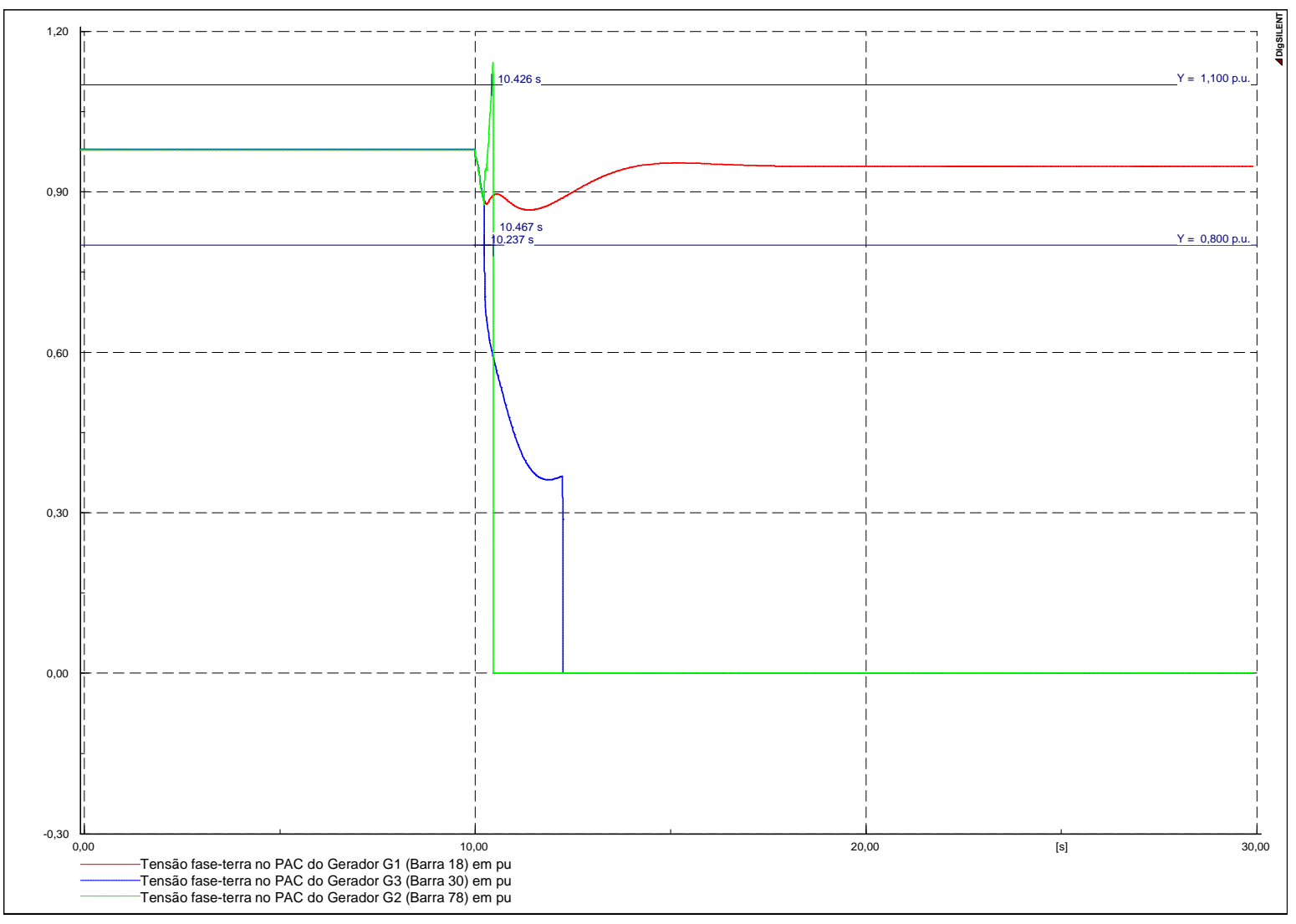

Figura 5.29 - Análise da região 5 - falta fase-terra (tensão nos PACs versus tempo).

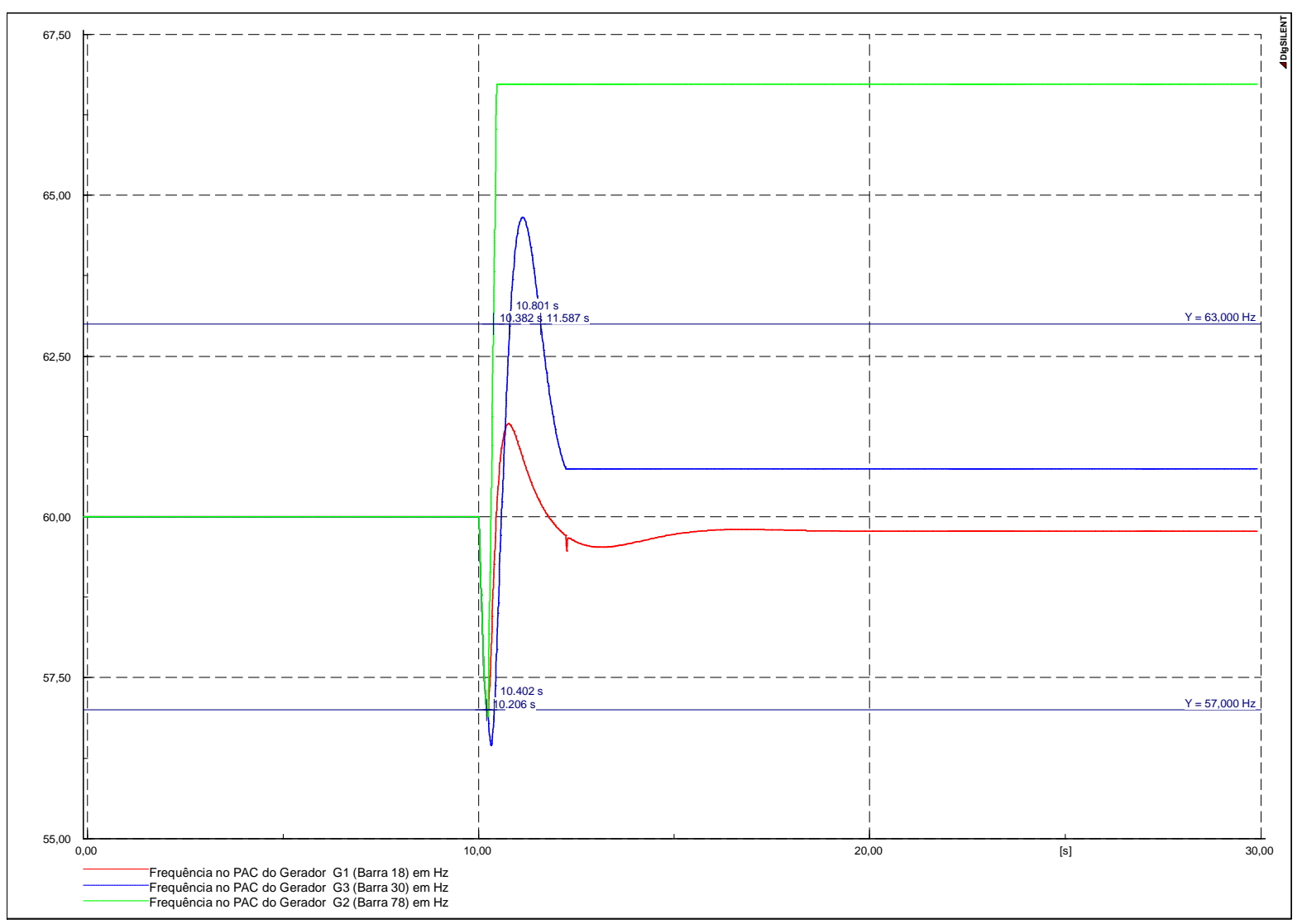

Figura 5.30 - Análise da região 5 - falta fase-terra (frequência nos PACs versus tempo). 


\subsection{Análise de Estabilidade Transitória da Região 9}

O gerador G2 apresenta o mesmo comportamento, tanto para a falta trifásica simulada na linha 31 , quanto para a falta fase-terra simulada na barra 78 , pois sempre que há a abertura do religador REL-2 ocorrem aceleração e grande variação de tensão do gerador G2, provocando a abertura do disjuntor DJ-2.

Na região 9, os elementos de proteção principal envolvidos na falta são o religador REL-2 e o relé do disjuntor DJ-2, enquanto os elementos de proteção de retaguarda são o fusível FU-3 e o religador REL-1. Embora o estudo de coordenação e seletividade não aponte a existência de coordenação entre o religador REL-2 e o religador REL-1 para a falta trifásica na linha 31 e fase-terra na barra 78, pois a margem de coordenação é estreita, 75 ms e 163 ms, respectivamente, o religador REL-2 abre antes. No entanto, a ilha formada pelas demais regiões permanece alimentada pelos geradores G1 e G3 apenas por um curto período de tempo, até que os disjuntores instalados no PAC atuem por subtensão. Nesta situação todo o sistema de distribuição é desenergizado, conforme ilustrada na Figura 5.31. Esse comportamento não era previsto no estudo de coordenação e seletividade.

As Figuras 5.32 e 5.33 apresentam a situação acima citada. Na Figura 5.32, a linha que representa o comportamento de tensão do gerador G3 se sobrepõe à linha que representa o comportamento de tensão do gerador G1. A mesma situação ocorre na Figura 5.33, em que a linha que representa o comportamento de frequência do gerador G3 se sobrepõe à do gerador G1.

Conforme mencionado anteriormente, como não há tensão nas barras dos PACs dos geradores G1, G2 e G3, após a abertura dos disjuntores DJ-1, DJ-2 e DJ-3, o programa registra os últimos valores de frequência obtidos antes da abertura desses disjuntores e os mantém até o final da simulação, por este motivo, na Figura 5.33, a frequência dos geradores G1, G2 e G3 é estabilizada imediatamente. 


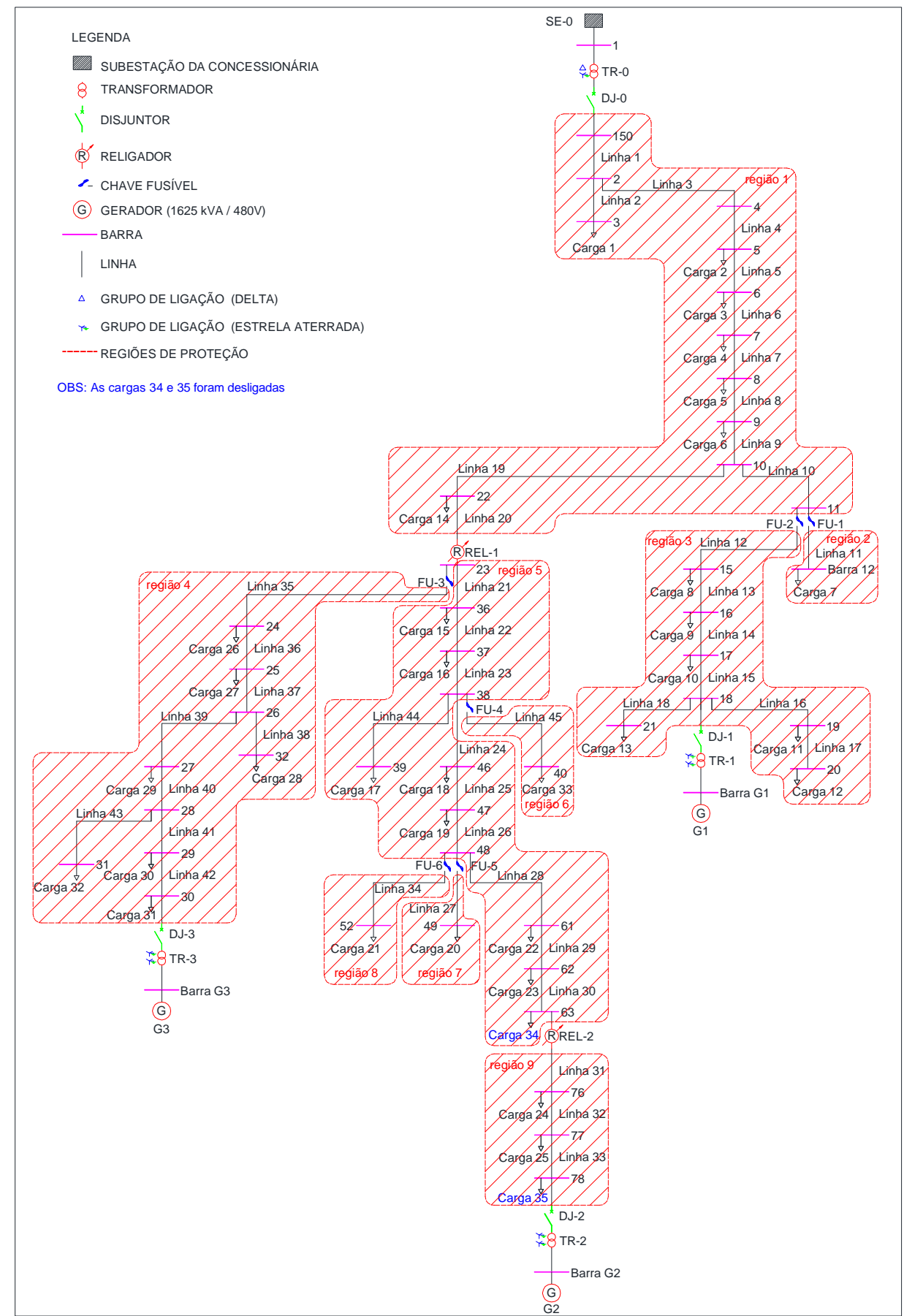

Figura 5.31- Topologia do sistema ilhado resultante de uma falta trifásica na linha 31 ou de falta faseterra na barra 78

(a área hachurada correspondente à região desenergizada). 


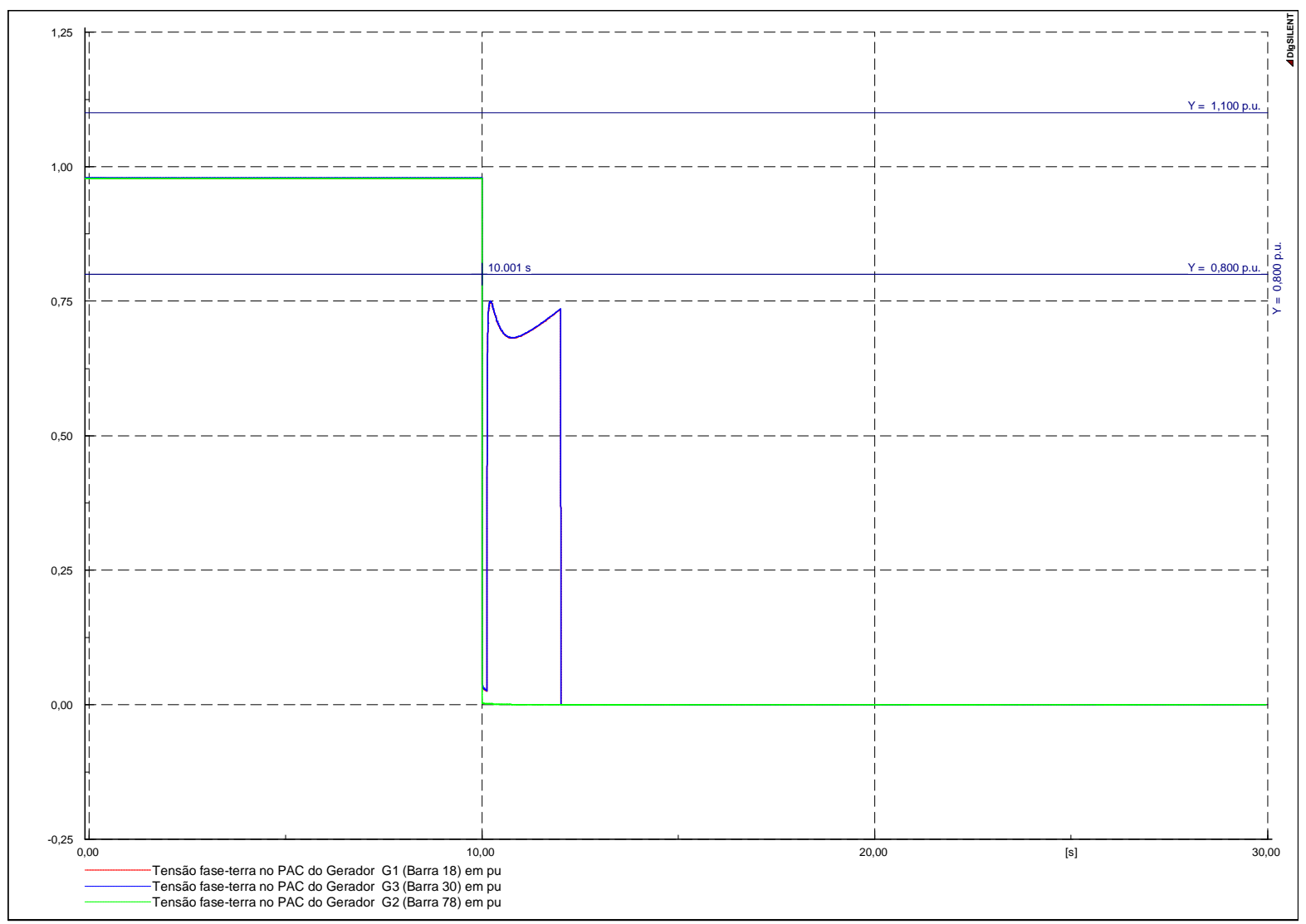

Figura 5.32 - Análise da região 9 - (tensão nos PACs versus tempo).

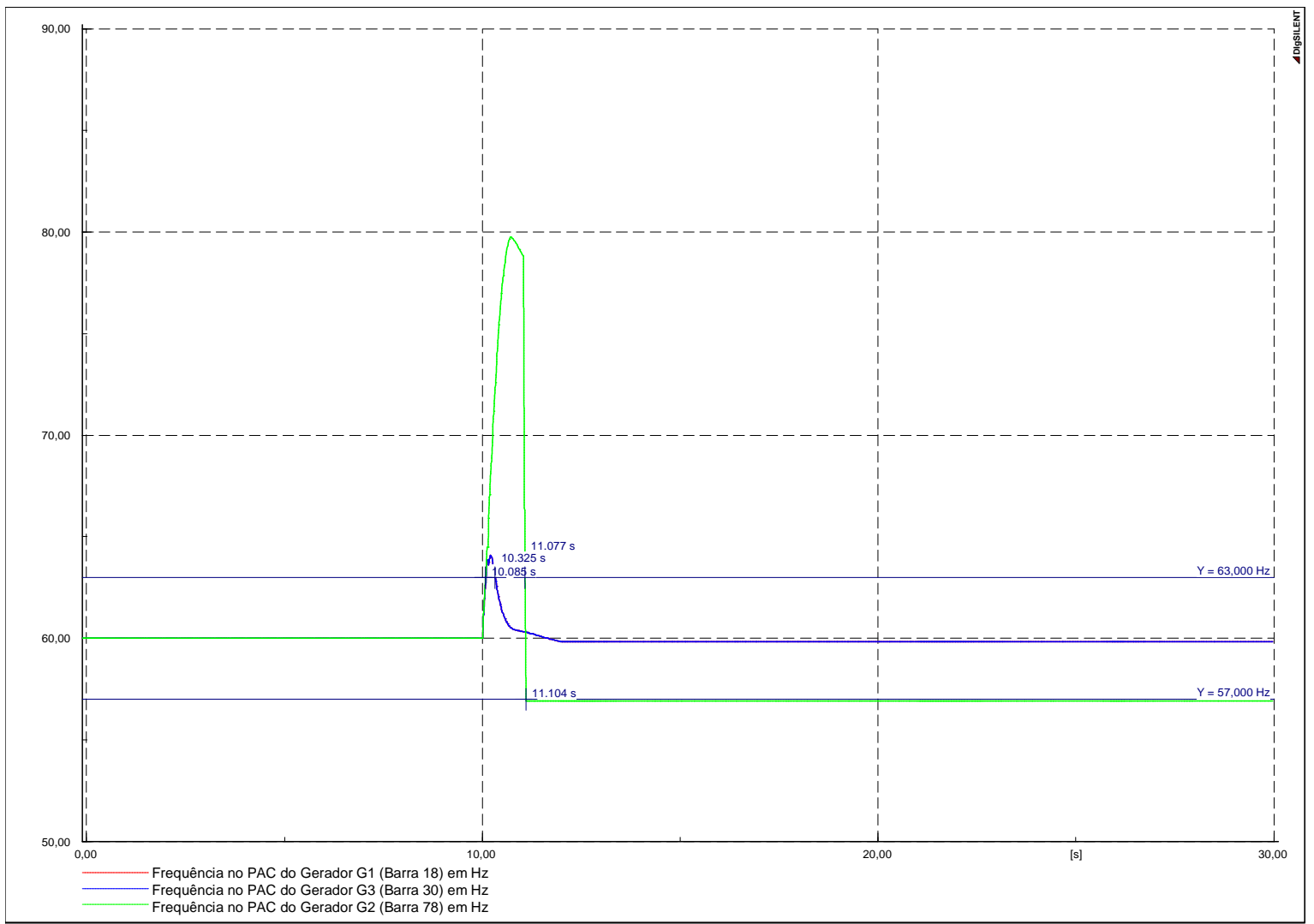

Figura 5.33 - Análise da região 9 - (frequência nos PACs versus tempo). 


\subsection{Fluxograma de Análise}

De modo geral, a Figura 5.34 apresenta o fluxograma das ações tomadas na análise do impacto da GD sobre o sistema de proteção de sobrecorrente da rede de distribuição operando em ilhamento intencional. Ela reúne os procedimentos adotados para minimizar o impacto da GD sobre o sistema de proteção de sobrecorrente e poderá ser utilizada para análise de outros sistemas de distribuição.

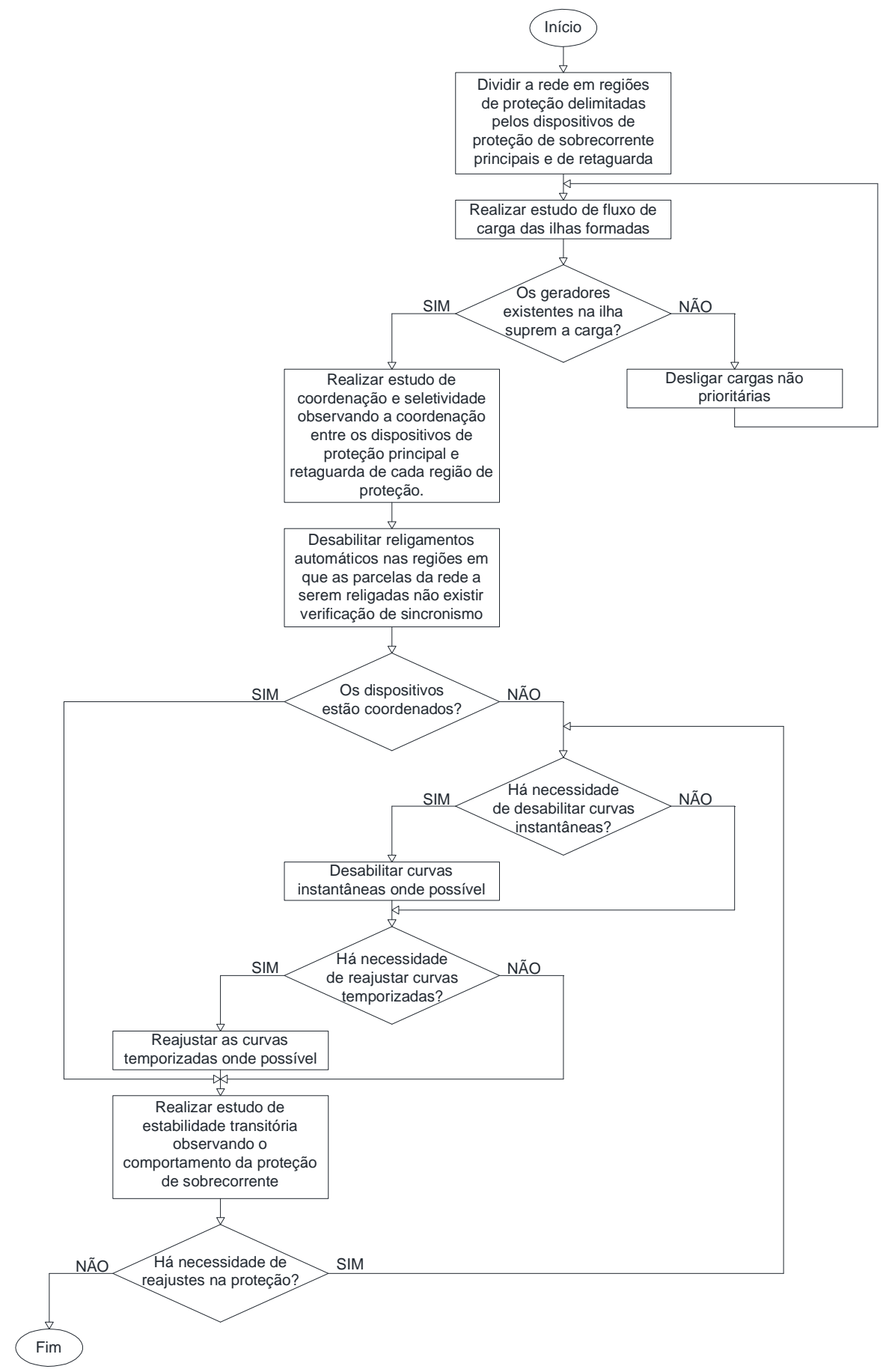

Figura 5.34 - Fluxograma de ações. 


\subsection{Considerações Finais Sobre o Capítulo}

Através da análise de estabilidade transitória das regiões de proteção, observa-se que nas regiões terminais em que os fusíveis são o elemento de proteção principal, a saber, região 2, 6, 7 e 8, a falta sempre é eliminada em tempo hábil para que os geradores recuperem a tensão e a frequência, mantendo as demais regiões energizadas. Isso ocorre nas simulações porque, embora a margem de coordenação seja pequena, os fusíveis ainda atuam antes que os demais dispositivos de proteção.

Quando a carga da ilha formada é baixa em relação à capacidade do gerador, como na região 9, provocada pela abertura do religador REL-2, há sempre uma aceleração da máquina e grande variação de tensão. Esse problema poderia ser solucionado através do remanejamento do religador REL-2, buscando maior equilíbrio entre a carga solicitada pela ilha e a capacidade de geração da mesma.

A região 5 é muito crítica do ponto de vista da estabilidade do sistema, pois a falta trifásica nesta região pode provocar a perda total da geração. Isto ocorre porque cada elemento de proteção principal desta região enxerga a contribuição isolada de cada máquina para a corrente de falta, ou seja, o religador REL-1 enxerga somente a contribuição do gerador G1, o fusível FU-3, somente a contribuição do gerador G3 e o REL-2 somente a do gerador G2. Isso não ocorre para a falta fase-terra, pois o religador REL-1 abre permitindo que o gerador G1 alimente as regiões 1, 2 e 3. Uma solução para essa situação poderia ser a utilização da proteção de sobrecorrente com controle ou restrição de tensão (função ANSI 51/27C ou 51/27R) instalada nos religadores, que permitiriam ajustes menores de corrente, atrelados a valores de tensão medidas no momento da ocorrência da falta.

Outra situação crítica encontrada foi para faltas na região 9, pois a abertura do religador REL-2 permite a formação de uma ilha com carga muito grande para ser sustentada pelos geradores G1 e G3 que têm suas proteções de subtensão sensibilizadas, provocando a desenergização total da rede de distribuição. Para solucionar esse problema seria necessário um desligamento seletivo de cargas, permitindo a recuperação da tensão dos geradores G1 e G3, ou relocação do religador REL-2, conforme mencionado anteriormente.

Em diversos casos, os relés dos disjuntores instalados no PAC atuaram primeiro pelas funções de proteção de tensão e frequência, evidenciando a importância da existência deste tipo de proteção nesses locais, conforme recomenda a maioria dos guias das concessionárias de distribuição de energia.

Como o objetivo deste estudo é avaliar o impacto da geração distribuída sobre o sistema de proteção de sobrecorrente utilizando os dispositivos já instalados na rede de distribuição, a troca de fusíveis não foi considerada. No entanto, esta situação também pode 
ser ponderada utilizando o mesmo princípio de divisão da rede de distribuição em regiões de proteção para o redimensionamento dos fusíveis, avaliando previamente a viabilidade de tal ação, em função da quantidade e localização dos fusíveis existente na rede e do tempo de duração do funcionamento da rede na condição ilhada. 


\section{CONCLUSÃO}

Este trabalho propôs um conjunto de procedimentos para analisar o impacto da GD sobre o sistema de proteção da rede de distribuição operando em ilhamento intencional. $A$ principal contribuição foi a análise do problema por meio da subdivisão do sistema de distribuição em regiões delimitadas pelos dispositivos de proteção, principais e de retaguarda, buscando solucionar o problema da perda de coordenação, utilizando apenas os recursos já existentes na rede de distribuição.

Conforme apresentado anteriormente, a maioria dos trabalhos de outros autores tem buscando uma solução definitiva para o problema da perda de coordenação durante a operação ilhada, baseada na utilização de relés direcionais inteligentes providos de sistema de comunicação e função adaptativa. Entretanto, de forma geral, parece que tais soluções só poderão ser consolidadas quando a infraestrutura das redes inteligentes (smart grids) estiver incorporada aos sistemas de distribuição de energia.

A abordagem apresentada procura oferecer uma solução imediata, capaz de permitir a operação ilhada intencional, utilizando apenas os elementos de proteção já instalados na rede de distribuição, sem acarretar custos elevados de implantação às concessionárias de distribuição de energia. Além disso, o conjunto de procedimentos proposto pode ser bastante útil para elaboração de um plano de contingências, em que as concessionárias pretendam operar em ilha para manter energizadas regiões prioritárias onde existam geradores distribuídos instalados.

Os procedimentos adotados neste trabalho poderão ser testados em outros sistemas de distribuição operando em ilha, uma vez que o atraso nos tempos de atuação das proteções localizadas nas extremidades do sistema, ou seja, nos PACs, permite que os elementos de proteção instalados em outros ramais consigam tempo suficiente para sua atuação.

É importante ressaltar que a operação ilhada intencional, por si só, pode ser tratada como um benefício para o sistema que perdeu a conexão com a subestação. Portanto, o esquema de proteção apresentado permitiu garantir alguma coordenação e seletividade, onde antes eram inexistentes.

A inibição do religamento automático e das curvas instantâneas dos religadores e dos relés dos disjuntores instalados no PAC, além da utilização de um segundo grupo de ajustes das curvas temporizadas desses dispositivos, garantiu segurança na operação e demonstrou melhorar a coordenação e seletividade das regiões de proteção. Embora não seja possível a garantia da coordenação quando o local da falta se aproxima do elemento de proteção principal em várias regiões de proteção, o sistema apresentou maior confiabilidade 
no modo ilhado de operação, em consequência da restrição dos efeitos de uma falha ao menor trecho possível do circuito.

O segundo grupo de ajustes da proteção poderá ser acionado manualmente ou automaticamente, caso exista comunicação entre o relé do disjuntor DJ-0 e os relés instalados no PAC e religadores.

A análise de estabilidade transitória fornece uma visão mais abrangente do comportamento do sistema de proteção de sobrecorrente, pois como puderam ser observados, os resultados obtidos no estudo de coordenação e seletividade, em várias situações, divergiram daqueles obtidos na análise de estabilidade transitória. O estudo de estabilidade transitória permite ainda a possibilidade de realizar reajustes do sistema de controle de tensão e velocidade das unidades geradoras em função do tempo de resposta dos dispositivos de proteção.

Outro fator importante, possível de ser observado apenas através desse estudo, corresponde ao modelamento da carga, pois quando ocorre o curto-circuito a tensão tende a cair e para cargas modeladas como impedância constante, a corrente de curto-circuito será menor, afetando o tempo de atuação dos dispositivos de proteção de sobrecorrente. Além disso, como este tipo de estudo exige modelos mais detalhados dos componentes do sistema elétrico, como por exemplo, a dinâmica dos controles dos geradores, a reposta do sistema proteção mediante uma falta é mais precisa. Enfim, muitos são os desafios a serem superados para que a operação ilhada intencional ocorra de forma automática. No que se refere à proteção, por exemplo, é necessário conhecer as razões que levaram à formação da ilha, ou seja, se a ilha foi formada em decorrência de uma manutenção programada, ou devido a uma falta na rede, no caso desta última, a região em falta deverá ser isolada e a carga da região deverá ser adequada à capacidade de geração da ilha.

\subsection{Trabalhos Futuros}

Como continuidade deste trabalho, apresentam-se as seguintes propostas:

- Análise da transição desde a ocorrência da falta até a formação da ilha por meio da análise de transitórios, evitando desligar os geradores que alimentarão a ilha;

- Quantificação do impacto da proposta na melhoria dos índices DEC (Duração Equivalente de Interrupção por Unidade Consumidora) e FEC (Frequência Equivalente de Interrupção por Unidade Consumidora) da rede de distribuição;

- Análise da mesma rede de distribuição, redimensionando e substituindo os fusíveis existentes;

- Utilizando a metodologia proposta, considerar uma infraestrutura de redes inteligentes para indicar soluções mais sofisticadas para o problema. 


\section{REFERÊNCIAS BIBLIOGRÁFICAS}

ABB. Disponível em:< http://www.abb.com.br> Acesso em: 17 fev. 2013.

AGÊNCIA NACIONAL DE ENERGIA ELÉTRICA - ANEEL. Procedimentos de Distribuição de Energia Elétrica no Sistema Elétrico Nacional - PRODIST Módulo 4: Procedimentos Operativos do Sistema de Distribuição. Brasília, 2010.

BENATO, R., CALDON, R. \& CESENA, F. Application of Distribution Line Carrier-based protection to prevent DG islanding: an investigating procedure. In: Power Tech Conference Proceedings, 2003, Bologna. IEEE, 2003. vol.3.

BENATO, R., CALDON, R. \& CORSI, S. Protection Requirements in Distribution Systems with High Penetration of DG and Possibility of Intention Islanding. In: CIRED, 2005, 18 ${ }^{\text {th }}$ International Conference and Exhibition on Electricity Distribution, 2005. p. 1-4.

BOBERLY, A.-M. \& KREIDER, J. F. Distributed Generation: The Power Paradigm for the New Millennium. Boca Raton: CRC Press LLC, 2001.

BRAHMA, S. M. \& GIRGIS, A. A. Development of Adaptive Protection Scheme for Distribution Systems with High Penetration of Distributed Generation. In: Power Engineering Society General Meeting, 2003. vol 4.

BUQUE, C., IPINNIMO, O., CHOWDHURY, S. \& CHOWDHURY, S. P. Modeling and Simulation of an Adaptive Relaying Scheme for a Microgrid. In: Power and Energy Society General Meeting, 2012, San Diego: IEEE, 2012. p. 1-8.

BRITTO, T. M. D. ET AL. Distributed Generation Impacts on the Coordination of Protection Systems in Distribution Networks. In: Transmission and Distribution Conference and Exposition: Latin America, 2004: IEEE/PES, 2004. P. 623-628.

CAMPITELLI, E. M. Análises e Estudos Para Alocação e Ajustes de Dispositivos de Proteção em Redes de Média Tensão de Energia Elétrica com Geração Distribuída. 2007. 99 f. Dissertação (Mestrado em Engenharia Elétrica), Unesp - Ilha Solteira, 2007.

COFFELE, F., BOOTH, C. \& DYSKO, A. An Adaptive Overcurrent Protection Scheme For Distribution Networks. IEEE Transactions on Power Delivery, 2014: Issue. 99, p. 1-8. 
COMPANHIA ENERGÉTICA DE MINAS GERAIS - CEMIG ND-5.31 - Requisitos para a Conexão de Acessantes Produtores de Energia Elétrica ao Sistema de Distribuição CEMIG Conexão em Média Tensão. Belo Horizonte, 2011.

COMPANHIA PAULISTA DE FORÇA E LUZ - Energia. Norma Técnica - 033 Ligação de Autoprodutores em Paralelo com o Sistema de Distribuição da CPFL. São Paulo, 2007.

CONTI, S. \& RAITI, S. Integrated Protection Scheme to Coordinate MV Distribution Network Devices, DG Interface Protections and Micro-Grids Operation. In: International Conference on Clean Electrical Power, 2009, Capri: IEEE, 2009. p. 640-646.

COURY, D. V., OleSKOVICZ, M. \& GIOVANINI, R. Proteção Digital de Sistemas Elétricos de Potência: dos Relés Eletromecânicos aos Microprocessados Inteligentes. 1. ed. São Carlos: EESC/USP, 2007.

DALKE, G. ET AL. Risk From Utility Supply Disruption: Islanding Protection For Industrial and Commercial Generators. IEEE Industry Applications Magazine, jan./fev. 2011, p. 4756.

DELMAR LTDA. Disponível em: <http://www.delmar.com.br> Acesso em 2 jan. 2013.

DEWADASA, M., GLOSH, A. \& LEDWICH, G. Protection of Distributed Generation Connected Networks with Coordination of Overcurrent Relays. In: IECON $2011-37^{\text {th }}$ Annual Conference on IEEE Industrial Electronics Society, Melbourne: IEEE, 2011. p. 924-929.

DIGSILENT GmbH. Disponível em :

$<$ http://www.digsilent.de/tl_files/digsilent/files/powerfactory/PowerFactory_Flyer.pdf>Acesso em 1 jan. 2013.

ELETROBRÁS, COMITE DE DISTRIBUIÇÃO. Proteção de Sistemas Aéreos de Distribuição. Rio de Janeiro: Campus, 1982

FUANGFOO, P., LEE, W.-J. \& KUO, M.-T. Impact Study on Intentional Islanding of Distributed Generation Connected to a Radial Subtransmission System in Thailand's Electric Power System. IEEE Transactions on Industry Applications, 2007: vol. 43, p. 1491-1498. 
FUANGFOO, P., MEENUAL, T., LEE, W.-J. \& CHOMPOO-INWAI, C. PEA Guidelines for Impact Study and Operation of DG for Islanding Operation. IEEE Transactions on Industry Applications, 2008: vol 44, pp. 1348-1353.

GERS, J. M. \& HOLMES, E. J. Protection of Electricity Distribution Networks. 3. ed. London: The Institution of Engineering and Technology, 2011.

GIGUER, S. Proteção de Sistemas de Distribuição. Porto Alegre: Sagra, 1988.

GÖNEN, T. Electric Power Distribution System Engineering. Sacramento: McGraw-Hill, 1986.

IEEE STANDARDS COORDINATING COMMITTEE 21. IEEE Aplication Guide for IEEE Std 1547, IEEE Standard for Interconnecting Distributed Resources with Electric Power Systems. New York: The Institute of Electrical and Electronics Engineers, Inc., 2008.

IEEE STANDARDS COORDINATING COMMITTEE 21. IEEE Std 1547.4 - IEEE Guide for Design, Operation, and Integration of Distributed Resource Island Systems with Electric Power Systems. New York: The Institute of Electrical and Electronics Engineers, Inc., 2011.

INDUSTRIAL AND COMMERCIAL POWER SYSTEMS DEPARTMENT OF IEEE INDUSTRY APPLICATIONS SOCIETY IEEE. STd 242 - Protection and Coordination for Industrial and Commercial Power Systems. New York: Institute of Electrical and Electronics Engineers, Inc., 2001.

JAVADIAN, S. A. M. \& HAGHIFAM, M.-R. Designing a New Protection System for Distribution Networks Including DG. In: IET $\mathbf{9}^{\text {th }}$ International Conference on Developments in Power System Protection, 2008a, Glasgow: IEEE, 2008a. p. 675-680.

JAVADIAN, S. A. M. \& HAGHIFAM, M.-R. Implementation of a New Protection Scheme on a Real Distribution System in Presence of DG. In: POWERCON - Joint International Conference on Power System Technology and IEEE Power India Conference, 2008b, New Delhi: IEEE, 2008b. p. 1-7.

JENKINS, N. ET AL. Embedded Generation. London: The Institution of Engineering and Technology, 2008. 
KUNDUR, P. Power System Stability and Control. 1. ed. New York: McGrraw-Hill, Inc., 1994.

LORA, E. E. S. \& HADDAD, J. Geração Distribuída: Aspectos Tecnológicos, Ambientais e Institucionais. Rio de Janeiro: Editora Interciência, 2006.

MAHAT, P., CHEN, Z., BAK-JENSEN, B. \& BAK, C. L. A Simple Adaptive Overcurrent Protection of Distribution Systems with Distributed Generation. In: IEEE Transactions on Smart Grid, 2011: IEEE, vol. 2, p. 428-437.

MAMEDE FILHO, J. Manual de Equipamentos Elétricos. 2. ed. Rio de Janeiro: LTC Livros Técnicos e Científicos S.A, 1994.

MAMEDE FILHO, J. \& MAMEDE RIBEIRO, D. Proteção de Sistemas Elétricos de Potência. Rio de Janeiro: LTC, 2011.

MARDEGAN, C. Guia Prático de Curto-Circuito e Seletividade em Sistemas Elétricos Industriais. São Paulo: s.n., 2013.

MOHAMAD, H., MOKHLIS, H., BAKAR, A. H. A. \& PING, H. W. A review on islanding operation and control for distribution network connected with small hydro power plant. Elsevier - Renewable and Sustainable Energy Reviews, vol. 15. Issue 8, p. 3952-3962, out. 2011.

PAULIS, L. M. ET AL. Ilhamento Intencional Automático Aplicado à Geração Distribuída. In: XIII SEPOBE - Simpósio de Especialista em Planejamento da Operação e Expansão Elétrica, Foz do Iguaçu, 2014.

PHOLBORISUT, N., SAKSORNCHAI, T. \& EUA-ARPORN, B. Evaluating the Impact of Distributed Generation on Protection System Coordination Using Protection Miscoordination Index. In: $\mathbf{8}^{\text {th }}$ International Conference on Electrical Engineering/ Electronics, Computer, Telecommunications and Information Technology (ECTI-CON), 2011, Khon Kaen: IEEE, 2011, p. 865-868.

REIS, L. B. Geração de Energia Elétrica: Tecnologia, Inserção Ambiental, Planejamento, Operação e Análise de Viabilidade. Barueri: Manole, 2003. 
THE MATHWORKS, INC. Disponível em: <http://www.mathworks.com/products/simulink> Acesso em: 06 abr. 2013.

VICENTINI, O. H. S. Proteção de Sobrecorrente de Sistemas de Distribuição. Itajubá, 2003. 79 f. Dissertação (Mestrado em Ciências em Engenharia Elétrica), Universidade Federal de Itajubá, 2003.

ZEINELDIN, H. H., EL-SAADANY, E. F. \& SALAMA, M. M. A. Distributed Generation Micro-Grid Operation: Control and Protection. In: Power Systems Conference: Advanced Metering, Protection, Control, Communication and Distributed Resources, 2006, Clemson: IEEE, 2006, p. 105-111. 


\section{A. PROCEDIMENTO PARA REALIZAÇÃO DO ESTUDO DE COORDENAÇÃO E SELETIVIDADE}

Este anexo apresenta os procedimentos e os critérios de coordenação e seletividade aplicados em sistemas de distribuição de energia elétrica para escolha dos fusíveis e ajuste dos relés de sobrecorrente e religadores. Os dados de entrada necessários são as correntes de curto-circuito para faltas em todas as barras, as margens de coordenação e restrições do sistema, e os ajustes disponíveis para os relés sendo coordenados. A margem de coordenação entre duas curvas características de tempo versus corrente sucessivas é um valor de intervalo de tempo que evita a perda de seletividade devido a um ou mais motivos descritos a seguir (Gers \& Holmes, 2011):

- Tempo de abertura de disjuntor;

- Tempo excedente do relé depois da falta ter sido eliminada;

- Variações nos níveis de falta, desvios de curvas características de relés (por exemplo, devido tolerâncias de fabricação) e erros nos transformadores de corrente.

Uma vez definidas as curvas de tempo versus corrente dos dispositivos de proteção, deve ser feita uma verificação para garantir que elas permanecem abaixo das curvas de capacidade térmica, designadas para máquinas, cabos e transformadores. Essas restrições garantem a segurança dos equipamentos.

Segundo Mamede Filho \& Mamede Ribeiro (2011), para elaborar um bom projeto de proteção de um sistema de distribuição é necessário seguir critérios básicos para instalação e coordenação dos equipamentos de proteção, descritos a seguir:

a) No primário dos transformadores de distribuição devem ser utilizadas chaves fusíveis.

b) No início de ramais, a utilização de chaves-fusíveis é indispensável, entretanto, em função da importância da carga, como alternativa pode ser utilizado religador ou seccionador.

c) Quando a proteção de retaguarda não for capaz de ser sensibilizada pela corrente de defeito a partir de um determinado ponto distante do alimentador, deve ser instalado um equipamento de proteção que pode ser chave-fusível, religador e seccionador.

d) Pode-se utilizar chave fusível, religador ou seccionador após uma carga considerada importante quanto à continuidade.

e) Deve-se utilizar religadores ou seccionadores em ramais cujos consumidores de média tensão a eles conectados são protegidos por disjuntores sem proteção contra 
defeitos monopolares à terra, como no caso de relés de ação direta, evitando o emprego de fusíveis.

f) Não utilizar mais que dois fusíveis em série nos alimentadores longos, caso seja necessário convém utilizar seccionador.

g) Não utilizar qualquer equipamento de proteção ao longo do alimentador tronco que permita manobra com outro alimentador, a fim de evitar as seguintes falhas:

- Funcionamento inadequado do fusível já instalado e perda de coordenação com a nova configuração.

- Alimentação invertida nos seccionadores, impossibilitando o seu funcionamento.

- Alimentação invertida dos religadores e perda de seletividade com a nova configuração. No entanto, atualmente já existem religadores capazes de serem alimentados por ambos os terminais sem nenhum prejuízo à sua operação.

\section{A.1. Proteção com Chaves-Fusíveis}

Os elos fusíveis são fabricados e utilizados segundo suas características tempo versus corrente, e são classificados da seguinte forma (Mamede Filho \& Mamede Ribeiro, 2011):

- Tipo $\mathrm{H}$ - possuem tempo de atuação lento e são utilizados somente na proteção de transformadores de distribuição. A característica de atuação lenta permite a não operação durante a energização dos transformadores, causada pela corrente de inrush. Sua relação de rapidez, também conhecida como Speed Ratio, ou simplesmente SR, que é a relação entre a mínima corrente de derretimento que causa a operação do fusível em 0,1s, e a mínima corrente de derretimento para operação em 300s, varia entre 11,4 a 36,4 para os fusíveis de corrente de 0,5 A a 5 $A$, respectivamente. São fabricados nas seguintes correntes nominais: 0,5 A - $1 \mathrm{~A}-$ $2 A-3 A-5 A$.

- Tipo $\mathrm{K}$ - possuem tempo de atuação rápido. São utilizados geralmente na proteção de ramais de alimentadores de distribuição, ou ao longo desses alimentadores em sua trajetória final. Possuem SR variando de 6, para elos fusíveis de corrente nominal igual a 6 A, e 8,1 para elos fusíveis de corrente nominal igual a $200 \mathrm{~A}$. São divididos em dois grupos distintos: elos fusíveis preferenciais, com correntes nominais iguais a $6-10-15-25-40-65-100-140-200 \mathrm{~A}$, e elos fusíveis não preferenciais, com correntes nominais iguais a $8-12-20-30-50-80$ A. Somente há coordenação entre os elos fusíveis de um mesmo grupo.

- Tipo T - possuem tempo de atuação lento, sendo utilizados na proteção de alimentadores de distribuição e seus respectivos ramais. Possuem SR variando entre 
10, para elos fusíveis de corrente nominal igual a 6 A, e 13, para elos fusíveis de corrente nominal igual a $200 \mathrm{~A}$.

As chaves que abrigam os elos fusíveis devem estar em concordância com as correntes nominais de seus respectivos elos, conforme indicado a seguir:

- Para elos fusíveis de 1 a $50 \mathrm{~A}$ : usar chaves-fusíveis de $50 \mathrm{~A}$.

- Para elos fusíveis maiores que $50 \mathrm{~A}$, até $100 \mathrm{~A}$ : usar chaves-fusíveis de $100 \mathrm{~A}$.

- Para elos fusíveis maiores que $100 \mathrm{~A}$, até $200 \mathrm{~A}$ : usar chaves-fusíveis de $200 \mathrm{~A}$.

A Tabela A.1 (Mamede Filho \& Mamede Ribeiro, 2011) fornece os valores das correntes nominais dos elos fusíveis do tipo $\mathrm{K}$ e $\mathrm{H}$, utilizados na proteção de transformadores monofásicos e trifásicos de distribuição.

Tabela A.1- Seleção de elos fusíveis H e K.

\begin{tabular}{|c|c|c|c|c|c|c|c|c|}
\hline \multicolumn{9}{|c|}{ Seleção de elos Fusíveis K e H } \\
\hline $\begin{array}{c}\text { Potência } \\
\text { do } \\
\text { Transformador }\end{array}$ & $2,3 \mathrm{kV}$ & $3,8 \mathrm{kV}$ & $6,6 \mathrm{kV}$ & $11,4 \mathrm{kV}$ & $13,8 \mathrm{kV}$ & $22 \mathrm{kV}$ & $25 \mathrm{kV}$ & $34,5 \mathrm{kV}$ \\
\hline \multicolumn{9}{|c|}{ Transformadores monofásicos } \\
\hline $3 \mathrm{kVA}$ & $3 \mathrm{H}$ & $1 \mathrm{H}$ & $0,5 \mathrm{H}$ & $0,5 \mathrm{H}$ & $0,5 \mathrm{H}$ & $0,5 \mathrm{H}$ & $0,5 \mathrm{H}$ & $0,5 \mathrm{H}$ \\
\hline $5 \mathrm{kVA}$ & $3 \mathrm{H}$ & $2 \mathrm{H}$ & $1 \mathrm{H}$ & $0,5 \mathrm{H}$ & $0,5 \mathrm{H}$ & $0,5 \mathrm{H}$ & $0,5 \mathrm{H}$ & $0,5 \mathrm{H}$ \\
\hline $7,5 \mathrm{kVA}$ & $3 \mathrm{H}$ & $2 \mathrm{H}$ & $1 \mathrm{H}$ & $0,5 \mathrm{H}^{*}$ & $0,5 \mathrm{H}$ & $0,5 \mathrm{H}$ & $0,5 \mathrm{H}$ & $0,5 \mathrm{H}$ \\
\hline $10 \mathrm{kVA}$ & $5 \mathrm{H}$ & $3 \mathrm{H}$ & $2 \mathrm{H}$ & $1 \mathrm{H}$ & $1 \mathrm{H}$ & $0,5 \mathrm{H}$ & $0,5 \mathrm{H}$ & $0,5 \mathrm{H}$ \\
\hline $15 \mathrm{kVA}$ & $6 \mathrm{~K}^{*}$ & $5 \mathrm{H}$ & $2 \mathrm{H}$ & $2 \mathrm{H}$ & $1 \mathrm{H}^{*}$ & $0,5 \mathrm{H}^{*}$ & $0,5 \mathrm{H}^{*}$ & $0,5 \mathrm{H}$ \\
\hline $25 \mathrm{kVA}$ & $12 \mathrm{~K}$ & $6 \mathrm{~K}$ & $5 \mathrm{H}$ & $2 \mathrm{H}$ & $2 \mathrm{H}$ & $1 \mathrm{H}$ & $1 \mathrm{H}$ & $1 \mathrm{H}$ \\
\hline 30 kVA & $15 \mathrm{~K}$ & $8 \mathrm{~K}$ & $5 \mathrm{H}$ & $3 \mathrm{H}$ & $2 \mathrm{H}^{*}$ & $1 \mathrm{H}^{*}$ & $1 \mathrm{H}^{*}$ & $1 \mathrm{H}$ \\
\hline $37,5 \mathrm{kVA}$ & $20 \mathrm{~K}$ & $10 \mathrm{~K}$ & $6 \mathrm{~K}$ & $3 \mathrm{H}$ & $3 \mathrm{H}$ & $2 \mathrm{H}$ & $2 \mathrm{H}$ & $1 \mathrm{H}$ \\
\hline \multicolumn{9}{|c|}{ Transformadores trifásicos } \\
\hline $5 \mathrm{kVA}$ & $2 \mathrm{H}$ & $1 \mathrm{H}$ & $0,5 \mathrm{H}$ & $0,5 \mathrm{H}$ & $0,5 \mathrm{H}$ & $0,5 \mathrm{H}$ & $0,5 \mathrm{H}$ & $0,5 \mathrm{H}$ \\
\hline $10 \mathrm{kVA}$ & $3 \mathrm{H}$ & $2 \mathrm{H}$ & $1 \mathrm{H}$ & $0,5 \mathrm{H}$ & $0,5 \mathrm{H}$ & $0,5 \mathrm{H}$ & $0,5 \mathrm{H}$ & $0,5 \mathrm{H}$ \\
\hline $15 \mathrm{kVA}$ & $5 \mathrm{H}$ & $3 \mathrm{H}$ & $2 \mathrm{H}$ & $1 \mathrm{H}$ & $0,5 \mathrm{H}^{*}$ & $0,5 \mathrm{H}$ & $0,5 \mathrm{H}$ & $0,5 \mathrm{H}$ \\
\hline $25 \mathrm{kVA}$ & $6 \mathrm{~K}^{*}$ & $5 \mathrm{H}$ & $3 \mathrm{H}$ & $2 \mathrm{H}$ & $1 \mathrm{H}$ & $0,5 \mathrm{H}^{*}$ & $0,5 \mathrm{H}$ & $0,5 \mathrm{H}$ \\
\hline $30 \mathrm{kVA}$ & $8 \mathrm{~K}$ & $5 \mathrm{H}$ & $3 \mathrm{H}$ & $2 \mathrm{H}$ & $2 \mathrm{H}$ & $1 \mathrm{H}$ & $1 \mathrm{H}$ & $0,5 \mathrm{H}$ \\
\hline $37,5 \mathrm{kVA}$ & $10 \mathrm{~K}$ & $6 \mathrm{~K}$ & $3 \mathrm{H}$ & $2 \mathrm{H}$ & $2 \mathrm{H}$ & $1 \mathrm{H}$ & $1 \mathrm{H}$ & $1 \mathrm{H}$ \\
\hline 45 kVA & $12 \mathrm{~K}$ & $8 \mathrm{~K}$ & $5 \mathrm{H}$ & $2 \mathrm{H}^{*}$ & $2 \mathrm{H}$ & $1 \mathrm{H}^{*}$ & $1 \mathrm{H}$ & $1 \mathrm{H}$ \\
\hline $50 \mathrm{kVA}$ & $12 \mathrm{~K}^{*}$ & $8 \mathrm{~K}$ & $5 \mathrm{H}$ & $3 \mathrm{H}$ & $2 \mathrm{H}$ & $1 \mathrm{H}^{*}$ & $1 \mathrm{H}$ & $1 \mathrm{H}$ \\
\hline 75 kVA & $20 \mathrm{~K}$ & $12 \mathrm{~K}$ & $6 \mathrm{~K}^{*}$ & $5 \mathrm{H}$ & $3 \mathrm{H}^{*}$ & $2 \mathrm{H}$ & $2 \mathrm{H}$ & $1 \mathrm{H}$ \\
\hline 100 kVA & $25 \mathrm{~K}$ & $15 \mathrm{~K}$ & $10 \mathrm{~K}$ & $5 \mathrm{H}$ & $5 \mathrm{H}$ & $3 \mathrm{H}$ & $2 \mathrm{H}$ & $2 \mathrm{H}$ \\
\hline $112,5 \mathrm{kVA}$ & $30 \mathrm{~K}$ & $20 \mathrm{~K}$ & $10 \mathrm{~K}$ & $6 \mathrm{~K}$ & $5 \mathrm{H}$ & $3 \mathrm{H}$ & $3 \mathrm{H}$ & $2 \mathrm{H}$ \\
\hline 150 kVA & $40 \mathrm{~K}$ & $25 \mathrm{~K}$ & $15 \mathrm{~K}$ & $8 \mathrm{~K}$ & $6 \mathrm{~K}^{*}$ & $5 \mathrm{H}$ & $5 \mathrm{H}$ & $3 \mathrm{H}$ \\
\hline 200 kVA & $50 \mathrm{~K}$ & $30 \mathrm{~K}$ & $20 \mathrm{~K}$ & $10 \mathrm{~K}$ & $10 \mathrm{~K}$ & $5 \mathrm{H}$ & $5 \mathrm{H}$ & $5 \mathrm{H}$ \\
\hline 225 kVA & $50 \mathrm{~K}^{*}$ & $40 \mathrm{~K}$ & $20 \mathrm{~K}$ & $12 \mathrm{~K}$ & $10 \mathrm{~K}$ & $6 \mathrm{~K}$ & $5 \mathrm{H}^{*}$ & $5 \mathrm{H}$ \\
\hline 250 kVA & $65 \mathrm{~K}$ & $40 \mathrm{~K}$ & $25 \mathrm{~K}$ & $15 \mathrm{~K}$ & $12 \mathrm{~K}$ & $6 \mathrm{~K}^{*}$ & $6 \mathrm{~K}$ & $5 \mathrm{H}$ \\
\hline 300 kVA & $80 \mathrm{~K}$ & $50 \mathrm{~K}$ & $30 \mathrm{~K}$ & $15 \mathrm{~K}$ & $15 \mathrm{~K}$ & $8 \mathrm{~K}$ & $8 \mathrm{~K}$ & $5 \mathrm{H}$ \\
\hline $400 \mathrm{kVA}$ & $100 \mathrm{~K}$ & $65 \mathrm{~K}$ & $40 \mathrm{~K}$ & $20 \mathrm{~K}$ & $20 \mathrm{~K}$ & $10 \mathrm{~K}$ & $10 \mathrm{~K}$ & $8 \mathrm{~K}$ \\
\hline $500 \mathrm{kVA}$ & $100 \mathrm{~K}^{*}$ & $80 \mathrm{~K}$ & $50 \mathrm{~K}$ & $25 \mathrm{~K}$ & $20 \mathrm{~K}$ & $12 \mathrm{~K}$ & $12 \mathrm{~K}$ & $10 \mathrm{~K}$ \\
\hline $600 \mathrm{kVA}$ & $140 \mathrm{~K}^{*}$ & $100 \mathrm{~K}$ & $65 \mathrm{~K}$ & $30 \mathrm{~K}$ & $25 \mathrm{~K}$ & $15 \mathrm{~K}$ & $15 \mathrm{~K}$ & $15 \mathrm{~K}$ \\
\hline
\end{tabular}

$\left.{ }^{*}\right)$ Devem ser utilizados em casos normais. Em caso de queima frequente, utilizar fusíveis imediatamente superiores. 
Os elos fusíveis são fabricados segundo suas características de atuação tempo versus corrente, as quais são fornecidas em gráficos que são utilizados na elaboração do estudo de coordenação e seletividade. Essas curvas são fornecidas com duas características distintas:

- Curva de tempo versus corrente para tempo mínimo de fusão a $25^{\circ} \mathrm{C}$.

- Curva de tempo versus corrente para tempo máximo de fusão a $25^{\circ} \mathrm{C}$.

Como exemplo, as curvas de tempo versus corrente para o tempo mínimo de fusão e máximo de interrupção dos elos fusíveis do tipo $\mathrm{K}$ são apresentadas a seguir, e foram obtidas do catálogo do fabricante Delmar (Delmar Ltda, 2013) e representada na Figura A.1.

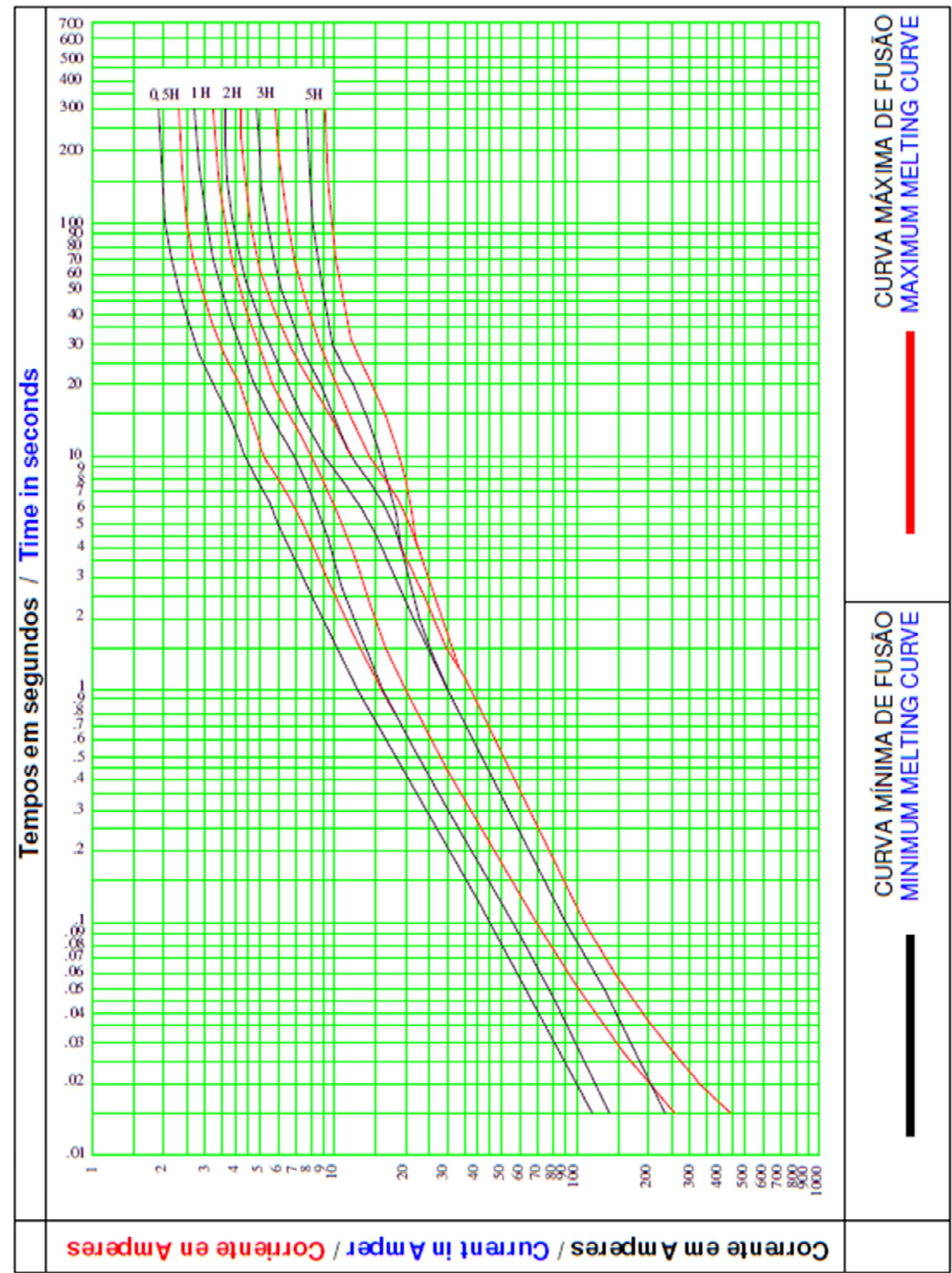

Figura A.1 - Característica tempo x corrente dos elos fusíveis H para tempos de fusão mínimo e máximo (Delmar Ltda, 2013). 
Como uma das funções básicas dos elos fusíveis dentro do sistema de distribuição é proteger os condutores da rede para que não atinjam sua temperatura de recozimento e como consequência sofram danos irreversíveis, as curvas de atuação dos fusíveis devem ser coordenadas com as curvas características de tempo versus corrente dos condutores que geralmente são de alumínio (CA) ou de alumínio com alma de aço (CAA) (Mamede Filho \& Mamede Ribeiro, 2011). A Figura A.2 apresenta a curva tempo versus corrente para início de recozimento dos condutores de alumínio com alma de aço. O recozimento provoca alterações nas propriedades mecânicas do material.

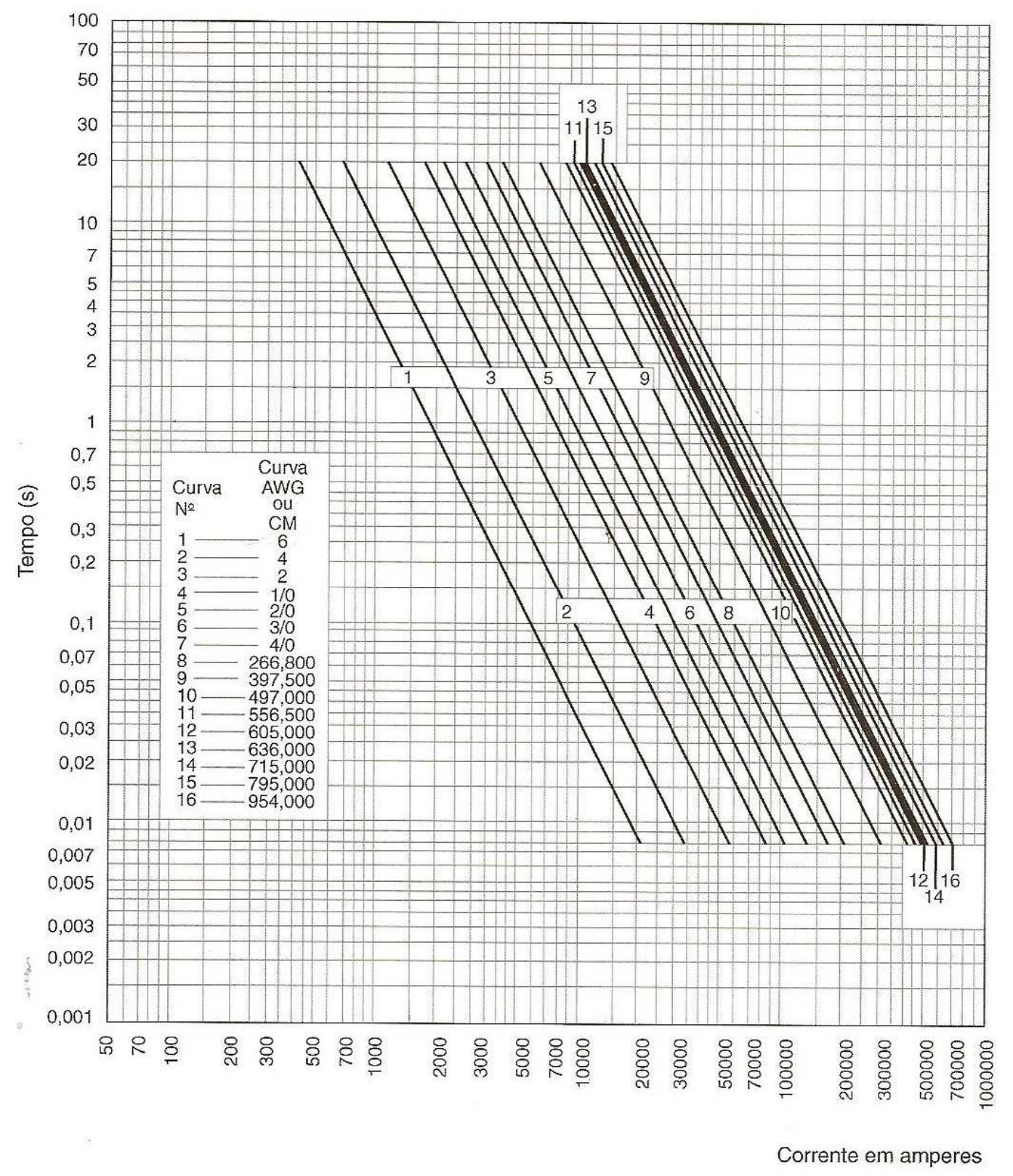

Figura A.2 - Característica tempo x corrente dos condutores de alumínio CAA

(Mamede Filho \& Mamede Ribeiro, 2011). 


\section{A.1.1. Proteção de transformadores de distribuição}

Para utilização de elos fusíveis para proteção de transformadores de distribuição contra os efeitos térmicos causados pelas correntes de curto-circuito, devem ser seguidos os seguintes critérios (Mamede Filho \& Mamede Ribeiro, 2011):

- O elo fusível deve atuar para a corrente de curto-circuito na rede de distribuição secundária, onde é tido como proteção de retaguarda, de forma a evitar que a corrente danifique o transformador e seja transferida para a rede primária. Para transformadores com potência nominal até aproximadamente $75 \mathrm{kVA}$, os defeitos na rede secundária provocam correntes de pequeno valor que, transferidas ao primário, podem não provocar a queima do fusível. Desta forma, para evitar que o transformador de distribuição seja danificado, pode-se utilizar disjuntores termomagnéticos como proteção no secundário do transformador.

- O elo fusível deve atuar de forma coordenada com a curva térmica do transformador, comumente conhecida como curva ANSI (Industrial and Commercial Power Systems Department of IEEE Industry Applications Society, 2001) e definida de acordo com a faixa de potência nominal do transformador. Como as curvas dos elos fusíveis são fixas, nem sempre se consegue alcançar esse objetivo.

- O elo fusível deve atuar para defeitos internos ao transformador que protege.

- O elo fusível deve fundir num tempo inferior a 17 segundos com correntes entre 2,5 a 3 vezes a corrente nominal do transformador, considerando-se a curva tempo versus corrente para o tempo máximo de atuação.

- Os elos fusíveis devem coordenar com as proteções instaladas à montante e à jusante do ponto de instalação do transformador.

- O elo fusível não deve atuar para as sobrecargas ocorridas no transformador, mesmo que isso venha a afetar sua vida útil. Essa consideração é importante, visto que os transformadores de distribuição são submetidos a sobrecargas temporárias de média duração, em função da curva característica de consumo de energia, mas que, em geral, não atingem a temperatura máxima de serviço que é de $95^{\circ} \mathrm{C}$.

- O elo fusível não deve atuar durante a energização do transformador. A corrente de inrush normalmente alcança valores compreendidos entre 8 a 12 vezes a corrente nominal do transformador em um tempo de duração de até 100 ms.

\section{A.1.2. Proteção de redes aéreas de distribuição}

Para proteção de redes de distribuição e ramais primários com elos fusíveis, os seguintes critérios devem ser seguidos (Mamede Filho \& Mamede Ribeiro, 2011). No 
entanto, eles podem sofrer pequenas alterações, de acordo com a filosofia de proteção praticada pelas diferentes concessionárias:

- Para o dimensionamento do elo fusível, deve-se prever o crescimento da carga para pelo menos um período de 5 anos.

- Prever no dimensionamento do elo fusível as cargas que possam ser transferidas por meio de manobras na rede de distribuição para realização de manutenção corretiva e preventiva.

- Na proteção de um ramal de distribuição, a corrente nominal do elo fusível deve ser igual ou maior que $150 \%$ da corrente máxima de carga prevista no projeto no ponto de instalação da chave fusível, conforme (A.1).

$$
I_{\text {nef }} \geq 1,5 \cdot I_{\text {máx }}
$$

Na qual:

$I_{\text {nef }}$ - corrente nominal do elo fusível, em A; e

$I_{\text {máx }}$ - corrente máxima do alimentador, em A.

- A corrente nominal da chave-fusível deve ser igual, sempre que possível, a no mínimo $150 \%$ da corrente nominal do elo fusível que será utilizado na proteção do ramal de distribuição.

- Devem ser determinadas as correntes de curto-circuito trifásicas, bifásicas e faseterra em todos os pontos onde serão instaladas as chaves fusíveis.

- A corrente nominal do elo fusível deve ser igual ou inferior a $25 \%$ da corrente de curto-circuito fase-terra mínima encontrada no trecho, considerando resistência de aterramento de $40 \Omega$, conforme (A.2).

$$
I_{n e f} \leq 0,25 \cdot I_{f t}
$$

Na qual:

$I_{f t}$ - corrente de curto-circuito fase-terra, em A.

- Determinar a corrente de carga máxima em cada trecho da rede de distribuição.

Como é impraticável medir simultaneamente a carga de cada transformador da rede de distribuição para obtenção do valor máximo de demanda, pode-se determinar a demanda máxima dos transformadores de distribuição com desvio aceitável para esse propósito se for determinada a taxa de corrente do alimentador. Para isso, divide-se o maior valor de corrente medido por um período, geralmente de um ano, no alimentador da subestação, pela soma das potências nominais dos transformadores de distribuição, desta forma obtém- 
se a taxa de corrente do alimentador $K=I / k V A$, que deve ser aplicada sobre a potência nominal de cada transformador de distribuição, para obter a demanda média desse equipamento.

Os valores de demanda dos transformadores de consumidores ligados em média tensão à rede de distribuição podem ser obtidos pela demanda máxima fornecida na fatura mensal de energia da concessionária. É aconselhável, considerar o mesmo período utilizado para se obter a taxa de corrente do alimentador.

A taxa de demanda final é obtida através da Equação (A.3).

$$
K=\frac{I_{\text {máx }}-\sum I_{\text {cons }}}{\sum\left(P_{c t}-P_{c p}\right)}(A / k V A)
$$

Na qual:

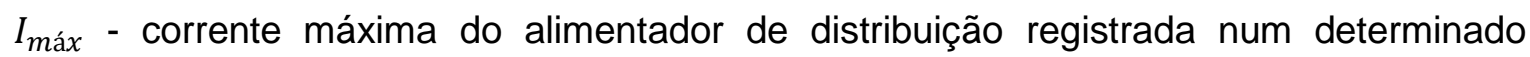
período de observação em $A$;

$P_{c t}$ - potência nominal dos transformadores do alimentador, compreendendo os da rede pública e os dos consumidores ligados em média tensão;

$\sum I_{\text {cons }}$ - soma das correntes de carga, calculada a partir da conta de energia dos consumidores conectados em média tensão; e

$\sum P_{c p}$ - soma das potências nominais dos transformadores dos consumidores conectados em média tensão (transformadores particulares).

\section{A.1.3. Critérios de coordenação entre elos fusíveis}

Devido à grande quantidade de elos fusíveis instalados nos alimentadores de distribuição é necessário que sejam obedecidos critérios de coordenação para evitar o desligamento de grandes trechos (Mamede Filho \& Mamede Ribeiro, 2011), a saber:

- Para que dois elos fusíveis ligados em série atuem de forma coordenada entre si para corrente de curto-circuito, ou sobrecargas elevadas, o tempo de interrupção do elo fusível protetor deve ser de no máximo $75 \%$ do tempo de fusão do elo fusível protegido, ou seja:

$$
T_{\text {máxfp }} \leq 0,75 \cdot T_{\text {mínfa }}
$$

Na qual:

$T_{\text {máxfp }}$ - tempo máximo de atuação do elo fusível protetor; e

$T_{m i ́ n f a}$ - tempo mínimo de atuação do elo fusível protegido. 
- Devem-se aplicar no máximo duas chaves-fusíveis em série, pois é impraticável obter coordenação para um número elevado de chaves-fusíveis. Caso haja necessidade de proteção, devem ser utilizados religadores de distribuição e/ou seccionadores.

- Procurar reduzir sempre que possível o número de elos fusíveis aplicados num mesmo alimentador a fim de permitir ampliar a faixa de coordenação entre os elos fusíveis protegidos e protetores. A série de fusíveis mais recomendada é: 6 - $10-15$ $-25-65$ A.

- O elo fusível protegido deve coordenar com o elo fusível protetor para o maior valor da corrente de curto-circuito no ponto de instalação do elo fusível protetor.

- A coordenação entre o elo fusível protegido e o elo fusível de proteção de um transformador de distribuição pode implicar em uma corrente muito alta do elo fusível protegido. Portanto, é preferível desconsiderar essa coordenação a perder a proteção do alimentador pela corrente elevada do elo fusível protegido.

- Para proteção de ramais ou de alimentadores longos não se deve utilizar fusíveis do tipo $\mathrm{H}$.

- Procurar utilizar a série de fusíveis denominada preferenciais, porém, isso não quer dizer que não se pode utilizar a série de fusíveis denominada não preferenciais no mesmo estudo de coordenação e seletividade. Esta escolha depende da condição de coordenação.

- Uma vez conhecidas as correntes de curto-circuito em todos os pontos de instalação das chaves-fusíveis, utilizar a Tabela A.2 para obtenção da coordenação de elos fusíveis do tipo K. A coordenação entre elos fusíveis do tipo $\mathrm{H}$ e $\mathrm{K}$ é obtida por meio da Tabela A.3. A coordenação entre os elos fusíveis do tipo T é obtida através da Tabela A.4 e finalmente a coordenação entre os elos fusíveis do tipo $\mathrm{H}$ e T pode ser obtida na Tabela A.5. Para utilização das tabelas mencionadas é necessário conhecer o valor da corrente de curto-circuito trifásica no ponto onde se encontra instalado o elo fusível protetor, o qual se deseja coordenar com o elo fusível protegido. Por exemplo, se o elo fusível protegido for de $50 \mathrm{~K}$, e o elo fusível protetor for de $20 \mathrm{~K}$, e a corrente de curto-circuito trifásico no ponto onde o elo fusível protetor encontra-se instalado for de $1200 \mathrm{~A}$, a coordenação estará garantida, pois segundo a Tabela A.2, o elo fusível protetor de $20 \mathrm{~K}$ está coordenado com o elo fusível protegido até uma corrente de $1700 \mathrm{~A}$. 
Tabela A.2 - Coordenação entre elos fusíveis do tipo K (Mamede Filho \& Mamede Ribeiro, 2011).

\begin{tabular}{|c|c|c|c|c|c|c|c|c|c|c|c|c|c|}
\hline & \multirow{2}{*}{ K } & \multicolumn{12}{|c|}{ Fusível protegido tipo K } \\
\hline & & 12 & 15 & 20 & 25 & 30 & 40 & 50 & 65 & 80 & 100 & 140 & 200 \\
\hline & 6 & 350 & 510 & 650 & 840 & 1060 & 1340 & 1700 & 2200 & 2800 & 3900 & 5800 & 9200 \\
\hline & 8 & 210 & 440 & 650 & 840 & 1060 & 1340 & 1700 & 2200 & 2800 & 3900 & 5800 & 9200 \\
\hline & 10 & & 300 & 540 & 840 & 1060 & 1340 & 1700 & 2200 & 2800 & 3900 & 5800 & 9200 \\
\hline 。 & 12 & & & 320 & 710 & 1050 & 1340 & 1700 & 2200 & 2800 & 3900 & 5800 & 9200 \\
\hline త్ & 15 & & & & 430 & 870 & 1340 & 1700 & 2200 & 2800 & 3900 & 5800 & 9200 \\
\hline 잏 & 20 & & & & & 500 & 1100 & 1700 & 2200 & 2800 & 3900 & 5800 & 9200 \\
\hline $\bar{\omega}$ & 25 & & & & & & 660 & 1350 & 2200 & 2800 & 3900 & 5800 & 9200 \\
\hline$\frac{\vec{n}}{0}$ & 30 & & & & & & & 850 & 1700 & 2800 & 3900 & 5800 & 9200 \\
\hline II & 40 & & & & & & & & 1100 & 2200 & 3900 & 5800 & 9200 \\
\hline & 50 & & & & & & & & & 1450 & 3500 & 5800 & 9200 \\
\hline & 65 & & & & & & & & & & 2400 & 5800 & 9200 \\
\hline & 80 & & & & & & & & & & & 4500 & 9200 \\
\hline & 100 & & & & & & & & & & & 2000 & 9100 \\
\hline & 140 & & & & & & & & & & & & 4000 \\
\hline
\end{tabular}

Tabela A.3 - Coordenação entre elos fusíveis do tipo H e K (Mamede Filho \& Mamede Ribeiro, 2011).

\begin{tabular}{|c|c|c|c|c|c|c|c|c|c|c|c|c|c|}
\hline \multirow{5}{*}{ 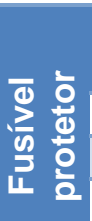 } & \multirow{2}{*}{$H$} & \multicolumn{12}{|c|}{ Fusível protegido tipo K } \\
\hline & & 10 & 12 & 15 & 20 & 25 & 30 & 40 & 50 & 65 & 80 & 100 & 140 \\
\hline & 1 & 280 & 380 & 510 & 650 & 840 & 1060 & 1340 & 1700 & 2200 & 2800 & 3900 & 5800 \\
\hline & 2 & 45 & 220 & 450 & 650 & 840 & 1060 & 1340 & 1700 & 2200 & 2800 & 3900 & 5800 \\
\hline & 3 & 45 & 220 & 450 & 650 & 840 & 1060 & 1340 & 1700 & 2200 & 2800 & 3900 & 5800 \\
\hline & 3 & 45 & 220 & 450 & 650 & 840 & 1060 & 1340 & 1700 & 2200 & 2800 & 3900 & 5800 \\
\hline
\end{tabular}

Tabela A.4 - Coordenação entre elos fusíveis do tipo T (Mamede Filho \& Mamede Ribeiro, 2011).

\begin{tabular}{|c|c|c|c|c|c|c|c|c|c|c|c|c|c|c|c|}
\hline & \multirow{2}{*}{$\mathrm{T}$} & \multicolumn{12}{|c|}{ Fusível protegido tipo T } & \multirow[b]{2}{*}{140} & \multirow[b]{2}{*}{200} \\
\hline & & 8 & 10 & 12 & 15 & 20 & 25 & 30 & 40 & 50 & 65 & 80 & 100 & & \\
\hline \multirow{14}{*}{ 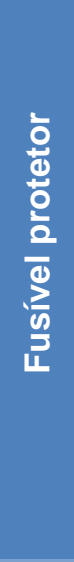 } & 6 & & 350 & 680 & 920 & 1200 & 1500 & 2000 & 2540 & 3200 & 4100 & 5000 & 6100 & 9700 & 15200 \\
\hline & 8 & & & 375 & 800 & 1200 & 1500 & 2000 & 2540 & 3200 & 4100 & 5000 & 6100 & 9700 & 15200 \\
\hline & 10 & & & & 530 & 1100 & 1500 & 2000 & 2540 & 3200 & 4100 & 5000 & 6100 & 9700 & 15200 \\
\hline & 12 & & & & & 680 & 1280 & 2000 & 2540 & 3200 & 4100 & 5000 & 6100 & 9700 & 15200 \\
\hline & 15 & & & & & & 730 & 1700 & 2500 & 3200 & 4100 & 5000 & 6100 & 9700 & 15200 \\
\hline & 20 & & & & & & & 990 & 2100 & 3200 & 4100 & 5000 & 6100 & 9700 & 15200 \\
\hline & 25 & & & & & & & & 1400 & 2600 & 4100 & 5000 & 6100 & 9700 & 15200 \\
\hline & 30 & & & & & & & & & 1500 & 3100 & 5000 & 6100 & 9700 & 15200 \\
\hline & 40 & & & & & & & & & & 1750 & 3800 & 6100 & 9700 & 15200 \\
\hline & 50 & & & & & & & & & & & 1750 & 4400 & 9700 & 15200 \\
\hline & 65 & & & & & & & & & & & & 2200 & 9700 & 15200 \\
\hline & 80 & & & & & & & & & & & & & 7200 & 15200 \\
\hline & 100 & & & & & & & & & & & & & 4000 & 13800 \\
\hline & 140 & & & & & & & & & & & & & & 7500 \\
\hline
\end{tabular}

Tabela A.5 - Coordenação entre elos fusíveis do tipo H e T (Mamede Filho \& Mamede Ribeiro, 2011).

\begin{tabular}{|c|c|c|c|c|c|c|c|c|c|c|c|c|c|c|c|}
\hline \multirow{7}{*}{ 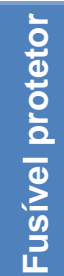 } & $\mathbf{H}$ & \multicolumn{12}{|c|}{ Fusível protegido tipo T } & & \\
\hline & II & 8 & 10 & 12 & 15 & 20 & 25 & 30 & 40 & 50 & 65 & 80 & 100 & 140 & 200 \\
\hline & 1 & 400 & 520 & 710 & 920 & 1200 & 1500 & 2000 & 2540 & 3200 & 4100 & 5000 & 6100 & 9700 & 15200 \\
\hline & 2 & 240 & 500 & 710 & 920 & 1200 & 1500 & 2000 & 2540 & 3200 & 4100 & 5000 & 6100 & 9700 & 15200 \\
\hline & 3 & 240 & 500 & 710 & 920 & 1200 & 1500 & 2000 & 2540 & 3200 & 4100 & 5000 & 6100 & 9700 & 15200 \\
\hline & 5 & 240 & 500 & 710 & 920 & 1200 & 1500 & 2000 & 2540 & 3200 & 4100 & 5000 & 6100 & 9700 & 15200 \\
\hline & 8 & 240 & 500 & 710 & 920 & 1200 & 1500 & 2000 & 2540 & 3200 & 4100 & 5000 & 6100 & 9700 & 15200 \\
\hline
\end{tabular}




\section{A.2. Proteção com Disjuntores Associados a Relés}

Todo alimentador precisa ser protegido em sua origem, ou seja, na saída da subestação. Essa proteção geralmente é feita por meio de disjuntores de média tensão associados a relés de sobrecorrente. Também podem ser utilizados religadores quando o alimentador apresentar características para tal, de acordo com os critérios operacionais da concessionária, e não ser alimentador de rede subterrânea (Mamede Filho \& Mamede Ribeiro, 2011).

Os seguintes requisitos precisam ser obedecidos para que os disjuntores atendam aos critérios de proteção (Mamede Filho \& Mamede Ribeiro, 2011):

- A tensão nominal do disjuntor deve ser igual ou maior que a tensão nominal do sistema. Deve-se observar a capacidade de interrupção de correntes de curtocircuito do disjuntor em função do valor da tensão nominal do sistema.

- O disjuntor deve ter capacidade de corrente superior à máxima corrente que possa ser conduzida por ele, obtida a partir do planejamento de longo prazo.

- O disjuntor deve possuir capacidade de interrupção igual ou superior à maior corrente de curto-circuito que deverá interromper, sendo esta trifásica ou fase-terra, no ponto de sua instalação.

- O disjuntor dever possuir nível de isolamento compatível com o nível de isolamento do sistema elétrico.

O ajuste de relés de sobrecorrente envolve uma seleção de parâmetros que definem a característica de tempo versus corrente da unidade temporizada e o valor de ajuste de corrente da unidade instantânea. Este processo precisa ser feito duas vezes, uma para relés de fase e outra para os relés de falta à terra.

\section{A.2.1. Ajuste da unidade temporizada do relé de sobrecorrente}

A unidade temporizada de fase é ajustada de forma independente da unidade temporizada de neutro, conforme mostrado a seguir:

a) Ajuste da unidade temporizada de fase:

A corrente da unidade temporizada de fase deve ser ajustada de acordo com a Equação (A.5).

$$
I_{t f}=\frac{K_{t f} \cdot I_{c}}{R T C}
$$


Na qual:

$I_{t f}$ - corrente de ajuste da unidade temporizada de fase, em A;

$K_{t f}$ - valor da sobrecarga admissível que pode variar entre 1,2 a 1,5;

$I_{c}$ - corrente de carga máxima do alimentador, em A; e

$R T C$ - relação de transformação do transformador de corrente.

Para que os critérios de proteção sejam atendidos, o ajuste da unidade de fase deve satisfazer aos seguintes requisitos (Mamede Filho \& Mamede Ribeiro, 2011):

- O relé temporizado de fase deve ser ajustado para operar para a menor corrente de curto-circuito fase-fase, em situações em que o relé seja proteção de retaguarda.

- A corrente de acionamento (pick-up) deve ser no máximo igual à corrente térmica do transformador de corrente (TC) da proteção.

Para garantir a integridade do TC quanto aos efeitos térmicos:

- A corrente de curto-circuito máxima deve ser menor ou igual a 20 vezes à corrente nominal primária do TC de proteção.

- O relé deve ser ajustado para operar de acordo com a curva de temporização para o múltiplo da corrente ajustada.

A determinação do tempo de ajuste do relé é função do plano de coordenação previsto. Costuma-se utilizar uma margem de coordenação da ordem de 0,40 s, entre os tempos de operação de dois relés funcionando em cascata. Esse tempo é justificado pelas seguintes premissas (Mamede Filho \& Mamede Ribeiro, 2011):

- Tempo próprio de operação do disjuntor: $\cong 0,13 \mathrm{~s}$.

- Tolerância do fabricante do disjuntor: $\cong 0,10 \mathrm{~s}$.

- Tempo de segurança do projeto: $\cong 0,17 \mathrm{~s}$.

No entanto, essa margem de coordenação tem sido reduzida para até $0,2 \mathrm{~s}$, em virtude da utilização de novos disjuntores e relés numéricos (Gers \& Holmes, 2011).

A seleção da curva de atuação do relé, dentre as várias curvas disponíveis para determinada característica (muito inversa, extremamente inversa, etc.) é feita com base no múltiplo da corrente de acionamento, de acordo com a Equação (A.6) e no tempo requerido para o disparo do disjuntor.

$$
M=\frac{I_{m}}{R T C \cdot I_{t f}}
$$

Na qual:

$M$ - múltiplo da corrente de acionamento (corrente de disparo); 
$I_{m}$ - corrente máxima admitida no circuito, que pode ser uma corrente de sobrecarga ou de curto-circuito;

$I_{t f}$ - corrente de ajuste da unidade temporizada de fase, em A; e

$R T C$ - relação de transformação do transformador de corrente.

As características de operação dos relés podem ser definidas por fórmulas matemáticas de acordo com os padrões IEC e ANSI/IEEE, conforme indica a Equação (A.7).

$$
t=\frac{k \beta}{(M)^{\alpha}-1}+L
$$

Na qual:

$t$ - tempo de operação do relé em segundos;

$k$ - ajuste de tempo, ou multiplicador de tempo;

$M$ - múltiplo da corrente de acionamento, definida por (A.6); e

$L$ - constante de tempo.

As constantes $\alpha$ e $\beta$ determinam a declividade das curvas características do relé. $\mathrm{Na}$ Tabela 4.6 são dados os valores dessas constantes para vários tipos de padrão de relés de sobrecorrente, manufaturados dentro das normas IEC e ANSI/IEEE (Gers \& Holmes, 2011).

Tabela A.6 - Constantes ANSI/IEEE e IEC para relés de sobrecorrente padronizados.

\begin{tabular}{|ccccc|}
\hline Descrição da Curva & Padrão & $\alpha$ & $\boldsymbol{\beta}$ & $\boldsymbol{L}$ \\
\hline Moderadamente inversa & IEEE & 0,02 & 0,0515 & 0,114 \\
\hline Muito inversa & IEEE & 2,0 & 19,61 & 0,491 \\
\hline Extremamente inversa & IEEE & 2,0 & 28,2 & 0,1217 \\
\hline Inversa padrão & IEC & 0,02 & 0,14 & 0 \\
\hline Muito inversa & IEC & 1,0 & 13,5 & 0 \\
\hline Extremamente inversa & IEC & 2,0 & 80,0 & 0 \\
\hline
\end{tabular}

b) Ajuste da unidade temporizada de neutro;

A corrente da unidade temporizada de neutro deve ser ajustada de acordo com a equação (4.8) (Mamede Filho \& Mamede Ribeiro, 2011).

$$
I_{t n}=\frac{K_{t n} \cdot I_{C}}{R T C}
$$

Na qual:

$I_{t n}$ - corrente de ajuste da unidade temporizada de neutro, em A;

$K_{t n}$ - valor de desequilíbrio das correntes e erros no nível de saturação dos TCs;

$I_{C}$ - corrente de carga máxima do alimentador, em A; e 
$R T C$ - relação de transformação do TC.

O valor de $K_{t n}$ deve ser entre 0,10 e 0,30, pois representa a taxa de desequilíbrio máximo admitido nos condutores de fase (Mamede Filho \& Mamede Ribeiro, 2011). Valores menores de 0,10 podem provocar desligamentos indesejáveis, e valores acima de 0,30 não oferecem sensibilidade adequada para defeitos fase-terra de alta e média impedância. Em geral, a corrente de curto-circuito fase-terra é calculada considerando resistência de contato à terra igual a $40 \Omega$.

A unidade temporizada deve ser ajustada para operar para a menor corrente simétrica de curto-circuito fase-terra no trecho protegido pelo disjuntor.

O múltiplo da corrente de disparo é determinado de acordo com a expressão (A.6), com as seguintes alterações:

- $I_{m}$ neste caso é a corrente máxima de curto-circuito fase-terra; e

- $I_{t f}$ é substituída por $I_{t n}$.

\section{A.2.2. Ajuste da unidade instantânea ou de tempo definido do relé de sobrecorrente}

Da mesma forma que a unidade temporizada de fase é ajustada independentemente da unidade temporizada de neutro, a unidade instantânea, ou de tempo definido de fase também deve ser ajustada de forma independente da de neutro.

a) Ajuste da unidade instantânea ou de tempo definido de fase:

O ajuste da unidade instantânea da fase deve obedecer aos seguintes requisitos para atender ao critério de proteção (Mamede Filho \& Mamede Ribeiro, 2011):

- Deve ser ajustada para operar para qualquer defeito que ocorra na zona protegida pelo disjuntor, devendo atuar para qualquer valor de corrente de falta trifásica ou bifásica.

- A unidade instantânea deve ser ajustada para não operar com a corrente de inrush do transformador, quando for o caso.

b) Ajuste da unidade instantânea ou de tempo definido de neutro:

Tal como a unidade temporizada, a unidade instantânea também deve ser ajustada para operar para a menor corrente simétrica de curto-circuito fase-terra do trecho protegido pelo disjuntor. 


\section{A.2.3. Critérios de coordenação entre relés}

Os seguintes critérios devem ser seguidos para coordenação entre relés:

- A unidade de sobrecorrente de fase do relé à montante deve atuar como proteção de retaguarda.

- A unidade de sobrecorrente de fase do relé deve atuar para defeitos trifásicos, bifásicos e fase-terra e coordenar com as proteções a montante e a jusante.

- Para relés instalados em série, a coordenação de uma unidade instantânea deve ser realizada por diferença de corrente, ou seja, seletividade amperimétrica, ou por ajuste escalonado de tempo em que a unidade instantânea assume a condição de tempo definido.

- Para relés instalados em série, a coordenação das unidades temporizadas deve ser feita por diferença de tempo, chamada de intervalo de coordenação, deve ser no mínimo $0,2 \mathrm{~s}$, a depender do tipo do relé, conforme comentado anteriormente.

\section{A.2.4. Coordenação entre relés e elos fusíveis}

Para que haja coordenação entre o relé do alimentador de distribuição e os elos fusíveis, os seguintes critérios devem ser obedecidos:

- A unidade de sobrecorrente de fase deve ser ajustada para atuar para a menor corrente do trecho protegido pelo relé.

- A curva tempo versus corrente da unidade de sobrecorrente de fase e de neutro não deve cortar a curva tempo versus corrente do elo fusível em todo trecho protegido pelo disjuntor.

- A curva tempo versus corrente da unidade de sobrecorrente de fase e de neutro e a curva tempo versus corrente do elo fusível devem ser afastadas no mínimo de 0,20 s para garantir a coordenação.

- A curva tempo versus corrente da unidade de sobrecorrente de fase deve ser ajustada abaixo do máximo valor da corrente de curto-circuito suportável pelos cabos ou equipamentos do alimentador de distribuição.

- A unidade de sobrecorrente instantânea de fase não deve atuar para a corrente de inrush dos transformadores 


\section{A.3. Proteção com Seccionadores}

Os seccionadores não têm característica de operação tempo versus corrente, portanto não há estudos a considerar de temporização entre o seccionador e o disjuntor ou entre o religador.

\section{A.4. Proteção com Religadores}

Os religadores podem ser instalados em subestações e em linhas de distribuição, o que Ihes confere características próprias para instalação fixa no solo e em poste. Por este motivo são conhecidos como religadores de subestação e religadores de distribuição, respectivamente. Ademais existem critérios que devem ser seguidos para a instalação de religadores automáticos de distribuição nos diferentes pontos da rede aérea, tais como (Mamede Filho \& Mamede Ribeiro, 2011):

- Em determinados pontos de circuitos longos, onde as correntes de curto-circuito, pela elevação da impedância, não têm valor suficientemente elevado capaz de sensibilizar o equipamento de proteção, disjuntor ou religador, instalado no início do alimentador.

- Na derivação se alguns ramais que suprem cargas importantes, suscetíveis a falhas transitórias.

- Em alimentadores que possuam dois ou mais ramais.

- Em um ponto imediatamente após uma carga ou concentração de carga que necessita de continuidade de serviço.

- Em um ponto de bifurcação de um alimentador.

- Em ramais que alimentam consumidores primários cuja proteção seja feita através de disjuntores dotados de relés de ação direta.

\section{A.4.1 Ajuste da corrente de acionamento de religadores de subestação}

Como os religadores geralmente são dotados de unidades de proteção digitais para proteção de fase e de terra, os seguintes critérios devem ser obedecidos para ajuste dos religadores instalados em subestações:

- Proteção de fase: unidades instantâneas ou de tempo definido (curvas rápidas) e unidades temporizadas (curvas rápidas e lentas).

- Proteção de neutro: unidades instantâneas ou de tempo definido (curvas rápidas) e unidades temporizadas (curvas rápidas e lentas).

- A sequência de operação depende de cada estudo e deve ser coordenada com os equipamentos de proteção instalados a jusante do religador. 
- O tempo de religamento também depende de cada estudo em particular e deve ser coordenado entre os equipamentos de proteção instalados à jusante e à montante do religador.

- O tempo de rearme pode ser determinado a partir da Equação (A.9).

$$
T_{r e}=1,10 \cdot \sum T_{t o}+1,15 \cdot \sum T_{t i}
$$

Na qual:

$T_{r e}$ - tempo de rearme, em segundos;

$\sum T_{\text {to }}$ - tempo total de todas as operações de abertura, considerando a corrente mínima de acionamento; e

$\sum T_{t i}$ - tempo total dos intervalos de religamento.

- A proteção de sobrecorrente de fase deve ser ajustada com os mesmos princípios de cálculo empregados para o ajuste dos relés de sobrecorrente de fase.

- A proteção de sobrecorrente de neutro pode ser ajustada com os mesmos princípios de cálculo empregados para o ajuste dos relés de sobrecorrente de neutro.

\section{A.4.2. Coordenação entre religadores de subestação e elos fusíveis}

Existem duas condições de coordenação entre religadores e elos fusíveis. Na primeira, o elo está instalado junto à carga. Na segunda, o elo fusível está instalado junto à fonte. Será considerada somente a primeira condição, por ser a mais comum (Mamede Filho \& Mamede Ribeiro, 2011).

Para existir coordenação entre o religador da subestação e os elos fusíveis é necessário que:

- A corrente mínima de acionamento da unidade de proteção de fase seja inferior à corrente mínima de curto-circuito bifásica no trecho protegido pelo religador.

- A corrente mínima de acionamento da unidade de proteção de neutro seja inferior à corrente mínima de curto-circuito fase-terra no trecho protegido pelo religador.

- A corrente mínima de acionamento da unidade de proteção de neutro seja superior à corrente máxima de desequilíbrio do alimentador.

- A curva de operação lenta do religador esteja abaixo da curva de suportabilidade térmica dos condutores elétricos e demais equipamentos instalados no alimentador.

- Deve-se adotar, preferencialmente, a curva do relé de sobrecorrente de fase e de neutro com característica tempo versus corrente muito inversa, por facilitar a coordenação com elos fusíveis, devido à declividade da curva. 
- O ponto máximo de coordenação entre o religador e o elo fusível é dado pela intersecção entre a curva rápida do religador, deslocada pelo fator de multiplicação $K$, e a curva de tempo mínimo de fusão do elo fusível, o que define o limite da faixa superior de coordenação, conforme exemplificado na Figura A.3.

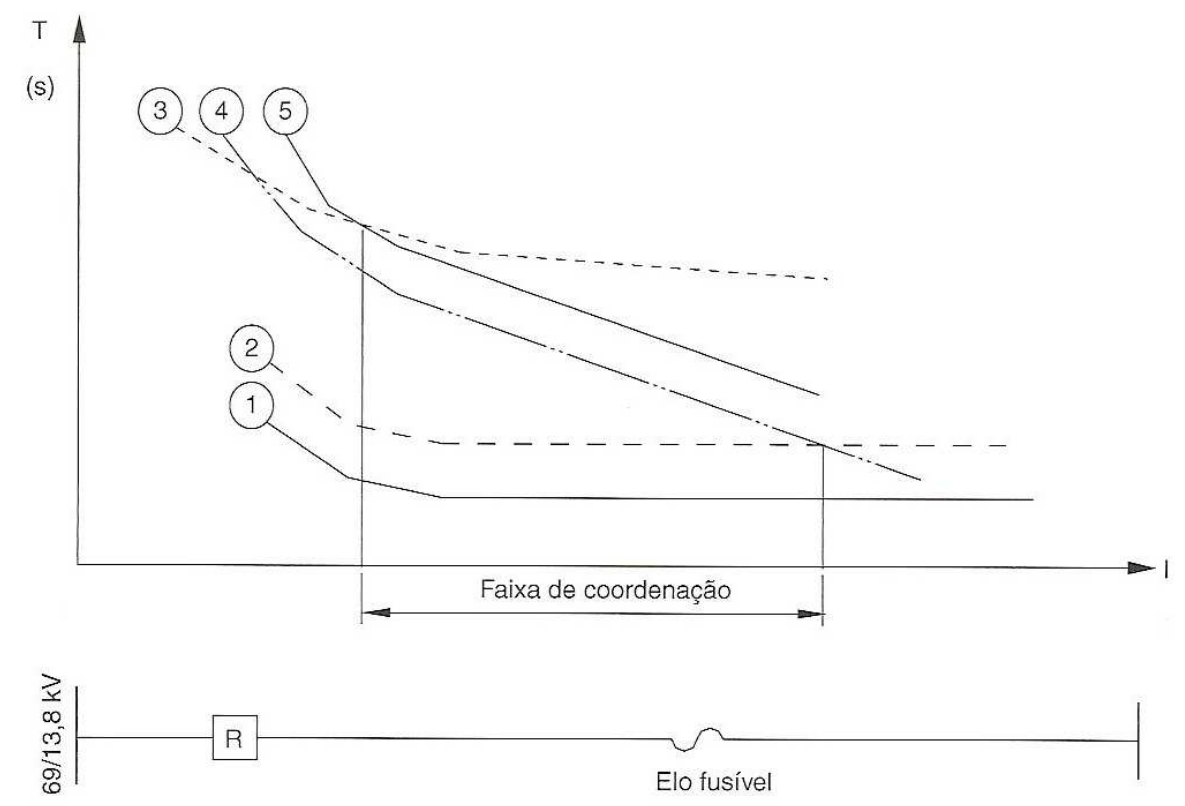

1 - Curva de operação rápida do religador

2 - Curva de operação rápida do religador corrigida pelo fator $\mathrm{K}$

3 - Curva de operação retardada do religador

4 - Curva de tempo mínimo de fusão do elo fusível

5 - Curva de tempo máximo de interrupção do elo fusível

Figura A.3 - Coordenação entre religador de subestação e elo fusível com fator K (Mamede Filho \& Mamede Ribeiro, 2011).

O fator $K$ está relacionado com o número de operações rápidas do religador e com os tempos de religamento. Ele corrige o tempo de operação do elo fusível devido ao seu aquecimento durante as operações do religador. $O$ fator $K$ pode ser obtido da Tabela A.7 (Mamede Filho \& Mamede Ribeiro, 2011).

Tabela A.7 - Fator de multiplicação K dos religadores.

\begin{tabular}{|ccc|}
\hline Tempo de religamento (s) & \multicolumn{2}{c|}{$\begin{array}{c}\text { Fator de multiplicação } \mathbf{K} \\
\text { Número de operações }\end{array}$} \\
\cline { 2 - 3 } & $\mathbf{1}$ & $\mathbf{2}$ \\
\hline 0,5 & 1,20 & 1,80 \\
\hline 1,00 & 1,20 & 1,35 \\
\hline 1,50 & 1,20 & 1,35 \\
\hline 2,00 & 1,20 & 1,35 \\
\hline
\end{tabular}


Quando não for possível identificar o valor do fator $K$, deve-se obter uma nova curva de tempo mínimo de fusão do elo fusível, multiplicando a curva original de mínima fusão por 0,75 , somente no eixo dos tempos, e multiplicar a curva rápida do religador pelo número de operações rápidas do mesmo. O deslocamento das duas curvas deve ocorrer somente no eixo dos tempos. O ponto de intersecção entre as duas curvas fornece o limite superior da faixa de coordenação entre o elo fusível e o religador, conforme mostrado na Figura A.4.
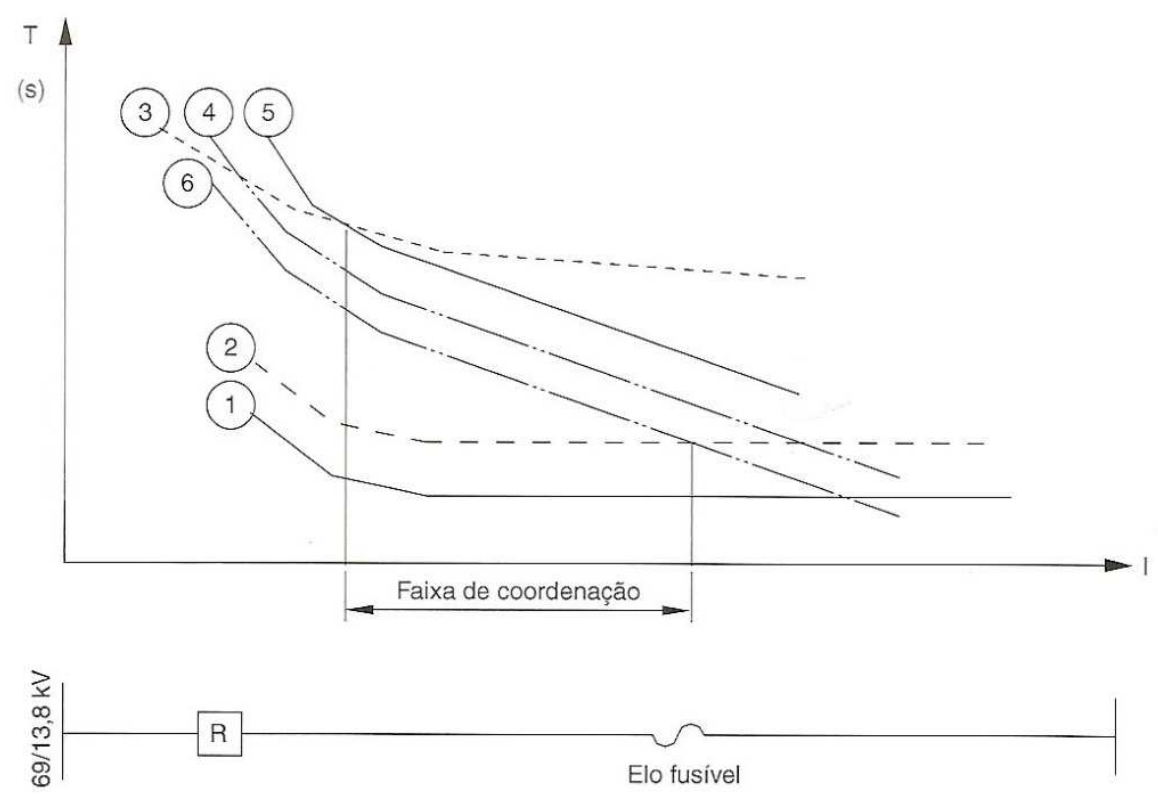

1 - Curva de operação rápida do religador

2 - Curva de operação rápida do religador corrigida pelo fator $\mathrm{K}$

3 - Curva de operação retardada do religador

4 - Curva de tempo mínimo de fusão do elo fusível

5 - Curva de tempo máximo de interrupção do elo fusível

6 - Curva 4 multiplicada por 0,75 no eixo dos tempos

Figura A.4 - Coordenação entre religador de subestação e elo fusível sem fator K (Mamede Filho \& Mamede Ribeiro, 2011).

- A intersecção entre a curva lenta do religador e a curva total de interrupção do elo fusível fornece o ponto mínimo de coordenação entre o religador e o elo fusível, que define o limite da faixa inferior da coordenação.

- A margem de coordenação entre a curva tempo versus corrente da unidade de sobrecorrente de fase e de neutro e a curva tempo versus corrente do elo fusível deve ser 0,2 s em todo o trecho protegido para que a coordenação seja garantida.

- O religador deve ser ajustado para atuar seletivamente com o elo fusível para a menor corrente de curto-circuito no trecho onde o religador é proteção de retaguarda, tanto para defeitos trifásicos e bifásicos como para defeitos fase-terra. 
- A curva de operação rápida do religador não deve atuar para a corrente de inrush dos transformadores.

\section{A.4.3. Coordenação entre religadores de subestação e seccionadores}

Os seguintes critérios devem ser seguidos para que haja coordenação entre os religadores de subestação e os seccionadores (Mamede Filho \& Mamede Ribeiro, 2011):

- O seccionador deve estar instalado à jusante do religador.

- O seccionador deve ser ajustado para abrir os seus contatos para um número de contagem inferior a um em relação ao número ajustado de operações do religador à montante. Desta forma, se o religador for ajustado para atuar com duas operações rápidas e duas temporizadas, o seccionador deve ser ajustado para abrir com três contagens.

- O seccionador deve ser ajustado para preparar a inicialização de sua contagem quando a corrente que passa por sua bobina série for superior à sua corrente de acionamento.

- A menor corrente de curto-circuito à jusante do seccionador deve ser maior que a sua corrente de acionamento.

- O ajuste da corrente das unidades temporizadas de fase e de neutro do religador da subestação deve ser igual ou superior à corrente de curto-circuito simétrica no barramento de média tensão da subestação.

- O tempo de memória do seccionador deve ser maior que a soma dos tempos de religamento, adicionados aos tempos de ajuste dos relés do religador da subestação.

- A corrente de ajuste do seccionador igual ou menor que $80 \%$ da corrente de acionamento do religador da subestação.

- O tempo acumulado do religador da subestação deve ser inferior ao tempo de memória do seccionador.

\section{A.4.4. Coordenação entre religadores da subestação, seccionadores e elos fusíveis}

Os seguintes critérios devem ser obedecidos para que haja coordenação entre religadores da subestação, seccionadores e elos fusíveis:

- O seccionador deve estar instalado à jusante do religador e à montante da chave fusível.

- A chave fusível deve estar instalada à jusante do seccionador. 
- O religador pode ser ajustado para atuar com uma operação rápida e três temporizadas.

- Para uma condição de ajuste do religador, como, por exemplo, uma operação rápida e três operações temporizadas, o seccionador deve ser ajustado para três contagens. Desta forma é possível eliminar defeitos temporários, antes de o religador entrar no ciclo de operação temporizada. Caso o defeito seja permanente e a jusante do elo fusível, o religador responderá na curva lenta, permitindo a abertura do elo fusível.

- O tempo de memória do seccionador deve ser superior à soma dos tempos de religamento, adicionados aos tempos de ajuste dos relés temporizados do religador da subestação.

- O tempo acumulado no religador da subestação deve ser inferior ao tempo de memória do seccionador.

- A instalação de um seccionador adicional em série e à jusante do primeiro significa que este deve ser ajustado para uma contagem inferior à do primeiro seccionador.

- O número de contagem ajustada no seccionador deve ser inferior a um em relação ao número de operações ajustadas no religador da subestação.

- A corrente de ajuste do seccionador deve ser igual ou inferior a $80 \%$ da corrente de acionamento do religador da subestação.

- A curva tempo versus corrente da unidade de sobrecorrente de fase e de neutro do religador não deve cortar a curva tempo versus corrente do elo fusível para todas as correntes de curto-circuito no trecho protegido pelo religador.

- A curva tempo versus corrente da unidade de sobrecorrente de fase e de neutro do religador deve estar acima da curva tempo versus corrente do elo fusível para todas as correntes de curto-circuito no trecho protegido pelo religador.

- A margem de coordenação entre a curva tempo versus corrente da unidade de sobrecorrente de fase e de neutro e a curva tempo versus corrente do elo fusível para todas as correntes de curto-circuito no trecho protegido pelo religador deve ser $0,20 \mathrm{~s}$, para garantir a seletividade.

- As unidades temporizadas de fase e de neutro do religador da subestação devem ser ajustadas para atuar para a menor corrente de curto-circuito à jusante do seccionador.

- O religador deve ser ajustado para atuar seletivamente com o elo fusível para a menor corrente de curto-circuito no trecho onde o religador é proteção de retaguarda, tanto para defeitos trifásicos, quanto bifásicos e fase-terra. 


\section{A.4.5. Coordenação entre religadores da subestação e religadores de distribuição}

Para haver coordenação entre esses dois tipos de religadores, os seguintes critérios devem ser obedecidos (Mamede Filho \& Mamede Ribeiro, 2011):

- O religador da subestação pode ser ajustado para atuar com a seguinte sequência de operação: uma operação rápida e três temporizadas.

- A corrente de ajuste da unidade temporizada de fase do religador de distribuição deve ser inferior à corrente de atuação da unidade temporizada de fase do religador de subestação para correntes de curto-circuito trifásicas ou bifásicas à jusante do religador de distribuição.

- A corrente de ajuste da unidade temporizada de neutro do religador de distribuição deve ser inferior à corrente de atuação da unidade temporizada de neutro do religador da subestação para correntes de curto-circuito fase-terra à jusante do religador de distribuição.

- A corrente de ajuste da unidade instantânea de fase do religador de subestação deve ser superior à corrente de curto-circuito assimétrica trifásica no ponto de instalação do religador de distribuição.

- A corrente de ajuste da unidade instantânea de neutro do religador de subestação deve ser superior à corrente de curto-circuito fase-terra no ponto de instalação do religador de distribuição.

- O tempo de ajuste da unidade temporizada de fase do religador de distribuição, para qualquer corrente de curto-circuito trifásica ou bifásica no trecho protegido, deve ser inferior ao tempo de ajuste da unidade temporizada de fase do religador da subestação.

- O tempo de ajuste da unidade temporizada de fase do religador de distribuição, para qualquer corrente de curto-circuito fase-terra no trecho protegido, deve ser inferior ao tempo de ajuste da unidade temporizada de neutro do religador de subestação.

- A curva selecionada da unidade temporizada de fase do religador da subestação não deve cortar a curva temporizada de fase do religador de distribuição em todo o trecho protegido pelo religador da subestação.

- A curva selecionada da unidade temporizada de neutro do religador da subestação deve ser superior à curva temporizada do religador de distribuição.

- A corrente de atuação das unidades instantâneas de fase do religador da subestação e do religador de distribuição deve ser superior à corrente de inrush dos transformadores de distribuição. 


\section{A.4.6. Coordenação entre os religadores de distribuição e elos fusíveis}

Para haver coordenação entre os religadores de distribuição e os elos fusíveis, os seguintes critérios devem ser obedecidos (Mamede Filho \& Mamede Ribeiro, 2011):

- O religador de distribuição deve ser ajustado, preferencialmente, para operar com a seguinte sequência de operação: duas operações rápidas e duas temporizadas.

- A curva rápida de tempo versus corrente da unidade de sobrecorrente de fase e de neutro não deve cortar a curva tempo versus corrente do elo fusível em todo o trecho protegido pelo religador.

- A margem de coordenação entre a curva rápida tempo versus corrente da unidade de sobrecorrente de fase e de neutro e a curva tempo versus corrente do elo fusível em todo o trecho protegido pelo religador deve ser $0,20 \mathrm{~s}$, para garantir a seletividade.

- O religador de distribuição deve ser ajustado para atuar seletivamente com o elo fusível para a menor corrente de curto-circuito no trecho onde o religador de distribuição é proteção de retaguarda, tanto para defeitos trifásicos quanto fase-terra.

- A unidade de sobrecorrente instantânea ou de tempo definido de fase não deve atuar para a corrente de inrush dos transformadores.

\section{A.4.7. Coordenação entre religadores de distribuição e seccionadores}

Para haver coordenação entre religadores de distribuição e seccionadores devem ser admitidos os seguintes critérios (Mamede Filho \& Mamede Ribeiro, 2011):

- O seccionador deve estar instalado à jusante do religador.

- O religador pode ser ajustado para atuar com duas operações rápidas e duas temporizadas.

- Para a condição anterior do ajuste do religador, o seccionador deve ser ajustado para três contagens.

- O seccionador deve ser ajustado para preparar a inicialização de contagem do número de operações do religador, quando a corrente que passa por sua bobina série for superior à sua corrente de atuação.

- A menor corrente de curto-circuito a jusante do seccionador deve ser superior à sua corrente ajustada no religador de distribuição.

- As unidades temporizadas (curvas lentas) de fase e de neutro do religador de distribuição devem ser ajustadas para atuar para a menor corrente de curto-circuito à jusante do seccionador. 
- O tempo de memória do seccionador deve ser superior à soma dos tempos de religamento adicionados aos tempos de ajuste das unidades temporizadas (lentas) do religador de distribuição.

- O número de contagem ajustada no seccionador deve ser inferior a um em relação ao número de operações ajustadas no religador de distribuição.

- A corrente de ajuste do seccionador deve ser igual ou inferior a $80 \%$ da corrente de acionamento do religador de distribuição.

- Os seccionadores que não possuírem sensor de falta à terra devem coordenar com a corrente mínima ajustada da unidade temporizada de fase do religador de distribuição.

- O tempo acumulado no religador de distribuição deve ser inferior ao tempo de memória do seccionador.

- A instalação de um seccionador adicional à jusante do primeiro significa que este deve ser ajustado para uma contagem inferior à do primeiro seccionador.

- A instalação de um seccionador adicional em paralelo com o primeiro implica que ambos devem ser ajustados para uma contagem inferior à do religador de distribuição.

\section{A.4.8. Coordenação entre religadores de distribuição, seccionadores e elos fusíveis}

Para haver coordenação entre religadores de distribuição, seccionadores e elos fusíveis, devem ser obedecidos os seguintes critérios (Mamede Filho \& Mamede Ribeiro, 2011):

- O seccionador deve estar à jusante do religador de distribuição e à montante do elo fusível.

- A chave-fusível deve estar instalada à jusante do seccionador.

- O religador de distribuição pode ser ajustado para atuar com uma operação rápida e três temporizadas.

- Para a condição anterior do ajuste de religador de distribuição, o seccionador deve ser ajustado para três contagens.

- O seccionador deve ser ajustado para inicializar a contagem do número de operações do religador de distribuição quando a corrente que passa por sua bobina série for superior à sua corrente de atuação.

- A corrente de ajuste do seccionador deve ser inferior à menor corrente de curtocircuito à sua jusante. 
- As unidades temporizadas (curvas lentas) de fase e de neutro do religador de distribuição devem ser ajustadas para atuar para a menor corrente de curto-circuito à jusante do seccionador.

- A capacidade de ruptura simétrica do religador de distribuição deve ser igual ou superior à corrente de curto-circuito simétrica no ponto de sua instalação.

- O tempo de memória do seccionador deve ser superior à soma dos tempos de religamento adicionados aos tempos de ajuste dos relés temporizados do religador de distribuição.

- O tempo acumulado no religador de distribuição deve ser inferior ao tempo de memória do seccionador.

- A instalação de um seccionador adicional em série à jusante do primeiro significa que este deve ser ajustado para uma contagem inferior à do primeiro seccionador.

- A instalação de um seccionador adicional em paralelo com o primeiro significa que ambos devem ser ajustados para uma contagem inferior à do religador de distribuição.

- O número de contagem ajustada no seccionador deve ser inferior a um, em relação ao número de operações ajustadas no religador de distribuição.

- A corrente de ajuste do seccionador deve ser igual ou inferior a $80 \%$ da corrente de acionamento do religador de distribuição.

- A curva tempo versus corrente da unidade de sobrecorrente de fase e de neutro do religador de distribuição deve estar acima da curva tempo versus corrente do elo fusível para todas as correntes de curto-circuito no trecho protegido pelo religador de distribuição.

- A margem de coordenação entre a curva tempo versus corrente da unidade de sobrecorrente de fase e de neutro e a curva tempo versus corrente do elo fusível para todas as correntes de curto-circuito no trecho protegido pelo religador de distribuição deve ser 0,20 s.

- O religador de distribuição deve ser ajustado para atuar seletivamente com o elo fusível para a menor corrente de curto-circuito no trecho onde o religador de distribuição é proteção de retaguarda, tanto para defeitos trifásicos, quanto bifásicos e fase-terra.

- A unidade de sobrecorrente instantânea ou de tempo definido (operação rápida) do religador de distribuição deve ser ajustada para atuar com valor inferior à corrente de curto-circuito, valor simétrico, no trecho até onde o religador é proteção de retaguarda. 
- A unidade de sobrecorrente instantânea ou de tempo definido de fase (curva rápida) não deve atuar para a corrente de inrush dos transformadores.

\section{A.4.9. Coordenação entre religadores de distribuição}

Para haver coordenação entre religadores de distribuição, devem ser seguidos os seguintes critérios (Mamede Filho \& Mamede Ribeiro, 2011):

- Os religadores de distribuição podem ser ajustados para atuar com uma operação rápida e três operações temporizadas (lentas).

- A corrente de ajuste da unidade temporizada de fase do religador de distribuição à jusante (curva lenta) deve ser inferior à corrente de atuação da unidade temporizada de fase do religador de distribuição à montante, para correntes de curto-circuito trifásico ou bifásico à jusante deste.

- A corrente de ajuste da unidade temporizada de neutro do religador de distribuição à jusante (curva lenta) deve ser inferior à corrente de atuação da unidade temporizada de neutro do religador de distribuição à montante para correntes de curto-circuito fase-terra à jusante deste.

- A corrente de ajuste da unidade instantânea ou de tempo definido de fase (curva rápida) do religador de distribuição a montante deve ser superior à corrente de curtocircuito assimétrica trifásica no ponto de instalação do religador de distribuição à jusante.

- A corrente de ajuste da unidade instantânea ou de tempo definido de neutro (curva rápida) do religador de distribuição à montante deve ser superior à corrente de curtocircuito fase-terra no ponto de instalação do religador de distribuição à jusante.

- O tempo de ajuste da unidade temporizada de fase do religador de distribuição à jusante (curva lenta), para qualquer corrente de curto-circuito trifásica ou bifásica no trecho protegido, deve ser inferior ao tempo de ajuste da unidade temporizada de fase do religador de distribuição à montante.

- O tempo de ajuste da unidade temporizada de neutro do religador de distribuição à jusante (curva lenta), para qualquer corrente de curto-circuito fase-terra no trecho protegido, deve ser inferior ao tempo de ajuste da unidade temporizada de neutro (curva lenta) do religador de distribuição à montante.

- A curva selecionada da unidade temporizada de fase (curva lenta) do religador de distribuição à montante não deve cortar a curva temporizada de fase (curva lenta) do religador de distribuição à jusante em todo o trecho protegido pelo religador de distribuição à montante. 
- A curva selecionada da unidade temporizada de neutro (curva lenta) do religador de distribuição à montante não deve cortar a curva temporizada de neutro (curva lenta) do religador de distribuição à jusante em todo o trecho protegido pelo religador de distribuição à montante.

- A corrente de atuação das unidades instantâneas ou de tempo definido de fase (curva rápida) do religador de distribuição à montante e do religador de distribuição à jusante devem ser superiores à corrente de inrush dos transformadores de distribuição do alimentador. 


\section{B. BASE DE DADOS}

Este capítulo apresenta a base de dados utilizada nas simulações e cálculos realizados nesta dissertação.

Tabela B.1 - Dados das cargas ligadas às barras.

\begin{tabular}{|c|c|c|c|c|c|c|c|}
\hline $\begin{array}{c}\text { Nome } \\
\text { da } \\
\text { Carga }\end{array}$ & Barra & $\begin{array}{c}\text { Potência } \\
\text { Ativa } \\
\text { Fase A } \\
\text { (MW) }\end{array}$ & $\begin{array}{c}\text { Potência } \\
\text { Ativa } \\
\text { Fase B } \\
\text { (MW) }\end{array}$ & $\begin{array}{c}\text { Potência } \\
\text { Ativa } \\
\text { Fase C } \\
\text { (MW) }\end{array}$ & $\begin{array}{c}\text { Potência } \\
\text { Reativa } \\
\text { Fase A } \\
\text { (MVAr) }\end{array}$ & $\begin{array}{l}\text { Potência } \\
\text { Reativa } \\
\text { Fase B } \\
\text { (MVAr) }\end{array}$ & $\begin{array}{c}\text { Potência } \\
\text { Reativa } \\
\text { Fase C } \\
\text { (MVAr) }\end{array}$ \\
\hline 1 & 3 & 0,0138 & 0,0138 & 0,0138 & 0,005878 & 0,005878 & 0,005878 \\
\hline 2 & 5 & 0,023 & 0,023 & 0,023 & 0,009797 & 0,009797 & 0,009797 \\
\hline 3 & 6 & 0,023 & 0,023 & 0,023 & 0,009797 & 0,009797 & 0,009797 \\
\hline 4 & 7 & 0,0345 & 0,0345 & 0,0345 & 0,014696 & 0,014696 & 0,014696 \\
\hline 5 & 8 & 0,023 & 0,023 & 0,023 & 0,009797 & 0,009797 & 0,009797 \\
\hline 6 & 9 & 0,023 & 0,023 & 0,023 & 0,009797 & 0,009797 & 0,009797 \\
\hline 7 & 12 & 0,048637 & 0,048637 & 0,048637 & 0,020717 & 0,020717 & 0,020717 \\
\hline 8 & 15 & 0,0345 & 0,0345 & 0,0345 & 0,014696 & 0,014696 & 0,014696 \\
\hline 9 & 16 & 0,0138 & 0,0138 & 0,0138 & 0,005878 & 0,005878 & 0,005878 \\
\hline 10 & 17 & 0,0345 & 0,0345 & 0,0345 & 0,014696 & 0,014696 & 0,014696 \\
\hline 11 & 19 & 0,023 & 0,023 & 0,023 & 0,009797 & 0,009797 & 0,009797 \\
\hline 12 & 20 & 0,0345 & 0,0345 & 0,0345 & 0,014696 & 0,014696 & 0,014696 \\
\hline 13 & 21 & 0,0345 & 0,0345 & 0,0345 & 0,014696 & 0,014696 & 0,014696 \\
\hline 14 & 22 & 0,0345 & 0,0345 & 0,0345 & 0,014696 & 0,014696 & 0,014696 \\
\hline 15 & 36 & 0,003802 & 0,003802 & 0,003802 & 0,001619 & 0,001619 & 0,001619 \\
\hline 16 & 37 & 0,0345 & 0,0345 & 0,0345 & 0,014696 & 0,014696 & 0,014696 \\
\hline 17 & 39 & 0,000919 & 0,000919 & 0,000919 & 0,000391 & 0,000391 & 0,000391 \\
\hline 18 & 46 & 0,000306 & 0,000306 & 0,000306 & 0,00013 & 0,00013 & 0,00013 \\
\hline 19 & 47 & 0,0345 & 0,0345 & 0,0345 & 0,014696 & 0,014696 & 0,014696 \\
\hline 20 & 49 & 0,092 & 0,092 & 0,092 & 0,039189 & 0,039189 & 0,039189 \\
\hline 21 & 52 & 0,057867 & 0,057867 & 0,057867 & 0,024649 & 0,024649 & 0,024649 \\
\hline 22 & 61 & 0,000919 & 0,000919 & 0,000919 & 0,000391 & 0,000391 & 0,000391 \\
\hline 23 & 62 & 0,001686 & 0,001686 & 0,001686 & 0,000718 & 0,000718 & 0,000718 \\
\hline 24 & 76 & 0,0345 & 0,0345 & 0,0345 & 0,014696 & 0,014696 & 0,014696 \\
\hline 25 & 77 & 0,001809 & 0,001809 & 0,001809 & 0,00077 & 0,00077 & 0,00077 \\
\hline 26 & 24 & 0,000919 & 0,000919 & 0,000919 & 0,000391 & 0,000391 & 0,000391 \\
\hline 27 & 25 & 0,0138 & 0,0138 & 0,0138 & 0,005878 & 0,005878 & 0,005878 \\
\hline 28 & 32 & 0,1035 & 0,1035 & 0,1035 & 0,044088 & 0,044088 & 0,044088 \\
\hline 29 & 27 & 0,0345 & 0,0345 & 0,0345 & 0,014696 & 0,014696 & 0,014696 \\
\hline 30 & 29 & 0,023 & 0,023 & 0,023 & 0,009797 & 0,009797 & 0,009797 \\
\hline 31 & 30 & 0,0345 & 0,0345 & 0,0345 & 0,014696 & 0,014696 & 0,014696 \\
\hline 32 & 31 & 0,0345 & 0,0345 & 0,0345 & 0,014696 & 0,014696 & 0,014696 \\
\hline 33 & 40 & 0,1173 & 0,1173 & 0,1173 & 0,049965 & 0,049965 & 0,049965 \\
\hline 34 & 63 & 0,213407 & 0,213407 & 0,213407 & 0,090904 & 0,090904 & 0,090904 \\
\hline 35 & 78 & 0,868322 & 0,868322 & 0,868322 & 0,369866 & 0,369866 & 0,369866 \\
\hline
\end{tabular}


Tabela B.2 - Dados das linhas aéreas de distribuição.

\begin{tabular}{|c|c|c|c|c|}
\hline Nome da Linha & Barra de Origem & Barra de Destino & $\begin{array}{c}\text { Resistência de } \\
\text { Sequência } \\
\text { Positiva ( } \Omega \text { ) }\end{array}$ & $\begin{array}{c}\text { Reatância de } \\
\text { Sequência } \\
\text { Positiva }(\Omega)\end{array}$ \\
\hline 1 & 150 & 2 & 0,38448 & 0,86481 \\
\hline 2 & 2 & 3 & 0,0542 & 0,0499 \\
\hline 3 & 2 & 4 & 0,04272 & 0,09609 \\
\hline 4 & 4 & 5 & 0,017088 & 0,038436 \\
\hline 5 & 5 & 6 & 0,08544 & 0,19218 \\
\hline 6 & 6 & 7 & 0,08544 & 0,19218 \\
\hline 7 & 7 & 8 & 0,08544 & 0,19218 \\
\hline 8 & 8 & 9 & 0,004272 & 0,009609 \\
\hline 9 & 9 & 10 & 0,02136 & 0,048045 \\
\hline 10 & 10 & 11 & 0,1644 & 0,1006 \\
\hline 11 & 11 & 12 & 0,09864 & 0,06036 \\
\hline 12 & 11 & 15 & 0,04932 & 0,03018 \\
\hline 13 & 15 & 16 & 0,01644 & 0,01006 \\
\hline 14 & 16 & 17 & 0,03288 & 0,02012 \\
\hline 15 & 17 & 18 & 0,06576 & 0,04024 \\
\hline 16 & 18 & 19 & 0,04336 & 0,03992 \\
\hline 17 & 19 & 20 & 0,0542 & 0,0499 \\
\hline 18 & 18 & 21 & 0,1626 & 0,1497 \\
\hline 19 & 10 & 22 & 0,012816 & 0,028827 \\
\hline 20 & 22 & 23 & 0,029904 & 0,067263 \\
\hline 21 & 23 & 36 & 0,034176 & 0,076872 \\
\hline 22 & 36 & 37 & 0,004272 & 0,009609 \\
\hline 23 & 37 & 38 & 0,004272 & 0,009609 \\
\hline 24 & 38 & 46 & 0,025632 & 0,057654 \\
\hline 25 & 46 & 47 & 0,008544 & 0,019218 \\
\hline 26 & 47 & 48 & 0,051264 & 0,115308 \\
\hline 27 & 48 & 49 & 0,02136 & 0,048045 \\
\hline 28 & 48 & 61 & 0,017088 & 0,038436 \\
\hline 29 & 61 & 62 & 0,004272 & 0,009609 \\
\hline 30 & 62 & 63 & 0,02136 & 0,048045 \\
\hline 31 & 63 & 76 & 0,008544 & 0,019218 \\
\hline 32 & 76 & 77 & 0,012816 & 0,028827 \\
\hline 33 & 77 & 78 & 0,02136 & 0,048045 \\
\hline 34 & 48 & 52 & 0,04272 & 0,09609 \\
\hline 35 & 23 & 24 & 0,0822 & 0,0503 \\
\hline 36 & 24 & 25 & 0,03288 & 0,02012 \\
\hline 37 & 25 & 26 & 0,04932 & 0,03018 \\
\hline 38 & 26 & 32 & 0,03288 & 0,02012 \\
\hline 39 & 26 & 27 & 0,06504 & 0,05988 \\
\hline 40 & 27 & 28 & 0,04336 & 0,03992 \\
\hline 41 & 28 & 29 & 0,02168 & 0,01996 \\
\hline 42 & 29 & 30 & 0,13008 & 0,11976 \\
\hline 43 & 28 & 31 & 0,02168 & 0,01996 \\
\hline 44 & 38 & 39 & 0,029904 & 0,067263 \\
\hline 45 & 38 & 40 & 0,04272 & 0,09609 \\
\hline
\end{tabular}

OBS: Os valores de impedância de sequência zero foram considerados iguais aos de sequência positiva. 
Tabela B.3 - Dados dos transformadores.

\begin{tabular}{|c|c|c|c|c|c|c|c|c|}
\hline Nome & Tipo & $\begin{array}{c}\text { Potência } \\
\text { Nominal } \\
\text { (MVA) }\end{array}$ & $\begin{array}{l}\text { Freq. } \\
(\mathrm{Hz})\end{array}$ & $\begin{array}{l}\text { Tensão } \\
\text { no } \\
\text { Primário } \\
\text { (kV) }\end{array}$ & $\begin{array}{c}\text { Tensão } \\
\text { no } \\
\text { Secundário } \\
\text { (kV) }\end{array}$ & $\begin{array}{l}\text { Grupo } \\
\text { de } \\
\text { Ligação }\end{array}$ & $\begin{array}{l}\text { Impedância } \\
(\%)\end{array}$ & $\begin{array}{c}\text { Perdas } \\
\text { no } \\
\text { Cobre } \\
\text { (kW) }\end{array}$ \\
\hline TR-0 & Trifásico & 7,5 & 60 & 138 & 13,8 & Dyn1 & 6,56 & 35 \\
\hline TR-1 & Trifásico & 1,625 & 60 & 13,8 & 0,48 & Dyn1* & 5,8 & 13,29 \\
\hline TR-2 & Trifásico & 1,625 & 60 & 13,8 & 0,48 & Dyn1* & 5,8 & 13,29 \\
\hline TR-2 & Trifásico & 1,625 & 60 & 13,8 & 0,48 & Dyn1* & 5,8 & 13,29 \\
\hline
\end{tabular}

$\left(^{*}\right)$ Também foram realizadas simulações com a conexão YNyn0 para esses transformadores.

Tabela B.4 - Dados dos geradores.

\begin{tabular}{|ccccccccc|}
\hline Nome & $\begin{array}{c}\text { Núm. } \\
\text { de } \\
\text { Pólos }\end{array}$ & $\begin{array}{c}\text { Potência } \\
\text { Nominal } \\
\text { (MVA) }\end{array}$ & $\begin{array}{c}\text { Freq. } \\
(\mathrm{Hz})\end{array}$ & $\begin{array}{c}\text { Tensão } \\
\text { Nominal } \\
(\mathbf{k V})\end{array}$ & $\begin{array}{c}\text { Grupo } \\
\text { de } \\
\text { Ligação }\end{array}$ & $\begin{array}{c}\text { Fator } \\
\text { de } \\
\text { Potência }\end{array}$ & $\begin{array}{c}\text { Tipo do } \\
\text { Rotor }\end{array}$ & $\begin{array}{c}\text { Resistência } \\
\text { do } \\
\text { estator } \\
(\Omega)\end{array}$ \\
\hline G1 & 4 & 1,625 & 60 & 0,48 & Yn & 0,8 & $\begin{array}{c}\text { pólo } \\
\text { saliente }\end{array}$ & 0,0023 \\
\hline G2 & 4 & 1,625 & 60 & 0,48 & Yn & 0,8 & $\begin{array}{c}\text { pólo } \\
\text { saliente }\end{array}$ & 0,0023 \\
\hline G3 & 4 & 1,625 & 60 & 0,48 & Yn & 0,8 & $\begin{array}{c}\text { pólo } \\
\text { saliente }\end{array}$ & 0,0023 \\
\hline
\end{tabular}

Tabela B.5 - Reatâncias e constantes de tempo dos geradores.

\begin{tabular}{|c|c|c|c|c|c|c|c|c|c|c|}
\hline Nome & $\begin{array}{l}\text { X"d } \\
\text { (pu) }\end{array}$ & $\begin{array}{l}X " q \\
(p u)\end{array}$ & $\begin{array}{c}X^{\prime} \mathbf{d} \\
\text { (pu) }\end{array}$ & $\begin{array}{c}\mathbf{X d} \\
(p u)\end{array}$ & $\begin{array}{c}X q \\
(p u)\end{array}$ & $\begin{array}{c}\mathrm{X} 2 \\
\text { (pu) }\end{array}$ & $\begin{array}{c}\text { Xo } \\
\text { (pu) }\end{array}$ & $\begin{array}{l}T d^{\prime} \\
(s)\end{array}$ & $\begin{array}{l}\text { Td"' } \\
\text { (s) }\end{array}$ & $\begin{array}{l}\text { Tq" } \\
\text { (s) }\end{array}$ \\
\hline$G$ & 0,1869 & 0,412 & 0,2515 & 3,748 & 1,8627 & 0,299 & 0,1065 & 0,2871 & 0,0057 & 0,0116 \\
\hline G & & & & & & & & 0,2871 & 557 & 0,0116 \\
\hline G3 & 0,1869 & 0,412 & 0,2515 & 3,748 & 1,8627 & 0,299 & 0,1065 & 0,2871 & 0,0057 & 0,0116 \\
\hline
\end{tabular}

A constante de inércia $(H)$ utilizada nos geradores é de $0,34415 \mathrm{~s}$.

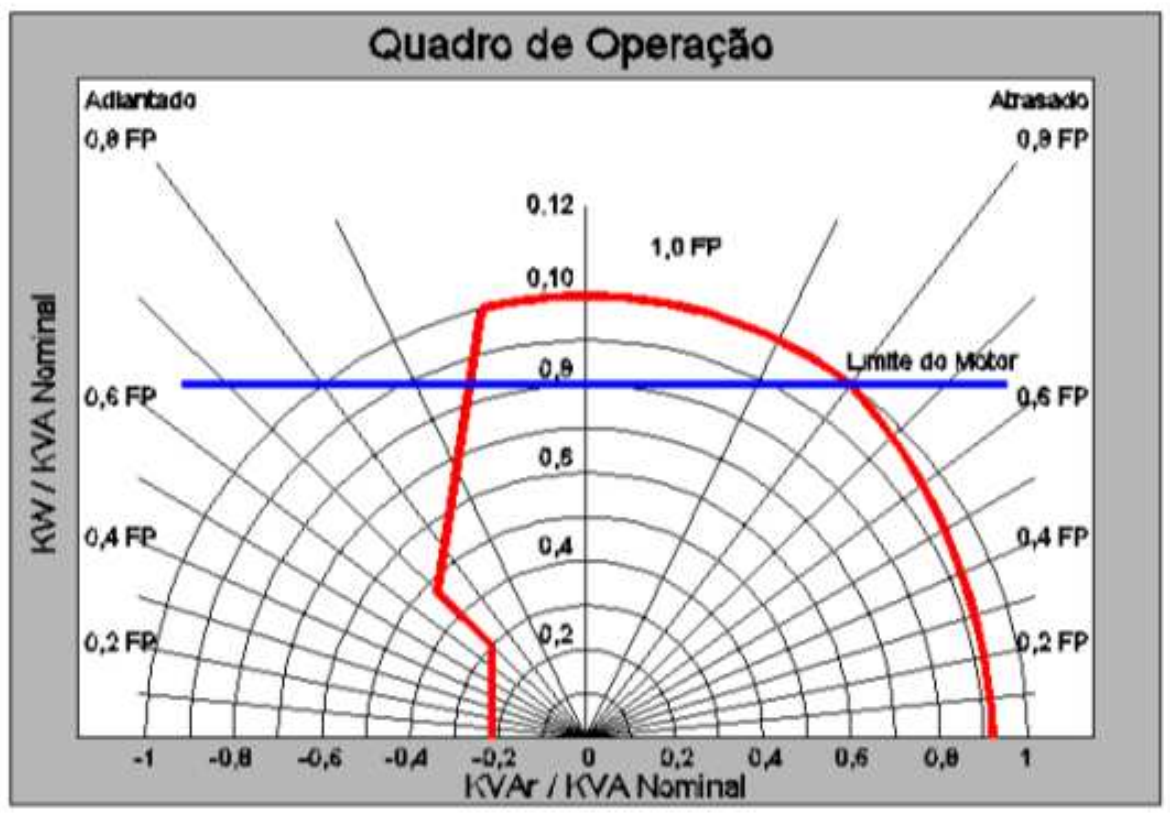

Figura B.1 - Curva de capabilidade dos geradores. 


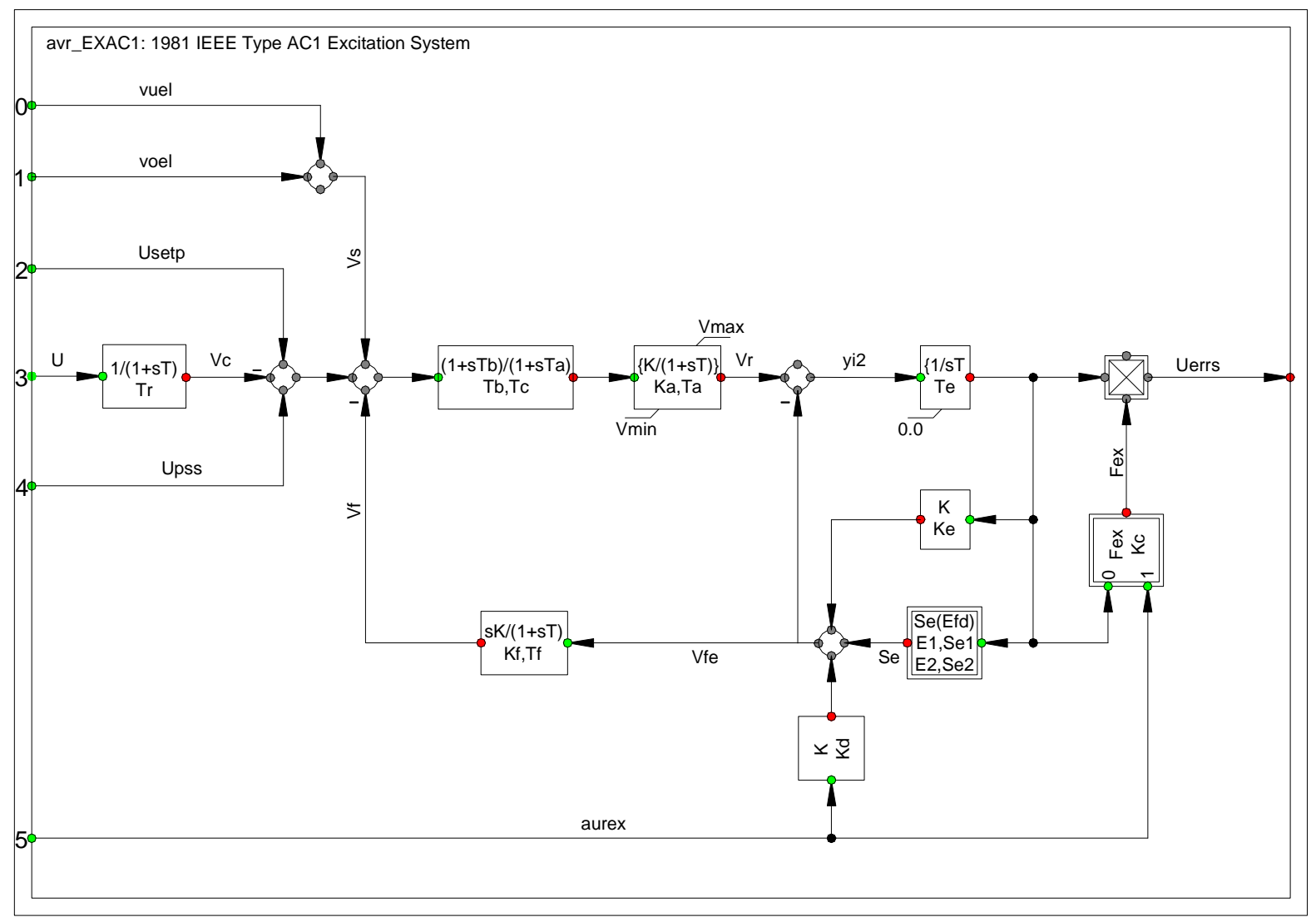

Figura B.2 - Diagrama de blocos do regulador de tensão.

Tabela B.6 - Valores utilizados no regulador de tensão.

\begin{tabular}{|c|c|c|}
\hline Parâmetro & Unidade & Valor \\
\hline $\mathrm{Tr}$ - Measurement Delay & $\mathrm{s}$ & 0,01 \\
\hline Tb - Filter Delay Time & $\mathrm{s}$ & 0 \\
\hline Tc - Filter Derivative Time Constant & $\mathrm{s}$ & 0 \\
\hline Ka - Controller Gain & $\mathrm{pu}$ & 3000 \\
\hline Ta-Controller Time Constant & $\mathrm{s}$ & 0,02 \\
\hline Te - Exciter Time Constant & s & 0,42 \\
\hline Kf - Stabilization Path Gain & $\mathrm{pu}$ & 0,0374 \\
\hline Tf - Stabilization Path Delay Time & $s$ & 0,77 \\
\hline Kc - Rectifier Regulation Constant & $\mathrm{pu}$ & 0,1 \\
\hline Kd - Exciter Armature Reaction Factor & $\mathrm{pu}$ & 1,2 \\
\hline E1 - Saturation Factor 1 & $\mathrm{pu}$ & 9,3 \\
\hline Se1 - Saturation Factor 2 & $\mathrm{pu}$ & 0,2353 \\
\hline E2 - Saturation Factor 3 & pu & 2,4 \\
\hline Se2 - Saturation Factor 4 & pu & 1,9737 \\
\hline Ke - Exciter Constant & pu & 1 \\
\hline Vmin - Controller Minimum Output & $\mathrm{pu}$ & $-11,2$ \\
\hline Vmax - Controller Maximum Output & $\mathrm{pu}$ & 12,4 \\
\hline
\end{tabular}




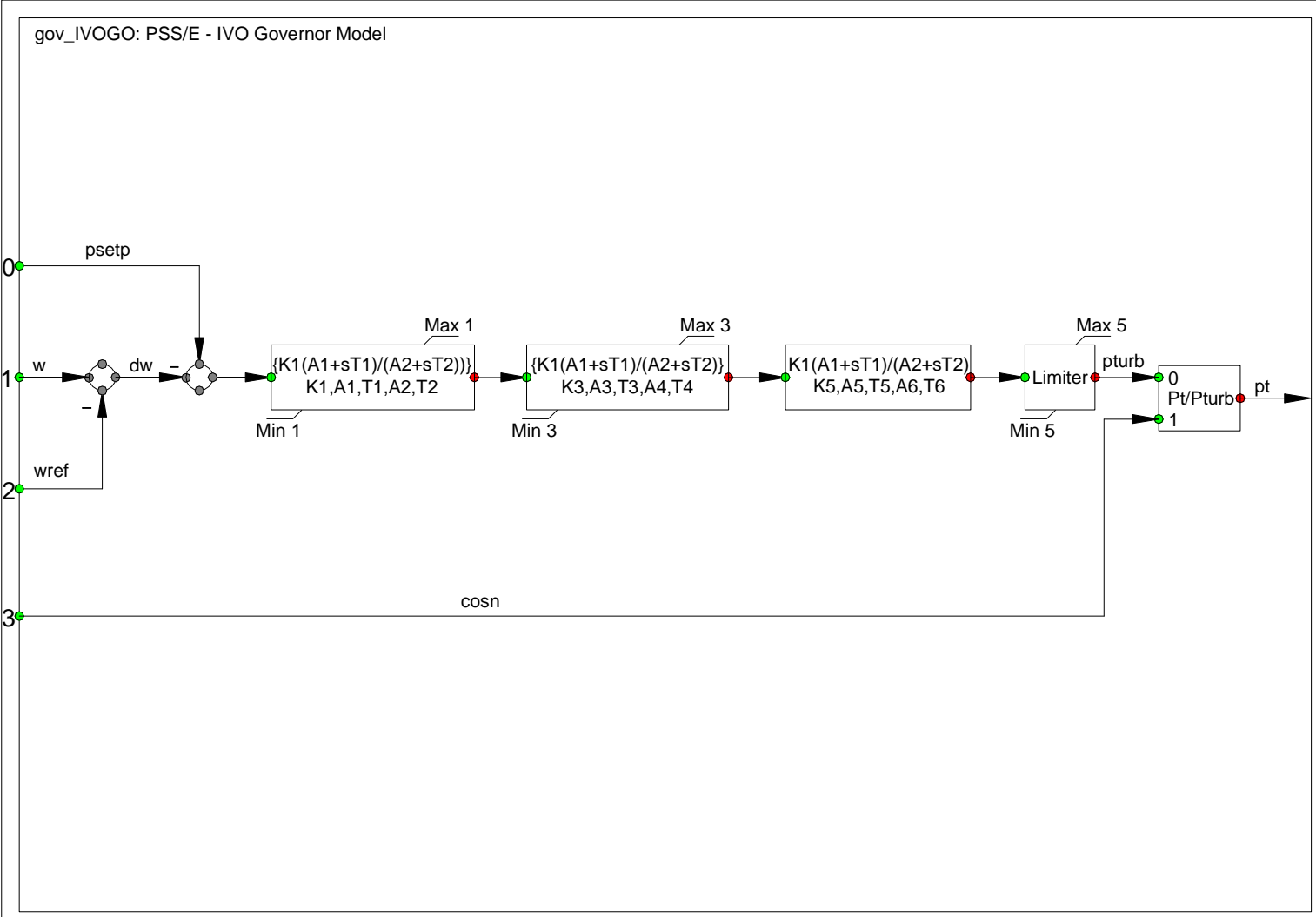

Figura B.3 - Diagrama de blocos do regulador de velocidade do motor.

Tabela B.7 - Valores utilizados no regulador de velocidade do motor.

\begin{tabular}{|ccc|}
\hline Parâmetro & Unidade & Valor \\
\hline K1 - First Block Gain & $\mathrm{pu}$ & 20 \\
\hline A1 - First Block Factor 1 & $\mathrm{p}$ & 1 \\
\hline A1 - First Block Derivative Time Constant & $\mathrm{pu}$ & 1 \\
\hline T2 - First Block Delay Time Constant & $\mathrm{s}$ & 1,5 \\
\hline K3 - Second Block Gain & $\mathrm{pu}$ & 1 \\
\hline A3 - Second Block Factor & $\mathrm{pu}$ & 1 \\
\hline T3 - Second Block Drivative Time Constant & $\mathrm{s}$ & 0,6 \\
\hline A4 - Second Block Factor 2 & $\mathrm{pu}$ & 1,5 \\
\hline T4 - Second Block Delay Time Constant & $\mathrm{s}$ & 1 \\
\hline K5 - Third Block Gain & $\mathrm{pu}$ & 1 \\
\hline A5 - Third Block Factor 1 & $\mathrm{pu}$ & 0,01 \\
\hline A6 - Third Block Factor 2 & $\mathrm{s}$ & 1 \\
\hline Th - Third Block Derivative Time Constant & $\mathrm{pu}$ & 0,1 \\
\hline Third Block Delay Time Constant & $\mathrm{s}$ & -10 \\
\hline Min 3 - First Block Lower Limit & $\mathrm{pu}$ & -10 \\
\hline Min 5 - Third Block Lower Limit & $\mathrm{pu}$ & $-0,062$ \\
\hline Max 1 - First Block Upper Limit & $\mathrm{pu}$ & 10 \\
\hline Max 3 - Second Block Upper Limit & $\mathrm{pu}$ & 10 \\
\hline Max 5 - Third Block Upper Limit & $\mathrm{pu}$ & 1 \\
\hline
\end{tabular}

Os ganhos utilizados nas simulações foram previamente testados, objetivando obter respostas rápidas e a operação estável das máquinas, sempre que possível. 